\title{
THE GREAT NORTH-WEST
}

AND THE GREAT

LAKE REGION OF

NORTH AMERICA

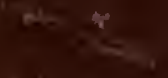




\section{LIBRARY.}

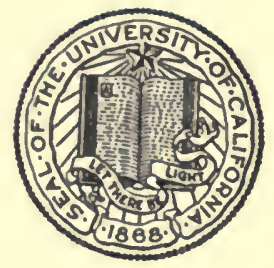

\section{THE LIBRARY}

OF

\& THE UNIVERSITY OF CALIFORNIA LOS ANGELES 


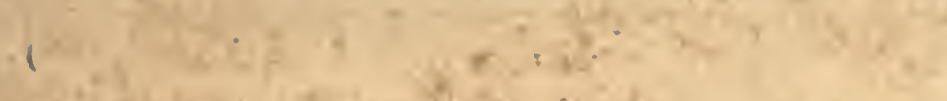

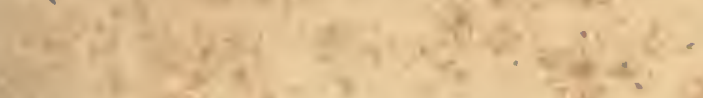

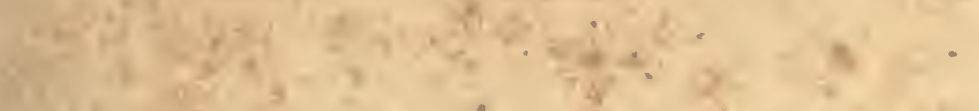

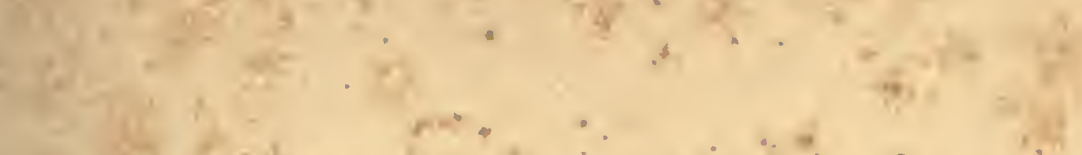

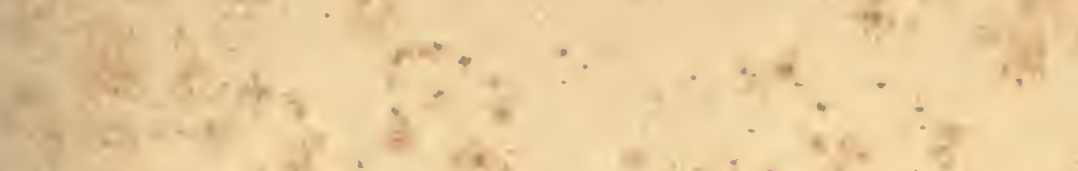

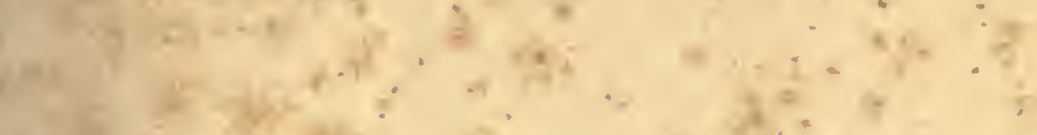

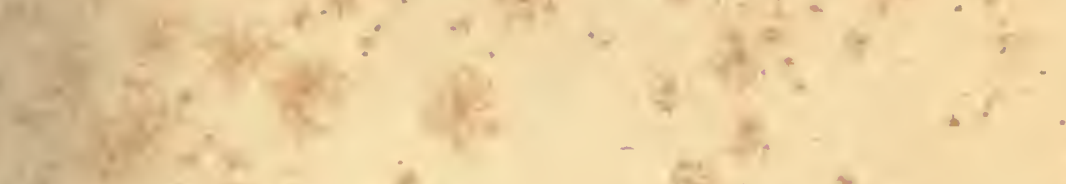

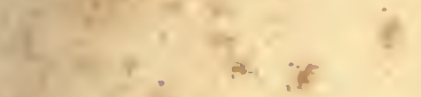
the if

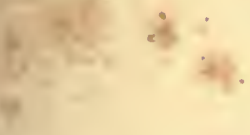

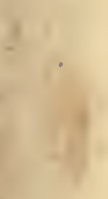

A.

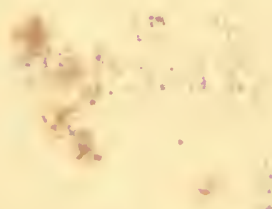<smiles>C1CC1</smiles>
is

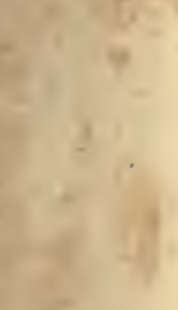

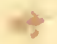

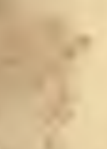

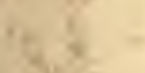

.
$\because k=$
$+,+$

$-9=$

:

$\frac{y}{y}$

arition.

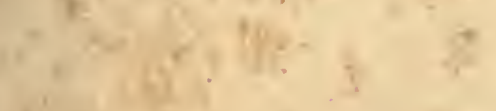

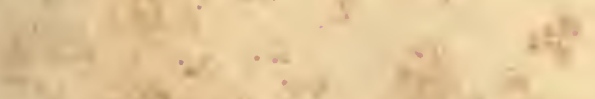

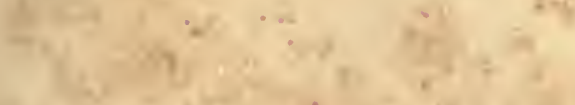

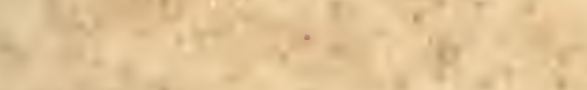

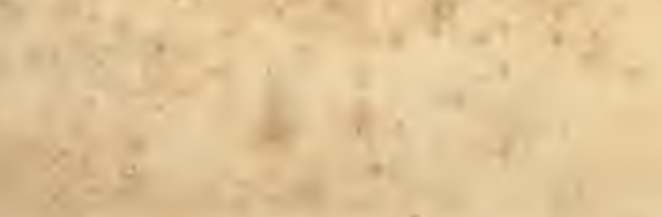

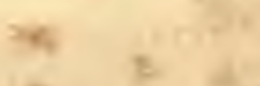

y 

$-$

$=0$ 
Digitized by the Internet Archive in 2007 with funding from Microsoft Corporation 


\section{THE GREAT NORTH-WEST AND THE}

GREAT LAKE REGION OF NORTH AMERICA 
BY THE SAME AUTHOR

THE GREAT DESERTS AND FORESTS OF NORTH AMERICA

With a Preface by W. H. Hudson

$8 \mathrm{vo}, 9 s .6 d$. net

THE GREAT MOUNTAINS AND FORESTS OF SOUTH AMERICA

With Portrait and 7 Illustrations

$8 v o, 10 s .6 d$. net

LONGMANS, GREEN, AND CO.

LONDON, NEW YORK, AND BOMBAY 


\section{THE}

\section{GREAT NORTH-WEST \\ AND THE}

GREAT LAKE REGION

\section{OF NORTH AMERICA}

BY

\section{PAUL FOUNTAIN}

AUTHOR OF "THE GREAT DESERTS AND FORESTS OF NORTH AMERICA," AND

"THE GREAT MOONTAIXS AND FORESTS OF SOUTH AMERICA"

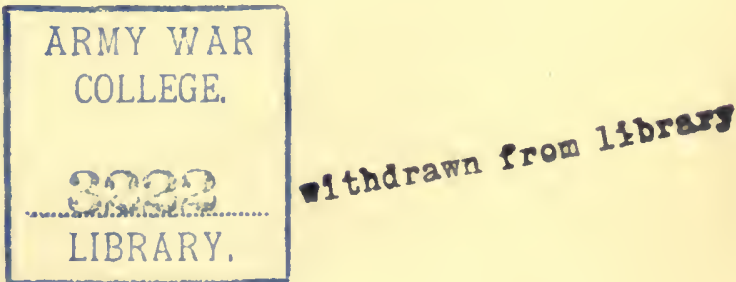

L O N G M N S, GREE N, A N D C O.

39 PATERNOSTER ROW, LONDON

NEW YORK AND BOMBAY

1904 



\section{2 \\ F \\ 1013 \\ F82. \\ P R E F A C E}

THIS work is a sequel to the two former books, "The Great Deserts and Forests of North America," and "The Great Mountains and Forests of South America," and is the last of the series.

I have endeavoured to make the present work as perfect as possible, and pleasing to the scientific as well as to the general reader. There are few animals of any class mentioned or described herein, unless I was in a position to give their specific name. I have thus endeavoured to make the book of as much value as I could to the professional naturalist, and have striven to avoid giving him offence. But on this matter I have my own knowledge (I do not say opinions, for they are not mere opinions), and I have not endeavoured, as too many modern writers have done, to make my facts fit the fads of the present generation of naturalists.

In the early part of my career I had the advantage of hearing, from his own lips, the peculiar views of Mr. Darwin. Darwin was so amiable a man, and of so great an intellect, that I never think of him without feelings of reverence; but I am not one of his converts. Evolution, the descent of man, natural selection, are for the armchair naturalist; not that I wish to sneer. I am not a man of tlat sort. But I have seen and learned for myself; th refore, if occasionally I do not agree with received op pions, I trust it will be remembered by the reader that am only stating my own convictions.

I think here is more of personal matter in this than in either ofd the two former books. I hope it will be found of ary interesting nature; at any rate the queer

\section{0}


accounts of some queer people are faithful description, if written in a style of my own.

I gather from what some of my critics have saidand I am much beholden to them for several valuable hints which I have tried to act on--that they would like a freer and more connected use of dates. I regret that there are circumstances, such as the irregular manner in which I sometimes made my notes, the intervals of trading journeys, causing a break in the time, \&c., which make it impossible for me to present a narrative in journal form. The first half of the book, however, giving my first experiences in America, when I was a mere boy, is tolerably connected.

Finally, let me say, that all my books are retrospective in point of time-a fault that I regret, but one which it is now too late to remedy. To a great extent I describe a beautiful past; for the face of the great American Continent is everywhere changing fast in appearance-too fast to please those who adore Nature in her virgin mantle.

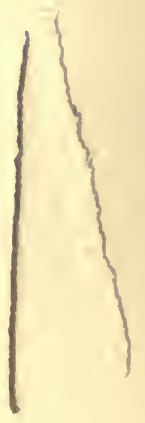




\section{CONTENTS}

CHAP.

I. THE WOODLAND LAKE . . . . . 1

II. MY COMPANIONS • $\quad$ - $\quad$ • 10

III. FISHING, AND OTHER SUMMER OCCUPATIONS . . . . . . . 18

IV. THE APPROACH OF WINTER • . • . 25

V. DEER-SHOOTING . . . . . • • • 41

VI. WINTER AT ITS HEIGHT . . . . . 51

VII. A JOURNEY TO THE RED RIVER • • • 57

VIII. RED RIVER SETTLEMENT • • • • • 77

IX. CONTINUATION OF THE VOYAGE IN THE WINNIPEG REGION • • • • • . 85

X. A MONTH'S ENCAMPMENT IN THE WILDERNESS $. \quad . \quad . \quad . \quad . \quad . \quad$ • 95

XI. A WINTER IN THE SOLITARY WILDERNESS 113

XII. CONTINUATION OF THE JOURNEY TO FORT SEVERN . • . • • . . . . 129

XIII. THE COMMENCEMENT OF THE RETURN JOURNEY TO THE OTTAWA RIVER • . 136

XIV. THE COAST OF JAMES BAY TO THE HEAD OF THE RIVER ABBITIBBE . . . . 148

XV. A JOURNEY TO THE GULF OF ST. LAW.

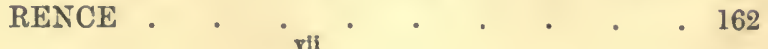


CBAP.

XVI. A WINTER WITH THE LUMBERERS

XVII. YANKEE-DOODLE . . . . . . . 194

XVIII. "BEES" . . . . . . . . . 205

XIX. THE OHIO DISTRICT . . . . • . 213

XX. SHAKERS AND RELIGIOUS MUMMERS IN

AMERICA . . . . . . . . 231

XXI. MICHIGAN $\quad$ • . . . . . • . 248

XXII. THE WILD BEES OF THE AMERICAN FORESTS . . . . . . . . 261

XXIII. LIFE IN THE WOODS OF NORTH MICHIGAN 269 XXIV. ANIMAL LIFE ABOUT MR. DUNFORD'S FARM, \&c. .

XXV. JOURNEY FROM MR. DUNFORD'S FARM TO MARQUETTE . . . . . . . . 300

XXVI. THE SOUTHERN SHORES OF LAKE SUPERIOR 314 XXVII. THE NORTH SHORE OF LAKE SUPERIOR • 335 XXVIII. PEDDLING IN THE UNITED STATES • . 343 GLOSSARY . . . . . . . . . 349 INDEX . . . . . . . . . 350 


\section{THE GREAT NORTH-WEST}

\section{AND THE GREAT LAKE REGION \\ OF NORTH AMERICA}

\section{CHAP'TER I}

\section{THE WOODLAND LAKE}

NEAR the head-waters of the Ottawa 'River, and some twelve miles from Lake Temiscaming, there is a small lake surrounded with woods. It is about three-quarters of a mile long and from two to five hundred yards across, and of irregular form, but of good depth, as nearly all these small Canadian lakes are. These "ponds," as they are called by the inhabitants, are numerous in all parts of the British American possessions, and the term "pond" is applied to very much larger bodies of water than this. Lakes of ten or twelve square miles area are "ponds" in local parlance; sheets of water, which in other countries would be esteemed considerable, sinking into insignificance in the proximity of the vast lakes which are the most remarkable feature of this part of America.

On the banks of the tiny lake I have mentioned, the surface of which, I suppose, was about a hundred and fifty acres in extent, I established myself in the summer of 1865 , being at the time not seventeen years old. I had as companions two Indians, a half-breed and the wife and daughter of the latter. The men were hunters, seeking furs for the Hudson Bay Company, and intended 
to trap and hunt in the neighbourhood of this lake during the ensuing winter; and I joined with them for the sake of companionship and mutual help while exploring this district.

I had intended to take up land in Upper Canada, and went the length of applying for a quarter section (a hundred and sixty acres) on a located township; but my youth, and the smallness of my capital, telling against $m e$, induced $m e$ to decide to wait a time, and meantime to see something of the wilder regions of the country and endeavour to increase my means. Consequently I took a journey to Moose Factory; and it was on the return route that I picked up with my present companions, and agreed to pass a winter with them on Wolf Pond, as they called it, from the number of wolves they had trapped in its neighbourhood.

The lake swarmed with fish, as nearly all, even the smallest, of them do. I have frequently found pools of only an acre or two in extent crowded with fish; and no matter how small these woodland ponds may be, they all seem to be permanent: I could never find that any of them dry up, even in the hottest summers.

There are at least a dozen different species of fish inhabiting the small lakes and ponds. I do not mean that the ponds are their exclusive habitat, or that all the species are found in one lake. Many of them are found only in certain lakes; and most of them inhabit running waters as well as lakes.

The most abundant in Wolf Pond was the pickerel. This fish seems to me to be a species of what the naturalists call "pike-perches." It resembles the pike in many particulars, such as shape, taste of the flesh, and similarity of prey; but not in size or habits : for it seldom exceeds three pounds in weight, and it goes in numerous shoals. It will be found in one or two favourite corners of a lake, and perhaps in no other part; but more singular still, one lake may abound with them but others in the neigh- 
bourhood not contain a single pickerel. In a dozen small lakes scattered over an extent of ten or twelve miles, I have found pickerel in two or three, the remainder being destitute of them.

The pickerel is not dainty eating; but it is a valuable fish to the Indians and trappers, owing to the facility with which it may be caught in winter-time. When the lakes are frozen, if a hole is broken in the ice and a live bait used, they may be pulled out as fast as the hooks can be baited; and it is usual to have many lines in use at the same time. The great difficulty is to discover the spot in the water where the fish are lying. To do this you may have to break a line of holes nearly right round the lake; but you may rely on it that the fish will always be in large shoals, and that if they once commence to bite you will have good sport. They are not often found in the middle of the lake, but they like twenty or thirty feet of water, and therefore do not come inshore. A fragment of meat may be used as a bait; but tiny fish, called in Canada minnows and sticklebacks (which they are not), are the best and surest bait.

In our pond there were two kinds of "bass." There are four kinds found in the fresh waters of this region. They have received the name "bass" from the colonists, and I am not aware that they are misnomered; but I have not been able to discover the specific name of any of the species mentioned in this account. The two kinds here were the white bass and the striped bass, the latter a handsome fish, but neither running to a greater size than the pickerel. There were also mullet and grey trout, which are often called salmon-trout, and the largest of which that I caught weighed about four pounds; but in some of the neighbouring streams I caught them of more than double that weight. There were no fish in the pond of a greater weight than four or five pounds; but in the rivers there were fish of vastly greater size, and also in the large lakes of the district-Temiscaming and Grand. 
Wolf Pond was a favourite haunt of my companions -almost their home in fact-because here they were always sure of a good supply of fish at all seasons, though in the winter, when the water was frozen, it was sometimes difficult to get the pickerel to bite, and the other fish rarely did so. The squaw and her daughter (a girl of eighteen) performed most of the fishing, and, I am sorry to say, the greater part of the hard work about the camp. But this they seemed to think quite their natural employment, and I never heard either of them murmur or complain.

In many parts of the great North-West, and particularly in some spots now well known (I am writing of thirty-seven years ago), as the Red River district, and the country north of Lake Superior, the Indians had often to subsist entirely on fish, and but for the supply of this food they would often have starved. Indeed, when the fishing failed, as it sometimes did in the winter-time, deaths from want were often numerous. I shall have more to say about fish and fishing presently.

Near Wolf Pond (which is not marked on the maps) game was not plentiful, as it is not in any part of the British possessions compared with what it is, or used to be, in the parts of the continent possessing a more genial climate. Pelt-bearing animals had to be sought for far and near; and the Indians, of whom there were several families near the pond, used to take excursions in all directions, remaining away many days at a time, leaving their squaws and children to catch and dry fish, and to cultivate a little grain during the summer.

The pond was closely surrounded with woods, mostly composed of pine trees; but farther back there were maples, hemlocks, junipers, and many others, and several cedar swamps, in places with the trees growing so closely together that it was impossible for a man to move about among them. The gloom in these swamps was so deep that a watch could not be read unless it was held close 
to the eyes. There were also swamps in which no cedars grew, but the ground was overrun with bushes, and these were favourite spots for many of the wild fruits which grow in the Canadian district. Here there were cranberries in abundance, a fruit much esteemed in all the American districts where it grows. Gathering them was a ticklish business, for the favourite habitat of the bush was a treacherous peat-moss into which I more than once suddenly sank in an alarming manner.

The blackberries which I found here were much finer than any which I ever saw in old England, and there were also wild strawberries which were small and of little worth. I was surprised to find wild cherries in these woods, and disappointed to discover that they were of such bad flavour as not to be worth the trouble of gathering. Of a few other wild fruits found here I must make the same remark. I was further reminded of the woods and lanes of the dear old country by finding plenty of hedge-nuts; but on the whole this country is not better provided with berries than England; and I could quite realise that a person lost in these forests could easily starve to death, an opinion the reverse of that I used to entertain: for I had repeatedly said that I could not believe that a person keeping his head, and displaying a little energy, might not easily find the wherewithal to sustain life for a considerable time in the dreariest forest. Here, however, it would all depend on his being able to procure fish from the waters; for the vegetable products are very scanty in winter, only a little moss being eatable, and that difficult to procure when the snow is on the ground. As to game, he might have to go many days without seeing anything large enough to kill, even if he had the fortune to come upon it within range; for most of the animals and birds about here, in the summer season at least, were very wild.

The commonest of the small birds at this time was the Lapland bunting (Calcarius Lapponicus), which har- 
boured in the swamps where there were few or no trees, and appeared to breed in such situations; for I found two nests, both of which were carefully hid in the bottom of bushes, and resembled sparrows' nests, being constructed loosely of hay lined with feathers, mostly those of ducks or geese and grouse. One of the nests contained unfledged young birds, the other eggs. The eggs were dull grey in ground colour, thickly blotched and spotted with two or three shades of brown.

A curious bird frequenting the trees, and often wandering about the camp in the boldest manner was a bird called by the employees of the Hudson Bay Company, the "whisky-jack"; but for what reason I could not discover. It greatly resembles the great grey shrike (Lanius excubiter) of Europe, being about the size of a missel-thrush; but the feathers are so loose and abundant that it looks a much larger bird than it really is. It is a noisy and a greedy bird, being particularly fond of scraps of meat and fat; and instructed by one of the Indians, I lay on the ground, covered with green boughs, and with the hand extended with a piece of fat in it I captured many by suddenly closing the fingers when they came for the bait. They cried loudly and pecked fiercely, but were not much frightened; for when released they flew to the nearest trees or bushes, and after shaking and arranging their feathers, and uttering a few angry notes, came back to look for more scraps.

Among the most interesting birds harbouring about this lake was a pair of great northern divers, called throughout this country, and the north-eastern part of the United States, loons. The specific name of this bird is Colymous glacialis and Urinator Imber in America, Colymbus glacialis in England; an instance of the confusion often engendered by "scientific nomenclature." Why plain "loon" would not do to designate the bird all the world over it is difficult to say; unless the desire to mystify is ineradicable in all the "learned." Loon is 
a corruption of the Icelandic word loom, which means a cripple; applied to the bird on account of its waddling, lop-sided walk. It scarcely ever attempts to walk, indeed, so awkward is it on dry land.

From the manner of the pair of loons on Wolf Pond I thought that they were breeding; but I could not find the nest. Towards the end of July, however, they appeared with a young one. Two is the nominal number; but probably one egg had been destroyed by accident. By careful watching I discovered that the breeding-place was in a tunnel formed in the rank grass where a small runnel left the lake, and so well hid that it could not be reached without great trouble and the aid of a canoe.

I did not disturb them at this time, but a few weeks later I tried to shoot the cock bird. This was not an easy task; for the instant I fired he dived so quickly that he avoided the shot. I always had to fire at long range, as the birds would not permit a nearer approach than about fifty yards. The squaw took me on the lake in a light hunting canoe, and we had quite an exciting chase after this bird, lasting nearly three hours. I marked the cock bird; but the hen, with her chick, kept at no great distance from him; and the beautiful little creature dived as adroitly as its parents.

The old bird displayed great cunning. I believe that it was frequently under water for as long as four or five minutes; but it repeatedly only pushed its beak up, as high as the nostrils, to breathe, and then dived again before I could get within shot. At length I shot it with a rifle bullet as it was so breathing, aiming low so as to strike it under water. The hen and the chick I left undisturbed; but they disappeared about a week after the death of the cock, probably going to another lake, as I do not think that the chick'was strong enough to fly far. These birds rise heavily, but fly high and strongly when once fairly mounted. It is very difficult to get them to rise from the water; for they seem to know that 
they are exceedingly expert swimmers and divers, and. have a better chance of escaping in that element than by flying.

The bird I killed was thirty-four inches in total length, and weighed seven pounds two ounces. I never found more than one pair of these birds on the same lake. Several other lakes within a few miles of Wolf Pond were frequented by pairs of loons; and I always saw these birds in couples, but I cannot say whether or not they pair for life, as they migrate at the approach of severe weather. On a subsequent occasion I took the eggs of these birds. The nest, which was scarcely more than a lair, was situated among thick marginal herbage; and the eggs, two in number, were very dark-a greyish brown sprinkled, rather sparsely, with dusky spots. They were about the size of those of a goose, and were lying within a foot of the water.

On the borders of this same pond a couple of ospreys had also taken up their quarters, having their nest in a tall pine tree, some eighty feet above the ground. One of the Indians climbed up and brought down the eggs, three in number; but the birds laid again: for they had two young ones which showed themselves at the end of July. The eggs were light buffish-grey in ground colour, much blotched with deep crimson-brown, so that the larger ends were an unbroken blotch of colour.

The osprey is always called the fish-hawk here, and in the States; and they are so plentiful that almost every little lake which contains fish harbours a pair; and the hunter knows, when he sees these birds near the water, that it is well stocked. There are never two pairs in near proximity; and they fight fiercely if an intruder dares to invade the territory of a neighbour. In such combats one of the birds is frequently killed.

About the 18th of September many of the Lapland buntings had gone, and they all disappeared by the end of the month. The loons migrated about the same time, 
the last being seen on the 2nd October. The Indians thereupon predicted that the winter would set in within a day or two; and accordingly, on the 4 th, when we arose in the morning the pond was found covered with a thin coat of ice.

The fish-hawks did not forsake us until a month later; for an odd bird was seen hovering about as late as 30th October, at which time the lakes were frozen hard and the ground covered with snow. It would seem probable, therefore, that the food of these birds is not confined to fish, though I never could discover them preying on other animals. 


\section{CHAPTER II}

\section{MY COMPANIONS}

THE half-breed I have mentioned was the son of an Englishman by a half-breed woman. His name was Andrew Whitting, and he was married (according to Indian custom) to an Indian woman named Chompel, abbreviated colloquially to "Chom." His daughter, Emma, had been christened a Protestant, and was a charming girl. She and her father could read and write a little, and were Christians. The Indians, Monchuapiganon ("Deep waters," in the Cree language) and Chuckochilgegan ("Cunning polecat"), were elderly men about fifty and sixty years old respectively. They were Crees from the shores of Hudson's Bay, and their names being such awkward ones to pronounce, I took the liberty of styling them Tom and Sam, familiar names to which they took kindly enough. These two men were brothers, and Chuckochilgegan, or Sam, was the father of Whitting's wife. He had had three squaws, one of whom was drowned in an accident while shooting some rapids; and another he told me was starved to death in a hard season; deaths from such causes being not an unusual occurrence, formerly, in the North-West.

Tom, the younger of the two Indians, had never had a wife; an unusual circumstance among Red Men. He was a man of very taciturn disposition; and though he liked to hunt, fish, and wander about the woods in my company, we often spent an entire day together without speaking a dozen sentences. I think he had met with some disappointment, or injury, that had soured him; 
but an Indian does not like to be questioned on such matters.

Within four or five miles of our camp there were several collections of Indian lodges, mostly belonging to members of the Seauteaux tribe, but with a few Crees among them. There was also an Englishman living about two miles from Wolf Pond, having adopted the habits of the Indians; but he was a man with whom I could not associate, though he sometimes wandered over to my hut to make himself objectionable. $\mathrm{He}$ was not liked by the Indians amongst whom he lived; and I wondered that they did not expel him, as, indeed, they ultimately did; but the Crees are a quiet and amicable people.

The Seauteaux differ but little from the Crees. Both tribes are very peaceably inclined, and are not such physically fine men as the Indians farther south, in the States. They are of medium height, few of them exceeding five feet six, and are sparely built, though lithe and strong. They are nearly all hunters and trappers, and though possessing some villages, do not congregate in large assemblages, and spend most of their time wandering over wide tracts of the country in search of game. They are affable to strangers, and hospitable; but this is a common trait of all Red Men. Those in my neighbourhood had a curious custom of threading beads on their hair; but, like other Indians, they wore no other headdress than an ornamental one of feathers. Their dress consisted sometimes of a striped jersey, and sometimes of a kind of frock and trousers of baize or coarse flannel. To this was often added a red or a green blanket, worn cloakwise. They all possessed firearms of common quality, with butcher's long knives and tomahawks or hatchets. Besides the very little cultivation of the ground performed by the squaws, their sole means of subsistence depended on the success of the hunters and an annual allowance of flour, blankets, \&c., from the 
Government. If they had good success in the winter months, the price of the skins, received in kind from the Hudson Bay Company, enabled them to live in tolerable comfort throughout the year. But they often suffiered cruel privations, especially the squaws and the children; for game is not always equally abundant, and the price paid for pelts by the Company was very small. So that it was only the successful hunter who could do tolerably well. But I shall have to return to this subject.

I first became acquainted with my party through an employee of the Hudson Company, and, in the early part of the summer, performed a journey from Moose Factory with them. There was nothing remarkable in that journey; but it enabled me to become acquainted with the method of travelling in these regions, and to learn to paddle a canoe, shoot a rapid, and make a portage. As the journey was a hurried one, there was no time for either sport or exploration, and we were back at Wolf Pond before the summer was half over.

My friends had permanent huts here, like other Indians in the neighbourhood, built of small logs and boughs placed in a sloping position against a rough framework, made air-tight with mud, moss, \&c., forced into the chinks. Such huts are snug and warm in winter; but these were very low pitched, and I built myself one, with their assistance, of a more pretentious elevation, and divided into two compartments. The Indians' huts had no chimneys, but the smoke was left to find its way out through a hole in the roof. In fine weather the fire was made outside, near the door. I, with considerable trouble, built a fireplace and chimney of short logs, which added greatly to the comfort of my home; and in this chimney, in the following spring, a pair of martins built their nest and successfully reared their young. Strange that these birds should select such a situation for their nest! For thousands of generations they must have been in the habit of selecting a 
different site; for it is certain that there were no chimneys in America previous to its colonisation by Europeans.

These martins were not seen here till the 4th of June, and there were no young in the nest till the 13th of July. The species greatly resembled the Progne purpurea of the States, but I am not sure that it was that bird. Only two or three pairs were seen in the neighbourhood; and though I was told that this bird builds generally in the hollows of trees, I could never find the nest in such situations, but discovered several in the clefts of rocks.

Though my companions thought that I was fastidious to desire so large a residence, they lent me willing hands to do the rougher parts of the work. The chimney and the internal fittings I had to do myself; and being as yet inexperienced, they were done rather roughly.

There were as many huts as wigwams in this district, many of the Indians preferring the former class of residence, especially as they were in the habit of returning hither to spend each summer. Some of the chiefs were owners of several huts, but none of them possessed one so large as that I built. The spare huts were mostly used as storehouses; but where chiefs had more than one squaw (which was exceptional, however), each woman had a hut to herself.

At this time, and I suppose to a much later period, there were few persons in North America, either in the British possessions or the States, who had not in the course of their lives lived in a log-hut; and though there were no log-huts among the Indians I have been speaking of - that is, regular log-huts, built in backwoods fashiona few words about them will not be out of place, for I have both lived in, and assisted to build, this kind of residence.

It was the custom in all parts of North America that I have had experience of, that when a man arrived at a township and desired to raise a log-hut, all his neighbours 
should immediately leave their own business, no matter how pressing it might be, and assist him in the work. No excuse was accepted, or permitted. The man who would not hasten to put his neighbour under cover would be ostracised as an ill-conditioned fellow. But I never knew, or heard of, a refusal. All, farmers and settlers from miles around, hasten cheerfully to perform this work of charitable good-neighbourship.

The most onerous part of the work, however, falls upon the owner of the hut; for he has to fell the timber and "clean" the logs-that is, lop off the branches, and cut the logs of the required length. When he has done this, he intimates to his neighbours that he is ready to have the hut erected. The rationale of this assistance is palpable: one man could not place the logs in position. It takes a party of men to do that, and when they start the work is soon finished. A very good log-hut can be erected in six hours or less, the logs being previously prepared. Sometimes the logs have the bottom side roughly "squared" or cut flat; if all four sides of the $\log$ are squared, they form a "block-house," in distinction to a "log-hut." A block-house is considered a superior sort of residence, and they are seldom erected, except by people who intend to inhabit them for a great number of years. For the log-hut is only the preliminary substitute for a more pretentious house of brick or stone, which the settler hopes, sooner or later, to have the means of erecting.

A foundation is generally placed for the lowermost logs, though not always. Stones or masses of rock, if procurable, are used for this purpose; otherwise "stumps," or the rooted ends of the felled trees, are substituted. If there is no foundation, the lowest logs soon rot, and this destroys the whole structure. If the hut is well constructed of good timber (beech is the best), it will last at least thirty years. As to its size, that is a matter of taste; but if the new chum cuts his logs of greater 
length than some eighteen feet for the sides, and twelve feet for the ends, he will be looked at with broad stares, and have to endure a good deal of chaff. The rule is to add a second hut to the first if more room is required; and this is work for time and leisure, not for first occupancy.

The foundation being prepared, two side logs are first laid on it and firmly secured, and then notched at the ends in such a way that when the end logs, also notched, are fitted to them they are locked fast. Two more side logs are then laid, then two end ones, and so on alternately, all being carefully notched and fitted, so that the structure is of great strength, and cannot possibly be displaced by the weight of any lateral pressure. The largest logs are placed at the bottom, then those of medium size, and the smallest at the top. The sides are raised to a height of about ten to fourteen feet, and the sloping roof is formed of the larger branches from the felled trees, covered with shingles (the stripped bark of the logs). If this shingle roof is skilfully constructed, no wet can penetrate, but it is often covered with turf as an additional protection.

The corners of the hut, where the logs meet, are not completely closed, because it is impossible to make the logs fit tightly at those places. There are, also, usually many interstices between the logs forming the walls. All these air-holes have to be closed, and this is usually done with moss mixed with tenacious mud from the nearest swamp.

The walls up, the roof on, and the chinks "chunked," your friends make themselves merry at your expense with as much whisky as you choose to provide, shake hands, and depart. Such fancy bits of architecture as doors, windows, and chimneys are your work, and you must do them alone and unassisted, unless you care to employ somebody to do them for you. This was often not possible in the back settlements; and I can say, from 
hard experience, that to saw through the heavy logs for the purpose of cutting out the doorways and windows is the hardest and most back-aching work in making a loghut. Sometimes no windows are made, on account of the trouble of glazing them. If you are wide-awake, you bring up a few sheets of window-glass with you, which must be carefully packed to avoid breakage; or you may nail the skin of a fox or other small animal over the orifice. If the skin is well stretched, all the hair scraped off, and the skin rubbed thin with a piece of broken glass or a knife, it will admit light. But better still is the skin of a large fish, if you can capture a muskinongi or a sturgeon.

For the fireplace, the best way is to cut an opening at the end of the hut, and build the chimney outside of fragments of rock or stone, using mud for mortar. A very tenacious mortar may be made with slime from the swamps, well mingled with deer-hair, feathers, \&c. \&c., from the game killed daily. Moss is excellent for mixing with mud to form cement, but if used for chimneys is apt to take fire. There is no danger of this with hair or feathers.

The floor of the hut is generally the earth beaten down hard and covered with small spruce branches, and the furniture consists of roughly made stools and tables. The bedstead is a low platform, or table, in one corner; and the cooking utensils, \&c., you will have brought up country with'you.

Settlers with families sometimes make a ceiling with rough boards, thus forming an upper chamber in the roof, reached, by means of a ladder, through a trap-door. In such cases the upper chamber is usually a storeroom as well as a sleeping-place; and really it is hard to believe, after witnessing the manner in which these people "pig" together in the midst of strong-smeling stores, that overcrowding is dangerous to health. It certainly is not in the backwoods, for healthier little 


\section{MY COMPANIONS}

rogues than the children of the pioneer settlers it is impossible to find. When I first went among them I pitied the sturdy children of my neighbours, seeing them running about without shoes or stockings, and with scanty clothing in very sharp weather, and I used to call them into my hut to share my dinner. That was accepted as hospitality; but when I offered the oldest boy a pair of my shoes and some stockings, he drew himself up with the dignity of a king, and said, "You are mistaken. We are not beggars," and I soon discovered that his father was rich enough to buy me up ten times over. A sturdy, independent race are these Nature-fighters of the great North-West.

Many such huts as those I have attempted to describe have I assisted to build, and on one or two occasions I have passed the winter in a log-hut. I may add that it is usual to peel the bark from the logs before building; but I am convinced from experience that it is a bad plan: for after the rains and snows of winter the fierce heat of summer will warp peeled logs, but not those on which the bark has been permitted to remain. 


\section{CHAPTER III}

FISHING, AND OTHER SUMMER OCCUPATIONS

A GREAT migration of small birds from this district took place at the approach of winter; but big game, on the contrary, seemed to be more abundant when the snow was on the ground. Very few large animals approached our camp during the summer; but they were not much sought after at this season, the pelts mostly being out of condition. Fish was much relied on for animal food till the waters became frozen, and the women spent a large portion of their time seeking it. The occupations of the summer months were largely preparations for the winter huntings, though, on this occasion, the hunters being back early from the depôt had a great deal of spare time on their hands, which they spent in lounging about and smoking, when not engaged in snow-shoe and fishingline making.

The half-breed imitated the Indians in his treatment of his women, and his wife and daughter were the drudges of the camp. When I went fishing the squaw would usually be commanded to accompany me, either to carry the catch or to manage the canoe, as the case might be, and the girl, Emma, would often accompany us. The women liked these little expeditions, especially when Andrew was in a bad humour, not an infrequent occurrence, for he was rather an ill-tempered fellow. Chom, the squaw, would often say, "Fine day. Why not go fish? Plenty fish to-day," and we would make an early start, the woman or her daughter carrying the canoe on her head, and thus we would proceed overland 
to one of the big streams tributary to the Ottawa, or the big lakes, where we were tolerably sure of a big catch of white fish or muskinongi, fish not found in the small lakes.

The white fish is considered, I think justly, the finest flavoured of all the fresh-water fish in this region-that is the great lake district, comprising all the North and North-West of the British possessions and the United States. It is found, I believe, in all the great lakes and most of the rivers; but I never found it in "ponds," the reason being, I believe, that it requires rivers to spawn in. All the great lakes have many streams, feeding or emptying them. White fish are not often found exceeding five or six pounds in weight.

There are no muskinongis in the ponds either, and this fish prefers rivers of some size to even the lakes. It is a huge pike, but of a different species from the English pike. It grows to an enormous size, and affords excellent sport. It is fond of haunting the shallows in the big streams, and is caught better with a rod from the shore than from a canoe; for it is so large and strong that there is danger of its upsetting the canoe or dragging it under. The first that I hooked pulled me into the water, as I was not prepared for such a mighty rush as it made, and I was nearly drowned; but with the aid of the squaw the fish was secured. I suppose that it weighed at least sixty pounds. As I see that a popular work on Natural History casts doubt on accounts of pike exceeding thirty or forty pounds' weight, ${ }^{1}$ I may say that I have actually seen weighed muskinongis which were nearly double that weight. One captured in the Red River was seventy-four pounds, weighed piecemeal, and it is certain that it lost several pounds' weight in the cutting up. Unfortunately there was no means of weighing it whole.

1 Note that big fish, like other big animals, are being rapidly exterminated. I have evidence that there were formerly bigger pike, not only in America, but in England also, than can now be found. 
Muskinongis are as voracious as other pike, and they capture the wild ducks as they swim. I have taken two ducks from the stomach of one, and from another thirteen pounds of fish, most of them about two pounds' weight each. The Indians say that they also devour musquashs and bull-frogs; but they never seem to attack larger animals, though their jaws present a formidable appearance. Afterwards I adopted the Indian plan of spearing these fish as they lay basking in the shallow waters. It is the safest method of capturing them, as they are thus soon disabled or tired out. When stricken or hooked they at once make for the deep water, and if they succeed in reaching it they generally escape. They either hide under big stones or wrap the line round some obstacle, and thus succeed in breaking it.

Fishing in the waters of this neighbourhood was very productive when the fish were in biting mood. Often I have caught in seven or eight hours as much bass, pickerel, and white fish as the two women and myself could carry back to camp - that is, at least, three hundredweight. Our custom was to place the fish in the canoe and carry the latter on our shoulders. I say our shoulders, but I cannot claim much share in the labour, for both the women were so powerful that they would carry for miles weights that I could not even lift from the ground. But, dreadful as it may sound, Indian women are beasts of burden, and use, I suppose, enables them to carry incredible burdens. In moving from place to place the whole of the wigwam furniture, plus a papoose (child), and perhaps two, are placed on her shoulders. The squaw has a lord and master, and knows it, and she is thoroughly cowed. The Indian women of this district are seldom good-looking, but they are of very lovable disposition. The half-breeds, on the contrary, while retaining all the sweetness of soul of their Indian ancestors, are exceedingly pretty, particularly so if their fathers were French-Canadians. The Indian women have a downcast, pensive look; the outcome, no 
doubt, of oppression; but I must admit that I have seldom seen their lords use violence towards them.

The men are not very jealous of their squaws, not so much so as the Red Men of the States. The women will invariably follow a white man, and if cast off they often die of broken hearts. The same may be said of the half-breeds. In my opinion these latter make the best wives in the world, for with the tenacious love of the Indian they combine the greater intelligence of the European. They are also (especially if of French-Canadian paternity) most thrifty little creatures.

I have heard people who have been to Canada speak of "the handsome Indian women" of that country. I think they are mistaken. Native women who can be called "handsome" are seldom of pure Indian blood.

I was not at this time in funds; and the little money I had it was necessary to husband; but I had brought up country sufficient stores to provision me for a twelvemonth. I had no locks or bolts, being of opinion that I could trust my companions, otherwise I should not have joined in fellowship with them. After several of my fishing excursions, however, I missed stores, such as food, ammunition, and clothing; but knowing how thin-skinned Indians are in matters affecting their honour, I did not like to mention the matter. I was surprised, too, beyond expression; for I believe it is a thing unknown for an Indian to rob a man with whom he is living in comradeship. At length my losses became so serious that I was compelled to mention them to Chom, the squaw, in the hope that she would broach the matter to her Indian relatives in a way that would not give offence. I heard nothing of the subject for two or three days; then, one evening, the taciturn Monchuapiganon, or Tom, as I called him, entered my hut, and, without a word, squatted on the floor. After smoking in silence for a long time, he handed me the pipe - the invariable token of amity among these 
people. I smoked a few whiffs, and handed it back to him.

"Lose rifle-powder-coat?" at length he asked.

"Yes," I replied.

"No give present to Big-nose?"

This was the nickname among the Indians for the Englishman of no character to whom I have already referred.

"No! certainly not," I said.

"Den rascal steal?"

"If it is he who has my property-yes," I replied.

Without another word Tom arose and left the hut. In about three hours he returned, bringing the rifle and many other articles. which I had missed. He laid them down, and went off without waiting to be thanked. The next morning the squaw of Big-nose came to me in great distress. Her tribe had turned her husband out, and ordered him to depart. I entreated that he might be permitted to remain, but my interference was useless; these Crees would have him among them no longer. He had to go, followed by his faithful wife and her two poor little children. I relate this anecdote to show the honour and disposition of the Indians. About two years afterwards I met "Big-nose" on one of the wharves at Montreal, and asked after his wife and children. "Well! you must be a goby if you think I bothered myself about them," was the reply. "But what became of them?" I, repeated. "Why, the wench followed me down till we came to the settlements, and I had to threaten her to drive her back," replied the miscreant. I turned on my heel, and went from the horrible wretch without another word.

As she did not return to her tribe, it is almost certain that in the fearful agony of her mind she threw herself and her children into the river.

During the remnant of the summer I spent much of my time wandering about the forests, studying the ways 
of bird and mammal. I often tried to induce one of the Indians to accompany me, but seldom with success. "What good? No shoot now. No fox. No deer. No shoot till snow come." And so they lay about, smoking and lounging their days away. The women were more active. Sometimes a squaw would go with me; and often Emma, the half-breed's daughter. For so surely as I asked an Indian to go with me he would send his squaw to act as my porter, that being the chief use of a woman in their idea; and the poor drudge would insist on easing me of every weighty article. No doubt I had won their hearts by rendering them any little help in times of difficulty that I could; and the gratitude of these poor people is never failing.

My success as a wandering naturalist was not great; and the little information which I gleaned will be more profitably recorded later on. I only say now, that I was surprised to find such a paucity of animal life here at this time of year; but no doubt the game had been much disturbed: for the number of Indians in the neighbourhood was great, many families collecting to pass the summer together, and their wigwams and hamlets being scattered over a wide stretch of country. They do not hunt much in summer, though any animal fit for food which comes in their way is taken or shot, but devote their attention more to fishing. The eggs of ducks and geese formed a minor article of consumption among them: for many of these birds bred extensively in the swamps of the district, parties of the squaws going as far off as twenty miles to gather them; while later in the year they sometimes returned with as many wild raspberries and blackberries as they could carry.

The Indians are very wasteful in their habits, permitting much of the fish and fruit to rot, though they have a method of preserving the former by drying it in the wind. This dried fish becomes as hard as wood, and 
loses all its flavour; but, boiled, it forms a meal in times of scarcity.

The Indians are also dirty as well as wasteful in their habits, and the ground was soon so filthy around their huts that I was thankful that I had erected my shelter at a convenient distance from them. My desire for cleanliness, and habit of daily bathing, was a source of amusement to many of the Indians, who seemed to think me fastidious on those points. They never so much as wash themselves, but enter the water readily enough while hunting, or fishing, or to swim to an islet in search of ducks' eggs.

I have never seen the Crees use nets to capture the fish, but they are very clever at impaling them with a kind of dart, called a fish-spear; and the children would spend most of the day exercising this art on the banks of the pond, or embarked in small canoes. They often upset these canoes; but as they could all swim, no serious accident occurred.

Either from continual persecution, or perhaps from natural instinct, the fish in the pond often disappeared into the deep water, and none could be hooked or speared for many days together. At such times, however, they could often be attracted by burning a torch at the bow of the canoe at night-time. That the fish really hid during the day seems to be confirmed by the fact that at such times I noticed the osprey bring large fish from other waters. 


\section{CHAP'IER IV}

THE APPROACH OF WINTER

The summer of 1865 was not as hot as usual, according to the Indians. I, however, was surprised to find so great a degree of heat in so high a latitude; but it is to be remembered that at this time I was an inexperienced boy, knowing nothing of the land whither I had come to pitch my tent, and every experience was to me new and striking to the point of the wonderful. According to the sarne authority the winter set in late. The lake was almost completely covered with thin ice on the 4th October. It is said that fogs are almost unknown to Canada, but there was a dense one here on the 6 th. It cleared away at noon, and for a week there was great heat again; yet I noticed that nearly every small bird, and most of the larger ones, had migrated by the first week of the month. On the night of the 11th there was a sharp frost, and when I arose in the morning the scene was one of surprising beauty. The frost had completely changed the appearance of the forest, the leaves of which were now rich with every tint of red, yellow, and orange, presenting a sight which, for richness of colour and variety, cannot be described. Frost succeeded frost, and in three days there was a sheet of ice over the pond strong enough to permit of its being traversed in all directions. There was no snow till the $23 \mathrm{rd}$, when several light showers fell, just covering the ground. Thenceforward there was more daily, till, at the end of the month, it was perhaps a foot deep, and the Indians prepared to start on the first of their hunting expeditions. 
The whole of the Red Men in the district broke up, or perhaps I should rather say assembled (for they were scattered all over the country), into small parties of four, five, or six, generally relations. I knew of no instances where single Indians went to hunt alone. In many cases the squaws were taken. Only very old men, women, and children were left behind in the wigwams. Hand-sleighs of light construction were taken by many of the parties; others, who departed more lightly equipped, deferred making these sleighs until they had obtained pelts to load them with. The hand-sleigh is constructed much on the same principle as the snow-shoes, with the addition of slight cross and side timbers, and is drawn by means of skin-ropes, and enables the hunter to draw burdens of two or three hundredweight with ease.

The hunting-parties did not always stay away from their homes for any length of time; but if successful in their search for game soon returned with their spoils, and in a day or two made a fresh start. But as the season advanced, and the snow became firmly frozen, they were often away for considerable periods. Game, also, was not abundant near the encampment, through, no doubt, having been frightened away by much persecution. 'The method of hunting, and providing for the hunter's necessaries in the forests and wilds, will best be learned from a description of my own experiences.

I, of course, joined with my friends Andrew Whitting (the half-breed), Monchuapiganon (T'om), and Chuckochilgegan (Sam); all of them old hands and much experienced hunters. Andrew at first thought to take the squaw and his daughter; but the two Indians opposed the intention, as, I need scarcely say, I did myself, thinking it cruelty to expose two women to the hardships of forest life; though, it is to be noted, I did not at this time know how hardy the Indian women are, nor that camping-out in this severe climate is by no means so trying as it may be imagined. 
Our first expedition was not an important one. It consisted only of a journey to some extensive pine woods to the north-east, where we, and several other parties, were attracted by numerous wolf tracks. I have already mentioned that this district was noted for its wolves, whence the Indian name of the pond. The various parties of hunters kept widely apart; in fact we saw none of our neighbours, except in going and returning.

There was but little snow on the ground, and that little loose, so that snow-shoes were not used. We took one hand-sleigh; and I, for my own convenience, carried a kettle, pot, and some cocoa, and other luxuries; and my nuzzle-loading Enfield rifle, and a Colt's six-shooter, a heavy, cumbersome weapon, but of great power. Breechloading firearms were scarcely heard of at this period; but I have always been in favour of muzzle-loading weapons for shooting dangerous animals. Referring to this fact, one of the critics of my first book remarked that I knew nothing of guns, nor the power of the breech-loader. Such a remark could only provoke a smile, and showed that the critic had had no experience. The breech-loader is the weapon of the dandy pot-shotter. It is excellent (if you are a marksman) for long-distance shooting, but is 50 per cent. inferior to a good smoothbore musket for close-quarter shooting. The bullet from an express rifle will go through the heart or brain of a bear and not stop him; indeed, if through the heart, ten to one it gives him no trouble. The wound closes after the bullet, and no bleeding takes place. But the spherical bullet from a muzzle-loader, with propelling charge of eight drams, tears heart or brain to pieces, and drops your quarry at once. All old hunters know the value of the muzzle-loader, and none know it better than Indian tiger-shooters. As a consequence of my experience during the first year or two of my sojourn in America, I had a couple of double-barrelled, muzzleloading muskets, with plenty of metal in the breeches, 
specially made for me; and they were ever after my favourite weapons. I used a rifle only for distant shots, and a breech-loader for birds. I may add that a good gun, like a good wife, is not to be picked up every day; and that gentlomen having arms made for them should go to Birmingham and make their own arrangements for their weapons. For all the so-called London guns are made there; though, possibly, they are put together in the City. Pay a maker his price, but insist that the weapon shall be capable of a pre-arranged performance; and then when you find yourself within six paces of a grizzly or black bear, you will have nothing to fear.

We reached the wood which was our destination at nightfall. The intervening country was well timbered, being, in fact, forest land; but this spot was said to be a favourite haunt of the wolves, and consisted of an extensive tract of pine forest, with few or no other trees. I suppose that the great number of hares here was the attraction to the wolves. These hares, called wood-hares by the trappers, presented a motley appearance; for they were just beginning to turn white. These were the Lepus Americanus of the naturalists, and not the wood-hares of the States, which do not change colour in the winter. The ground they occupied was hilly; and they were most abundant on the outskirts of a wood facing nearly north-east, where there was a tract of ground covered with thorny bushes with hare tracks between. The hares, if not actually gregarious, were thickly scattered about; and we had a couple of brace, which I shot, for supper; but they were as flavourless as the mountain-hare. I could have shot at least a couple of dozen, for they had a habit of crouching under the bushes until closely approached, thus affording a fixed mark for the Colt revolver, with which I knocked them over, steadying my hand against a tree.

My companions objected to this firing, alleging that it would alarm the wolves. That the Canadian wolf is 
as cowardly as that found farther south in the States is certain, and yet it is a vicious and dangerous brute. There were about here also a number of red foxes, and these certainly preyed on the hares: for I found bones and fragments of skin in the lairs of the foxes.

Arriving on the ground where it was intended to pass the night, my companions cleared away the snow, and formed a dome-shaped hut about four feet high, capable of containing the four of us. Loose snow being piled over this structure, and a good fire made close to the entrance, we had a warm and comfortable sleeping-place for the night, and many other nights afterwards, in this, or a similar, hut. No bedroom in an English house could have been warmer. Of course we had our blankets with us, and a thick bed of spruce boughs under us. The hut, I should have said, was constructed of spruce boughs; and the trees I have loosely spoken of as pines, were really the hemlock spruce (Abies Canadensis). The forests of this tree presented a fine spectacle growing to a height of sixty or seventy feet, and clustering in the valleys or ravines between the hills. There were two other kinds of spruce firs here : the red spruce, growing in the swamps, and a species I could not identify, growing in clusters only in very sheltered situations.

The novelty of the situation, I suppose, together with my over-tired condition, rendered me restless during the night, and I slept but little. There was a slight breeze blowing, and this caused a peculiarly sad yet musical sound among the firs. But this was the only noise that disturbed the stillness of the night. I listened intently, hoping to hear the distant howling of the wolves; but no animal uttered its cry throughout the hours of darkness. Towards morning a fox sneaked up, and seized a hare skin. I threw my knife at it, but missed, and the noise thereby occasioned aroused my companions, who arose, though it was still quite dark, and prepared for the labours of the day. 
First we had breakfast, consisting of cakes made of roughly pounded corn, with dried fish, and the cocon which I had brought. The breakfast was not a heavy one; but the Indians do not eat very heartily in the early morning. They prefer an evening meal, when the labour of the day is over; then, indeed, they are first-class examples of trencher-men.

Before daylight the traps were unpacked, and with the first streak of dawn we started to set them. We had a dozen strong steel traps, like those used by keepers to catch foxes, but larger. These traps are procured from the Hudson Company's posts, and are, I should think, made specially for their service. They are furnished with several yards of strong chain, for they must be secured to a branch, or tree, to prevent the fox or wolf walking away with them when caught. And the trap, as well as the chain itself, must be hid under the moss, or these cunning brutes will not go near it. The bait, in this case consisting of the entrails and skins of the hares, was not placed on the trap, but cut up into small pieces and scattered around it; so that, in walking about to gather them, the wolf or fox should accidentally step upon it. If the bait is placed in the trap, no wolf or fox would be caught if you tried till doomsday, so wide-awake are these creatures.

The Indians, before handling the traps, carefully rubbed their hands with the entrails, so as to cover the scent of their fingers, and used every precaution to leave as few traces of their presence as possible, wiping out the marks of their feet in the snow with a spruce bough. The traps were placed a considerable distance apartperhaps a quarter of a mile-at spots where the Indians found traces of wolves or foxes. These traces consisted of the remains of animals preyed upon, and footmarks, and a few other signs which I could not discern, though my friends detected them quickly enough. The droppings of a wolf were pointed out to me several times, 
though I could not have distinguished them with certainty from those of a fox or some other animal. But the general opinion was that there were not yet many wolves about here.

The selecting of suitable spots and setting the traps occupied a great part of the day, and we returned to our temporary hut to partake of the evening meal, having had nothing to eat during the time we were at work. On the way back my friends knocked over several hares with sticks and stones, and these were stewed, or rather boiled, for supper, and eaten up to the last mouthful.

During our absence the foxes had paid our haltingplace a visit, and wandered all around it. Fortunately such a visit had been anticipated, and every article eatable, or made of leather, hung on the branches of trees out of their reach; for these little wretches, and wolves, are so exceedingly voracious that they will tear to pieces and eat a pair of boots, or a belt, in a surprisingly few minutes. It is not safe to leave anything of the kind, or any sort of food, within their reach.

I could have shot several foxes, but my companions begged me not to fire any more, saying that the shot would injure the pelt and make it valueless. The real reason was fear of frightening away the wolves; for it is a fact that these creatures soon learn to fear the report of a gun, and a few shots fired within their hearing will often drive them quite out of a neighbourhood. The skins of wolves are of much more value than those of the common sorts of foxes.

The second night spent in the forest I slept " like a top," being completely worn out; but I was aroused by my companions at dawn to partake of breakfast, which they had prepared before disturbing me. They were in a hurry to visit the traps to see if anything had been taken during the night, at which time the animals, and wolves especially, prowl about more than during daylight. Only one of the traps had an occupant-a poor little red 
fox caught by both fore paws, which howled or whined pitifully as we approached. A single blow on the head quieted him for ever.

We had visited all the traps and were back at the camping-place before noon, and the rest of the day was spent in looking for something to eat. Sam had discovered the tracks of cariboo deer in the snow; and proposed to follow them up. The tracks, however, were not fresh; and considering how few hours of daylight remained, it was thought better to defer attempting to stalk them until the following morning. It was arranged that Tom and myself should undertake this work while the others attended the traps, and we started before break of day. The tracks were easy enough to follow, but it was a long time before we found any that had been recently made, and then we took a circuit of seven or eight miles to avoid the chance of the deer scenting us; for these cautious animals are the most easily alarmed of any American deer, and all are jealous of the neighbourhood of man.

I watched anxiously for the appearance of the deer, but the only signs of them that I could perceive were the marks of their remarkably broad hoofs in the snow. In reply to a remark of mine that I feared we should not overtake our game, Tom waved his hand towards the forest below us and said: "Cariboo dare. All right. Hab shot by-um-by." And so we continued on our way so silently that these were almost the only words spoken during the whole day. I was dressed much in the Indian fashion, and wore moccasins, so that we moved like ghosts, absolutely without sound.

In the afternoon Tom intimated that it would not be possible to overtake the deer that day, and proposed that we should camp out, as going back to our companions would amount to giving up the chase. Though we were almost without food, I consented; for, apart from the fact that I did not like to appear chicken-hearted before 
an Indian, I was possessed with a boyish anxiety and excitement to have a shot at a deer, an experience which I had not yet enjoyed. Among the Indians it is not unusual for the hunters to go an entire day, or perhaps two, without food when engaged in the chase; not from choice, but through dire necessity.

We constructed a temporary hut, similar to the one already described, to pass the night in, and our supper consisted of a few pieces of corn-cake, made of the coarse flour, ground, or pounded between two stones by the squaws. As there were no hares here, nor other small animals or birds, we had to do without meat; and our only drink was the bitingly cold water from a small rill, which we had to break four inches of ice to obtain. We had the comfort of a famous fire, however, and there is a surprising amount of cheerfulness to be acquired from a good fire in these silent wildernesses, as everywhere else.

Another early start, this time without a breakfast, but with the comforting assurance of Tom that we should " hab plenty venison presently." We toiled, however, for some six hours through the forest, where, as yet, there was scarcely any snow, there not having been falls heavy enough to cover the ground under the trees. There was no brushwood, or even herbage, in this forest, and the ground was covered with a thick carpet of fir spines, the accumulation of many seasons, which was as soft to the foot as the finest Turkish carpet. Through this dense forest, where the light was but dim even at noon, the unerring eye of the Indian traced the course of the cariboo. So clear were the tracks to his discernment that our pace was scarcely checked in following them. I could see myself, here and there, where the carpet of decayed leaves, or fir spines, had been disturbed, and also the broken branches and saplings, snapped by the weight of the animals, or nibbled as they passed.

It was early afternoon before we came up with the herd, which seemed to number about seventy. They 
were scattered about among the trees in an open part of the forest, and were resting, a few browsing on the tops of the very young spruce saplings. They were some two hundred yards away, on lower ground than that where we stood, and had not the slightest suspicion of our presence. The Indian had previously cautioned me that the utmost noiselessness was necessary, for the deer would bolt the moment they detected us, and in the present state of the ground it would be impossible to overtake them a second time.

Using the utmost care to keep ourselves concealed and avoid noise, we managed to creep fifty yards nearer. A further advance without discovery was impossible; but the nearest deer was quite a hundred and fifty yards off, double the distance that Tom's common musket would carry with anything like accuracy. Partly by whisper, partly by gesture, he intimated that he would move to the right to a hollow way along which he thought the deer would fly, and take his chance of a running shot. I was to give him time to reach his post, and then pick off the animal I had marked to try my skill on.

My excitement was intense. I actually trembled with eager anxiety to secure my prize. I had never yet shot anything bigger than a hare, and I was possessed with all the enthusiasm of a young sportsman. When I thought that Tom must have reached the hollow way, I, crouching behind a bush, took steady aim and fired. The cariboo fell on his knees and rolled over on his back, but he immediately strove to rise again, and was quickly on his legs. I rushed forward, shouting like a mad fellow, oblivious of everything but the fear of losing my victim, and never noticed the sound of the shot which Tom fired as some of the herd rushed past him. My buck hobbled along on three legs at a good speed, and I lost sight of him for a minute or two several times; but he was badly hurt, and the thick stream of blood on the ground enabled me to follow him as fast as I could run 
(I was lame, and could not run as fast as an ordinary man), and presently he fell again, and I came up and finished him with a shot in the head from the Colt six-shooter.

This was my first deer, and I believe I fairly danced with wild joy at my success. I know that I shouted myself hoarse, and had a sore throat in consequence.

Tom had also had a successful shot, killing his victim outright, and so we were in possession of two fine deer, each of which must have weighed nearly three hundredweight, for these woodland cariboo are much larger animals than the barren-land cariboo of farther north.

Tom soon came up and cut the throat of my prize, and asked me to drink the warm blood which flowed. With disgust I refused; but he took a hearty draught of it, and I afterwards found that this is a usual custom with the Indian hunters. The warm blood of deer is said to be most nutritious and supporting. I have heard that the Esquimaux have the same habit.

The disembowelling and skinning of the two bucks occupied the whole of the remainder of the day, and we camped for the night on the spot where we had slain them. Needless to say that cariboo meat was abundant enough at supper that evening, and as I was ravenously hungry, I think I made the heartiest meal I have ever devoured; and my sleep after it was profound and sweet, until I was aroused by the sound of a musketshot. The wolves, it seems, had been attracted by the smell of blood, and Tom had shot one of them that had been bold enough to come close up.

As it was nearly dawn of day we slept no more; but took a breakfast of broiled cariboo steak, and made an early start to rejoin our companions, carrying as much of the meat as we conveniently could. The rest, with the pelts, and that of the wolf, was placed in the lower branches of the surrounding trees to be out of the way of the wolves. It must be hung at least seven or eight feet 
from the ground, or these brutes will reach it by leaping. Bears sometimes discover, and succeed in tearing down game so deposited; but the disappointed wolves and foxes will hover around for days, and the returning hunter often secures a wolf pelt or two from the would-be robbers.

I should certainly never have been able to find my way back to the camp; but the Indian seemed to take a bee-line to it, and without difficulty found our way. After experience made me a better woodman; but without a careful noting of objects and bearings it is very easy to become inextricably lost in these vast forests. The Indians, though seeming to go carelessly along, are really most acute observers, noting objects that seem very commonplace to novices, and though making none but mental notes, never forgetting a mark or sign.

Owing to the character of the ground and other circumstances, I can give no idea of the distance traversed on this occasion; but we did not reach Sam and Andrew until nearly nightfall. They were somewhat alarmed at our prolonged absence; but exceedingly glad of the supply of meat, for their scanty stock of provisions was all but exhausted, and very few hares could be knocked down, those animals, as a result of being disturbed, having become very shy.

Our companions had had but poor luck with the traps, only one fox having been captured during our absence. The opinion was that the wolves had not yet come south in any great number. It is not to be assumed from these words that Canadian wolves make regular migrations; but they follow game which does, long distances (hundreds of miles) locally. Moreover the wolf is a shifting, restless animal, and much in the habit of making changes in its hunting-ground.

The next morning Tom and Andrew went for the rest of the cariboo meat, taking the hand-sleigh with them, and leaving the care of the traps to Sam and me. When we made our rounds we found three of the traps 
with occupants, two foxes and a badger. All were caught by the feet. One fox had bled to death; but the other two animals were alive and strong, and made desperate attempts to escape, whining mournfully at their impending fate when we approached.

The position of the traps was altered every day; this being a necessity to counteract the cunning of the animals, who scent danger with remarkable quickness and intelligence. Now we could bait the traps with fresh meat, and the effect was seen the following day by the capture of half-a-dozen animals, three red foxes, a mottled fox and a wolf, also another badger; and a fourth fox had escaped, leaving a severed fore-paw in the trap. The flesh of the skinned carcasses is used to bait the traps, but it is not so attractive as deer meat, which is always used when procurable.

To save time when examining the traps I and Sam went different ways, each attending to half the traps. The first that I came to contained a dead, and the second a living, fox; then I found the wolf. The cunning brute was lying on its side quite motionless, and I supposed it to be dead; but when I was about to handle it it sprang at my throat, uttering a savage growl. Fortunately it was held firmly by the fore-paw, and it only succeeded in reaching my leg, which was encased in a strong leather legging, and further protected with the irons which I was compelled to wear. The flesh was bruised and grazed, but I was not actually bitten. The irons were bent, and bore the mark of the brute's teeth, and the legging torn. It is said that the wolf bites pieces out of the man or beast which it seizes, and I know from experience that they will rip a dog or other small animal to shreds in a few seconds, so fierce and strong of jaw are they.

I killed my savage foe with a blow from my tomahawk. It was the only wolf trapped on this occasion.

The mottled fox alluded to above was what is called " a cross fox" by the Hudson Company's people. These 
traders recognise no fewer than six varieties of fox, viz. the red, black, silver, white, cross, and "blue," which last, I, and many other trappers, call a grey fox. It is the white, or arctic (Canis lagopus) fox, in its summer coat. In high latitudes it becomes perfectly white with a black tip to its tail, and a blackish muzzle. Between grey, or blue, and absolute white, these foxes may be found of all shades. Some remain grey, and some white, at all seasons, summer and winter; and I have never found any of them south of the shores of Hudson Bay. They breed in holes among the stones, cavities of rocks, \&c., but never, in my experience, form burrows for this purpose, though they do in the snow for concealment and repose. They do not hibernate.

The other foxes are all of one species. The contrary is asserted in many works, and on "scientific authority." I, however, have found all four varieties in litters of red foxes; therefore, without wishing to be offensive to either critics or "scientists," I say positively that those who assert that these foxes are distinct varieties are mistaken. The cross fox is very common. Often half a litter are so marked. They have a black mark, in the form, more or less distinct, of a cross, on the back and shoulders; and are also often dabbled, or mottled, with black. - The silver fox is black, with a great number of white hairs in its coat, giving it a speckled appearance. When these hairs are few in number the fox is said to be black. A perfectly black fox is utterly unknown. They generally are marked with white in the same manner that a cross fox is with black; and the tails of all are tipped with white.

The red fox breeds in self-made holes, the hollows of trees and rocks, and similar places. The usual number in a litter is four or five, but sometimes six or seven. Seven is the greatest number I have found, but the Indians say that sometimes there are as many as nine. I suspect that in this case there may be two litters in one 
hole. In about every third litter you will find either black, silver, or cross whelps; and occasionally all three in a single litter. The whelps are exceedingly beautiful little creatures, playful, and can be reared up and rendered as tame as domestic dogs. They will not, however, submit to the teasing of children, and are always fonder of their immediate master than other persons in a house.

When there are but few white hairs in a black foxskin, they are picked out by hand, and thus is made the black skin of commerce. What the price of such a skin is now I do not know; but three years after the period I am writing of (1865), during a flying visit to England I sold a very fine pair without a white hair in them, ${ }^{1}$ to a Bond Street furrier for sixty pounds sterling. For similar skins the Hudson Company gave the poor Indians from six to eight castors - that is about twelve to sixteen shillings actual value, not paid in money, but kind.

The pelts of the "blue" and of the white fox are of but little value. The hair, though thick and long, is much coarser than that of the red fox and its varieties. It is certain that these latter foxes never pair with the former, though the habitat of the one overlaps that of the other. The white fox is a pelagic species; and though it wanders inland sometimes considerable distances, I have never seen it myself farther away from the shores of Hudson Bay than eighteen or twenty miles.

The badger referred to above was the Taxidea Americana, an animal that does not differ in outward appearances, or habits, from the common badger of Europe. There are said to be structural differences between the two animals. Perhaps so; but they are very slight, if anybody but the scientific straw-splitter can perceive them. It has been said to me that the American is

1 Chom and her daughter had picked out the few white hairs which originally disfigured these skins. 
smaller than the English badger. It is not; except in certain restricted localities. Those about here measure twenty-six to twenty-eight inches from snout to root of tail. The latter is six or seven inches long. Like the English badger, this is a courageous animal, lives in burrows, and when captured can be rendered exceedingly tame, and will follow its owner about like a dog. They pair in autumn before they hibernate, and the young are brought forth in spring, about May, and perhaps as late as the end of June. They are three to five in number. In captivity they show no desire to hibernate; and even when wild they seldom retire altogether till the very severe weather sets in about the end of November. Like those in Europe, they seldom show themselves during the day; but on bright moonlight nights I have watched them for hours gambolling and playing like dogs.

Tom and the half-breed did not return until the middle of the third day. In spite of our precaution the wolves had got down one of the deer-skins and completely spoiled it; indeed, devoured the greater part of it. We had no further luck with the traps; and a heavy snow-storm setting in, and showing signs of lasting a long time, we returned to the huts at the lake. The snow was partially thawed in a day or two, and a sharp frost ensuing at night, the next morning the trees were covered with millions of small icicles, forming one of the prettiest sights I have ever seen, as the bright sun caused them to glitter and sparkle and emit all the prismatic colours. 


\section{CHAP'TER V}

\section{E E R - S H O O T I G}

THERE is a great fascination in tracking and shooting big game, a fascination that wants a certain amount of checking, or the sportsman degenerates into a common butcher. Excessive slaughter is, in my opinion, one of the most selfish of crimes; for though man has an hereditary interest in the wild creatures of the world, it is an entailed, not an absolute, interest, and it is his bounden duty to remember and guard the interests of his successors. He who exterminates all the game on an estate deprives his descendants of one of the chief pleasures of possession. On a private estate the mischief may not be irreparable: on a public one (the waste places of the world at large) it certainly is. Therefore the man who would not be considered a public enemy, ought to shoot, however remote the hunting-ground, with moderation. There are others to come after him; and a world denuded of wild creatures would be a spoiled world.

The fall of my first buck gave me such pleasure that I was anxious to repeat the exploit. There were, however, no deer in the immediate neighbourhood of the huts, and continual falls of snow made distant journeys undesirable for a time. At length, however, we had fine, bright weather, with the surface of the snow frozen hard. This was the condition required for snow-shoe travelling, and I took my first lessons in this method of progression. Everybody has read descriptions of snow-shoes; I need not therefore waste time here by describing them, or their use, at length. Suffice it to say that they are a 
racket-like contrivance for supporting the weight on the surface of frozen snow, and that they enable the wearer to cover twenty-five or thirty miles a day, whereas without them he would break through the frozen crust, and probably be unable to walk five miles in the same time. Heavy animals, such as deer and bears, ${ }^{1}$ do break through it, and therefore at such times are completely at the mercy of the hunter, who can walk round them, and slaughter them at his convenience, without trouble or danger, for the poor brutes can make no resistance.

Some deer, as wipiti and moose, often get surrounded by deep snow, which they tread down for a limited distance, forming a kind of pit, or hollow, from which they cannot escape. Such hollows are called moose or wipiti "yards," and usually contain family parties of three or four to six or eight deer, and being imprisoned for the winter have to subsist on the fuliage of the trees. Apparently they do this without difficulty, for they are nearly always in good condition. Deer imprisoned in "yards" have no more chance of escape or resistance than oxen in a slaughter-house, and the hunter finding them "pots" the lot, old and young. I believe that the game-laws of Canada now forbid this wholesale slaughter; but at the time of which I am writing men did their own pleasure, and never failed to destroy a yard to the last fawn.

It happened that my second experience of deershooting was at the destruction of a moose-yard. I soon learned to use snow-shoes with facility, and when the weather became favourable for journeying, I and four Indians, including Tom and Sam, started on an expedition in search of game.

Deer-yards are never easy of discovery, because there are seldom any tracks leading up to them, and the pit is deep enough to completely hide the occupants. On this occasion our attention was attracted by a pack of lurking,

1 Note that bears hibernate, but their hibernation is sometimes interrupted. I have seen them about in the snow. 
snarling wolves, which was hovering round the yards in hope, I suppose, of a snap at one of the calves. There were seven moose confined between the snow walls: one old bull, one young bull, three cows, and two calves, the latter of a pretty good size. Bulls, cows, and calves, are the terms applied to these animals, and usually to wipiti too, by the trappers.

The poor brutes seemed to foresee their impending fate, for they made desperate attempts to escape. But they were in a complete trap. The older animals were shot: for the moose is an ugly customer at close quarters ; and the calves killed by cutting their throats.

For the flaying and cutting up of these animals help was required, for they probably produced more than two tons (over 4000 pounds) of meat. One of the Indians was therefore sent back to the village while we proceeded to make shelter huts, and camp in the yard, which was crimson with blood. Here there was soon a disgusting spectacle, my companions gorging themselves with flesh till they were literally unable to swallow more. But this was nothing to what occurred the next day when our messenger returned with about sixty persons at his heels, nearly all squaws and children, with Chom and Emma amongst thein (Andrew was away trapping near Grand Lake). These people were beside themselves with delight, for their husbands and fathers being away in the woods shooting and trapping, they were on short commons, the late severe weather having made it difficult to find fish or small game. Here, however, was meat and to spare, though even the entrails were eagerly sought after as too valuable to be wasted. The wretched little urchins of the party were soon smothered in blood from head to foot, and not a few of them, and their mothers, ate pieces of the meat raw, too hungry, or impatient, to wait until fires could be lit to cook it. Plenty of hand-sleighs had been brought, and the meat was soon all taken away. The women had helped to 
skin and cut it up; indeed they did the greater part of the work, laughing, chatting, and rejoicing the meanwhile.

The skins were our property, and as much of the meat as they could drag away was given to Chom and her daughter. The rest was divided among the crowd of squaws, who in return undertook to drag the pelts back to our huts. All spent one night at the yard, which was fourteen or fifteen miles from the village, and many did not depart till the following day was well advanced, being too intent on feasting to hurry away. Altogether the scene was one of the most remarkable of savage life which I had yet witnessed.

I have anticipated a little. For our people, seeing that many wolves had been attracted to this spot by the scent of the deer, laid traps all round the neighbourhood, with the result that in the three nights we remained here, nearly twenty wolves were captured, besides four which I shot. The Indians might have shot many, but they prefer to trap them, as the marks of the bullet or shot depreciate the value of the skin: so they say.

The wolf-skins were distributed equally amongst us, but lots were drawn for the moose-pelts, as they were of various sizes and values. The method of drawing lots was that which I think is universal in all countries, viz. by holding a number of twigs of various lengths concealed in the hand, he who draws the longest having the first choice. This happened to fall to me; but as I had taken no part in the slaughter, I paid in powder and shot for my share, and in so doing I rose so much in the minds of these simple people that they raised me to the rank of a chief, and as such I was ever after treated by this tribe of Crees whilst I remained amongst them. It may be worth adding that at this time I dressed as an Indian, and have more than once been taken for one at the Hudson Company's posts. Others thnught me a halfbreed. Contrary to the rule in this country, where 
Europeans generally lose colour and become pale faced, exposure to the weather turned my skin a deep red.

We continued our journey, moving in a north-easterly direction, through country that was mostly covered with dense spruce or pine forests, with many small lakes or ponds, all of course frozen hard as iron. There was at least three feet of snow on the ground at this time, the surface frozen so hard that I found, by stepping cautiously, that it was possible to walk on it without breaking through. But for rapid and safe movement the snow-shoes could not be dispensed with.

This country was much frequented by cariboo, several of which we shot, two falling to my rifle. They go in herds, somewhat scattered at times, of fifty to two hundred at least, and my companions used to try to kill two at one shot. This is often done when the animals stand side to side, the bullet having power to go through them both.

But the cariboo, which, the reader probably knows, is the reindeer, is very tenacious of life; and of all those shot on this occasion, not one was killed outright. Several gave us a long run. Where we caught them in the snow it was simply murder. They broke through the frozen snow and could scarcely flounder along, and the Indians walking up to them, cut their throats or stabbed them, and saved their powder. But the animals evidently knew their danger, and on scenting us made for the lakes, where the snow had either drifted or was frozen so hard on the ice that they could run with speed. Here they gave us infinite trouble, some of those wounded running nearly all day before we could get up to them, and one or two escaping altogether.

On the larger of the lakes the snow had drifted into mounds and hillocks before freezing, and these were high enough to afford complete cover to the fugitive deer. Probably all those wounded that escaped got away only to die, for we found the carcass of one which had been shot three 
days previously, and had been given up as lost. Besides cariboo, the only game of greater size than hares and grouse that we met with in this little expedition were a few foxes. We were away from home nearly a month, when, having collected as much meat as we could drag, we returned. The meat being hard-frozen will keep all the winter. It becomes so hard that it can only be cut with an axe.

Cariboo meat is coarse and flavourless, as nearly all American venison is. Americans, both Yanks and Canadians, praise their venison highly, supposing it to be far superior to English. I suppose that not one American in ten thousand, and perhaps not one in a hundred thousand, has ever tasted English venison. At all events, there is absolutely no comparison between the two meats. It is as reasonable to compare flaccid, inferior Australian frozen mutton with prime Southdown, as to place American venison beside English. All American venison is coarse. That of the cariboo, moose, and wipiti resembles coarse beef. Wipiti meat is the best. The word "venison" is but little used in America, especially among trappers. All venison is called "meat." The freezing of it certainly does not improve the quality; but it is a boon to the poor, often half-starved, people, as it enables them to keep a stock when a fortunate chance places it within their reach.

During the winter I made several short excursions, similar to that which I have just described, sometimes having several companions, and sometimes accompanied by Tom only. Tom was quite my chum, but a more silent pair of friends never associated together. Hours would pass without the exchange of a word, and Tom was never, on any occasion, demonstrative. But he suited me-for I am not a talkative man-and it is evident that I suited him; for he was always ready to accompany me anywhere, and for any length of time. He took all arrangements into his own hands, and made 
every preparation without comment; and he would perform all the hard work when we were alone together, though at other times he was prone to spare himself.

Often he would enter my hut, and squatting on the floor, would remain hours quietly smoking and looking at my books, for he was exceedingly fond of pictures. $\mathrm{He}$ never uttered any greeting or took his leave, but came and went abruptly, as is the usual manner of all the Indians; and he would answer with a grunt when spoken to, unless a reply was absolutely necessary. Yet he was a brave and faithful man. I had abundant evidence of that before circumstances compelled us to part.

On the excursions I have mentioned, and which were always performed on snow-shoes, we met with but little big game during the latter part of the winter. I shot, altogether, three moose and about a dozen cariboo, but I met with no adventures in their pursuit. I will therefore, before changing the subject, make a few remarks on American deer-shooting generally, and these remarks apply to the northern parts of the States, as well as to the British possessions. In the former region there are small deer which are not found in Canada - at all events, as far north as most of my wanderings refer to. These small deer, as well as the cariboo, moose, and wipiti, and many other animals, are passionately fond of salt, and they habitually frequent "salt-licks" wherever these are found.

Salt-licks are not abundant in this part of America; therefore, if you can find one, you are sure of good sport until the deer become too much scared to venture to the lick. A salt-lick is simply a saline spring. They generally dry up in the summer-time, but, the earth being thoroughly impregnated with the salt, they are still visited by the deer, which lick the ground to obtain the saline particles. The deer and other animals come from such great distances to obtain this salt that it is clear they must retain a very lively recollection of its position. 
At a settlement I visited one day I saw a man give a horse a piece of salt, which I at first thought was a piece of loaf-sugat Tho animal ate it eagerly, and followed him for more; and he told me that he could always catch the loose horses in the fields easily by offering them a small lump of salt. This put the idea into my head of trying to attract the wild deer by placing pieces of salt in their tracks. During the winter, when there was snow on the ground, I found this to be of no avail; but in the antumn it proved a highly attractive bait, and many is the moose and cariboo whose destruction I have compassed by sowing the ground with fragments of salt, while I lay concealed in a convenient spot to shoot them down. On one occasion I shot six deer in one day as the result of this trick.

Salt is scarce, and often unobtainable, in these wildernesses, and the Indians would do or give anything they possessed to obtain it. They often use powder in lieu of it, having learned the habit of using it thus from the trappers. Fortunately I had brought up a large supply of this necessary article, and was frequently applied to by my Indian friends for it, and the children would eat it as children in England do sweetmeats.

Regarding the habits of the deer of this region, the moose seems to eat the foliage of trees as its principal food; the wipiti eats all sorts of vegetation; and the cariboo, also, will eat almost anything it can find, but it certainly prefers mosses to other kinds of green food, and in summer lives almost entirely on this class of vegetation. The moose and the wipiti, particularly, devour the spruce and pine shoots, and, in consequence, their flesh is often strongly impregnated with the flavour of these trees. Cariboo and wipiti are fond of feeding in swamps, but the moose prefers dry ground. All deer take to the water readily, and are good swimmers, but the wipiti seems to me to be most often seen in the water. As a matter of fact, I do not remeraber to have ever seen a 
moose swimming, but that they have the same habit in this respect as other deer is certain. All trappers and Indians assert it.

The wipiti is "the elk" of Americans; and it is almost as bulky an animal as the moose, but it varies greatly in size-more so than any other species of deer with which I am acquainted. Sometimes cows do not weigh much more than three hundredweight, while bulls will be nearly half a ton. I have shot specimens which were quite as heavy as the largest bull moose. The average weight of both moose and wipiti when in good condition may be safely put at five hundredweight for cows and eight hundredweight for bulls. They are therefore magnificent animals, fully three times the weight of Scottish red deer. In height neither moose nor wipiti ever exceed by more than an inch or two six feet at the withers; though trappers, and especially American ones, tell of monsters eight and nine feet high. As a moose, or wipiti, of this height, if proportionate throughout, must weigh 6000 or 7000 pounds at least, the exaggeration of this estimate is palpable. I should state, as a modification of what I have written above, that the moose is slightly the tallest animal; and that on looking over my notes five foet ten inches appears to have been the greatest height of a wipiti killed by me, and six feet three or four that of a moose. The usual height for bulls is five feet six for wipiti, five feet nine for moose.

Both these deer bring forth their young in the desert and most retired thickets they can find; and so jealous are they of discovery at this time that it is rare to see a cow with her calf until it is evidently some weeks, if not months, old. There is usually but a single calf; but I have seen both moose and wipiti with two. They pair in the autumn, and drop their calves in the spring.

The smaller deer, found in the northern parts of the States, do not seem to reach these high latitudes. At all events I have never seen any signs of their so doing. 
Regarding distribution and numbers, that has almost become matter of past history. At the time of which I ain writing wipiti and moose had already begun to show signs of a serious falling off in numbers. Cariboo were still abundant; but all three had forsaken certain spots which were much frequented by white trappers from the settlements. In the United States, wipiti were found, in places, in large herds. Here I never saw any number greater than what seemed to be a family party together; that is, six or eight. Their habits, in this respect, resembled those of the moose. Single deer and pairs were most frequently met with.

I do not think that wolves ever succeed in pulling down these deer, except, perhaps, old or injured individuals; but they try to capture the calves; and the cows have desperate fights in defence of their progeny. I once witnessed an encounter between a wipiti cow and about thirty wolves. The poor mother was furious, and though she did not actually kill any of the wolves, she tossed one and crippled him. I think it is probable that the wolves would have ultimately destroyed the calf; for they were so many that the cow could not keep them all engaged in front of her, and some attacked the calf while others yelped at the mother's front. At length one of the wolves made a grab at the calf, inflicting a severe bite; and I thought it high time to interfere. From my place of concealment I shot three of the wolves, and while the remainder scampered off in one direction, the cow and her calf retreated in another. The maimed wolf was unable to follow his comrades, and he also went to increase the weight of my "bag," though the cow had mauled him so.that his pelt was little worth. 


\section{CHAP'TER VI}

\section{WINTER AT ITS HEIGHT}

IT was not until about the middle of January that I felt the cold much. It was then intense; and I suffered rather severely from frost-bites. These I soon cured by rubbing with snow, and applying vegetable poultices prepared by the squaw. The Indian remedies for all kinds of cuts, sores, and bites are excellent; and their medicine men are generally skilful bone-setters. About this time I suffered much with bowel troubles, not an unusual occurrence, I believe, with recent arrivals in the country, and for six weeks I was too unwell to move about. I owe the Indian women much gratitude, several of them volunteering to nurse me; and Chompol was indefatigable in her attendance.

At the end of February I was able to get about again, and make snow-shoe excursions for a few miles around our huts; but by this time all the game had been driven far from our neighbourhood, and the men were all away seeking it in the great forests to the north.

At this time there were scarcely any small birds to be found, they having either migrated or sought shelter in impenetrable cover. The former was most likely to be the case; it certainly was in the great majority of cases ; and thus it would seem that this country is remarkable for the almost complete migration of all its smaller feathered animals. Many of the larger ones had also disappeared, and a few fresh species had arrived from more northern regions. Amongst the latter were a few ptarmigan. These were met with on the lake (frozen, remember), and where- 
ever there was a space of open ground. They were in their white winter plumage, and were remarkable for their tameness; for when I shot one the others flew but a short distance, and sometimes only a few yards, so that I generally managed to make a pretty fair bag. The socalled partridge also remained here all the winter, but did not change its plumage. This bird was even tamer than the ptarmigan; for often when I shot one as it sat on a tree, its companions would only fly a little distance and then come back to look down upon it, as it lay on the ground, with an inquiring air, so that I have sometimes shot five or six from one tree. Other species of grouse are almost equally tame; but they become wild enough when the breeding season and summer approach. During the winter I on several occasions met with the ruffed grouse (Bonasa umbellus) in considerable numbers. On the 17th March I shot nine brace in about four hours. There were at least two other species of grouse shot during the winter. The partridge (Canachites Canadensis of the English, or Dendragapus Canadensis of American ornithologists) and the ruffed grouse both breed in this neighbourhood. They nest quite early, before the snow has entirely disappeared. I took the eggs of both in April. Those of the ruffed grouse were placed amidst rough, scrubby vegetation in a rocky place, were nine in number, of a buffy colour with a few specks of light brown, and were so well concealed that if the hen had sat close instead of flying off I should not have discovered them.

The Canadian partridge, also, does not make a nest, but the herbage is trod down, or flattened, in a circular shape, at the foot of a tree or under a bush, if not in the woods at least where there are plenty of trees. I believe they lay nine or ten eggs, but the number which I took was six in one clutch, seven in another. The eggs were a deep buff colour, thickly speckled and spotted with large spots of rich brown. 
The only birds of prey that I saw during the winter were owls, one of which was much like the common barnowl of England. A bird of this kind used to frequent the roof of my hut at evening time, where he found some kind of small prey under the shingles. I have heard him hooting between midnight and two o'clock in the morning; never later, and seldom sooner. After I took to placing pieces of meat for him he became a constant visitor until spring arrived, when I saw him no more.

The great grey owl (Syrnium cinereum) was frequently seen, generally in pairs, from which circumstance I conclude that they pair permanently. Like other owls in this district they are seldom seen during daylight, but appear pretty early in the evening. Their favourite perch is on the withered branch of a pine tree, or on such a tree that is blasted by lightning or other cause. They are usually a silent bird, and prey on all sorts of birds and small mammals, and the Indians will cook and eat them without scruple. For the sake of experiment I tried one roasted myself, with the result that I think that there is nothing but prejudice to prevent a meal being made of them. The Indians generally boil them, as they do grouse and ducks and geese, and I may say that all these birds are insipid enough so cooked. The ducks, \&c., are at best but poor eating in this country. The owls are caught in traps without bait; for the Indians mark where the bird is in the habit of pitching, and place the trap there. As the owl is sure to come to its favourite perch, and is quite oblivious of trap, it is thus caught. Sometimes a pole with a crosspiece is erected where the owls haunt, and the trap (a large steel rat-trap) fixed atop. This is also an efficacious way of catching them, as it is of several other species of owls, particularly the one next mentioned. The great grey owl is found, in limited numbers, all the year round, but the bulk of them retire southwards as the winter comes on. As when the cold was very severe and in bad weather I never saw them about, I conclude that at such times 
they keep to their holes or retire to the dense woods. They harbour in holes in trees, and, I suppose, breed there, but I have no certain evidence of this.

A much more numerous, as well as a much larger bird, is the snowy owl. The splendid white plumage of this fine owl (which is as large as a turkey) is spotted with black, and the expanse of wing is more than five feet. It is by far the most splendid of all the American owls, and probably of all others. It is more often seen solitary than the great grey owl, but is also often in pairs. Like all the big owls of this district, it is very destructive to birds of the grouse family, which form the bulk of its prey. It is not a noisy bird, but occasionally it may be heard uttering cries at night time. It is less nocturnal than the other owls, but its favourite preying time is the dusk of evening, when it captures the ptarmigan and partridges (Canadian grouse) as they are seeking their roosting-places. This owl breeds amongst rocks and in clefts, a little rough grass, roots, \&c., forming the nest; and it has the strange habit, for a bird of prey, of laying its eggs in succession at considerable intervals of time, so that there are sometimes an egg or two and an unfledged and a fledged young one all in the nest at the same time. The usual number of eggs laid in one season seems to be from four to six. I have known the nest to be placed on the top of a broken tree-stump; but the snowy owl is found in the most desolate spots of the great North-West, and throughout boreal America. It moves southward to a certain extent in the very severe cold season, but its migrations are very partial.

Throughout the winter there were no ducks or geese in this district, and scarcely any small birds. I noticed, however, a few snow-buntings, here called snow-birds, snow-finches, or snow-flakes. These pretty little birds also make partial migrations; and a spell of cold weather will cause the few which remain behind to disappear. They, however, return when the weather moderates. 
The cold of Canada and the northern regions is too hackneyed a subject to permit of much dwelling on; but I may just mention that no fire, however roaring, would warm my hut; and that water kept within a few feet of the fireplace often became a solid block of ice. Such liquids as ink and oil also froze, but spirits did not. My guns, as they stood in the corner, were covered with a bright inflorescence of frost, as well as every other metal article; and I was always obliged to put on gloves before venturing to handle them, otherwise the skin of the fingers would be left adhering to the metal.

As to the effect of the cold on my constitution, it certainly was trying. For the first time since childhood I was seriously laid up this winter, and among minor evils I suffered greatly from chilblains. Otherwise I found the cold bearable, especially while I kept in motion. The only severe frost-bites that I experienced I acquired while fishing at a hole in the ice.

The ice on the lakes was of a great thickness-as much as three feet on some of the larger lakes and rivers, and it was no inconsiderable task to cut a hole through it to the water. The fish generally rose freely to these holes; and sometimes thirty or forty of them were cut within the space of a few hundred yards. The methods of fishing were various. I used baited hooks, and sometimes tried the Indian plans, the commonest of which was spearing. The tish are attracted by a bait, and as soon as they are perceived are impaled by a light barbed spear, and sometimes by a trident. At night the fish are attracted by a bright light, and sometimes an artificial fish, made of painted wood, is used as a lure. Much practice is necessary to make a successful spearer of fish; but the Indian men and women, and even the children, are very dexterous at it. In this way sixty or seventy fish, weighing three or four pound each, are often taken by a single fisher in a few hours' time. But it is not always that the fish can be attracted to the holes. 
Among other amusements I adopted to wile away the winter-time was taking snow-shoe journeys to the nearest outlying settlers. Some of these farmers and gentlemen lived not more than forty miles away, and I could accomplish that distance easily in two short days' travel. To sleep out in the depths of a Canadian winter may seem a desperate expedient, but the fact is that a small hovel of spruce-boughs, well covered with snow, and with a blazing fire in front of the opening, is warmer to sleep in than a large log-hut. Of course I had my blanket, and sometimes dragged a small hand-sleigh after me.

I was always sure of a warm welcome, and a pressing invitation to prolong my stay till the winter was over. Of course all outdoor work is put a stop to in the winter, but there are many expedients for passing the time profitably and pleasantly, most of which are borrowed from the Yankees, to which I shall subsequently make reference.

All the settlers near here were exceedingly prosperous; and could I have borne the climate, I should certainly have turned farmer myself, instead of becoming, as I did, a wanderer in the States. They suffered but from one serious drawback - an insufficiency of labourers. None of the Indians, and but few of the half-breeds, can ever be induced to take to a life of agriculture. 


\section{CHAPTER VII}

\section{A JOURNEY TO THE RED RIVER}

I Took no other extensive ramble with my Redskin friends, but spent the remainder of the winter shooting and fishing in the neighbourhood of Wolf Pond, making a few excursions to Grand Lake, and other points at no great distance froin my hut, and doing the best I could to regain my usual health and strength. In this I was so far successful that I determined to make an unusually long journey during the approaching summer, for the purpose of seeing the land and enjoying the sport of shooting, of which I am passionately fond, though I am no wholesale slaughterer, holding that to be no sport which degenerates to animal murder. The tracking of a single deer, or bear, all day long is to me a delight of the highest degree, even if, after all, I fail to get the anticipated shot.

Most of the Indian men had returned to their families by the end of March, in anticipation of the break up of the frost. While the frost lasts, the snow is as dry as sand. All loose particles that cling to your clothing are easily brushed or shaken off; but everybody knows how exceedingly penetrating is wet snow. The Indians do not mind it, nor do they ever seem to suffer much from rheumatism - certainly not to the extent of becoming cripples from it; but when the thaw has fairly set in, snow-shoes are no longer of use. It is impossible to drag through the wet and clogging mass with them; far less to drag a burden over it. So the last days of winter are employed by the Red Men in preparing for the journey to 
the Company's depôt, to dispose of the pelts collected during the winter hunt.

All my friends were in good heart, the collection of pelts having been a good one, much above the usual average. But it is not to be supposed that all hunting ceases with the winter. On the contrary, some of those animals which yield the most valuable furs hibernate, and, consequently, can only be captured in the spring and summer.

The method of travelling and bartering the pelts to the Hudson Company being of necessity incorporated in my future narrative, I shall say nothing concerning it here. Broadly, in winter, snow-shoes are resorted to to enable the traveller to get over the ground, enabling him to do twenty or thirty miles per day; and more than forty is sometimes covered by Indians when there is occasion for making a quick journey. In the summer, canoes and river and lake navigation is the invariable method of travel, and "portages" is the distinguishing feature of this kind of journey. The incidents of such journeyings is a prominent factor in all descriptions of the British possessions in North America, and will therefore, to avoid.sameness in my narrative, only receive such incidental notice as is unavoidable.

My friends were in the habit of taking their pelts to Moose Factory, on James Bay (an inlet of Hudson Bay), for the purpose of barter, that being the most easily reached, though not the nearest, of the Company's depôts; but I, wishing to have Indians whom I knew and could rely on with me in my journey to Red River, offered to purchase all their furs. As I gave them double what the Company would, besides saving them a troublesome journey, they readily consented; and I packed all the pelts in my possession in my hut, to be disposed of on a more convenient occasion.

The Indians I selected to accompany me were Tom, Sam, Natanyan, and Otmasquiloton; the two latter young 
men from the Cree hamlet, who were not yet married. I thus interfered with no family arrangements in selecting my companions; and the remuneration agreed on, consisting of powder, balls, and articles of particular use to Indians, was looked forward to by my younger men as a certain means of enabling them to settle in life on their return. I thus became the leader of my first exploring party, if I may be permitted to dignify it with such a term-a hearty and willing party, who had to sever no family ties to follow me.

The journey was to be by water, and therefore our preliminary task was to make a canoe suitable for such an expedition; that is, one large enough to contain five persons and several hundredweight of stores, and yet light enough to be portable overland on the shoulders of two men. The task of constructing such a canoe I left entirely in the hands of the four Indians who were to accompany me, and they completed the work in less than three days without exertion, using birch bark, sewn with sinew, and all seams paid with resin.

During the month of April there were several slight thaws, followed by sharp frosts, which made the surface of the snow in may places as smooth as glass. Perhaps from this cause, there seemed to be much suffering among the animal inhabitants of the district, many deer, principally cariboo, coming to the vicinity of the Indian lodges, followed by wolves and smaller beasts of prey. The wolves carried away one child, and severely bit a larger boy; and committed many minor depredations amongst the dogs and property of the Indians. Many wolves, foxes, gluttons, and small fur-bearing mammals were trapped or shot in this month.

Early in May the thaw became general, and the ice on the rivers and lakes broke up; and on the 13 th we made a start by carrying the canoe and stores to the Ottawa River. This was a very easy stage, as there were scores of willing hands to help us. My hut, and the 
goods therein stored, I left in charge of Andrew Whitting and his wife and daughter.

The Ottawa was in a dangerous state, full of huge blocks of floating ice; but we were only on it a few hours. After descending the stream, which had a good current at this time, for about thirty miles, we landed and prepared to pass the night ashore; and a bitterly cold night it proved, with wind and rain, which continued throughout the following day. The whole of this day was taken up in making an eleven miles portage to a small stream which ran into Lake Nipissing, and thence to Lake Huron. The ice in Nipissing had been drifted to the north-westward by the wind, but the mouth of the river was blocked, and we were compelled to make a very troublesome portage to avoid it. However, once on the waters of the lake we found the centre clear of ice, and made a rapid passage, though not without danger on account of the strength of the wind. The river discharging the waters of Nipissing into Huron was comparatively free of ice, and there was but little in Huron itself. By the time we reached Huron the wind was blowing a hurricane, and we were compelled to lose nearly a week; for no canoe can live on the great lakes when a gale is blowing.

It will not be expected that I should give a description of this well-known great lake. That would be carrying coals to Newcastle. Cursorily I may note that Huron is one of the deepest of them, being not less than 600 feet deep in places, at least; for I failed to find the bottom with a line of that length at a spot outside the Manitoulin Islands. In other places, however, it appeared to average from 400 to 500 as the greatest depth. Thousands of small islets throng the waters near its northern shores; and the Manitoulin group contain several large islands, one of them about seventy miles long by twenty broad. The surface of these great lakes, though the water is quite fresh, is never frozen over, but there is sometimes a considerable mass of ice round the 
shores. The tide is scarcely perceptible: I have been told that the rise and fall does not exceed eighteen or twenty inches.

The navigation of these lakes in canoes is a very ticklish business. The canoe is not adapted for navigating rough water; but these lakes, like all large inland bodies of water, are subject to sudden squalls. Unless, therefore, you have time to reach the land, an upset is inevitable. Consequently it is necessary to creep round the shore; but when a bay or inlet is come to, the crew, naturally, to save time and labour, like to strike straight across from headland to headland. In the technical language of the voyageurs this is termed making a traverse. As some of these traverses are not less than twenty miles broad, it is necessary to study the weather, and to be an accurate judge of meteorological probabilities if serious accidents are to be avoided; for the waves of Huron and Superior are not inferior in size and power to those of the ocean, if, indeed, they are not more to be dreaded. Then, again, there are long stretches on the northern coasts of these lakes where a landing would be impossible, or only possible at the cost of the loss of stores and canoe.

The time required to make a canoe voyage round the northern shores of Lake Huron is calculated to be not less than. a week, and more often nine or ten days. The same calculation is made for Superior. But this is the actual time for paddling. If there is much wind, and the weather is bad, a week or a fortnight may be lost in waiting ashore, and occasionally double that time is wasted. Fifty miles a day is a fair rate of paddling for a large canoe; and this can be done day after day without over-exertion. One man, in a light hunting canoe, can maintain a much higher rate of speed in smooth water.

The small islands on the north of Huron, and Superior too, are rocky, with sometimes a pine or two growing on 
them. Some are well wooded, and others pretty well covered with bushes; but some of the small rocks have a barren appearance; nor is the timber on the coast of Huron, as far as can be seen from the water, remarkable for either size or abundance. There is plenty of fish in the waters. Will it ever be exterminated by the waste of a superabundant population on the shores? White fish swarms at present; and a big trade in it has already sprung up. It is salted and sent all over Canada and the Northern States.

Our voyage along the shores of Huron was fairly rapid, and without incident. On the ninth day we arrived at St. Mary's River; and the following day had to make a portage across St. Mary's Leap, or the St. Mary Rapids as the maps call it. This is the spot where the waters of Superior rush into Huron, and it is a dangerous place where many lives are reported to have been lost. There is "a fort" on the United States side; a mere military post where a few soldiers are kept, most of whom seemed to me to be Germans or Hollanders, and a village has sprung up round this military shanty. I think that term correctly describes it: for it appears to be built of timber, and about two shots, I, should think, from a gun of moderate size, would blow it to atoms.

On the Canadian side there is also a hamlet, or a bit of one. It had a tumble-down appearance; but there was a fish-curing establishment or two there on a small scale; and the Yankee, or German, soldiers seemed to frequent it a good deal more than their own place, for the purpose of getting drunk and quarrelling with the sailors belonging to the police craft on the lakes.

The voyage on Lake Superior took us twelve days, including one or two short stoppages; but here also we met with no incident worth record until we arrived at Fort William. Superior is described in a later chapter.

Fort William was once a very important depôt of the North-West Company, the rivals of the Hudson Com- 
pany. The former traders ultimately amalgamated with the Hudson people; but before this took place, something very like a pitched battle occurred between employees of the rival trades, in which Mr. Semple, a governor of the Hudson Company, and a number of his men, were killed. The fighters were mostly half-breeds, and it is said that their officers could not control them when their blood was up.

Fort William is now a Hudson post; but very little trade in peltry is done here. ${ }^{2}$ It is a great fish-curing depôt, and this trade seems now to give it all its importance. The fish mostly caught are the ever-celebrated (in America) white fish, and large trout weighing twenty or thirty pounds. These two fish are the finest flavoured in this part of America; and the trout, notwithstanding their size, are not coarse, but of a delicious flavour. They, as well as the white fish, are split open, salted, and dried in the sun; and thus cured sent pretty well to all parts of North America. This kind of saltfish is, however, in my opinion, far inferior to the cured Newfoundland cod.

Before quitting the Great Lakes I should like to remark that the rocky cliffs of the northern shores, the immense expanse of the waters, and the heavy, rolling character of the billows, gave me the feeling of being on a sea-coast. The lakes deserve the name of, and ought to be called, inland seas. They are quite as much seas as the Caspian, Black Sea, \&c. The waters are beautifully clear and pure; and objects lying on the bottom can be seen at a great depth; as can also the fish swimming in immense shoals. The bottom seems to be everywhere, on the north coasts at all events, either sandy or rocky.

Fort William is not worth two lines of description. There is absolutely nothing attractive about the place, dicted.

2 That is my opinion, and I must let it stand; but it has been contra. 
or the store-houses, which seem huddled together in designed confusion. The country around, however, is exceedingly attractive. Looking north and west the eye wanders over a great stretch of level ground, giving the first indication of those vast prairies which we are now approaching; but the ground here is covered with small trees, among which willows hold a chief place. The view is bounded by hills which, seen from here, appear picturesque and of considerable elevation. The grass was beautifully green and fresh, and reminded me more of our dear English meadows than any I had hitherto seen in Canada. I noticed many small birds about the trees and under the bushes; but I had no time to go after them. I have reason to think that they were of the same species as those met with on the voyage up to Red River, and which will be described presently.

Looking eastward and to the south the view was over the lake, an interminable expanse of glittering water of a deep blue colour, especially in the distance, quite a different tint from that of the salt ocean. A great number of craggy islets rendered the scenery in this direction as picturesque in its way as the view landward. Seagulls (or lake gulls) were hovering everywhere over the waters, and pitching on the rocks; and there was a sufficient number of fishing boats, and other craft, to give one the idea of being at a minor port. The great number of large canoes, however, could not fail to strike the eye of a stranger, and convince him at a glance that he was in a strange country.

Fort William is a depôt for canoes; and they may be purchased here. The canoes used on the lake are larger, and of a different construction, to the light river canoes of the Indians and trappers. They are called canotes de maitre, are paddled by a dozen or fourteen men, and will carry a ton of cargo in addition to the crew. But they are too large and heavy for the internal river navigation; and the rule is, when the Company's servants arrive here 
from the northern and western stations, to transfer the cargos of several of the smaller canoes to a canote de maitre for the completion of the journey. The smaller canoes are called "north canoes"; it would puzzle a Philadelphia lawyer to tell why, for they are used south as inuch as north.

Fort William is a palisaded structure; and the two shots I suggested for the Yankee post at St. Mary's Leap would be equally efficacious here. In other words, it is useless as a military post. It is placed at the mouth of a stream called the Kamenistaquoia, which empties itself into the lake a little to the southward of Thunder Bay. There are two other small streams in the neighbourhood; and in the days of the French these were called "Three Rivers." and there was a post, or mission, here at a very early period in the seventeenth century. This "Three Rivers" must not be confounded with the "Trois Rivers" of Lower Canada. One of the three streams has been known for at least two hundred years as the river Long. They are all shallow, and of no importance for navigating purposes except by canoes.

This was the Fort William of a quarter of a century ago. But to-day the place is an electric-lighted township of, with the suburb of Port Arthur, some 10,000 or 12,000 inhabitants! There is an electric tramway, a railway station, and a corporate body who make "byelaws." The pleasant tree-covered prairie is converted into a huge, wide-spreading cornfield; and the former fishing depôt is now an important corn-shipping port dealing with many million bushels of grain yearly. In a word, the land that I knew, and describe in this chapter as a glorious wilderness, is now a civilised region suffering from all the blessings and curses of that state.

Of the gulls on the lake there were several species, only one or two of which I could recognise with certainty from skins afterwards submitted to American naturalists. According to the people of Fort Williain several of these 
birds (probably all are not strictly gulls) are only occasional visitors to that district. Some are said to breed in the marshes, but I found no eggs myself. The common tern, Sterna hirundo, was here in considerable numbers. This is, I suppose, the Sterna fuviatilis of the English. It appears to me to be the same bird. Of the next most numerous there is no doubt. The kittiwake, Rissa tridactyla, as well as the Sterna, is probably not a permanent inhabitant of the lakes, but visits parts, at all events, in great numbers. Another numerous gull I should certainly think to be a mere variety of Larus canus, the common English gull. There was also a curlew, Numenius borealis; but I only saw odd birds of this species.

After a day or two's rest we paddled up the Kamenistaquoia, and resumed our journey on 10 th June. The river had a strong current, and after paddling, as I suppose, some fourteen or fifteen miles, which took us five hours, we had to make a portage at the "Mountain Portage" as it is called by the voyageurs, to whom, of course, it is well known. The Kamenistaquoia is full of rapids, and is most difficult of ascent; but it is to be noted that one part of a journey is always more troublesome than another. Thus, for days you will be ascending the high grounds, and daily making several portages at great expense of time and work; and then for an equal time be descending, shooting the rapids, and making portages only where the cataracts are too dangerous to be shot.

Near Mountain Portage there is a magnificent waterfall-the "Mountain Fall." It has a sheer fall of about two hundred feet, is broad and of great volume; and the majestic rocks which surround and hem it in are half obscured by the clouds of spray which arise from its basin. Though the roar of its rushing, falling waters is very loud when you are standing on the brink of the precipice, it cannot be heard for any great distance. 
This seems to be owing to the confined character of the fall, which is completely surrounded with huge pine-clad rocks. It is one of the finest falls in Canada, and is well known to the Indians by the name of Keckibecki; and they have some weird traditions about it, and consider the falling and precariously-rooted pines in the abyss to be the spirits of condemned men.

After leaving the Mountain Portage, rapid-shooting and portage-making were of almost daily occurrence. The latter was often a troublesome and tine-consuming operation; for while two men carried the canoe overland on their shoulders, the remaining three of us were not sufficient to carry the whole of our goods in one journey. We had consequently to make a second, and sometimes a third, trip. As some of the portages were several miles in length, it will be easily understood that it frequently happened that the greater part of a day was taken up in making them.

The rapid-shooting was performed, I carnot say wherever it was safe to resort to it, but wherever my reckless companions thought that there was a comparative chance of successfully running the rapid. Reckless! yes, that is the word. These Indians seemed to delight in a haphazard risk of life. Remonstrance on my part was useless. They simply made no reply, and took no notice of me; and rushed down torrents that I should describe as almost waterfalls. I was often terrorised (I make no pretence of attempting to conceal the fact) and held my breath, with a silent prayer at heart, expecting instant death. But these cool rascals quietly smoked, not even deigning to notice my terror, and sent the frail canoe flying, at express-train speed, down frightful-looking cataracts. After a time I gradually became ashamed to show my nervousness, and then grew used to it, and finally took the danger as a matter of course. But we had several narrow escapes, and it is a wonder that I survived one of them to write this narrative. 
The Indians are marvellously clever in avoiding the rocks and shoals that always impede the navigation of these rapids. Often it seemed to me to be inevitable that we should dash against one of the rocks, and be riven to pieces. We seemed to be rushing straight for the obstacle, and not until we were within two or three feet of it would a slight, but skilful, turn of an Indian's wrist cause the canoe to swerve slightly to one side into safety. By-and-by I attained to some skill in the use of the paddle myself; but I never dared to rush such formidable rapids as these men took as a matter of course. However, my confidence in the Indians ultimately became very great; and I have seen these men stand astride on the gunnels of a canoe that was rushing down a very considerable torrent, and spear the salmon in mid-stream as they did so.

At a place called the Rose Portage, which is a very long and troublesome one, divided into two parts, I saw a pair of American yellow birds, which seemed to be breeding, but I could not find the nest. I was more fortunate with another well-known United States bird, the "chippy," Spizella domestica, the nest of which I found in a bush, nine or ten feet from the ground. There were four very small eggs, light blue in colour, speckled with red. I am not aware that this bird often breeds so far north as this; but I have noted that cases occur in which single pairs of many American small birds are found widely out of their habitual haunts. Taking the "chippy" for example, I have met with this bird certainly as far south as Florida.

But the commonest small bird in this neighbourhood was a grosbeak, Hedymeles virginianus, which bred amongst the rocks here, apparently in some numbers. The nest was placed in pine or spruce trees, but not near the top. Some of the nests were not higher than a dozen feet above the ground. They were composed of small roots and coarse grass, and lined with deer hair. 
In June and July there were both eggs and young in the nests, generally four or five, but in some cases only three. I think that finches, which have five as a normal number of young, usually lay but three eggs in their first season of breeding. Second broods are also small in number. The eggs referred to above were of a whitish colour, spotted, and slightly blotched, with two shades of brown. This bird is the rose-breasted grosbeak, Habia ludoviciana of American ornithologists: another instance of how widely specific nomenclature differs in America and England. The range of this bird is enormous, embracing nearly the whole of North America; and I have found it in several countries of South America, particularly on the lower regions of the Northern Andes. I may remark that many species of small birds (as well as those of considerable size) that range as far north as this, are found quite as far south as the equator. I should like to be able to prove whether the birds alluded to migrate all these thousands of miles, or are permanently settled in some parts of their range. They certainly leave this region on the approach of winter; in fact many parts of Canada and the North-West lose all their small birds before the cold sets in.

There were at least a dozen other species of birds hereabout, whose size did not exceed that of the common song-thrush; but as I cannot speak with certainty of those whose skins I did not obtain, or succeed in preserving, I need say no more about them than that most of them were species of Melospiza and Spizella.

The Canadian grouse, commonly called the "partridge" in this country, was quite abundant, and was breeding at this time; many young birds, just able to run, being about. This bird was stupidly tame, as I have noticed that it always is during the breeding season.

The heat became very great, often $90^{\circ}$ to $100^{\circ}$ and more, in the shade, during the latter half of June, but the weather was, on the whole, delightful. Scarcely 
a day elapsed that there was not a refreshing breeze blowing in the morning and evening. From about 1 P.M. to 4 or 5 o'clock was the oppressive time, and at all times, day and night, the mosquitoes and other flies were a terrible plague. They swarmed everywhere in great numbers, and setting appearance at defiance I was compelled to cover my face and hands thickly with grease as a protection. Oil or grease is a deadly poison to all flies, apparently by blocking their breathing apparatus, and my expedient proved an efficacious protective, the flies when pitching on the exposed parts being too troubled at finding themselves sticking to bite.

The appearance of the country on all sides was beautiful, hilly but not mountainous, well wooded in many places, but yet there was no tract that could be called forest. The trees were pines, spruce, birch, maple, willow, and others that I did not recognise.

At the Dog Portage, from whence there is a very extensive view over the country, we met a party of voyageurs travelling towards Fort William. They were Hudson's Bay people, and there seemed to be something rather wysterious about their journey. It is too early in the season for the "brigades," as the canoe parties are termed, to be moving down to the lakes, and these men, six in number, kept somewhat aloof from my party. In crossing the Dog Lake we overtook a party of thirteen Seauteaux Indians in three canoes who were taking pelts to Fort Frances, a small depôt on the Rain River.

Soon after crossing the Dog Lake we had evidently come to the apex of the range of hills; for now instead of making portages we were continually shooting rapids. Some of these rapids were very dangerous, others exceedingly long, and occasionally we were still compelled to make a portage; and our rate of travelling was now much faster than it had been during the first part of the journey. We were daily passing through small lakes and rivulets, many of the former mere ponds, and 
so shallow that we sometimes ran aground. Where the lakes were shallow they were often covered with reeds and rushes, which prevented us seeing the escape of the water-fowl which flew away at our approach. I, however, succeeded in shooting a few ducks and other birds, which made an agreeable addition to our provision. The country near the lakes was mostly covered with a kind of thorn-bush, which it was difficult to move amongst without tearing the clothes and lacerating the flesh.

Of the lakes mentioned above many were not noticed in my map, though evidently permanent; others had no name, and some I learned only the Indian or voyageur designation of. Of those marked on the map, and which varied in size from two or three miles across to perhaps twenty or thirty, the principal were the Death, Sturgeon, Sarannah, Cross, and Lake of the Thousand Islands. The country in which these are situated forms now the colonies or districts of Winnipeg and Manitoba, and has become, or is rapidly becoming, the greatest corn-growing land in the world. There was no sort of cultivation here when I passed this way, and in fact the country was uninhabited except by wandering Indians and an occasional voyageur or trapper; yet the Company's hunters had so well scoured the land that several kinds of big game were already becoming scarce, and some of the smaller sorts were nearly exterminated-the beaver, for example.

As a rule I could not get an extensive view of the country in any direction. It appeared to be tolerably level, but the banks of the rivers were generally high, and those of the lakes low, or sloping, except in the case of some of the smallest. Large tracts of ground were covered with bushes intermingled with trees, and sometimes the woods were extensive. The scenery, on the whole, was pleasant, but not grand or striking. Some of the ponds, however, were very charming spots, 
surrounded with beautiful trees in the most picturesque way. On these ponds I again saw the loon once or twice. The beds of the rivers, and the bottoms of the lakes were generally muddy, and fish abounded in all of them; fish of species already mentioned, with the addition of one or two others.

Of these new fish the most notable was the sturgeon on account of its size, and the "golden-eye," for its vast numbers, there being myriads of them in some of the rivers. It seems to be a kind of perch, and is very good eating, though it does not grow to any great size. Of neither of these fish have I anything of interest to record.

During the journey I caused the Indians to travel at any easy rate, as I was by no means in a hurry to pass through the land, and endeavoured to make collections of small birds, eggs, and insects en route. In this work I was only partially successful. The space to spare in the canoe was so limited that accidents to my collections were provokingly frequent, the more so as my Indian friends had no sympathy with my hobby, and used but little care. A great deal of what I collected with great pains was spoilt or lost.

Butterflies, moths, and beetles, as the most attractive of the insect tribes, were my most eagerly sought victims in this branch of Natural History, but these are not particularly striking in this northern region. I was struck, however, with the fact that there is a small butterfly here of a blue colour, as there seems to be in every district of America, North and South, though differing in species, and another of a bright red, prettily marked. None of the species are identified, and it is only possible to give an intelligible idea of them, and the beetles, by means of coloured plates. Among the dragonflies was a very handsome pink and green species with golden marks.

I made excursions of a few miles in extent into the country as we passed through it, always returning to 
sleep at the spot where the canoe was drawn ashore for the night. . Our bed was the ground, where we lay wrapped in our blankets when the heat was not too great to make that course unendurable. Often the ground was quite warm from the heat gathered during the day long after the sun had set. During my excursions I did not meet with any deer, to look for which was one of my chief objects; nor did I see many Indians, most of them having started on their journeys to the Company's posts and depôts to barter the results of the winter's hunt. I did, however, meet with a few parties of old men, women, and children, from whom I obtained a welcome supply of Indian meal. Five hungry men take a considerable amount of food daily; and we had not met with as much game as had been hoped for. I was therefore at length compelled to abandon my pleasant wandering excursions, and hurry on my journey in order to obtain a food supply at one of the Company's forts.

The nearest depôt was Fort Frances, which we reached in two days. It is a small building, in a state of decay, built close to a waterfall of picturesque appearance. It was occupied by only two men, a "trader," and a halfbreed "labourer" of the Company's service. I may mention here that the Hudson's Bay men are classed as labourers, who serve as handy-men, doing the work at the forts, \&c., interpreters, to communicate with the Indians when necessary, postmasters, whose work is often more onerous than their title indicates, and who have great responsibility committed to them. These three grades are subordinate, though the postmasters are admitted to associate with the "gentlemen." These latter are the apprentices, clerks, traders, and factorsthe two last being also shareholders in right of their office. They are nearly all "canny Scots," and right goodhearted fellows. The labourer classes are half-breeds and Indians, rarely pure whites. All alike are generally 
hardy, self-made men, who have often for years led a monotonous and solitary life. A stranger is always welcome among them. But there was little to be had at Fort Frances; for the Company do not sell provisions; or indeed sell at all, all their trade being by barter. So we pushed on, and two days later arrived at the not euphoniously named "Rat Portage House," where we fared no better. The gentleman in charge of the house had nothing to sell; but he treated us very hospitably, and as an act of courtesy, supplied us with a little salt pork, and a few other necessaries. From some Indians here we purchased some fresh fish for immediate use, and as much wipiti venison as we could carry. The stowage capacity of our canoe was very limited, and I desired to take a smaller canoe in tow in which to pack some of our stores; but to this arrangement my Red friends offered so much opposition that I was compelled to abandon it.

To reach Rat Portage House we had crossed the Lake of the Woods, and this was, to my mind, the most enchanting piece of water we had yet passed over. The thousands of islets that crowd the bosom of this lake, rocky and clothed thickly with pines, and trees of feathery foliage ; the bold rocky shores, rising to mountainous heights, and reflected in the smooth. glass-like waters, made up a scene that for beauty and sublimity I had not hitherto seen the like of in this country. The Lake of the Woods is rightly named; for as far as I could see it is surrounded with primeval forest. The waters are the quietest and most unruffled of any we have passed as yet, and this is probably the result of being protected, especially on the north, with mountainous ridges. I have heard, though, that the lake is subject, like all others, to sudden and fearful storms. It is of such size that looking south and south-west, no land is visible, and the horizontal line resembles that of an ocean. From this point the scenery became more and more 
picturesque, and was often grand. Not long after leaving the Rat Portage we noticed a small church or chapel, built at the bottom of a sort of inlet, under the rocks. I suppose this has some connection with the Company; but if there are houses here they are not visible from the river.

The river now rushed onwards between high rocks, riven and pine clad. I am sure that we often flew down the rapids at the rate of fifty or sixty miles an hour; and some of these rapids were ten or twelve miles long. Once or twice even my daring Indians thought the current too wild to be trusted, and we made some short portages to avoid dangerous spots.

The rocks, though not remarkably high, were broken into fantastic shapes, and often seemed to have been blasted or riven into great fissures and cavern-like openings. The country around was, at this point, thickly clothed with forest, and here were the tallest pines I had yet seen. Even the most rapid running rivers every here and there widened into small lakes or ponds; and on most of these small pools, and all of the larger lakes, gulls were seen of the same species, generally, as those on Superior; but on Lake of the Woods, and the lower corner of Winnipeg, I shot a gull with a beautiful white plumage lightly tinged with crimson. This gull was afterwards identified as Pagophila eburnea of the English. It is abundant in Hudson Bay and the boreal regions, and also in many of the North-West districts in the wintertime; for it migrates southward on the approach of cold weather. The fact that I saw it at this season is a proof that, like many other gulls, it occasionally, at least, takes inland journeys at any time of the year.

At the north corner of the Lake of the Woods we entered the Winnipeg River, and in two days arrived at Fort Alexander, a small similar depôt to those at Fort Frances and Rat Portage. It is situated a little way up from the Winnipeg mouth of the river, and though, per- 
haps, of less importance than the other two depôts, we procured here a supply of flour and salt pork, with half a sheep and some potatoes: so that our nearly exhausted provision was seasonably replenished.

From this point to Fort Garry, Red River Settlement is about eighty miles by water; and that distance we performed in another two days, arriving there on the 13 th August, a date that will show that we had dawdled a good deal on the first part of our journey.

I was compelled, apart from my desire to see the Settlement, to call here, in order to obtain a guide for the remainder of my journey, none of my companions having ever before been beyond Lake of the Woods; and my experiences, so far, had convinced me that it was desirable that I should have an older man than myself of European blood with me. I have no positive complaint to make against my Red Men; but it was evident, sometimes, that my extreme youth was against my maintenance of authority. 


\section{CHAP'TER VIIT}

\section{RED RIVER SETTLEMENT}

RED River Settlement was, at this time, an extremely isolated colony. It is situated in the fork between the Red River and the river Assiniboine, and is on the verge of the immense prairies of Northern America. It was, even at this time, an exceedingly prosperous place, though scantily peopled, and is now the centre of the world's cornfields. It is now merged, I believe, in the political division of Manitoba. In 1866 the population did not, according to such information as I could glean, exceed 13,000 or 14,000 souls; and of these the bulk were foreigners, Scandinavians, Germans, Russians and Yankees, and half-breeds. The colony was founded by Lord Selkirk in 1811 or 1812 ; but there had been a furtrading post here from time immemorial. This seems to have been a free-trading post; and it was here that the North-West Company, the rivals of the Hudson people, had their firmest footing. Just outside Fort Garry, the capital of the Settlement, the fight took place in which Governor Semple lost his life; and the subsequent troubles (in 1870) with the Canadian Government, are remembered by most middle-aged people.

At the time of my visit these troubles were already brewing. It was known, or feared, that Canada would certainly purchase, or otherwise become possessed of the territory before many years had passed; and I often heard the threat uttered that there would be armed resistance to any such acquirement. The foreign, and especially the half-breed, element, fomented by certain 
Yankee agitators, were particularly inveterate against "English rule," as they termed it. This expression was, I think, put in their mouths by Irish Fenians, who came here from the States for the express purpose of having "a slap at the d-d Saxon," as I heard one of then phrase it. But, beyond incidental mention, this book has nothing to do with politics; and I do not think I need say more on this subject.

The entrance to the Red River from Lake Winnipeg is between very flat, marshy banks, which are covered with sedge and giant bulrushes, three or four times the size of those growing in England, but otherwise like them. The country in all directions that could be seen from the canoe was very flat, and Winnipeg so shallow that the rushes grew in the water at a greater distance than a mile from the actual shore. These rushes gave harbourage to swarms of ducks, geese, and other wild-fowl; and for the first time on our journey I had a day's good sport among the ducks. I was greatly disappointed, however, to find at supper that night, that these wild ducks are very poor eating. There is nothing remarkable in the flavour of an English wild duck, but it is far better than the best of these. In fact, with the exception of the canvas-back of the States (which is more thought of than it deserves) and one or two others, all the North American ducks are of poor quality for the table. Not so the geese; but more of that hereafter.

I shot thirty-two ducks in the space of a couple of hours, and lest it should be thought that I indulged in a wanton slaughter, I may mention that they were all eaten before we reached Fort Garry, two days later; any one of my Indian friends thinking nothing of consuming a brace of ducks at breakfast or supper, and Tom picked the bones of two brace at one meal. With the exception of two species (possibly young birds, for many young were flying, and the plumage varies much at different stages of growth), all these ducks greatly resembled those found 
in the fens of England. The first was the common pintail, Dafila acuta of English ornithologists. This was tolerably abundant, and evidently bred in the marshes at the Winnipeg end of the Red River. I shot one gadwall, Anas strepera, miscalled a widgeon at Fort Garry, three dusky ducks, Anas obscura, and fourteen that were not distinguishable from the common wild duck, Anas boscas; but, as I have said, none of these ducks were equal in flavour to those of the same species found in England. In addition to the ducks, I shot five American widgeon, Mareca Americana, and these were much superior as food to the ducks. The geese were so wild that, on this occasion, I could not get a shot at them.

As we proceeded up the river the country became less marshy, and before we reached Stone Fort there was forest on both sides of the river. I afterwards found that this forest formed a belt from one or two, to five, and in a few places twelve, miles broad on the banks of the Red River, Assiniboine, and their tributaries. The country outside the forest belt was open prairie, the soil undoubtedly rich, and the climate at this season balmy and delightful, though hot during the middle of the day. Already the timber had been appreciably thinned in many places, and unless some bye-law is made for its preservation, there seems to be danger of its being speedily entirely destroyed. The inhabitants were using it recklessly as firewood, and in some instances burning it off the land to make clearings, a practice common all over the country at one time, and one which no language is too strong to condemn. Could I have my way, I would insist on so much of the timber being left intact; and I would punish with the most drastic penalties all wanton destruction of either trees or animals. I dare say that I am "behind the times," and a "faddist," but there are other people besides money-grubbers and merchants to be considered; and it is no great demand to ask that a portion of the world's beautiful surface should be left as 
God made it, for the pleasure of those who love Nature, and the good of those who are to come after us.

As we neared Fort Stone we seemed to be approaching civilisation; the unusual sight of a church spire first attracting attention. This was at the "Indian settlement." Where we find "Indian settlements" in America, we may be sure that the march of eivilisation has made rapid strides through the clistrict, and that there is a religious and moral force at work which is performing great things-for good or evil, or that terrible mixture of both which, to my mind, is the source of all misery, and which is always found in greatest excess when men congregate in cities and populous colonies.

The settlers' houses seemed to be mostly, if not entirely, built on the banks of the river facing the water, and I was much surprised at the substantial manner in which many of them were built. Some might be truly called handsome mansions, and the grounds were laid out with a taste and care that could not be exceeded in any centre of an old civilisation. Stone was the material mostly in use, and Stone Fort was the first building of that description that I had seen in the country, constructed of any class of masonry. It is a place of no great strength, and could be easily taken by escalade; but its walls were high and well built, and furnished with demi-bastions at the corners.

Corn-growing seemed to be then, as it certainly is now, the chief industry of the settlers; but there was an abundance of all sorts of domestic animals and poultry. During our stay we lived on fresh mutton, and I bought a fine hog and salted it to be eaten when we resumed our journey. Flour, ground locally, was to be had for a song, so that I was enabled to replenish all our stores.

We arrived at Fort Garry, the chief post of the Settlement, on the 15th, and stayed a week, anxious as I was to resume our voyage. The colonists treated me with the greatest hospitality, and I almost made up my 
mind to return to Red River and become a farmer. Perhaps it would have been as well if I had done so.

Having borrowed a horse, I rode out some miles on the prairie to have a look at the country. It is a different sort of prairie from that of the Mississippi Valley, not being distinguished by that billowy, rolling appearance that is the distinguishing trait of the latter district. Occasionally there is some undulating ground; but for the most part the country, outside the timber region, is almost flat. Wherever there is a brook or rivulet, there is a narrow belt of woodland on its banks. At other parts it is difficult to find so much as a bush, the ground being covered with a rich growth of long grass, with flowers as abundant in summer as on the prairies of the south.

Here and there are shallow lakes and marshes, which, in many cases, are not permanent, but dry up in summer ; but they attract enormous numbers of wild-fowl; and at evening time I sometimes saw flocks of ducks, \&c., that must have numbered at least tens of thousands. It is only at certain times, however, that they thus congregate. Generally they fly in small parties, and the geese and swans, particularly, will be seen in wedged-shaped parties, or straight lines, of a dozen to fifty or sixty birds. In a ride of twenty miles out across the prairie I saw no big game; but many small mammals and birds congregate in the woods. As none of them seemed to be peculiar to this region, I need not dwell on them here.

Having marked a small shallow lake, partially dry, which was much frequented by the wild-fowl, I had a day's shooting there, going alone. The birds were rather wilder than I should have expected to find them at a spot situated seven miles from the nearest habitation of man, and for a long time I despaired of obtaining a swan, which was the chief object of my wishes. At length, however, after creeping slowly and painfully for fully a mile under cover of the reeds, I arrived within fifty or sixty yards of nine birds which were feeding near the 
shore, and fired both barrels just as they arose from the surface of the water. Up they all went soaring round in a great circle, and in a wedge-shaped form, not one of them showing the least sign of being wounded, though my gun was charged with double B shot. I watched them, with no slight vexation, ascend to an enormous height till they looked scarcely bigger than starlings, when suddenly one dropped as straight as a plummet. The seemingly slow fall of that bird was really a beautiful sight, and filled my soul with joy. I saw it strike the ground, and rebound amidst a cloud of loose feathers, a good half-mile away.

It proved to be a truly magnificent bird, sixty-five inches in length; and, I feel sure, was larger than any tame swan I have ever seen. It was an American trumpeter swan, Cymnus buccinator; and was not much disfigured by its tremendous fall, which could not have been much less than a mile. All my efforts on this, and a subsequent day, to obtain a second specimen were fruitless.

Nor did I have much better success with the geese. These cunning birds were as unapproachable as the swans; and it was not until I had recourse to the assistance of my Indian friends that I succeeded in obtaining a shot at them. Lying hid among the rushes, Tom so cleverly imitated the cry of these birds that a flock of about twenty was allured to within gun-shot, and I gave them a right and a left. With the first barrel I killed my bird, but in the second case the goose was only wounded, and led my Indian friend a fine chase over the prairie before it could be secured. It made repeated and most adroit efforts to get to the water, and it required all Tom's nimbleness to prevent it effecting its purpose. Once there it would no doubt have swum out to the reeds and effectually have hid itself. This trick of imitating the cry is very common among Indian hunters; and some whites learn it sufficiently well to deceive the birds. Not only geese, but many other birds, and also 
mammals, are thus allured within easy shot; but on this occasion the birds could not be deceived again, and the brace I secured was all that I obtained at Red River. They were of the common Canadian kind, Bernicla Canadensis, which is a large dark-coloured bird, blackish and dark brown being the prevailing tints of its colour, with white cheeks and throat, and whitish belly.

The most important object of nay visit to Fort Garry was accomplished by my succeeding in engaging Achil Guelle, a French Canadian voyageur, to act as guide and assistant during the remainder of my purposed journey. He was a man of fifty years, well acquainted with Indian ways and notions, and highly recommended as a faithful fellow, who would be prepared to sustain my authority. Of course the real reason for engaging him was not revealed to my Indian friends, who would have been highly offended, and would have probably left me if they had suspected that I was in any way dissatisfied with them, or mistrusted their fidelity. I had so managed down to this point as to avoid all subject of dispute; but, as I have already hinted, it had become evident to me that these braves, to a certain extent, despised my youth and want of experience. This may seem strange to persons unacquainted with the nature and ways of Indians, considering that I had been made a complimentary chief; but chiefs among the Crees have no great authority.

We left Fort Garry on the 23rd August, and re-entered Lake Winnipeg the following day, again taking toll of the ducks and widgeon, of which Sam and I shot, between us, nearly fifty. The canoe was now so heavily laden that I began to fear that she was hardly safe; but the rapid consumption of provisions speedily remedied this.

We slept ashore, of course, every night, under the shelter of bushes and trees, and with a good fire at our feet. This was scarcely needed, as the heat was so great, even at night, that I could rarely endure the weight of a blanket 
over me, and lay with it folded under my head in place of a pillow; but a fire is always desirable at night. In the first place, it makes wolves and foxes chary of approaching the camp; and though men have nothing to fear from these animals, they will often make sudden grabs at provisions and leather articles, even boots and belts, the loss of which is a great inconvenience to travellers in uninhabited districts. Moreover the light of a fire may be of great use in the event of any unforeseen occurrence; and is in any event cheerful and comfort inspiring. I should say that any temporary bivouac is styled "a camp" in the American wilderness. 


\section{CHAPTER IX}

CONTINUATION OF THE VOYAGE IN THE WINNIPEG REGION

THERE is a marked difference in the appearance of Winnipeg and those lakes hitherto passed over and described. I had expected, though I admit from groundless preconceived notions, to find it the most picturesque of all the lakes; as a matter of fact it is the least so of any of them. It is a prairie lake; that is, bare sloping banks run down to the water, and often form long stretching peninsulas in it. The ground is covered with green, bright-looking grass, and in the proper season there are an abundance of wild flowers; but it is only at places that there are woods near the water. The water is very shallow, showing that it is an extensive hollow of the prairie which is permanently flooded. There are many islands of small size, some of which are occasionally covered with the rising water, and on a few of which there are bushes and a tree or two. Near the shore there is a dense growth of reeds which harbour enormous numbers of water-fowl of all kinds-swans, geese, ducks, widgeon and others. The length of this great lake must be nearly, or perhaps quite, three hundred miles, and it is generally from forty to fifty broad; so, like the other great lakes, it has the appearance of an inland sea. There are plenty of fish in its waters, of the same kind as those in the other lakes; and at some spots near the shore the mud was black with myriads of fry on which the gulls and ducks were feasting greedily. There were myriads of mosquitoes also, and of small green flies which 
bit cruelly; also dragon-flies, and other flying insects which secmed to be attractive to a number of small birds, amongst which I thought I recognised the common swamp-sparrow, Melospiza georgiana; but I can say nothing certain of these small birds, as specimens could not be obtained, those shot falling amongst the thicket of reeds where they could not be found. However, it may be taken for granted that the small passerine birds described farther on in this, and the next chapter, were all seen on the banks of Winnipeg.

The gulls were of the same species as those already mentioned as frequenting the great lakes; but that most numerous was the species very closely resembling Larus canus, insomuch that at most it is but a variety of that bird.

At certain spots close inshore I almost daily saw snipe in small parties of three to a dozen. They were very wild, rising as soon as the canoe got to within a hundred and fifty yards of them; but I succeeded in securing three, several others being lost owing to the nature of the ground where they were shot. These birds are called by American ornithologists the common English snipe, Gallinago delicata. It is "Wilson's snipe" of English naturalists, and certainly differs from the "common" snipe. Their breeding-grounds are undoubtedly on the shores of this lake, as I am certain that some of them were young; but, of course, all birds have finished their nesting in this region before the end of August.

We kept along the eastern shore, generally two or three miles from land, making some forty or fifty miles a day with the aid of paddles alone. For though sails are sometimes used in canoes, they are never safe, and we had none. We slept ashore, as a matter of course, throughout the journey, generally on the ground, but, where procurable, on a bed of spruce branches. If a settler's hut lay in our way we were sure of a friendly 
reception, and the same may be said of the Indian huts; but we usually eschewed these latter on account of the filth that always made them an abomination inside and out; for an Indian has not even an elementary notion of cleanliness. Should he gut a fish, or a small animal, for instance, he will throw down the offal close to the entrance to his lodge, and there leave it to ferment and rot. Not unfrequently his children will amuse themselves by scattering the horrible filth all over the place; and both they and their parents will handle their food after mauling the most abominable corruption that can be conceived. So I need hardly mention that I was always chary of accepting Indian hospitality, though it is but just to say that the poor people of this region were always, not only willing, but anxious, to show kindness.

Neither settlers nor Indians, however, were often met with in the wilderness. The latter seem never to have been very numerous in this northern district; and yearly they display a greater tendency to congregate near the townships and settlements, where they sometimes follow similar small trades and professions to those of the Gypsy vagabonds of Europe. The squaws, or women, particularly, hawk trifling articles about the settlements; and there is, or used to be, always a party of them at Niagara, selling moccasins and beadwork; and not unfrequently winning the hearts of susceptible trappers and backwoodsmen, who often take Indian wives.

On the 28th August we passed a deserted post of the Hudson Cornpany, situated at the bottom of a creek. The place was in ruins, and the stone-built chimney standing alone had a weird and saddening effect on the spirits. We passed the night at this place as it furnished us with a convenient cooking-place; and just after dusk I killed a musquash on the bank of the creek. This was the first of these animals which we 
had seen since commencing our journey on the lakes. Many of the small mammals are nocturnal in their habits, which, no doubt, accounts for their being but seldom seen. The best way of testing their presence and number in a district, is to set traps overnight, when, if they are numerous, some are sure to be caught. Thus, the accidental killing of this musquash set the Indians to making springes, and placing them before every likely-looking rat-hole along the banks, with the result that five more musquash were found captured in the morning. These springes are made with wire, which we had with us for this purpose. Many small mammals and birds were afterwards caught in them, and as they are usually entangled by the neck, they are almost always dead when found in the morning. Birds can be caught with springes made of bents, \&c., but rodents, like the musquash, will bite through these and escape. It is astonishing what a lot of small pelts will be collected by a skilful trapper, or Indian, without expending a single charge of powder. I have known some of these men have nearly two hundred traps, of various sorts, set about a district a few miles square-as many, in fact, as he could possibly attend to.

Near the northern end of Winnipeg we entered a small stream known as the Jack River, though I could not find it entered on my map by that or any other name. It is a stream which connects several small lakes together, and though it was practically currentless, empties, I suppose, the waters of Winnipeg and these small lakes into the Nelson River, which carries them into Hudson Bay.

The same night we arrived at another of the Company's depôts or stations--Norway House, which is situated at the embouchure of the Jack River. The first notice we had of the approach to this house was a flagstaff fixed on a high rock with the Union Jack floating from it, the house itself being hid in a snug ravine. 
There was quite a little village here of one-storey huts ranged in a square, the fort being of the usual gimcrack construction. Whether any of these depôts were ever seriously attacked by the Indians I do not know, but if so, it is wonderful that they were not destroyed; for all those that I saw, with the exception of Stone Fort and one or two others, were built of timber, and that in anything but a formidable style of construction. A blockhouse, skilfully made, is capable of offering a stout resistance - of enduring a prolonged siege, unless heavy guns are brought against it; but these forts of the Company are without ditches, or proper outward casing of earth, and their contour and elevation are not of the best; nor are any obstructions placed at weak points; and trees and other shelter for an enemy are permitted to remain standing close to their walls. I doubt strongly if they could hold out twenty-four hours against the attack of a party of riflemen.

The interior of these forts, or depôts, is on a par with the exterior. The agent, or factor, in charge of one of these stations has, of course, his private apartments which, I presume, he furnishes according to his own taste, and at his own expense; but the junior clerks are allotted a common room in which the only furniture I have ever seen is a few rough plank tables, three-legged stools, a stove, and similar articles. There is no pretence at comfort. The young men have usually a gun or two, and fishing-rods, hung about the walls; and perhaps the implements of a few games, such as cricket, croquet, \&c. There is a "labourer" to attend them, if it is a permanent station; but when travelling they have to do for themselves the best that they can. The general discomfort of the place is increased, in my opinion, by the custom of white-washing the rooms inside and out. Even in summer I consider whitewash an eyesore: in winter it is simply an abomination. Clean and wholesome! No doubt. And carpets on the floor are apt to breed 
disease! Indeed. But I am too old a bird to swallow all the medical profession say; and, moreover, the fleshly lusts have got such a hold on me that I go in for comfort even if there is "death in the pot." I have found this rule of life agree remarkably well with me so far; and it is to be noted that a scarecrow often keeps the bird from a good feed.

Part of every depôt consists of offices and storerooms. 'The factor receives and values the pelts brought in by the white trapper, or the Indian. The former rarely troubles the Company, as he knows that he can take his goods to a much better market. Payment for the furs is made in "castors," and all the trade is by barter. A castor is a small cube of wood used in lieu of money, and its value is usually reckoned at two shillings. Having received his castors, the Indian goes to the store, or trading-room, and the Company's goods are displayed to his longing eyes. Common guns, butchers' knives, fish-hooks, steel traps, blankets, cast uniforms, and powder and shot, are the articles for which there is the greatest demand; and these are selected and paid for in castors until the Indian has expended his season's earnings. It is a slow process: for the Indian is a cautious dealer; and child-like, delights to examine the whole glorious stock before making his choice. Needless to point out that this barter system gives the Company a double profit. So far as my experience goes they seem to pay about one-twentieth of the value of the furs; and pay in goods which they reckon on the retail, not the wholesale, list of prices. I have not the slightest ill-feeling against the Hudson Bay Company; but I shall speak the plain truth-the more so as a critic of my first book, treating of North America, seems to think I failed to give the Company credit for what they had done for the Indians. I do not know what particular good they have done for them. I know that at one time the Indians were seldom sober when the bargains were struck; and I know that the utmost value 
which an Indian could get for a black bear-skin, in prime condition, was a common Birmingham gun for which I should refuse to give thirty shillings: while I have actually sold a black bear-skin in London for fifty pounds sterling. This may be excellent trading - it is not fair conduct. On the other hand, I believe that, at a later date, the Company strictly forbade their servants to barter rum to the Indians; but I am under the impression that they only did so under strong remonstrance from the Government and public opinion at home. These impressions of mine were made, and made honestly, thirty-seven years ago, when I was a mere boy; but I stick to them now. I say that the Company's policy was a selfish, if not an absolutely dishonest, one. They strove to keep a thirtieth part of the earth's surface as a private hunting-ground for their own profit; and did not pay the working part of their employees (that is the hunters and trappers) anything like a fair price for their labour. They strove to keep out of this extensive region all men but their own servants; and wherever and whenever they could, treated as intruders all private hunters and travellers. Like the twelve Hebrew spies of old, they raised up an evil report of the goodly landfor a goodly land it is; and strove to make their brethren believe that it was a howling wilderness, in which no settler could prosper. All this is past, and I have done. Doubtless I shall be told that this is a matter which has long ago lost its interest. Perhaps so: but it is history, let me say.

I do not intend to return to this subject of the Hudson Company, therefore before finally quitting it, I think fit to record my own treatment by its servants. Privately I was treated with great courtesy and hospitality by several of the chief traders, or factors; but there was an evident tendency on the part of the Company's servants, generally, to discourage my journeys. No active opposition was in any case offered to me; but 
discouraging reports were the invariable rule. I was advised to abandon this, to forego that, and to hasten back to from whence I came. No stores or supplies could be sold to me for money. The Company did not trade in that way. I was offered the Indian rate of barter for such furs as I had, but no regular purchase and sale transaction would be entertained. I was even refused two or three pounds of powder, to replace that expended, by way of purchase; though the gentlemen of the depôt afterwards gave me half-a-dozen pounds. And so with every other class of store. If I asked to purchase it I was told that the Company were not store-keepers; but I was never permitted to depart lacking what I had asked for. The impression left on my mind was that the gentlemen of the depôts had an ungrateful task to perform, which their loyalty to their employers compelled them to carry out to a certain extent, while their feelings, as men and gentlemen, refused to let them endanger the life of a fellow-man by thrusting him forth lacking those things on which his safety, in great measure, depended. Discouraging advice $I$ received in abundance, but no active opposition.

Advice, however, good, bad, or indifferent, is a thing I have never been much influenced by. I am a born Bohemian, and the wildernesses of this splendid continent harbour a siren whose enchantments I never could resist. Where many men have grumbled at their hardships, and some talked of perishing, I have been in paradise. Although to some extent a cripple (though not seriously lame at this time), I have been all through life a man of Herculean powers of endurance; and the solitude of the wilderness has for me the same allurements that the sea is said to have for many natures. Not but that I love the sea also-what Englishman does not? On this, my first extensive journey in the New World, I was in such a state of delighted excitement that no fear, no force, could have induced me to abandon 
it. Somehow, by some means, I would have fulfilled iny will.

Although Norway House lies in a ravine, or hollow, its foundations are placed on rock, and the whole district is rocky. The gardens, which are well kept, and surround the stockades of the fort, as well as the huts, seem to have been made, with great labour, of the sandy mud of the river. It is impossible to see the fort until you are just on it, and it is commanded by a huge rock close to the stockades, so that the place is not tenable from a military point of view. The river swells into a lake here, which, although small for this part of the world, is in reality so extensive that the eye cannot reach the opposite shore by a very long way. It is called Play-green Lake, and the scenery about it begins again to become very picturesque.

At the time of our visit there was much bustle at Norway House, for in addition to many Indians who had arrived with their bundles of pelts, there was a "brigade" of canoes temporarily halting, and waiting to be joined by others. Many of the voyageurs were well known to Achil, and for a day or two we had a very merry party.

The Canadian voyageur is a good chum, as a rule, and would be a downright fine fellow if it were not for his confounded political opinions. Whoever imagines that the majority of the French Canadians are loyal to the British makes a woeful mistake. Eighty per cent. of them at least have made up their minds that the Britisher must go, and they will never lose an opportunity to be a thorn in our sides, especially should we have a war with France.

But this feeling apart, the voyageur is, as I say, a very good fellow-a desperately hard worker, patient and faithful to his employer. He has usually an exceedingly pleasant face, is polite, like his French ancestors, and, though inclined to be penurious, is not so selfish as 
Monsieur Crapaud himself. $\mathrm{He}$ is willing to live as hard as he works, and in all canoe management and woodcraftsmanship is almost as skilful as an Indian.

I made my stay at Norway House as brief as possible, and, after passing across Play-green Lake and ascending the stream for about forty miles, we branched off to the right into a creek, or brook, which led us another twenty miles into the wilderness. The banks of this and all other streams in the neighbourhood were high, often precipitous, so that we could not see the country we were passing through without climbing up them, a height of forty or fifty feet, and sometimes double that. The country was flat, covered with bushes in some places and forest in others, and occasionally open and park-like. It was everywhere well watered with streams and small lakes. That part which I had selected for our camp was covered with forest, with open intervals here and there at distances of a few miles apart. A beautifully clear brook flowed close to the spot we occupied, and furnished us with the necessary water. As there was only a foot or two of water in it, it could be stepped across with ease.

Here I intended to stay a month. The canoe was carried up to a place of safety and lodged between the forks of two small trees, and several temporary huts were made of branches, thatched with twigs and grass, for sleeping-places and the protection of our stores. In fact, in a couple of days' time we had made ourselves quite comfortable, and I was happy, as I believed that there were no other inhabitants, except a fow wandering Indians, within a hundred miles of us. Norway House, distant some seventy or eighty miles, was probably the nearest post of whites. 


\section{CHAPTER X}

\section{A MONTH'S ENCAMPMENT IN THE WILDERNESS}

Our guide, Achil Guelle, knew this district generally, but could give it no particular name. A few spots he designated with trapper's nomenclature; but the place was, and probably still is, a coinpletely out-of-the-way wilderness, never visited by any beings but Indians and hunters, and but by comparatively few of them, for it was not generally known. According to Achil, however, it was a splendid spot for game; and so it proved. I suppose it to be situated about midway between Playgreen Lake and the Hill River, and some fifty miles from either; but the map I had was not sufficiently good to locate the spot with precision.

The night of our arrival I was much struck with the peculiar cry of some bird which I was told was the whippoor-will, and which was answered by another at an apparently considerable distance. As I had never before heard the cries of these birds I could not judge for myself, but I had not the least doubt that the notes were those of a crepuscular hawk of some kind, though I had hitherto thought that the whip-poor-will was confined to the warmer parts of America. On this and subsequent nights I heard the birds calling and answering for hours, but it was a long time before I caught sight of them. At length I shot one, and from its skin I subsequently learned it to be the Chordeiles virginianus of Americans, Caprimulgus virginianus of the English. I believe that this bird has never been found so far north 
before, and doubt has been cast on my having found it at the spot indicated. There is the skin, however; and the fact cannot be disproved, though both American and English naturalists have seemed to be inclined to be sceptical about it. These were not, however, naturalists of repute. It seems to be local hereabout, although Achil says he has seen and heard it hundreds of miles to the eastward. I heard it for the last time on the $27 \mathrm{th}$ of September; and as it was not seen after that date I presume that it had migrated south.

The bird called by the trappers the whisky-jack, first seen near Lake Temiscaming, was numerous here. It is undoubtedly a shrike; but the American naturalist to whom I sent the skin, with others, never acknowledged their receipt: I therefore cannot give it specific identification. For this reason several small birds of this region must remain unnoticed; while others will be described presently.

The wild fruits about here were similar to those of Canada proper ; that is, cranberries, raspberries, and blackberries. But for the first time I met with the wild plum. Those about here were of the "blue" or purple kind; but there is also a "white" sort. They were not ripe on our first arrival; and I cannot praise their flavour when at the best; but Canadians and Yankees alike think a great deal of them for making jams. The people of these countries preserve any sort of wild fruit; and are never tired of praising them, so that one would think this the first country in the world for wild fruits if he depended only on what he heard. Few parts of the northern half of the continent, however, are better provided with this class of productions than England. Americans have the sweet-tooth highly developed, and resemble children in their fondness for sweets.

On the very first day of my search in the woods for game I met with an exciting adventure, and one that raised me greatly in the esteem of my Indian friends. 
This was nothing less than the meeting with and killing my first bear-a huge creature of the black species, Ursus Americana. It was the skin of this huge beast for which I received fifty pounds in England; and it was acknowledged by all the trappers who saw it to be one of the finest that they had ever examined, and to be in perfect condition. That I obtained it as easily as I did was an almost miraculous piece of good fortune, for I was armed only with a shot gun.

I had been out looking for small game, and was some distance away from our camping-place in a piece of rocky ground, with a stream of water in front and a swamp on the right. I had not expected to meet with any large animal as there were no tracks of deer in the neighbourhood, and bears never entered my thoughts; yet when returning I came quite suddenly on a very large black bear, which was busy devouring blackberries, and also beetles: for I saw him turning over stones and detached pieces of rock in search of them, and eagerly scratching them out of crevices. He was not nearly a hundred yards off when I first saw him; and though I was walking rather carelessly at the time, he neither saw nor heard me. I came to a sudden halt, rather startled, I must own, for this was the first wild bear I had ever seen, and it at once occurred to me that I was very poorly armed for an encounter with such an animal. I had a twelve-gauge gun loaded with number 4 shot, and a pair of heavy pistols without which I never moved; but pistols were scarcely fit weapons to attack a bear with, though they carried balls averaging twenty-five to the pound weight.

The bear was slowly advancing towards me, and I was compelled to retreat: for the space between the brook and the swamp was so narrow that I could not risk an attempt to pass the bear. I tried to ford the brook, but not only did the water come above the waist before I reached the middle, but the bottom was a treacherous quicksand, and I had to get out of it hastily, after a 
narrow escape of sticking fast. The swamp was quite impassable.

The bear continually elevated his muzzle and sniffed the air, and I thought that he winded two or three ducks which I had recently killed. I therefore took them from my belt and threw them down, hoping to gain time; and as I retired I drew the shot from my gun, and substituted two bullets in each barrel, with six drams of powder behind them. The bullets I fortunately made it a habit to always carry with me in case I should meet with deer.

I saw the bear stop to maul the ducks, and congratulating myself on the ruse which had succeeded in delaying him, I hastened to get round the swamp. The bear must have caught sight of me, for suddenly he came after me with surprising nimbleness. I cannot say what my feelings were, but a sort of furious fear took possession of me, and stimulated me to strive to save my life. I fired full at the bear's chest when he was about twenty paces distant. He fell, but got up again, as I have noticed that animals often do when merely shot through the lungs, and blood was dripping from his mouth. I suppose I realised, on the spur of the moment, that nothing but coolness could make my last poor chance a winning one. I know that fear (I may as well confess it) made my aim a desperately sure one. The head of the bear was not six feet from the muzzle of the gun when I fired the second barrel, and it killed him instantly. In fact the head was shattered, and part of the brain blown out. What a sigh of relief I gave! I think I realised the feeling of a bird when it escapes the trap; of a fly when it breaks from the web just in the nick of time to escape the rushing spider.

I hope I shall be excused for giving such a minute account of this combat. It was my first serious adventure with a formidable animal, and I was boyishly proud of my success, and of the astonished praise of my companions. 
The bear was so heavy that I could not turn it over or drag its leg from under it, and the skinning of it was work for the whole party. The length from the snout of the root of the tail was 6 feet 7 inches; the weight to the animal could not have been less - than from 800 to 900 pounds. The skin was perfect. My companions admitted that they had never seen a finer, and it was glossy black throughout-a rare occurrence.

I will not here add greatly to the remarks I have made about American bears in a former work, and what I now say refers to Canadian examples. The average length of the black bear in this country (Canada and the North-West) is only a few inches more than 5 feet, and the weight from 600 to 650 pounds. In particular localities they grow larger; in others, without being much smaller, they are considerably lighter. They also vary in weight with the season, being lighter after the hibernation, and heaviest just before it. They vary much in colour, being sometimes black, and sometimes light brown, with many intermediate shades. Locality has sometimes something to do with colour. Some hunters and naturalists say that the brown is a distinct species. I do not share that opinion. It is certain that the pelts are classified as black and brown by the Hudson Company's people. I have heard that the black bear is no longer found in any part of Canada or the North-West. I do not know, as it is more than twenty years since I was in the country. At the time of which I am writing they were not abundant anywhere, and in large areas could not be found at all. In a word, they were already beginning to show signs of a speedy extermination.

The black bear is omnivorous, and will eat anything from a beetle to a deer, from a blackberry to a cabbage. They certainly kill cariboo, breaking the neck with a blow of the paw. Whether they ever attack the larger deer I do not know, but I can perceive no reason why they should not. They are enormously strong, and can 
walk off with a cariboo as easily as a cat with a mouse. Notwithstanding my first experience, I subsequently convinced myself that they rarely attack men; but they do so on rare occasions, and it seems to me more from caprice than driven to it by hunger. Yet they are always uncertain-tempered animals. Those captured young, and brought up by the colonists or hunters, become as attached as dogs to their masters. In their native haunts they are very active animals, and no person who had watched them in the wilds would speak. of a bear as a "clumsy" animal.

In the district where we were camping the bears were unusually fine. Several were seen during our stay, and two more were killed. One, measuring five feet eight inches, was killed by the whole party of us combined, receiving no fewer than fourteen bullets, to the no small detriment of the pelt. The other, just over six feet in length, was killed with a single bullet in the head by Achil, single-handed. This last was whitish about the muzzle, and had some brownish patches about it. All were males; the females are quite a third smaller than their lords.

There were wolves here, and gluttons; the first time I had seen the latter animal; and I thought that it might be owing to the abundance of these animals that the deer had forsaken the neighbourhood. We were soon at work with the traps, and captured several wolves and a fox or two, but no glutton was ever captured, though several were shot. They seemed even more cunning and suspicious than the wolves, and even the latter appeared to soon acquire a suspicion of the fate of their companions; for after the first week or two none ventured near the traps, skilfully as we concealed them under moss and leaves, or with a light layer of sand over them.

Of the gluttons I shot two myself by lying in wait at night, for these animals rarely show themselves during daylight. They are among the fiercest and cruellest of 
the smaller beasts of prey, and are so wily that when once they have discovered that hunters are established in a tract they will forsake it. It is useless to try to shoot them otherwise than by lying in concealment at places they are supposed to frequent. They cannot be ferreted out of the caverns and holes which they usually occupy, for they will kill dogs, and their dens are always so well selected that they cannot be dug out. Their habits are just those of bears, but superficially they strongly resemble hyenas. They are only met with singly, or in pairs, or a dam with her cubs. The latter are two or three in number. Like bears, they are almost omnivorous, and are in the habit of burying their prey; but they do not eat fruits that I am.aware of. If they come across the hidden store of a hunter, or sneak into his hut during his absence, they will devour all sorts of provisions-biscuit, grease of all kinds, cheese, meat, and fish. They sometimes catch the latter for themselves. They are about as big as a medium-sized dog; that is, they average thirty inches in length from the snout to the root of the tail, and the latter is a foot long, and bushy; and the hair is very long on the bottom of the back and on the under parts, so that the legs are half hidden.

They are very active animals, but capture their prey as much by artifice as speed, and they lie in wait near the holes of such creatures as ermines, martens, musquashes, and minks, which form a large share of their prey. They also surprise hares, and rob foxes of their captured prey. The latter susprise many birds of the grouse and duck family, but I do not know that the glutton does. If the fox should happen to defend its preywhich I have known it to do when several are togetherit is ten to one but a fox itself is killed and devoured by the glutton; and I have known a case where one dug down to the buried prey of a bear, and another instance of a sheep having been destroyed and partially 
eaten; but no case of deer being pulled down by gluttons ever came under my notice. It is an exceedingly greedy animal, but does not deserve the name of glutton more than some other preying animals. It is not correct to describe it as gorging itself to the point of helplessness, or to say that it is slow in its movements. Though it is very bear-like in many of its habits, unlike that animal, it does not hibernate.

The trappers and colonists in Canada call it the quickhatch. In the States, and among naturalists, it is termed the wolverine-Gulo luscus. It is a very local and scarce animal in the States, where I have only seen or heard of it on one or two occasions. Like most or all other animals of this family, it often leaves a strong and offensive scent behind it.

As nearly all the typical small mammals of the Canadian region were found in this district, this is, perhaps, a good place in which to mention them.

First, the mink. The skin of this animal forms an important article of trade of the Hudson Company, and many thousands of them are annually bartered by the Indians and trappers. They are always caught in traps, as shot would injure so small and fine a pelt. The animal is about the size of a wild rabbit, but of much slimmer build; in fact it is more like a small otter than any other animal to which I can compare it, and its habits are those of an otter. It swims and dives with great facility, and captures fish on which it preys. It also devours reptiles, and small aquatic birds, which it surprises while they are swimming or standing in the shallow water. During our stay here my companions caught more than a hundred, besides which I shot a number. As I generally succeeded in hitting them on the head with small shot, I did not find that the skins were at all injured. But the trappers will have it otherwise. These men make a principle of saving powder whenever they can. 
They are caught in two ways: first, in steel traps; secondly, by means of a poised log of wood, which, falling on the mink, kills or disables it. These little creatures are as tenacious of life as an eel. They smell abominably; and the carcasses must be skinned with care, otherwise the bundle of pelts can scarcely be endured while under transport, and the sweetening process is a long and troublesome one.

From the numbers mentioned above it will be perceived that the mink was tolerably abundant hereabout; but the ermine was by far the most numerous of all the small mammals that we found here. In this animal, which is very much smaller than the mink, having the body some ten to twelve inches long, the fur changes colour at the approach of winter, becoming snow-white, with the exception of the end of the tail. But most persons know the fur of the ermine. We obtained several hundred skins, nearly all of which I afterwards brought to England; for the Hudson Company were, at this time, scarcely giving thanks for them, and many trappers only captured them in traps set for other small animals.

Of the other members of the genus Mustela in this neighbourhood, I am uncertain that my remarks have a general interest, as I am almost sure to be told they have not to the professional naturalist. My view is that they are simply local varieties of animals common to all countries within certain parallels of the northern hemisphere. Take the common American marten, for instance (Mustela Americana): in what does it differ from the European marten? or the Asiatic sable? In nothing, in my opinion, of sufficient importance to constitute it a distinct species; or nothing that would be considered a remarkable difference in any species of domestic animal if found occurring in even the same country. I doubt if it could always be told, by even an experienced naturalist, which was the European, which was the American marten; 
for in Upper Canada, at least, a certain amount of variation occurs in species, though, I admit, it is not great.

What occasions this variation I cannot say. At first I thought that a seasonal change of fur was going to take place, but that I soon found was not the case. Then it occurred to me that the erratic individuals might be cross-bred. That I now think to be extremely unlikely. It is a strange fact that all these small, carnivorous mammals, agreeing, with but little difference at all events, in their habits, should retain their ordinary colour of fur at all seasons of the year with one exception-that of the ermine; and further, that none of them hibernate. With regard to the latter fact, as far as my experience goes, no species of marten, polecat, or weasel ever does hibernate, not even in the polar regions.

With the exception of the mink, all these weasels, as I will collectively call them for the sake of avoiding confusion, appeared to me to spend part of their time aloft in the trees. They certainly take readily to trees in moments of danger; and all alike are fierce and capable of attacking and overcoming animals vastly their superior in size; for instance, they destroy numbers of the large American hare, which is nearly twenty times the weight of the smallest of these weasels.

Besides those I have already referred to, I shall mention but one more-the tree-fox, or tree-cat, of the trappers. This is Mustela pennanti, often called the fishmarten. It is an animal about the size of a small fox, of a dark brown colour, with a lighter shade down the back; very active in its habits, but spending much of its time on the ground in damp, swampy situations. Unlike the mink, it does not seem to often frequent running water, but prowls about stagnant pools and small, shallow lakes, preying on reptiles, fresh-water molluscs and crustaceans, and small fish, which it beats out of the water with its fore-paws in the manner of a cat. It also robs other animals of fish which they have captured, and I 
have seen one eating the refuse which had been ejected from the nest of an osprey. All and every small creature that it succeeds in surprising, bird or mammal, is also devoured by it, and even other mustela; but in this it is not singular, for I have seen a marten devour an ermine, and have reason to think that when these little animals fight together, which they sometimes do, for they are all fierce and bloodthirsty, the conquerors devour the vanquished. I have also seen the tree-fox and the common otter (Iutra Canadensis) fight together, the object of the fox being to obtain the fish captured by the otter. In this case the fight was not fatal to either combatant; for the otter, after a time, returned to the water, taking its fish with it.

It is probable that these fights would be much more frequently witnessed if persons taking an interest in natural history would watch for them, being careful to keep themselves concealed. My own plan was to make a screen of leafy branches, completely covering myself with leaves; and having selected a spot which I knew that the animal which I wanted to watch frequented, I have waited for six or eight hours to make iny observations. It is necessary to remain perfectly quiet, not to smoke, and to take care that the wind is blowing from the direction in which you expect the animal to appear.

The otter mentioned above does not differ much from the species found in England. It is a little larger, of a dark brown colour, and has the same habits as those of Europe. It is scarce here, only a few odd ones being seen; but its pelt is valuable, fetching from two to five pounds in England; while that of the tree-fox is scarcely worth a charge of powder.

There were small birds here in great numbers, but only a few species were identified with certainty. Among them were the American yellow bird, which is a species of siskin, Chrysomitris tristis, which we had already seen 
on the open prairies, where they are attracted by the many grass seeds. The ruby-crest, Regulus calendula; tree-sparrow, Spizella monticola (a single specimen was shot); the pine grosbeak, Pinicola enucleator; and the rose-breasted grosbeak, Habia ludoviciana, in America; Hedymeles virginianus, in England. Besides these we found several of those small passeres, or finches, known in the States as pewees, and ground and swamp sparrows; but circumstances prevented me from learning their specific names. It is certain that these birds are migratory, and before we left this region they had all disappeared, having evidently gone south.

So much for the natural history of this district. Long before the end of September we had collected so many pelts, great and small, that my Indian companions became quite excited at our, success. They also became impatient to return home; and as I had made up my mind to winter in the wilderness, three of my four Indians resolved to leave me; and forthwith set about making a canoe, a work that is never onerous to an Indian. In three or four days they had completed it, and on the 18th September, Chuckochilgegan (Sam), and the two younger men, Natanyan and Otmasquiloton, left me in the usual phlegmatic Indian fashion. I had expected that Sam's brother, Monchuapiganon, Tom as I called him, would have gone too; but he did not. Taciturn as he always was, he made no remark, and took no leave of his brother. He scarcely noticed his departure; but what seems cold-hearted and strange behaviour to us, may not really have been so. It is the Indian way; and demonstrativeness is always offensive to an Indian. I have much reason to think that Tom remained behind owing to his attachment to me. I have, all through my career, been very fortunate in this respect with my followers, and have generally had at least one member of my party strongly attached to me. Whatever the reason of Tom's faithfulness, it was not solicitation on my part; 
and an Indian must not be questioned as to feelings and motives.

It may be of interest to detail our daily life. We did not usually rise before dawn of day. A roaring fire of $\log s$ was always kept in at night in front of our huts, which was fed with fuel by whoever chanced to wake, and as early as the beginning of September this was a great comfort, if not an actual necessary; for the nights were frequently bitterly cold, though the days were quite hot. We had plenty of pelts in addition to our blankets, so that we really did not suffer from the cold; and a bed of spruce boughs spread on the ground is one of the most comfortable that can be conceived.

Whoever was first on his pins in the morning put a large iron pot of water on the fire to heat for breakfast. This meal always consisted largely of game: for we were so short of flour that dough cakes, baked in the ashes, had to be sparingly used. The Indians, indeed, ate scarcely any bread. Tea or cocoa was made in tin cans, and drunk without sugar as soon as our limited supply of that article was exhausted. The fat of the bears killed served us in lieu of butter, and was, indeed, even to my taste, superior to it; while the meat was excellent, and some of it, dried in the wind, lasted us for a long time. Bears' meat is, in America, far superior to the venison of either wipiti or moose. Of small game, principally hares, grouse, and ducks, we could daily kill as much as we wanted, so that there was no lack in the quantity of our food, though I certainly for a long time greatly missed the bread and vegetables to which I had been used. There were plenty of wild fruits at this season, and these were useful to counteract the effects of the excessive quantity of animal food which we consumed. So our health did not suffer at all; indeed, we were all in the very pink of condition.

As soon as our morning meal was over we started to visit the traps, leaving one of our number to keep the 
foxes, \&c., from intruding, and to cook the meat for dinner. Sometimes we went singly on this duty, sometimes divided into two parties: especially when we discovered by their tracks that bears were numerous in this place. After the departure of Chuckochilgegan ("Cunning polecat, or marten") and his companions, Tom and I invariably went into the woods in company, leaving Achil to cook; for at that business he was an adept. Sometimes it took us many hours to visit the traps; but if few animals were caught, and the victims had not to be killed and skinned, we soon got through with this work, and I spent the remainder of the day in either shooting or watching the habits of the animals in the forest. We ate but two "square" meals per day, but the quantity of meat consumed at these two meals would have astounded an easy-working, idle cit. I usually ate a few mouthfuls of food while wandering in the woods; but ultimately I got into the habit of being satisfied with two full meals per day. We all, however, would eat any of the wild fruits that we might meet with when wandering about, and I dare say the quantity thus consumed was considerable.

Of course we all got back to our camp before the darkness of night set in; and the evening meal was the principal one of the day. By the blazing light of the fire we followed our occupations, or lay idly about and smoked. On this journey, owing to the need of travelling as lightly as possible, I had but two books with methe Bible and my note-book. I jotted down my notes for the day by firelight, and then read such portions of the Bible as I thought would be most impressive to the Indians. We prayed to God, and then retired to rest, seldom later than seven or eight o'clock. Such was our daily life.

On subsequent occasions during my long sojourn in the Americas, I always carried as many books as I could find room for. I cannot be happy without books, and I 
always found the rudest followers of my party interested greatly in the nightly read, provided only that I took care to select a book that treated of a subject which they could understand. Masterpieces of fiction were always favourites. On this particular occasion I suffered so much in mind (the only discomfort I noticed) for want of books, that I determined never again to subject myself to the deprivation. Afterwards I carried with me from one to several dozens of the paper-covered sixpenny editions of popular works, such as are published by several of the leading London firms. These are so easily packed, and take up so little room, that I found them invaluable.

May I say a word or two concerning religion? I never permitted, in my company, the Supreme Being to be ignored, and, what is more, I never had in my parties a man who showed a desire to ignore Him. Often I selected men of great ignorance and doubtful character, because I consider that such men, properly handled, made the best servants for such expeditions as mine. It is necessary for the leader of a party in the wilderness to be a man whom his followers admit and feel to be markedly their superior in some way or other, or in sorne knowledge or other; otherwise they will so learn to despise him, and perhaps to ignore him. Now a man who knows everything, or thinks himself equal to any occasion, always makes a bad follower, and an even worse leader. But, nevertheless, the leader must be a man of superior knowledge to his men, and yet have the art to let his men find out for themselves that he is a capable leader. Anything like parade or bounce, and above all, selfishness, which is injustice, is sure to have a bad influence on followers. And I have never found a better way of establishing my position with my men, than by letting them see that I feared God. I beg that I may not be misunderstood. I am no advocate for religious argument or for camp-preaching, though I despise not 
those who think they are doing good in this way. But the state of mind into which I usually led my followers may be the best illustration of the value of my system, if I may say so without incurring the charge of selfconceit. Achil Guelle, and many years afterwards, George and Joseph in Brazil, besides several other Roman Catholics with whom I associated in my journeyings, fell heartily into my views on this subject, and resumed those devotions which they had neglected since childhood. The Indians were often indifferent, yet gradually came to acquiesce in the propriety of daily acknowledging the Almighty; while even such a morose and undemonstrative an inclividual as Tom exclaimed that "it was right that the Great Spirit should be thanked." I mention these matters as incidents of life in the wilderness that may have some interest.

Having made up my mind to spend the coming winter in the wilds, we, at the end of September, made a move, and journeyed nearly a hundred miles in a north-easterly direction. The principal reason for this change of camp was that we never met with any deer at the place first selected, and venison was required for our support. The journey to the new camp took us five days to accomplish, the first three of which we walked overland, carrying the canoe with the stores in it on our shoulders. It is probable that we did not advance more than twenty miles in those three days, for the ground was rough and rocky, without being very hilly. At the end of the third day we came to a stream large enough to float the canoe, and down this we proceeded in the direction of Hudson Bay. 'Our new position was about two hundred miles north-east of Lake Winnipeg, on a tributary of the River Severn, and some twenty miles from that river. I did not follow the tributary right down to the Severn, because it seemed to me that we had reached a spot that was in every way fit for our purpose. Achil agreeing with me, we commenced at once to make a small 
low-pitched log-hut, similar to those used by the lumberers. The hut was erected in front of a sinall cave which served us as an inner chamber and storehouse, and added greatly to the warmth and comfort of our dwelling. Outside the hut was overhung by trees growing on the tops of the rocks; for we were in the bed of the stream, about twelve feet above the water, and it was impossible to conceive of a snugger or more picturesque site. The cave was large enough to contain the canoe, besides our beds and all our belongings; and in winter when the outside of the hut was completely covered with snow, the place was so warm that we might have resided in it without a fire had it been necessary. But we had taken the precaution to make a substantial fireplace and chimney of stone within the hut, and every available space was packed with logs for firing, with several stacks close at hand to be brought in as occasion required. All this work was completed by the 12 th October, down to which time we had had no severe weather, though there were sharp frosts at night, and one day a few flakes of snow fell which soon melted when the sun shone.

In our journey hither from our first camp we did not meet with a living soul, either Indian or trapper, but we found a dead Indian in a tree. He had been dead so long that the flesh had shrunk and hardened in a curious way, giving the corpse a mummy-like appearance. The features were quite gone, but there is no doubt that the body was that of an Indian. He was firmly lashed to the boughs of a tree about sixteen feet from the ground, and we surmised that he had been so placed by his companions to prevent beasts of prey from devouring him. He had probably met his death from accident while on a trapping expedition, or he may have been disposed of in this manner according to the custom of his tribe. There were several reasons why he may not have been buried. The ground was so hard and rocky that the making of a grave would have been a work of 
much time, and altogether impossible if the party had no proper tools with them, and they were probably in a hurry. Moreover, many of the Indian tribes dispose of their dead on platforms erected above the ground, at spots set apart for that purpose, and held sacred.

During the whole extent of this journey we found the ground to be a hard rock, with a very shallow coating of earth on it. It was covered with moss, and trees were numerous in a succession of woods, with clear and rocky spots between. The trees were mostly conifers, and were of small growth, with here and there a tine clump. As everywhere else in this country, swamps and small lakes were frequently found. 


\section{CHAP'TER XI}

\section{A WINTER IN THE SOLITARY WILDERNESS}

Throvghout its entire length the nameless stream on the banks of which we were now encamped ran between high walls of rock, very steep in many places, which were covered with a curtain of creepers. As the cold weather came on this mass of creepers made a magnificent display of scarlet, crimson, yellow, and brown foliage. It must have been a favourite breeding-place of the small birds, for I found hundreds of their old nests in it, and greatly surprised was I to find one or two of these nests lined with hair from the tails or manes of horses. It was not likely that there were any horses within two or three hundred miles, but the hair could not have been fetched by small, shortwinged birds from that distance. Whence, then, did it come? It seems unlikely that the wind could have driven more than a few scattered hairs so far, but it might have been brought here accidentally by travellers.

In after years I often found substances utilised by American birds which they could not have obtained except by mere accident-paper, for instance, in Colorado, in a part then probably fully a hundred miles from the nearest European post. And paper, horse-hair, woodshavings, and rags are substances of which American birds could have known nothing till within the last three or four centuries, yet they are constantly used now, together with many other much more incongruous substances. And American martins now build in chimneys, and other birds under the eaves and thatch of houses, and that in a country where there were neither houses nor chimneys 
till the advent of Europeans. This shows a remarkable power of adaptability on the part of our little feathered friends, although there is certainly no great difference between a hollow tree and a chimney.

At the time of our arrival on the Severn nearly all the small birds had gone. There were still a few pine grosbeaks and swamp sparrows about, but these had all disappeared before the last day of the month. A pair of Lapland buntings was seen as late as the 3rd of November, when there was snow on the ground. After that date there were no small birds at all about here, though one or two were met with at odd times during the winter, as will be noticed presently.

The ducks and geese seen here were of the same species as those found at Red River and Winnipeg. They were migrating south during the whole of October, though a few still lingered during the first week in November, but the winter this year was again late in appearing. I noticed that neither ducks nor geese went off in large flocks. It was but seldom that I saw as many as twenty or thirty geese in one flock. About a dozen or fourteen was the rule. Sometimes only four or five would appear while I was watching, coming straight from the north and flying rapidly in a straight line, sometimes parallel, sometimes one after the other. The flocks always had a sort of military formation, either in line or in wedgeshaped flanks. This latter formation was alnost always adopted by the ducks, if the flock was large. I use the word large comparatively, for I do not think I saw a flock here numbering many more than a hundred. Thirty or forty was the most common number. This is quite contrary to what I have noticed in the Southern States and South America, where I have seen tens of thousands of ducks in a single flock, and almost equally large flights of geese.

1 All kinds of birds seem capable of utilising foreign substances in the construction of their nests. I yesterday saw a cormorant's nest which had been built on a wrerk, and the seaweed of which it was composed bound together with fragments of the wire-rigging. 
Yet ducks are quite as numerous here, on the whole, as in any part of America. Perhaps large flocks find it difficult to find sufficient food in the boreal regions.

Several parties of both ducks and geese were allured to within gun-shot by Tom, who imitated their calls and cries so well that I could not tell the difference between the voice of the man and that of the birds. And they themselves were deceived, as was sufficiently proved by the twenty odd victims which we secured.

There were deer in this neighbourhood, for we found the tracks of both cariboo and moose; but our efforts to stalk them were futile until there was snow on the ground. The animals were very wary and wild, and there is no doubt but that they had been much persecuted by the hunters from the Company's posts on the Severn. Indeed, we found many traces of visits about here by trappers, including two graves side-by-side, with wooden crosses at the heads. On one were cut the initials, J. P. A. 1853 : on the other an $\mathrm{O}$ only could be deciphered, with part of the date, thus-_. 8 . 3. The two men must therefore have died at the same time, and we may conclude that their deaths were violent. The graves were about four miles from our hut, in the midst of the woods. The crosses were quite rotten and covered with lichens. We therefore cut fresh ones, and placed them at the foot of the graves, with such of the inscriptions as we could decipher burnt on them, and, of course, left the remains of the old crosses standing.

It is very melancholy to meet with these relics of our dead brethren in the solitude of the wilderness, especially when there are circumstances that point to a premature end. Was all well when these men passed the border? or did greed or fury have a hand in hastening their departure? Had the graves been nearer the water I should have thought that they were the victims of a canoe accident, for there is a dangerous rapid nearly abreast of the graves. 
I have several times had the painful experience of meeting with human remains far from the haunts of men-unfortunate creatures who must have perished without a consoling voice near them, without a friendly hand to hold the longed-for cup to their parched lips. On one or two occasions I have found bodies by the roadside in the States, probably those of poor tramps wandering from place to place in search of temporary employment; and on another occasion, in Texas, I found the bodies of two men who had evidently fought to death like savage animals, for they lay opposite to each other, each clasping a six-shooter. There they lay, a mass of corruption, in a state too shocking to be described.

At the latter part of October we had a series of bitterly cold east winds. I never felt the cold more severely in my life, yet the weather was beautifully bright. On the 4th of November the wind shifted several points to the west, and on the afternoon of that day it commenced to snow heavily. Paradoxical as it may seem, the shifting and fall of the wind caused the air to seem quite warm, but by the next morning there was at least two feet of snow on the ground. This snow was loose, in which state it is always difficult to move about in it. Until the surface has become frozen it will not support the snow-shoes, and to walk far in the deep, clinging mass is impossible. Moreover, while in this state, it wets the clothing and boots, and causes great discomfort; but as soon as the severe frosts set in, it seems as dry, and is as easily brushed off as sand; while it is easy to travel over its hard surface, on snow-shoes, twenty to thirty miles a day; indeed the Indians sometimes do much greater distances than this within the twenty-four hours.

After snowing for thirty hours there was a cessation of the fall, and a partial thaw occurred, followed by a sharp frost at night, which transferred the trees into a fairy forest, the frozen icicles having the appearance of 
millions of electric sparks, so brilliantly did they glitter in the bright sun. In a day or two there was more snow, and on the morning of the 8th it had collected in such quantities that we could not leave our hut until we had dug a way out. How suddenly, and with what severity, the cold had set in may be judged from the fact that there was now three inches of ice over the brook with six feet of snow covering it, but the snow had drifted into the hollow way formed by the rocky banks. It was quite a morning's work to dig down to the ice, break it, and obtain water. This necessary can be obtained by melting snow and ice, but water so obtained is not very good, and is, moreover, apt to engender several complaints if regularly drunk. There was six feet of water in the brook under the ice, but in mid-winter the ice was quite a foot thick. The fish, I suppose, had left this shallow water and taken refuge in the deeps of the Severn or some of the lakes in its course, for we could never find any during the winter.

By the second week in November the surface of the snow was frozen sufficiently hard to enable us to travel on snow-shoes. These shoes we had made in anticipation of the winter, the materials being always at hand. For all that is needed is tough withes of birch and strips of raw hide. Sometimes the shoes (which much resemble rackets) are made pear-shaped, and sometimes a pointed ellipse, like a Zulu's shield. I prefer the latter shape. The loops of hide through which the foot is passed when the shoe is used, require to be carefully adjusted, and there is a knack in walking, or rather gliding, which must be learned, or the wearer will be continually skinning his instep owing to the friction. Light sledges are also made on the principle of the snow-shoe, and enable the traveller to drag a hundredweight or more of provisions and pelts behind him. As either shoe or sledge can be repaired anywhere in a few 
minutes, it will be seen what a boon these articles are to the wanderer in these lonely wildernesses.

When fresh showers of snow fall on the frozen surface it often lies there loose for a time; and it is a curious sight to see the wind driving it about like dust on a dry road. Of course it drifts into hollows and crevasses; but there is little or no danger of these becoming dangerous pitfalls to the unwary wanderer, for where the snow remains stationary in mid-winter it is always frozen firmly over in a single night; and it is possible that the snow-shoes often carry a person over spots that would be frightful to look down when free of snow. For here and there about this country there are crevasses, or cracks, in the ground similar to those found in Colorado and other parts of the States, though on nothing like so extensive a scale. Some of these crevasses are at least thirty feet deep, and so steep and narrow that a man falling in could not possibly get out without assistance. The cause of these crevasses is difficult to conjecture, unless it is owing to the freezing of water collected in cracks of the ground. In the deserts of the Southern and Western States they seem to originate in the extreme dryness of the soil.

As soon as the ground was in a fit state to travel over we started in pursuit of deer. I am of opinion that when there is snow on the ground, and deer are not disturbed, they do not wander much, but spend the entire winter within a very confined area. I allude to all species of deer found in the northern regions. Already the moose-yard has been referred to; and with regard to cariboo they seem to take up their quarters under the shade of a wood and remain there, if not disturbed by wolves or trappers. That is the case about here; but farther north, where there are few trees and wide areas of open rocky ground, their habits must be different. During the winter moss forms the chief food of the cariboo; but they also browse on the leaves 
of trees and bushes where they can. The wipiti is the most wandering of the deer found in this district; and we destroyed several while they were helplessly floundering through the snow, by either stabbing with a pike or cutting the jugular vein with a knife. For the heavy deer, breaking through the crust of frozen snow at every step, is quite incapable of either flight or fight, though they try to assume an offensive attitude to intimidate when closely approached. One of those thus killed uttered a hoarse roar when about to be stabbed. The cry, or bellow, of the wipiti is difficult to describe. It is a sort of hoarse blowing sound, low pitched in tone.

Notwithstanding what is written in Natural Histories of the wonderful adaptability of the hoofs of reindeers for progress over the snow, cariboo break through the frozen snow as easily as wipiti, and are destroyed with equal facility. The best defence of both deer is in their remarkable acuteness; for they will scent the approach of the hunter when he is miles away, and long before he comes in sight. They must therefore be approached against the wind, for if time is given them they will move off to broken ground where they cannot be followed on snow-shoes, or will gain such a start on a frozen lake that it is hopeless to try to overtake them. The greatest part of the snow is always swept from the surface of lakes by the wind, owing, I suppose, to the smooth hard ice which affords it little opportunity of drifting and clinging, as it does on the ground; and it is on the ice, probably, that the broad hoof of the reindeer is of use to him.

When the Indians find a herd of cariboo in difficulties, they destroy them all. In spite of this dreadful waste, cariboo were plentiful in many parts of Canada at this time, and nowhere more so than at this place. A great many were killed by us in the same way as the wipiti, by stabbing or cutting their throats, as this method saved powder. I was vexed that so many were killed, but I 
could not altogether control my companions, neither Achil nor the Indian being in sympathy with what they thought silly squeamishness. The hides of the animals were certainly useful to us, and also the grease. From the last we not only made a large store of candles, using small rushes for wicks, but the tallow mixed with wood ashes made an excellent soap.

As to the venison, we might have supplied twenty or thirty men all the winter with it. Frozen, it remained good till the spring, and most of it was lost from mere wantonness. Thrown about near the hut it attracted numerous wolves and foxes; insomuch that we trapped, or shot, forty-nine of the former and a hundred and eight of the latter during the winter. A solitary glutton was also trapped, the only occasion on which I knew one of these cunning brutes to be caught. It was taken in a steel trap hidden under the loose snow, and its attitude, and expression of its face when approached were diabolical. It screamed and fought, and tried to fly at us, and showed far more tenacity of life than a fox, repeated blows being required to kill it.

An incident occurred early in December (the 5th), which raises an interesting question. Is the hibernation of bears continuous throughout the winter? or is it broken at intervals? There can be no doubt, I think, that the latter is the case. I have seen bears about in the snow; but am not sure that the hibernation had commenced in these cases. On the day named we found the tracks of a bear on the snow, and traced them for a mile and a half to a cave in the bank of the stream. Though the tracks did not seem to be very fresh, they must have been made long after the first heavy fall of snow, and since the last, or they would have been covered.

That the bear was in the cave there was no doubt, and various expedients were tried to arouse it without success, and at last one of us cautiously ventured in 
with a torch, and found the animal curled up in a corner, on a bed of leaves and vine-twigs, evidently torn from the rocks outside by the bear, and brought here for the purpose. It gave no signs of life, and it could not be perceived that it was breathing. It was lying just like a huge dog, with its snout turned toward the tail. The muzzle of a Minié rifle was placed to its head, and with one shot its brains were blown out. It uttered no sound, but turned instantly on its side and stretched out. Thus easily was it slain; but I was sorry afterwards to find that it was a female with young. Had I suspected this it should not have been destroyed with my consent, for I think it is an abominable act to kill animals in this condition. However, the grease was of great use to us, for bear's grease passes for butter in the backwoods.

This bear was very much smaller than those previously described, being only four feet nine inches from end of snout to root of tail. It was dark, rusty brown rather than black, and the cave it haunted was only thirteen or fourteen feet deep, with an entrance which a man could pass through without stooping, though it was partly hid by the trailing creepers. Achil, who had had great experience with bears, said that they often sleep (hibernate) in dens and hollow trees that give but scant protection from the cold and weather, though he had known cases in which they occupied burrows that ran more than forty feet into the ground. There is never more than one bear in the same den. I am inclined to accept this statement with caution, for I have seen a female bear with two cubs, one of which was certainly in its second year, and had, therefore, probably hibernated with its mother.

Concerning a break in the hibernation, or occasional arousing, I could never glean any certain information. Achil and the Indian both asserted that they had heard of bears being sometimes met with in mid-winter; but they had no experience of such cases themselves, nor did I 
ever meet with a trapper who had. My conviction, however, is that such instances occur: the case I have just narrated being an instance in point.

During parts of the months of December and January 1867 I was very unwell, suffering from a stricture of the bowels, which seems to be a very common complaint among persons during the first year or two of their residence in the north of America. Fortunately I had brought a few medicines with me, and I succeeded in rallying, but for a time I was so ill that my companions, as they afterwards admitted, despaired of my recovery. As a consequence Christmas day passed unnoticed, as did the first day of the New Year.

When I began to recover I became ravenous for green food, my great desire being for a boiled cabbage with pickled pork. This, of course, was not to be had, but my companions boiled a quantity of the moss from the rocks, which they gathered at great trouble, for they had to dig under six feet of snow for it. This reminds me that we often found spots where the cariboo had scraped away the snow from a tract of land that often extended to several acres, to get at this same moss, of which they are exceedingly fond. It seemed to me, possibly because I was in an erratic state from disease, to be delicious as a boiled vegetable, and I ever after greatly relished it, and used it constantly when in the districts where it grows. It is certainly a highly nutritious substance, and I believe that in the more northern regions the cariboo have no other food, at least in the winter.

By the end of January I had recovered, but I remained weak for a long time, and should have returned to the settlements if travelling had been possible. However, youth has large recuperative powers, and before spring came round I had entirely recovered, and from that day forth I had seldom to complain on the score of health while I remained in America. 
During the early part of the year 1867 the weather was excessively cold, but there was but seldom a snow shower, and, as a rule, the sun shone brightly, though without perceptible power. From the beginning of November last to the 18th of January in this year small birds were not seen, except in one or two cases as stated below. On the 18th a tlock of about forty small finches, or perching birds, flew across in front of the hut. They were too far off to be fired at, and the species are therefore unknown.

On the 11th December a pair of snow buntings, Plectrophenax nivalis, were observed on the snow near the hut. They were running about briskly, and examining the refuse that had been thrown on the dust-heap, and I saw them picking the fragments of meat from bones. As there was no doubt about the species they were not disturbed, and they'appeared daily until the 8th of January. Chopped venison fat and fragments of meat, \&c., were placed close to the door of the hut, and they came constantly for it, and became tame enough to permit us to come within three or four yards of them. 'They often uttered a faint twittering cry, and a favourite time for their appearing was about an hour before darkness set in, though they came in the morning time too. On the 7 th and 8th January, one only appeared, and that was the last we saw of them. It seems certain that the solitary bird had lost its mate; probably it had fallen a victim to some small beast of prey.

On the 22nd December the Indian brought in a pine grosbeak, Pinicola enucleator, which he had picked up dead under a tree. Owing to the extreme coldness of the weather, which had preserved it, it was impossible to tell how long this bird had been dead, but it seemed quite fresh.

These instances seem to prove that birds which undoubtedly migrate in this country, yet leave a few odd members of their species behind, which may, or 
may not, survive the winter. I am also certain that odd specimens of many different species often wander very far out of the limits of their usual habitat. It appears to be the same in all countries. Birds are found in England which are only noticed in accidental specimens, perhaps not oftener than once or twice in a century. It is clearly the same in America. I have over and over again found birds which, if museum authorities and books are to be relied on, must have been hundreds of miles away from their usual geographical limits. Moreover I am certain that accidental circumstances, such as the meeting with an abundant supply of a favourite food, will often induce migrating birds to stay an entire season short of the usual limits of their migration. I mean, of course, certain flocks, not the entire body, of a species. These instances would be oftener noted if naturalists devoted more of their time to careful outdoor watchings, and are probably one reason why the numbers of a migrating species often fall short of the usual number in their summer haunt.

The great snowy owl, Nyctea scandiaca, haunted this neighbourhood through the winter. It is not correct, as is asserted by American naturalists, that this owl prefers the open desolate plains to any other description of haunt. I have seen it on the outskirts of woods as frequently as in any other description of place. It is fond of perching on the extreme tops of dead trees, branches, \&c., and may often be seen on the tops of poles about the Company's forts. It visited our dust-heap several times, feeding on the scraps which were thrown out, which seems to indicate that it was hard pressed for food. It was usually alone, but sometimes pairs were seen. The usual habits of this bird are solitary. It kills hares and smaller animals, but if it does not actually eat carrion, will consume the carcasses of small animals which it has not itself killed. At first it was shy of approaching the hut, but being unmolested 
grew tamer, and I have seen a pair of them perched on the roof, which was only seven feet high. They came forth from their hiding-places early in the afternoon, and continued out till after midnight, as they were often heard, and seen, flitting about on moonlight nights. As the bird has a very wide expanse of wing, they presented a grand and weird sight, moving about, notwithstanding their great size, in perfect silence. Not the slightest flutter of the wing could be heard.

Throughout the winter no moose deer were seen; but this was not because they were absent from the district, for when the frost broke up several were killed. It would seem that when they are once snowed up in their "yards" they are prisoners for the whole winter. It is singular that the wipiti never forms these yards, or gives up the habit of wandering when the snow is on the ground; but wipiti are sometimes accidentally snowed up in hollows of the ground. Cariboo seem to escape this accident by going in great herds. The belt of forest here approaches to within four or five miles of the shores of Hudson Bay, and both moose and wipiti are said by the trappers to be found to the limit of the forest, but not a yard beyond it. The Company's people agree that these deer are not found on the coasts of the bay.

Besides owls the only bird of prey seen before spring was a white falcon, Falco candicans of the British, which I shot on the 28th. This truly magnificent bird is remarkable for the size and extreme brilliancy and fierceness of its eye. The colour of the plumage is white covered, on the upper parts, with triangular black spots. It was an unusually fine specimen, but unfortunately the skin was much damaged in transit, as were many of my specimens, for I had no proper cases or appliances for packing, and my bundles were often thrown about with little deference to their contents, and not unfrequently subjected to the wet of a heavy shower, or a bath at the portages. 
A very remarkable meteorological circumstance was noticed several times during the winter. At a distance of about five miles from our hut a belt, or current, of warm air was observed to frequently blow across the plain. The wind on such occasions was always in the west, varying a point or two south, and I inferred that the current referred to found a passage through the Rocky Mountains direct from the Pacific. It is difficult to surmise how otherwise a warm current should be perceivable in these regions. The warmth was very perceptible, one appearing to pass right into it at once from a low temperature. There was often a partial thaw within the belt affected by this air, which was about ten miles wide. The temperature within this distance seemed to be about the same. We noticed when we entered and when we left it--and that this was no fancy was proved by the fact that the vegetation showed, in a perceptible degree, a superiority of development compared with the forest outside its limits. Doubtless this phenomenon has been noticed by other travellers, and possibly it is fully accounted for; but I have not myself seen it mentioned in any work I have read. Achil said that he had perceived it much farther to the west, and that there the belt seemed to be wider, and he had heard from the Indians accounts of a region to the south-west where the climate was always more genial than in this or other parts of the great North-West.

I made several journeys with the object of learning the extent and direction of this current. It traversed the district from south-west by south, in a curve, to about north-east by south, but was only perceptible with westerly winds. Its longitudinal length it was impossible to conjecture, but the width was not greater than ten miles; often it was only four or five. The increase of temperature was first noticeable just where the graves of the two trappers (as I presume them to have been) were made. Within these bounds mosquitoes, or gnats, were 
usually flitting about on fine days, and after the middle of January were often seen about our hut, and in other sheltered situations. They were in sparse numbers, and did not bite at this season; but it is an interesting question whether these insects, and other flies, die off in any number at the fall of the year, or whether they simply hide away. It seens certain that great numbers of mosquitoes survive the winter; how otherwise could they reappear on fine days?

I have several times referred to the heap of dust or refuse at the side of our hut. This was an attraction to many insects as well as to the animals of higher organisation already referred to. The mosquitoes were fond of hovering over it, which seems to confirm the opinion I have formed that these insects prey on the juices of decaying animal matter, as well as on the blood of living mammals.

Of other insects I have little or nothing to record. During the severe cold none were seen; but as the spring approached several species of coleoptera harboured about the hut. None of them seemed to differ noticeably from similar species at home, and all were of small size. There was the usual tiny black beetle with ribbed elytra, another of shiny bronze and green; just such as may be seen in any garden in England. Ladybirds were also seen in the spring and summer, the commonest kinds being a red with small black dots, and a black with fine yellow dots on each elytra.

Of spiders, a class of creatures in which I take some interest though they inspire me with loathing, and moths and butterflies, the variety was so small and poor in specimens as to be scarcely worth noticing. A large kind of house-spider soon established itself in our hut, and often took to wandering about at night, sometimes falling on our food. It may be an error on my part to call it a house-spider; but its numbers, and the acumen with which it occupied corners and angles of the hut 
showed that it was quite at howe in houses; and it is a singular fact that, like the European house-spider, I could never find this arachnida out of doors. Its natural habitat is probably caves and holes in rocks. During mid-winter it hid away, but reappeared before we left the hut.

There was a very mischievous moth in this district, similar in appearance to the clothes moth, which compelled us to keep constant watch over our pelts in the summer and autumn. 


\section{CHAPTER XII}

CONTINUATION OF THE JOURNEY TO FORT SEVERN

THE break-up of the winter was early, according to my companions, who were well acquainted with the times and seasons in this region. Throughout February the weather was bitterly cold, with easterly for the most prevalent winds; but in March there was much bright sunshine, and a few partial thaws which made moving about deplorable work. At the end of the month the ice began to break, and we were up to the knees in slush.

On all the brooks the ice was from about six to twelve inches thick. Where there were falls or strong rapids it was of course absent, but in other parts the streams were frozen quite over. But for the portages it would have been an easy matter to travel along the waterways; but the great number of rapids prevented this being done until the ice broke up and permitted the canoe to be used. I mention this as the reason why we did not move sooner, because at this time our dry provisions were quite exhausted, and we were living on venison and game, and boiled grass. The want of tea or cocoa was a great deprivation to me, though my companions, the Indian especially, treated the loss with but little concern. Other necessaries also, and particularly ammunition, were running very short; and these circumstances induced me to start at the earliest possible day for one of the Company's posts for the purpose of trying to replenish our stock.

On the 15 th $A$ pril the river was open though full of blocks of ice, which in the neighbourhood of the portages 
was floating along at a swinging rate, and according to my companions would make navigation exceedingly dangerous. But I showed a will of my own on this occasion, and insisted on a start. A pretty start it proved. We had scarcely got the canoe launched and loaded, and pushed off from the shore before over we went into the water, goods and all. "I told you so!" said Achil, but the Indian took the accident quite coolly. However, we had to go back to the hut and dry ourselves and our belongings, and the start was postponed till the following day.

We got fairly away on the 16th and began our voyage on the Severn on the 17th April. The distance to the fort was about 230 miles, the river being in reality a chain of lakes, some of them of considerable size, and nearly all of most picturesque appearance, being buried in the heart of a great forest.

The journey was a trying experience, as one of us had to constantly ward off the floating blocks of ice, which were heavy enough to have smashed in the side of the canoe. In the lakes we had not this difficulty to contend with as the ice had mostly drifted into the banks. Both river and lakes were rather shallow; but in the former there are a number of what geologists call pot-holes-deep pits in the bed caused, it is said, by the current whirling round heavy stones or fragments of rock.

There are several troublesome portages on the Severn, as well as dangerous rapids, which, however, we ventured to shoot, in spite of the blocks of ice which went down with us, and a collision with which would have been inevitably fatal. The Severn is connected, with other streams and a chain of small lakes, with the Albany, which enters James Bay to the eastward, thus forming a large island, three hundred miles across in every direction, in which there are half-a-dozen streams of the magnitude of rivers, and many lakes. 
On our way we sighted several parties of Indian and half-breed trappers, with all of which, except one, we had communication. One party, with a Hebrides man at its head, occupied a small stockaded post on one of the lakes under the Company's ægis ; and we also passed a deserted post, or house, with the stockades around it intact. But there was not a soul there, for we landed in the hopes of obtaining necessaries. This river seems to be a favourite one with the trappers, for we found many of their old camping-places and deserted huts along its banks; but we saw no game except a few birds of the grouse family, and gulls on the larger lakes. A few fish were caught, and these and dried venison subsisted us till we reached Fort Severn.

Here we parted with all our pelts except those I reserved for my own use, receiving in return flour, salt pork, coffee, tea, sugar, and powder, to the extent of about (in my opinion) one-thirtieth the value of the furs parted with. But it was a case of Hobson's choice; and, I must admit, a boon to get the goods at any price. Starvation is a wonderful depreciator of money value.

I need say nothing about Fort Severn. The description of one fort is, almost without exception, the description of all. My opinion of them as military posts has already been given. The stockades with which they are surrounded are so badly constructed that they would not keep a determined enenyy outside ten minutes. Fortunately they never, in any instance, seem to have been put to the test, for the Indians in these parts are a most inoffensive race of people. I never heard of a murder or outrage being committed by them; but, strange as it may seem, the half-breeds are very fierce if provoked, though, as with the Indians, serious crime is almost unknown among them; and the solitary white hunter may wander from one end of the land to the other and be far safer than he is in a walk through many of your rascally cities. $\mathrm{He}$ is sure of kindness and hospitality, and if he is robbed it 
surely will not be by Indian or half-breed. I have heard a different account of the Esquimaux of the extreme North-West, but it is rare for a white to venture among them.

I did not make a prolonged stay at Fort Severn. We arrived on the 22nd of April, and left again on the 27th. I had formed the resolution of coasting round Hudson and James Bays as far as the mouth of the Abbitibbe River, but we found the shore fringed with ice as I might have known it would have been, and ice blocks were still flowing down the rivers and streams, and these were all carried inshore by the tide on reaching the sea. A voyage on the bay would not have been possible in our frail canoe, and I was told that probably many weeks would elapse before it would be ; besides which Achil and Tom absolutely refused to venture on the briny element at all. So I was reduced to the necessity of returning the way we came.

I explored the shores of Hudson Bay for many miles on both sides of the Severn during the four days we were there. It was everywhere a marine marsh, flat as a pancake, covered with reeds and rushes, and a few scattered willow trees. I could see no other trees in any direction, not even inland; and the country in the latter direction appeared to be a level, grass-covered plain, with mostly a very barren look about it. The gardens at the Fort were the only patches of cultivated ground, and those looked as if they produced little or nothing, at this time of the year at all events.

There were already ducks and geese in the marshes, although these birds are only found in the summer months. The geese, in pursuit of which I tramped many a weary mile in the abominable slushy mud, notwithstanding the short time of our stay, were of a different species from those inhabiting the Winnipeg district. These were brent geese, Bernicla brenta var. glaucogaster. The Canadian goose, Bernicla Canadensis, previously described, 
was not here in April ; but I learned that it comes during the summer. These two geese are closely allied. As yet neither ducks nor geese were particularly plentiful, but they are said to arrive in immense flocks by the end of May or beginning of June. I secured but five geese.

There were plenty of plover, and among these birds I had good sport, bringing down thirteen brace one day and fifteen on another. They are fair eating, though not equal to the grouse of these regions. The species differs but little from the common ring-plover of English downs, but I am informed that it is distinct, and specifically termed Aigialitis semipalmata.

All the ducks and the widgeon found in the neighbourhood of Winnipeg, and described on my visit to Stone Fort, were found here, and in addition the longtailed duck, Harelda glacialis, and the golden-eyed duck, Clangula islandica. Of the latter a single specimen was all that was procured, but I shot sixty ducks altogether, mostly for food.

No small mammals were noticed here, and no reptiles; but the mosquitoes were beginning to be an intolerable nuisance.

Small birds were still almost absent, but they are plentiful during the height of summer. My informant could only give the vernacular names of the species, but the Lapland bunting, the sparrow of these regions, I saw myself almost everywhere. Two or three other small birds haunted the reedy spots in the marshes, and seemed to belong to the family American naturalists call " ground sparrows." They are not sparrows, and seem to me to be the representatives of the European warblers or pipits. The size, appearance, and habits are much the same; while the small eggs are nearly always richly blotched and clouded with various shades of purple, red, and brown. The eggs are the same size as those of the pipits (much less than those of sparrows).

There is much difficulty in classifying the small birds 
in this country; and, in my opinion, the professional naturalists are largely responsible for rendering confusion worse confused. The vast multitude of tiny birds, ranging in size from that of a sparrow to that of a tit, cannot, with any degree of clearness, be split up into scores of families or groups; and I shall take it upon myself to say, that half-a-dozen families at most is quite sufficient to relegate them to. The pipits and warblers are so closely allied to the American ground and swamp sparrows, that no amount of professional jargon will prevail upon me to acknowledge any material difference between them. In fact no other term than warblers, or better still finches, is wanted for the whole genus. Then again, take the American bluebirds. Their appearance, habits, food, and the colouration, all prove them to be thrushes; but so much as hint to an American naturalist that they are not a distinctly New World group, entirely unallied to anything European, and you will make him furious. His European cousin will also do a bit of professional capering at the assertion. I, however, think that habit and external appearance count for a great deal; and I am not sure that the cut-and-dried specimenstuffer, who in all probability has never seen the birds in their native haunts, or indeed, even alive, is altogether qualified to absolutely classify them. At any rate $I$ am quite convinced that there is a large number of small birds in this country (the whole of America, I mean), split up into families between which there is no marked difference, if, indeed, any difference at all, other than the fad of their cataloguers. And the separating these families from their European allies is an even more ridiculous anomaly.

This is a digression; but I have an object in making it, for I do not accept the classification now in vogue with European ornithologists, still less that of Americans. Whatever value the professional naturalists may put on 
my notes, $I$ have evidence that a considerable number of my readers read them with pleasure; and for the benefit of these readers, it is my intention to give considerable attention to the ornithology of the British possessions and northern parts of the United States, with which I am better acquainted than with that of any other part, and in doing so I intend to give myself a free hand. I do not wish to be aggressive; but the more I seek information from museum and other " authorities," who have had no what the tailors call "practical experience," the more I am convinced that I can safely rely on my own notes and observations. I wish to give offence to none, and I will therefore say no more than this: If there are errors in my remarks, they are honest errors; and I cannot conceive that any notes can be of much value if the writer of them is afraid of his own opinions. I like the trees in my garden to grow as wildly as they please. I decline to trim them into the shapes of cocks and pots to please the profession. 


\section{CHAPTER XIII}

THE COMMENCEMENT OF THE RETURN JOURNEY TO THE OTTAWA RIVER

Having supplied ourselves with sufficient stores to last at least six weeks, supplemented, of course, with such game as we should shoot en route, we started on the return journey on the afternoon of the $27 \mathrm{th}$, paddling about nine miles up the river, and passing the night on the bank. The days were fine, generally; the nights bitterly cold. On the last day of April there was a snow shower, but it thawed soon after falling, though there was much snow still lying in sheltered spots. May day was memorable for a heavy rain, which drenched us to the skin, and made us as miserable as miserable could be.

I am not going to give a daily relation of the incidents of this journey, because it was too monotonous to be of general interest. Briefly, it entailed the hardest work I had as yet performed since arriving in America. The portages were frequent, and some of them several miles in length; and those short reaches of the river which connected two lakes had generally so strong a current that if a portage was not absolutely necessary the work of paddling against the stream was most laborious, especially to a comparative youth, as I was at the time.

The banks of the river were usually of great heightas much as eighty or ninety feet, quite shutting out a view of the country; but it was flat for a considerable distance from the shcres of Hudson Bay. The forest region commenced about seven or eight miles from the mouth of the Severn; but it was somewhat broken 
here and there by small savannahs or openings. Along the river banks we saw places where much timber had been felled, more than I should have expected in such an out-of-the-way place. As we approached the higher, rocky ground, there were spots from which a fine view of the surrounding country could be obtained. It was studded with small lakes and ponds, embosomed in the forest.

Very little small game was to be found on the banks of the river; and as game was absolutely necessary for our subsistence we were compelled to stop to seek it in the adjacent country. There was large game about, but it was exceedingly shy; the result of persecution. For, as already stated, this district was much frequented by the trappers. We met a party of Indians, one of whom had suffered a bad accident through the bursting of his common Birmingham gun. Two or three of his fingers were blown off; but he took the deprivation very coolly. At this time I had not the knowledge of surgery which is an essential to a wanderer in the wilderness, and which I afterwards acquired; but I had a few bandages, \&c., with me, and these I gave to the injured man. In return they offered us half of a cariboo deer, which was the first meat that we obtained. Afterwards we shot a wipiti, but it led us a long chase, quite ten miles from the river; and, consequently, we could save but a small portion of the meat, the ground not being now in a fit condition to admit of a hand-sledge being drawn over it.

By-the-bye, it is always called a hand-"sleigh" in the States, and also in British America; and I was often rebuked for persisting in saying sledge. I, however, am rather obstinate when I know that I am in the right; and $\mathrm{I}$ have always declined in both speaking and writing to substitute a Dutch word for an English one, in spite of the pompous assertion of Fenimore Cooper that the millions of America are a people who may coin a word if they see fit. I decline to admit that the conglomeration 
of all nations (not always the cream of the nations either) have a right to play with the English language, which is not their exclusive property.

While looking for game on the shores of one of the small lakes, we suddenly came on a large bear, which must have been lying asleep amid the bushes. Bruin went off with such a rush that before we recovered our startled nerves he had almost got completely under cover again. Several random shots were sent after him, but I suspect that he suffered but little hurt. At all events be got away. Subsequent experience convinced me that this is the usual conduct of the black bear when surprised. He bolts, and sometimes cuts a remarkably cornical figure in his haste to escape. On the other hand, it is beyond question that he does occasionally turn aggressor, and make attacks on men. I think this only happens where he has not been much disturbed, and has not yet learned how formidable an antagonist man is; or perhaps the maddening effects of extreme hunger may account for these occasional displays of rash ferocity. I think I have forgotten to remark that the black bear (and I believe all other bears) neither sees nor hears well; and yet, by means of some sense or instinct, he can discover when there is a nest of wild bees in a tree, and will ascend to plunder it, taking absolutely no notice of the angry owners, which, it is clear, are incapable of stinging him to any great purpose. I suspect the bear also climbs trees in search of raccoons; but, on the whole, bears in America rarely leave the ground. When the nest of the bees is placed on a branch, away from the trunk, the bear will not venture. after it unless he is quite assured that the branch is strong enough to sustain his weight. If taken when a cub the black bear will become as tame and attached to its owner as a dog; and though apt to be rather rough in play, never develops any of its natural ferocity. I have known several settlers who kept such bears for years. 
Continuing our voyage we journeyed from eight or ten to thirty miles a day, according to what I may term my dead reckoning; for, needless to say, we had no certain means of recording the distances traversed. I consider this, allowing for the number of portages, and the fact that we were paddling against the current, to be equal to nearly three times the distance that might have been covered on smooth water.

On the 5th May we branched off into a tributary of the Severn, called the Owl River by the trappers, but which was not marked on my map. The reason for doing so was because we were informed that we should in this way make a considerable saving of time and labour by going to the head of this creek and carrying the canoe overland about twenty miles to the headwaters of a second creek tributary of the Albany. For it is to be observed that, having overcome the opposition of niy companions, I had determined to return to our huts on the Ottawa by way of James Bay and the Abbitibbe, and not by returning through the great lakes. Two Indians of the party, which gave us this advice, volunteered to accompany us and lend a helping hand. The journey overland may have been only twenty miles; it seemed to me at least forty. It took us three long days to perform it, the whole distance being over rocky hills covered with pine forests; and we were so exhausted on reaching the second creek that we had to rest two days to recover.

This creek is named Peerra by the Indians, and it is only a brook of a few inches' depth where we struck it, and we had to drag the canoe five or six miles farther before there was water enough to float it, with all our traps in it. However, we had now a downward-running current, with few rapids, where it was necessary to make a portage. Some parts of the shallows of this stream were choked with a growth of yellow-coloured water-lilies. We entered the Peerra on 12 th May, and in three 
days more entered what I supposed to be the upper part of the Albany; but on the 16 th we found this stream to run into a lake of such dimensions that we could not see across it. According to our Indian guides, who still remained with us, we might now easily, in another three days, reach the Company's post, Osnaburgh House. I agreed with them to proceed with us so far, as neither of my companions knew this part of the country, and they were very useful fellows at the paddles.

The remainder of our journey to Fort Albany is almost without incident. I therefore propose to pause here to say something of the natural history of this region; and, to commence with, I may say that the great snowy owl was the most numerous of any bird of prey seen throughout the entire journey. I do not think that we failed to see one or more each day since leaving Fort Severn. About the Fort itself they were very numerous, but always singly or in pairs. As far as it was possible for me to ascertain in so short a stay, I think I may safely say that, as with so many other birds of prey, each pair had a territory which they jealously guarded from the intrusion of others, and that they also kept the smaller hawks at a distance. For its size, however, which is often equal to that of an eagle, it is not a courageous bird, and a hawk a fifth of its size is more than a match for it. Other owls, however, are in abject terror of it, though I have not often seen the snowy owl chasing them, but this may be accounted for by the fact that other species are far more nocturnal than the snowy.

At the period of which I am writing all the big game found in Canada and the North-West was abundant in the area of the big island I have described; but, of course, the same must be said of all the adjacent districts, for there was nothing to prevent the animals crossing the rivers at almost any point. But I was not the first to discover that this was a favourite haunt of deer, moose, 
and bear; and these animals were here so wild that it was actually easier to track them down in the well settled parts of Canada than in this spot, where the trappers and Indians had terrified them out of their wits. This is not an exaggeration, for the very bears fled as soon as they perceived us; and easy of approach as they usually are, we could not get a shot at one of the six or seven we saw during the voyage from Fort Severn to Albany. And not more than five deer in all could be killed, badly as we were in want of meat. Moose was seen, but could not be approached. I tried to shoot one at a range of about five hundred yards, but, like the boy who fired at a sparrow, I had no better evidence that I had hit it than seeing it wag its tail, which it did at a rate that precluded the chance of a second shot. Once only did I come well within range of a moose, and then it was a cow which undoubtedly risked herself to protect her newly born calf. The little thing seemed to be scarcely more than a day old, and the cow faced me in a most determined manner, pawing the ground and making a sort of snuffling or blowing sound, indicative, I suppose, of her anger. The calf could only just toddle along, and I cannot say that it was in any way pretty. It gave me the idea of being nearly all head and legs. The cow kept between it and me, but it moved away so slowly that I had a thoroughly good look at it and its mother. I am sure that it was not many hours old, and therefore it must have been born close at hand. The spot was a swamp densely overgrown with tall bushes, which were covered with thorns long and strong as pins. Notwithstanding the thorns, I have seen moose, in another part of the country, browsing on similar bushes.

The moose can be very formidable when it makes up its mind to fight. Cows will always stand by their calves to the last. They rear on their hind-legs like a horse, striking downwards with their fore-hoofs, which cut like an axe. Indians say they sometimes thus kill several of 
a pack of wolves, and that they will even make the bear fly. The calves, are, however, often destroyed by wolves, for while part of the pack are engaging the mother's attention, the rest pull down the defenceless little creature. But even then the mother sometimes stands over the carcass and defends it for many hours.

This deer, which should be called the elk, and the wipiti, which is invariably in North America miscalled the elk, were found by me in every part of British America that I visited, with the exception of a few limited areas where the former animal had been exterminated or driven away. I believe that both animals always avoided the barren, treeless margin around Hudson Bay, but as soon as the forest line was reached they were found. When America was discovered, and for two centuries afterwards, the moose was found in every known part of the Northern division (Mexico to the Arctic regions), which was well wooded. This assertion, first made in a former work, has greatly provoked certain Arnerican naturalists, who have communicated with me, denying the fact.

It is not my intention to provoke controversy, and I do not wish to offend any man by contradicting him, but I must repeat and endorse my statements regarding this matter. I am thoroughly well acquainted, by actual experience, with the distribution of big game in America between the years 1865-80, and have had a partial experience in more recent dates down to a few years since. With regard to past periods, I ground my statements partly on the writings of the first great explorers in North America, partly on the evidences I have myself discovered that moose and wipiti formerly ranged over vast districts, from which they have been wiped away for generations past. How speedily such animals may be exterminated is shown by the circumstance that since the journeys I have been describing the moose, at least, has been quite destroyed in four-fifths of the territory it 
then roamed over. Probably there are not a thousand head left in the entire country I have been treating of. There are certainly none remaining in Canada proper, and unless some very stringent laws are passed both moose and wipiti will speedily become extinct, and the black bear will go with them. How long the polar bear and the cariboo will survive them is a question that may be answered without any great mental strain, though, as the latter wander to high boreal regions, it is just possible (and no more) that the man is not yet born who will see the last of them.

With the exception of a few small birds, many of which make this district the highest limit of their summer migrations, and a few only partially so, nearly all the animals met with in the extensive country I passed over were everywhere of the same species. I never remember, in all my extensive travels, to have passed over such vast tracts without meeting with a much greater change in the character of the fauna. Deer, bears, foxes, wolves, small mammals, birds of prey, grouse, \&c., were everywhere the same. The most prominent exceptions were in species in which I should have least expected to find a change, viz. ducks, geese, and fish, and, as I have said,.small birds. The latter is not a strange circumstance.

Certain species of ducks were found in all parts at the proper season; but the Canada goose, the brent goose, the wild swan, and one or two species of ducks were more or less local. As for the fish, those of the Western rivers contained species which I never saw east of about the 86 th longitude; notably the "golden-eye," which seems to be a perch. Unfortunately I cannot specifically designate the fish, it being impossible to bring away specimens; but I noticed a difference in those inhahiting the waters of both rivers and lakes, east and west of the degree I have named, which I should not have expected to find. But it must be understood that 
I do not say that this difference was universal, though it was very noticeable. I do not know if eels inhabit the waters north of the Canadian frontier; but I never caught or saw any, nor did I ever see a snake of any description without the bounds of Canada proper.

Amongst the owls frequenting the banks of the Albany was one that was even larger than the great snowy owl. This was the great grey owl, Syrnium cinereum, odd specimens of which were seen at times all over the North-West region; but it is much less numerous, or at least frequently seen, than the snowy. It must be remembered, however, that it is much more a nocturnal bird than the latter. I saw a snowy owl attack one of these grey owls which did not wait to settle the dispute, but beat an immediate and ridiculous-looking retreat, hooting and fluttering while the snowy made the feathers fly in a crowd. I suppose that the grey owl was a trespasser on the other's hawking ground; for presently the snowy came back and took up its perch on the top of a young spruce tree, staring at me with glaring eyes that seemed to ask, "What do you think of that? Mind your turn doesn't come next." There was no shyness in this owl, for it was not forty yards from me. I afterwards saw this same bird devouring a grouse on its perch; and it seems that both this, and the grey species, have all the habits of hawks in seeking their food. By-the-by, the snowy owl attains a much greater size than the stuffed specimens I have seen in London. If these are European snowies, the North-West Territory bird is probably a distinct variety; but it is a bird that varies a good deal in size.

There was another large owl in these forests, and one or two smaller ones of which I did not learn the specific name. But in addition to those mentioned I nuay add, as being certainly identified, the saw-whet owl, Nyctala acadica, called the Acadian owl by British naturalists, and the owl called the screech-owl in the United States, 
which appears to be the Scops asio of the British; but the bird varies so in different parts of the continent that I cannot speak with certainty about it. There is no uncertainty, however, about the long-eared owl, Asio Americanus, or Asio otus of the British, about which there is an everlasting dispute in the States, the Americans insisting that their bird is a distinct species, uncontaminated by contact, in the most remote degree, with its European ally. The long-eared and the great grey are two of the most widely distributed species of owls in British America, the latter being found throughout the country wherever there are trees, for it is essentially a wood-haunting bird. The long-eared owl has an even greater range; for I have found it nearly everywhere, from Fort Severn to New Orleans.

Several times in the course of our journey we perceived eagles hovering at a great height; but they did not come near enough to be identified. I think, however, that there can be no doubt that they were the golden species, Aquila chrysaëtus. In Canada I have heard attempts made to claim this eagle as a distinct species. Most American ornithologists, however, admit that it is identical with the European species. If I am not mistaken, the golden eagle is found close to the shores of Hudson Bay. The white-headed eagle, the national emblem of the United States, certainly is; for I shot a fine specimen on one of the small lakes not more than forty miles from the sea, and others were seen. Notwithstanding the great size of these eagles, I have never seen any reason to believe that they are courageous birds. They are certainly not so plucky as some of the small falcons.

Animals of the pole-cat genus, such as the pinemarten and fish-marten, were seen in all parts. These have already been described. A glutton was also seen near the lake on the banks of which Osnaburgh House is situated; but this animal, on account of its shy habits, 
is seldom seen anywhere; and it is probably much more numerous about this region than the seldomness of its mention might lead one to surmise.

I was often much amused in watching the squirrels skipping about, not only on the trees of all kinds, pines and broad leaved, but about the ground also, even when covered with snow; for this pretty and lively little animal certainly does not hibernate-if, indeed, any squirrels do. The fact that they all seem to lay up winter stores of food would seem to prove that they do not. However, the chickaree, as the Yankees call him, Sciurus hudsonianus, is as lively when the frost is skinning your nose as when the heat of summer is frying you alive, and rushes about in little companies, making the snow fly right and left. One moment he and his companions are skipping in the snow, often disappearing quite under it, if it is not frozen hard, the next they are chasing each other up the trees. Though not gregarious in a strict interpretation of the term, the chickaree is fond of company, and several are often seen together, perhaps a family party. As seldom solitary animals are seen-that is, at least a couple go together-I think it is probable that they pair for life. The colour of the fur is usually a brownish grey, with white on the chest and abdomen; but there is much difference in individuals. Sometimes there are dark, irregular markings on the fur; and often black specimens are found.

There are several of the Company's posts, or houses and forts (there is no difference that I could perceive between a "house" and a "fort"), on the Albany, at one or two of which we made a temporary stop, and bartered for those necessaries of which we were in want. The river is a characteristic Canadian stream, with high banks and rapid current, necessitating portages here and there; and for the purpose of avoiding monotonous descriptions, I shall not detail the journey to Fort Albany, preferring 
to give more attention to the voyage on the coast of James Bay, and up the Abbitibbe, or Abitibe, as the old, and, I think, more correct, geographers called it; but it is spelt half-a-dozen different ways in old French maps. The descriptions of country that I must there give would answer fairly well for the Albany; at all events, to describe both rivers would read like a repetition. And the description of the fauna on the Abbitibbe is precisely that of the Albany, unless specially noticed to the contrary. 'The reader will perhaps kindly bear this in mind while perusing the next chapter. 


\section{CHAPTER XIV}

THE COAST OF JAMES BAY TO THE HEAD OF THE RIVER ABBITIBBE

WE arrived at Fort Albany on 1st June, and left again on the 4th. The distance from Fort Albany to Moose Factory is about a hundred miles, and, short-handed as we were, we paddled that distance in thirty hours' actual work, arriving on the 6th. The coast-line here is as different as possible from that about Fort Severn, being high, bold, and rocky, affording some remarkable scenery, though barren and inhospitable looking. The sea, at the time of our voyage, was calm, but it broke on the rocky shore at places, and we more than once found tides or currents, I am not sure which, drawing us inshore at a rate that induced us to give the land a wide berth. On the first night we landed under the rocks, and slept in a cavern; but the cliffs were so precipitous that it was impossible to climb up them. I have therefore no idea what the country inland was like. The second night it was impossible to land on the mainland, and we were compelled to pass the hours of darkness on a rock about a quarter of a mile from the shore, drawing the canoe up after us to prevent accidents, as, if it had happened to break loose, we should have been in a terrible plight.

Our temporary possession of this rock, which may have been an acre in extent, disturbed a large colony of guillemots, Uria troile. They winged their flight to the main shore, looking not unlike ducks when flying, and uttering a tremendous clamour. We saw other flocks during the three days; and there was another guillemot 
noticed, though in sparse numbers, and keeping strictly aloof from the other species. This was of a very dark or blackish colour beneath, while the first kind was white below, as high as the throat. It was much smaller than the common guillemot, and was probably a variety of Uria grylle, differing but little from stuffed specimens of that species which I have examined. No guillemots were seen on the flat coast about Fort Severn, or inland on the rivers.

The rock mentioned seemed to be a favourite breeding-place of the common guillemot, for it was covered with their young, most of which took to the water, and swam away rapidly towards the shore. The breeding season appeared to be already well advanced, but there were still a number of eggs unhatched, some with young birds in them, some fresh enough to be eaten. They were not particularly rank in taste, as sea-birds' eggs usually are. They were larger than those of a hen, pearshaped, and here did not differ so much in colour and marking as guillemots' eggs are said usually to do. The bulk of them were of a pale rosy buff in ground colour, blotched with purple-black, over grey and greenish undermarkings. Some were blotched with dark brown; others looked as if they had been smeared with ink.

The eggs were scattered about all over the top of the rock, which was about thirty feet high, singly and in clusters. The birds, I believe, lay only one each, so many must lay close together. Probably there were (with those which escaped) fifty times as many young birds as eggs.

Amongst the gulls the following were clearly recognised, if not actually procured: the fulmar petrel, Fulnarus glacialis, not seen on the flat coasts to the westward; a skua, believed to be Stercorarius pomatorhinus, scanty in numbers, and also not seen westward; the kittiwake, seen in immense numbers; a gull very like the Larus argentatus of Europe, and probably a 
variety of it; Sabine's gull, Xema sabinei; and at least three or four other gulls, which were not identified. It will thus be seen that this part, at least, of James Bay is bountifully supplied with gulls; and as all these were recognised in a three days' canoe voyage, there are probably many others which were not seen or noticed.

A sharp lookout for seals and other animals was kept, but none were seen. I do not know if seals are found about here, but if so they had probably been pretty well worried by the hunters from the Company's posts. We also kept lines towing behind the canoe, but no fish were caught. Some small finch-like birds were seen flitting about the rocks of the mainland, but they did not come near enough to enable me to secure a specimen; and a small mammal like a rat was seen to enter a hole half-way up the face of the cliffs.

At places the cliffs were much broken and jagged, and of great height-three or four hundred feet, I should conjecture. As far as I could see, I should think that there are but few places where they could be successfully, or at all events safely, climbed. The most broken and accessible places were where streams ran into the sea, and there were also spots in which the cliffs sank down to a moderate height; but nowhere did we succeed in getting a glimpse into the interior of the country until we arrived at Moose Factory, which is situated at the junction of the Moose and Abbitibbe, on the left bank of the former. It is the chief or depôt post of the "Southern Department" of the Company's territory.

We were now probably within three hundred miles of home, but having reached this point in such good time I was in no haste to hurry over the last stage of the journey. As a matter of fact I should have liked to see a little more of James Bay, but my companions had not much liking for sea travelling, objecting that the canoe was badly qualified for encountering rough water. To a certain extent this might be true, but I have proved that a 
canoe will do a great deal even in a sea-way, and in my opinion there is less danger in a coasting voyage on the sea-coast than on that of the great lakes. In the latter case the storms and wind tornadoes come down with such fearful suddenness that escape is hopeless, even sometimes when the canoe is close inshore.

However, I was compelled to give in to the older heads, and compromised the matter by making a halt of a week's duration to enable me to explore a little of the coast in a small canoe, either alone or with one companion only. This companion was, on one or two occasions, a young gentleman from the Factory-a Scot, of coursewho had a liking for natural science; though it seems to me that Scotchmen seldom devote much of their time to natural history, however devoted to other branches they may be. If I mistake not, Scotland has produced but few good naturalists, though in all other branches of science her sons are greatly distinguished. My Yankee friends will think to have me here, and remind me that Wilson was a Scotchman. Wilson may have been a great lover of Nature: he is not very reliable as a naturalist.

Our journeys scarcely repaid the time devoted to them. Conchology attracted my friend more than any other branch of natural history; but the few and small shells he succeeded in collecting made but a sorry show, and contained nothing worth describing here. I had hopes of meeting with some of the larger marine mammals. In this I was disappointed, and had to rely on second-hand information, which was of the meagrest. I was told at the Factory that several species of whales had been seen and captured in James Bay, as well as other parts of Hudson Bay; but the only species that I succeeded in establishing was the common Greenland whale, which at this period (thirty-five years ago) was often seen in James Bay, and had been known to enter the river. I gained but a very indifferent account of the size of specimens captured here, but it may be of some interest to 
mention that an ancestor of mine, Captain Gotham, who had had great experience of whale-fishing, both in the Arctic regions and in southern waters, has left it on record that he has killed Greenland whales of upwards of sixty feet long and sperm whales of more than eighty feet. Such giants are never met with now, but from what is known of the captain's character I am sure he would not exaggerate. Whalers always attacked the finest fish (as they insist on miscalling them), and hence, no doubt, the reason that so few large animals survive. The whale certainly takes many years to attain its full size, and I greatly doubt if any whale now lives to reach full maturity. If the assertion that $I$ find in a certain work has any foundation in fact-viz. that whales live to many hundreds of years, possibly to a thousand-it is not surprising that few or none now attain to the full size. The steam-whalers see to that, for they can easily single out and capture the biggest animals.

On this river, and also on the coast near its mouth, there were many bats, one of which was the silvery bat, Vesperugo noctivagans. Both on the sea and the river these bats hawked very near the surface of the water, on the latter sometimes actually striking the water. They also flew high in the air, and inland among the trees, and so rapid and irregularly that I had great difficulty in obtaining a specimen, not being used to bat-shooting. Of the other species of bats in this district $I$ can give no description. Almost everywhere, from Winnipeg to this place, bats were seen, generally in scanty numbers, but I never had the opportunity of securing specimens until now. I think, however, judging from style and appearance on the wing, that this species is one of the commonest bats in the Canadian region.

Nearly all the birds of the duck kind hitherto mentioned were found here, either on the river or the sea-coast, where countless numbers seemed to be just finishing the duties of reproduction, and the young birds 
were comparatively so tame that almost any number might have been shot. Not much powder and shot is wasted on them here, for when ducks are wanted they are trapped by the score.

Few places visited in this journey afforded a greater number or variety of birds than the neighbourhood of Moose Factory. That is in the summer season, for on the approach of winter, I was told, the birds migrate in a body, and desolation reigns for many weary months. Among the rarer birds shot here was a turnstone or Norfolk plover, Strepsilas interpres, and several other plovers, the only one of which I identified was Numenius borealis-the Esquimaux whimbrel. The little grey phalarope (which is also a plover) was rather numerous, feeding in flocks on the mud of the river near its mouth. Wilson's snipe, already referred to, was also seen here; and the arocet, Recurvirostra americana. Of the latter I shot five or six, but it was not abundant here. Higher up the river, however, flocks of it were seen, numbering eighty or ninety to a hundred and fifty birds. A few were seen eastward of Lake Winnipeg, but I did not then succeed in shooting one.

Continuing our way up the river and moving leisurely, I made a few excursions into the country on either bank, and shot a few cariboo and another bear. The latter was a huge animal with a dark brown coat, and was literally as "fat as butter." So far from danger or excitement in the shooting of it, the poor brute made desperate attempts to get away, and I had to put five balls into it before my victory was assured. The grease afforded us a welcome stock of fat for culinary purposes. The pelt was not nearly so fine a one as that of the first bear I shot. As to the colour, I notice that many bears in this region have brown fur, or patches of brown about their coats. The Company's people classify the pelts into black, brown, grizzly, and white. The grizzly and the white (Polar) bear are, of course, distinct species, but I can perceive no 
difference between the black and brown varieties; in fact the gradations of colour from black to brown are so many, and so commonly met with, that it is clear they are simply variations of the same species. I learn, also, that some naturalists are inclined to think that the polar bear is merely a variety of the brown bear. I remember thinking, more than once, when observing the two species in America, that there is no great difference between the two, except in colour and habit.

The river, like most others passed over, has high banks, and the adjacent country is covered with forests. Pine or spruce trees often overhung the banks, or grew in the crevices of the rocks, many of them nodding to their fall into the water beneath, and the precipitous banks were often covered with the graceful festoons of some trailing plant which quite hid the rocks. I do not know if ivy is found in this country, but I cannot find any reference to it in any of my note-books, nor do I remember to have ever seen it growing wild in any part of America. The creepers on this, and other rivers of the North-West, though occupying similar sites to those that would be covered with ivy in England, are certainly not related to that plant, and, beautiful as they are, are not so picturesque. Indeed, is there anything in the wide world of a like nature to be compared to the gallant British oak, or the creeping, ruin-hallowing ivy?

There is a singular absence of wild flowers in these northern woods. In that respect they are much behind English woods and coppices. What few flowers there are are small and inconspicuous-mere weeds in fact. None of them seem to have struck me as being worth notice, yet I am much given to minute observation, and, writing from menory, I do not remember anything more striking than our forget-me-not. There is a small blue flower, something like the forget-me-not, and a variety of the same of a white colour, but it is very local. There is also a pretty little red flower, and also violets and 
daisies, but our primroses, buttercups, lady's smocks, bluebells, and poppies are sadly missed by the man fresh from the "old country."

Owing, probably, to Moose Factory being the depôt, there is a great deal of traffic on the Abbitibbe, by trappers and Indians; but the season for transporting the pelts had not yet arrived, and we met but few canoes. There were parties of hunters about the banks, as there were on the Albany, and among those we communicated with were some Crees from Tom's village, or our village, as I think I may call it - the place where my hut was situated on the Ottawa. These men could tell us that all was well with our friends; that Sam and the two Indians had reached home in safety, and that many conjectures were rife among them as to our safety and probable return, "and," added one of the men, "Chompol's daughter" (the young girl Emma Whitting) "often goes down to the river and watches for the canoe all day long." And, he added contemptuously, "Girl always weeping." Weeping is held in great contempt by Indians as a mark of weakness, or cowardice ; and even the children seldom cry. These casual remarks caused me some uneasiness of mind, for I suddenly remembered many little kindnesses and attentions on the part of this poor girl, and how she seemed to anticipate my wishes, and to be ever on the watch to serve me.

There are generally, if not always, outposts to the Company's principal stations, and this district is no exception. There are minor posts at Lakes Temiscaming, Grand, and Abbitibbe, though I did not find that out on my first arrival at Temiscaming. There are other posts, but from time to time the smaller posts were abandoned for better or more convenient sites, and sometimes the hunters carried their first packages of pelts to the nearest trading station, and disposed of them at once before the season was over. The forts and minor posts, some of which had but one or two men in charge, were so 
distributed as to give the hunters the greatest facilities in disposing of their furs when hunting at a distance from their homes.

The head of the river is Lake Abbitibbe, in which it takes its rise; and we arrived there at the end of June, and made preparations for another short stay, as I wished to still further examine the fauna of the country before finally quitting it, as I had determined to do. Again we erected temporary huts at some distance from the point where the river issues from the lake, but at a point where a small brook joins it. Some two miles up the course of this brook there was an old beaver dam. This is the first time I have mentioned this animal, the national emblem of Canada, but not the first time I saw traces of it. However, beavers are rarely seen unless specially searched for. Their nocturnal habits, and the fact that they spend their days hidden in their lodges, account for this; and beavers are also getting scarce. The Company have beaver preserves now; but I forget if they were already established at this time. At all events I never saw one.

The beaver is not now of the importance which it formerly was. The fate of the animal is intimately connected with hats. Before the introduction of the city gentleman's "silk hat," people with a pretension to respectability wore "beavers," and at one time the export of beaver pelts far exceeded that of any other class of skin. More than a million per annum were formerly sent out of Canada by the Company. Now it is doubtful if fifty thousand are killed annually, and they are gradually becoming fewer and fewer in number.

The subject of beaver dams and beaver meadows is too well worn for me to enter on it here. The wonderful instinct, reason, ingenuity-call it what you will-of these little animals is surprising enough, but it has been much exaggerated by most writers. The dams are not the intricate and elaborate works they are often described 
to be, but they are wonderful evidence of the industry and perseverance of the animals. Traces of them are found in every part of the country I visited, and the numbers of the animal must formerly have been enormous. The "beaver meadows" alone can be counted by thousands. These are generally tracts of from two to twenty acres which have become damp, grassy swamps through formerly having been covered with "beaver" ponds"-floods occasioned by the dams.

Beavers are eaten by Indians and trappers. The flesh, like that of most other rodents, is rather dry and devoid of fat. There is sometimes a strong flavour with it, apparently derived from the castorum, a secretion which is much sought after as a medicine, though, in my opinion, it is a mere quack remedy. It is worth about three shillings an ounce, and it takes several beavers to furnish an ounce. The castor, or beaver pelt, is the standard of value of the Hudson Company's bartering transactions with the trappers, hence the name of the wooden cubes used in lieu of money. It varies in value in different districts, being sometimes reckoned at one shilling, sometimes at two. The value of a beaver pelt, in the European market, was formerly ten shillings: what they are worth now I do not know. I could never discover that beavers eat anything but bark, and principally birch bark. Afterwards, in some parts of the United States, I saw more of the beaver than I did in Canada. In some secluded spots of the New England and Southern States it was still abundant in the sixties and seventies; but as fast as these spots were discovered the animal was exterminated by the selfish greed of gain of the discoverers; and by the late seventies beavers seemed to be getting very scarce in all the old States. The beaver is one of the most easily captured of all animals. By netting the streams above and below their dams-that is, stretching nets across on stakes-the capture of every individual of a colony is assured. Escape is impossible, as the animal 
can neither leap nor climb. I never knew them attempt to bite when dragged by hand from their lodges, though no doubt their teeth are capable of inflicting severe wounds.

On the lake there were plenty of ducks, Canadian geese, and a loon or two. These birds have already been described, as has also the widgeon, which were here abundant. There were also flocks of large white gulls, Larus glaucescens, hovering over the lake; and I obtained a specimen of the ivory-gull, Pagophila eburnea. It was one of a flock of about twenty; but though I kept a sharp lookout for others, I did not again see them, from which I conclude that the flock were casual visitors. It is supposed that during the summer this bird does not quit the far north. My experience is that nearly all gulls are great wanderers, and take journeys of thousands of miles inland. I know certainly that gulls often wander right across both the northern and southern divisions of the American continent. The bird referred to above was a most lovely creature, of a faint rosy-white plumage.

Round about the lake, and especially on a small plain about four miles to the westward, "rabbits" were numerous. There are no true rabbits native of the American continent, and these are a species of small hare, Lepus polarius, very much less in size than the great prairie hare, Lepus campestris, of the Winnipeg district, already referred to.

Among the ducks was the pin-tail, Dafila acuta, found on most of the lakes, but swarming here; and the "black duck" of the trappers. I am not certain that I have identified this species, but it seems to answer to Anas obscura, which it probably is.

On the 2nd of July, I, while out shooting five or six miles away from camp, heard a great shouting, with barking of dogs, in a wood to my right; and hastening thither found a party of hunters attacking a bear. There were more than twenty Indians, some armed with axes 
and some with tomahawks, while one had a harpoon and another a pike. While the dogs attracted the bear by snapping at his heels, the men alternately attacked him on all sides. So intent on their work were they, and withal so noisy, that I did not attract their attention for fully a quarter of an hour; and could not shoot for fear of hitting the men, while they had not a gun among them. Two of the dogs were slain when I came up, and two or three more disabled; and while I was watching bruin killed another, and making a sudden dash threw down one of the men. He was beaten off, however, before much hurt was done, and being now streaming with blood, was soon after finished off, having killed three dogs, wounded half-a-dozen, and more or less clawed several of the men. His hide was so cut and chopped that I should think it could have been of but little value; but the grease is always the chief object with Indians when they attack a bear.

When I could gain attention I asked how it was that the hunters were without guns; every Indian owning a gun nowadays. "Plenty gun: no powder," was the reply. This is not an uncommon case, the Indians are as improvident with their ammunition, as with everything else. An Indian often carries his powder loose in a pouch, and his method of loading is to take a handful and pour it down the barrel, wasting a portion, and using twice as much as is necessary for a charge. So it happens that the hunters are often without powder, and in such cases devote their entire attention to trapping. If they come across any large animal they will attack and destroy it in the manner just described; but they never thus tackle bears unless there are at least a dozen men in their party. Deer they easily track down in the snow and despatch with a knife; and I have heard of their actually running deer down, when the ground is clear and the latter can run at full speed. The hunter probably tires the deer by incessant pursuit; for these 
Indians are wonderfully enduring, and will pursue an animal for three or four days at a stretch rather than lose it.

Their dogs are not much good, though they serve to attract the attention of bears, \&c. They are a sort of lanky cur, evidently the descendants of wolves. It is singular that many years afterwards I saw precisely similar dogs in the possession of a tribe of South American Indians.

I need not say much more of the Indians themselves than what I have already incidentally written in the course of my narrative; but I may just mention that I am not at all one with those who term him an irreclaimable and irredeemable savage. I do not know what is meant by a "savage" unless it is a brute, in manner and conduct. If so, the Indian is not a brute, and therefore not a savage. His chief offence in the eyes of his conquerors is that he does not want civilisation. In that I have some sympathy with him. A man bred in the wilds cannot look upon civilisation as an unmixed blessing; in fact it is not an unmixed blessing to any man. I have spent so much time myself in the wildernesses of the earth that I am to a great extent unfitted for a town life. I almost pine for the forests and prairies that are so speedily disappearing. What then must be the feelings of a race of men who for countless ages have roamed the desert, at seeing their hunting grounds seized by the money-grubber-by the land-grabber? Put yourself in his place. What would you think of a conqueror who turned you neck and crop out of your home, remarking that he was immeasurably your superior in all things from his mind to his togs $;^{1}$ and demanded that you should live as he does, worship the Great Spirit as he does, and believe in him for all things, and in all things, or be wiped out? That is really what is happening. And because the Red Man declines compliance

\footnotetext{
1 Togs! slang for clothes, but evidently derived from the classical toga.
} 
with these demands, his master strikes the attitude of a saint, and says, "Justice shall be done you. You have a right to please yourself. But we cannot permit you to keep us out of your extensive hunting grounds. We will give you a ten thousandth part of your own property as a reserve. Go there and live, and keep there, or look out for squalls. We will give you a little meal, a couple of pounds of powder and shot, and a butcher's knife per annum. We will look after your morals, and teach your kids how many million miles away the sun is; but we won't have you interfere in our politics, or show your ugly carcasses in our beautiful refined streets."

If I am thought to exaggerate, I shall flatly deny that I am doing anything of the sort. At the time of which I have been writing, there were a fow Indians making a precarious living, or loafing, about the townships: now, I believe, that a Red Man in a Canadian town is as great a rarity as one in an English street. They have put him out of the way on his "reservation."

I shall trouble the reader with no further remark on a subject that I could write a volume on: I will simply conclude by saying that I would fight to the last gasp before I would tolerate such treatment. Of course the political economist will be down my throat. "Are we then to leave a large portion of the earth's surface a howling wilderness for the pleasure of a few Indians and hunters?" Certainly, is my reply. You have no right to clear forests by the ten thousand square mile at a stretch, in order to make millionaires. Millionaires can be spared better than bears and deer; but I am no extremist. Leave us a percentage of the forests and prairies; but no "parks," no keepers, no hotels, and, above all, no legal ancients with their wise saws and preposterous rules. Deal as harshly with the waster and exterminator as you like; but no interference with the true sportsman. 


\section{CHAPTER XV}

\section{A JOURNEY TO THE GULF OF ST. LAWRENCE}

We crossed Lake Abbitibbe on 8th July. It is so large a body of water that when we were about the middle of it no land could be seen, except a few islets and the tops of some hills to the north-eastward. On the south, passing the Company's fort, we entered a small stream, and by the evening of the next day were less than thirty miles from home. We had with us four Indians of the bearkilling party whom I had engaged to carry the canoe overland to the huts. Next morning, at daylight, I started with Achil, leaving Tom to look after the Indians, hoping to walk the thirty miles in one day; but when we had covered about two-thirds of the distance my right leg, always the one from which I suffered most, gave way; and I was in a sorry plight in the midst of the woods, unable to take another step in any direction. Fortunately the weather was hot; and it was no hardship to lodge under the shade of the trees. Next day the Indians came up, with the canoe on their shoulders, having followed in our tracks; and as I was still unable to walk I was placed in the canoe, and thus carried to the huts.

The surprise of Andrew and his wife, and Chuckochilgegan, at seeing us thus return was very great, for they had expected that we should return the way we went, via Lakes Superior, Huron, and Nipissing. As illustrating the peculiar phlegmatic character of the Indians, I may mention that Tom's return received not the slightest notice from either his brother, or his niece Chompol, Andrew's wife. I am sure this did not proceed from any 
lack of natural feeling. It is the custom of the Red Men. Anything like demonstrativeness is considered childish, if not positively rude, by an Indian. I noticed that, by-andby, Tom went to Andrew's hut, and was soon followed by his brother Chuckochilgegan, or Sam, as I called him; and I saw them all sitting on the floor (the usual seat), and smoking together; but I did not observe that much conversation took place. I have already mentioned the extreme taciturnity of Tom's disposition.

I had, of course, inquired for Emma, and was told that she was down at the river fishing; or watching, as I suspected, remembering what the Indian hunter on the Albany had said. She did not return till evening; and when she came to my hut she threw herself at my feet weeping for joy, and from that time was scarcely ever out of my sight. I was very much upset on the poor girl's account, and determined to hasten away as soon as possible. I had already decided that the climate of Canada would not suit me, being too cold in the winter; and there were other reasons for inducing a speedy departure into the States, though as yet I had not thought of bossing a prairie schooner-my ultimate fate, as far as my wandering inclination would permit of my sticking to any form of business.

I soon recovered from the sprain of my leg; and during the short time of my further sojourn here nothing worthy of record occurred, unless it be the shooting of a lynx. This animal, according to my experience, is very scarce. I have but seldom seen any trace of it; and in all my wanderings have obtained but three specimens. This one was thirty-four inches in length from the nose to the root of the tail, which was a fair size. For it is an animal that varies more in size than any other cat I know of. Some full-grown examples are only two feet, or even less, in length. The average appears to be about thirty inches, while large examples run to thirty-eight or forty, if the accounts of the trappers are to be depended 
on. I have seen larger skins than those I obtained; but this is not much criterion, as the trappers have a trick of stretching pelts to make them appear as fine and large as possible. The fur is one of those sought by the Hudson Company, but it is only occasionally that the hunters bring in an odd one or two. The animal is not only scarce, but cunning also, and difficult to find; and makes its escape at the slightest alarm.

It has a curious lolloping sort of run, and having but a very short, stumpy tail looks, at first sight, more like a dog than a cat. Its legs are very long for a member of the feline family, which is probably the reason of its curious gait, which is indescribable on paper. It is a sort of leaping gallop. It is very expert in climbing trees; but its favourite lurking places are holes and caves among rocks, or under the matted roots of trees. It undoubtedly increases the depths of its lurking holes; and has generally at least two entrances or exits. I do not know how a good dog would fare in attacking the lynx, but the Indian curs are afraid of it. They bark and snap at it, but do not close; and unless the hunters are close at hand the lynx will make rushes among them, and every dog he catches he kills.

The lynx, however, I am assured by many Indians and half-breeds, will tly in terror from a very small pack of wolves. The latter often drive them to the trees, and sometimes keep them there for days together. The lynx never kills large animals for prey. 'The bulk of its prey consists of birds of the grouse family, which it surprises when on the ground, and hares; but it often contents itself with very small game, rats and mice, and even frogs; and

1 The following are the articles for which the Company barter: all kinds of bear, and all kinds of fox skins; they recognise six varieties of the last-red, black, white, blue, silver, and cross. All kinds of deer skins -moose, wipiti, and cariboo. Skins of the badger, beaver, musquash, otter, lynx, seal, all martens and pole-cats, wolf and glutton. Also all kinds of feathers, particularly those of the goose and swan. Seal and whale oil, and castorum, walrus tusks, and dried salt-fish. Formerly "buffalo-robes"; but these are no longer procurable. 
like the jackal, is not above feasting on the leavings of its betters. For if the bear neglects to bury the remains of its prey, and the wolves fail to be the first discoverers of the feast, the lynx will eat greedily until he is disturbed, returning again and again while the meat lasts, but always retiring on the approach of the master of the prey.

I never could learn anything satisfactory of the breeding habits of the lynx. It is a very quiet animal. I never heard it crying at night, as the puma does; and it never approaches the solitary camp of the hunter, which is quite a common habit of the former animal. The fur of the lynx is of a reddish grey colour, and there are dark markings indicative of spots on several parts of it. There is no material difference between the European and the American lynx.

The time had now arrived for me to move southward. I had seen enough of Canada and the great North-West to convince me that it would be a mistake for me to attempt. to settle in the country, dearly as I love the grand old flag and wished to remain under its ægis. It is to be understood that I have no fault to find with the country itself, which is a magnificent territory; but, though I am no weakling, I could not stand the Canadian winters. Excessive cold has the same effect on me that excessive heat has on most persons-it weakens and it enervates. This is, no doubt, owing to the infirmity from which I suffer, the result of an injury during boyhood, to which I have alluded often enough.

Having made up my mind to remove to the United States, I was yet in no hurry to leave British territory. I wished to explore the shores of the splendid Gulf of St. Lawrence. Circumstances, and the need of husbanding my means, prevented my fully gratifying this desire; but the results of my partial journeys are now given.

The leaving my Indian friends was a painful affair. I had lived long and closely enough with them to feel 
acutely the parting with them, especially with the poor half-breed girl Emma. It was my misfortune to have made a great impression on this poor girl, and I hesitated a good deal before finally making up my mind to leave Canada. But I was not yet twenty years of age, was not blest with sufficient of this world's goods to provide for a family, and not at all inclined to settle down in life. These considerations finally influenced me; but many years elapsed before I ceased to think of poor Emma without a painful sadness of heart.

The parting with my friends was an Indian one. There was very little said, but evidently a good deal thought; and the whole of the Indians in the neighbourhood, men, women, and children, stood on the banks of the river to see the canoe depart; and I had so many little presents showered on me that I could scarcely find room in the tiny skiff to carry them away. The men stood upright, looking stoical, after the Indian manner, the surest sign of deep feeling; the women and children squatted on the ground behind their husbands and fathers, while poor Emma made no attempt to conceal her grief, but, when we stepped into the canoe, was prostrate in her mother's arms.

Andrew and Monchuapiganon (Tom) paddled the canoe down the tributary to the Ottawa River, and went with me as far as the immediate neighbourhood of the city, where the last parting took place, for I could not persuade them to go farther. I had intended to send back many little presents from the shops of civilisation, but I had to be content with entrusting Andrew with a fow trifles for Chompol and Emma, and one or two others. My favourite Minié rifle ${ }^{1}$ I gave to Tom, knowing how much he valued the weapon, with all the cartridges I had left. Every muscle of his face twitched as he took it; and I was surer than ever that his morose exterior covered a

1 The so-called Minié rifles I used in my early American journeys were of the Enfield pattern. 
heart of deep feeling. After the canoe had put off for the return journey, he stood up and shouted, "Some day, come back;" and that was the last I ever saw or heard of these friends.

I did not stop at Ottawa longer than a day or two, but went on to Montreal. There is not a man living less liable to be impressed by the works of his fellow-men than the writer. I have absolutely no eye for architecture, and the meanest shrub is to me a more beautiful object than the finest building ever erected; but I certainly was struck by some of the fine works at Montreal: the Victoria Bridge of the Canadian Grand Trunk Railway, for instance, which is 3428 yards long, the central span alone being 117 yards. It crosses the southern arm of the St. Lawrence, connecting Canada with the United States, and is justly considered one of the greatest engineering feats the world has seen. The Prince of Wales (our present King) was present at its inauguration five years ago (forty-two years now, in 1902), and the people of the city are yet full of praise of His Royal Highness, and never fail to give strangers a full account of his visit, down to a minute account of the clothes he wore. In this fondness for minute description of exalted personages the Canadians resemble their cousins the Yankees.

Among a multitude of points of interest in the city is the Roman Catholic cathedral. French Canadians say that this is the largest church in the whole of America, and that it will seat more than 10,000 persons. Possibly; it certainly is a very fine building. The whole appearance of the city has an air of substantiality that has not its equal in any other American town-not even in New York; and Montreal should certainly be the capital of the British dominions.

Considerable difficulty arose as to the manner in which I should perform my proposed exploration of the gulf. I wished to make a canoe journey similar to that performed on the great lakes, but there were no Indians 
or trappers here to be hired, and I soon found that the expense of a properly equipped boat-expedition would be beyond my means. Ultimately my journeyings about the gulf were reduced to a few trips along certain portions of the north shore, and a visit to the great island (about 2000 square miles in extent) of Anticosti. My sojourn on the latter was so short that I had absolutely no time to study the natural history of the country. That portion of it that I visited was low and swampy, and covered with forests of trees of stunted growth; but there were black bears in abundance at certain spots, which were not at all inferior in size to those found in other parts of Canada. This seems to me rather strange, since the larger quadrupeds are usually of much smaller size on islands; as may be instanced by the elephants of Ceylon, which are not a distinct species, and the tigers of Sumatra, \&c. The bears are certainly of the sarne species as those on the continent, and they must have got hither on the ice, since it is impossible to believe that the breed could exist for untold ages in so confined a space without degenerating in size, or could have swam the sea-channel, which is at least thirty or forty miles wide in the narrowest portion.

Having passed down the river to Quebec, and snow being by this time on the ground, I made arrangements with a Mr. Finnock, boss of a party of lumberers, to journey with him to his station on the gulf. Before quitting Quebec I went to see the Montmorenci Falls. I do not think that I have ever read a description of them in which the epithet "celebrated" or "famous" was not used by the writer. There is nothing remarkable about them; and after seeing Niagara they are positively tame, though their height is as great, and appears much greater, on account of the smallness of their width. Niagara and Montmorenci are too hackneyed to be described here; but there was a singular phenomenon at the latter which I have never seen referred to, though I 
was informed that it is of annual occurrence. The spray had formed an ice steeple, nearly a hundred feet high, in front of the falls; and this was the only point about them which could be described as grand or imposing. The steeple rose sheer from the water, and must have been grounded on the rock beneath it, since its weight was many tons. When the thaw sets in this steeple must fall with a terrific splash, but I could not hear of any one who had witnessed its fall.

Quebec, the capital of the country, is also the first town in it, for there is no collection of houses worthy the name of township below it. For many miles there are scattered villages and farms, and along the roads there are inns where the traveller may get good, if occasionally rough, accommodation. He is sure of a good feed, and a jovial, hospitable welcome; and that is more than can always be said in some lands a great deal nearer the great centres of civilisation than the outlying portions of Canada.

Finnock (who was a hard-fisted, sturdy Scot, with a heart worthy of his great body) and I travelled on a "sleigh"; it being almost a solecism to say " sledge" here. Sleigh travelling is very pleasant on good roads, but positively devilish where the ruts and holes are frequent and deep, as is, or was at this time, usually the case when the immediate neighbourhood of Quebec is passed. The makers of sleighs, and sleigh-harness, appear to know well what test their work is likely to undergo, and I admit they do it well; for the strain both successfully resist is simply enormous. Down drops the sleigh into a hole eighteen inches or two feet deep, but on dash the horses and bring it out again with a jerk that jolts you, it seems, a yard up from your seat, and causes a most uncomfortable sensation to shoot up your body, something between a pang and a shock. If you complain, those used to the "sport" laugh; if the confounded thing upsets and is dragged over you, they laugh; if you are shot out into 
a dozen feet of slush and water, they laugh; if you lose your temper, they go into ecstasies; in a word, whatever accidents happen, everything seems to be a source of amusement to those used to this form of travelling; and, I am afraid, the point of the game is to "get your shirt out," as they elegantly phrase it, and which seems to be synonymous with failing to "keep your hair on."

At places there were very good roads, made, it would seem, by the private enterprise of the farmers and the inhabitants of the adjacent hamlets. Sometimes the road was formed in the old American fashion, by laying tree trunks side by side; but this is a frightful sort of pathway when it is out of repair. When the snow lies thick, and is hard frozen, filling up the interstices between the trunks, the sleigh travels well on it, and smoothly; but at the first hole! - mention it not! It is my opinion that the very horses enjoy the "spill" that then occurs. I am sure the dogs do. Strange; but it is the "new chum" that invariably gets the sleigh atop of him; and he is the only being, man or beast, that does not seem to see the fun of the thing. "Never mind, old horse. Get up. We have all been through the mill. Eh!!! Broken a bone! Oh! I see you want the girls to take you on their lap." And the guffaw that greets this sorry sally effectually shuts you up at anything under a broken back.

On this occasion we got on pretty well until nearing the village of Mal Baie, when the sleigh plunged through the snow into a hole so deep that the horses failed to pull it out again; but instead went sprawling with terrific results. I went up first, and came down with my legs and wings spread out in elegant cruciform style, an involuntary "Oh!" being forced from me as I came down face undermost; while behind I heard an energetic —_ in strong Scotch accents, and a jabber of very wicked-sounding French from the driver. "There, my friends," said I, when I had picked myself up, "perhaps 
you see something to laugh at in that." The Scotchman had as fine a pair of black eyes as ever I saw. Baptiste, or whatever our French driver was called, was bleeding like a bullock from the nose; while $\mathrm{I}$, in spite of $\mathrm{my}$ efforts to carry it off airily, was soon compelled to sit down and groan. The horses meantime, being used, I suppose, to this sort of thing, lay as quiet as lambs.

Presently a sleigh came along containing a gentleman and two most charming French ladies, and immediately all was sympathy and condolence. The gentleman, handing the reins to his wife, got out to help us; the sleigh was pulled out of the hole, the horses set on their feet, and we invited to refresh at the gentleman's farm, which was not more than a mile distant. Here we received such kindly hospitality that we were induced to remain until the third day. By this time we had pulled ourselves together somewhat, though it was a week or two before Finnock ceased to look like a fighting-man who had got the worst of it. So kind was this hospitable farmer, and the dear ladies especially, that I quite regretted having to leave them so hurriedly.

The country hereabout was as flat as a pancake, though elevated considerably above the river or gulf, which could be seen on our right hand; and I am much mistaken if it is not the bed of an ancient lake which has eaten through the boundary rocks and emptied itself into the gulf. This flat valley, which is of great extent, is highly fertile, and was thickly strewn with farms and homesteads, being highly cultivated, though there were patches of forest, reminding me of our English woods, left standing here and there. The roads, as a rule, are good through this valley, and the district one of the best peopled I had seen in any part of Canada. We daily passed many sleighs, the inhabitants, at this season, riding about for pleasure; for all agricultural operations in Canada are suspended while the ground is covered with frozen snow, and the people devote their time to 
sleighing, tobogganing, and other outdoor games, and to social arnusements indoors, many of which are borrowed from the Yankees, and will be described farther on.

The road that we have been travelling over runs parallel with the river, or nearly so, and at no great distance from it. Often we got enchanting views of the water. As to the general appearance of the country, it varied a great deal, presenting a succession of scenery from flat plains to rugged mountains. In some spots the river banks were several hundred feet high, and very precipitous, but generally covered with trees, which found a lodgment in the crevices, or on narrow shelves of rock; at other places the banks were low-almost level with the water. The ascent to the higher ground was gradual, by a series of terraces. Inland from the river the country is hilly, often rising into rugged ranges. I was told that still farther north the country was very mountainous, with a bold, rocky outline-in fact a very similar range to the Rockies of the west; but this part of the country was not visited by me. I saw enough, however, to show me that the country below Quebec, trending northward, is very mountainous; and the rivers have deep, rocky beds, with fierce currents, and a continuous line of cataracts and falls that make the navigation, where attempted, most laborious, more than three-fourths of the men's time being taken up in making portages; in fact there is practically no navigation on the rivers falling into the gulf. The estuary of the St. Lawrence is very wide, insomuch that I could not tell the point where the gulf really commenced. A great portion of the channel, which is often called, and marked on the maps as, the River, is, I think, more properly a portion of the gulf, and is so considered here. All portions of the river below the mouth of the Saguenay being not less than thirty miles wide, and absolutely salt, I look upon as the waters of the gulf.

Below Mal Baie the forests cover large tracts, although 
much of it has been cut down by the lumberers. Higher up the country, along the road we came, there was comparatively little forest, it having been destroyed by the settlers for fuel, or for farm purposes; and of big game we saw none at all. All the deer and bears have been exterminated near the settlements, and only wanderers occasionally appear. There are said to be foxes and gluttons hereabout, and packs of wolves generally appear during the winter; but their coming is the signal for a general assembly of the farmers for a wolf hunt, and all are destroyed before they have time to do much hurt. The system of hunting is to form a great circle of men, who gradually close in on the centre, killing everything that is worth powder and shot. Such a system is only worthy of savages and pot-hunters. It is not sport.

About thirty miles beyond Mal Baie the road ceased, but still there was a track, showing that we had not quite got to the bounds of tolerably well-inhabited country. For some time the road had been a very rotten affair, and we had several spills, but without much damage done. On this section of our route we passed many lumberers' huts, and a few small outlying farms. We generally passed the night at one of the latter, where we were always kindly received, and the best the house could provide placed before us; but on one occasion we had to stop at a lumberer's hut where the accommodation was simply awful-but of this more presently.

On the 5th December we arrived at the Duck River, where our sleigh drive terminated, the driver having only bargained to take us so far. Near here I obtained a splendid view of the gulf. The water near the shore, and seemingly for a mile out, was frozen over, presenting a broad sheet of ice. Beyond, the dark blue line of the open sea was visible, full of floating masses of loose ice and small icebergs. A large island could be seen in mid-channel, but the opposite shore was not visible. 
Five or six miles down channel we perceived the masts of a considerable cluster of shipping.

Although we could not persuade our driver to take us any farther, he having secured a return fare at one of the last stages, we succeeded in borrowing horses at a neighbouring post where lived a superintendent of the lumbering trade, and on the 7th we reached Tadoussac, a trading station of the Hudson Company, but quite unlike any of their posts or forts I had hitherto seen. Tadoussac is a scattered hamlet at the mouth of the river Saguenay, and reminded me of pictures of a Swiss village; for the huts are perched here and there, up and down the precipitous rocks, in such a way as to cause me to wonder how the inhabitants could reach them.

The country is quite mountainous here, and very rugged, the rocks being often quite precipitous and destitute of vegetation. Indeed, just about Tadoussac the mountains have only a few clumps of pine trees scattered about them. No doubt most of the trees have been destroyed, for this is a great lumber depôt. There is no fort at Tadoussac.

A little farther on, and to the right hand of Tadoussac, is another and larger village, St. Catherine, which owes its existence to the lumber trade. The Saguenay is a large, broad river of great depth at its mouth, indeed said by the ignorant lumber-men to be unfathomable. The truth seems to be that the current is so strong that any light sounding weight is forced outward towards the St. Lawrence before it can reach the bottom. The leadsman therefore pays out fathom after fathom without finding the bottom. Nevertheless the depth is certainly very great, and from this cause, and the swiftness of the current, the river never freezes over near the mouth. Broad as it is it is hemmed in by gigantic rocks with wall-like faces in many places, and the view up the river is cut off by a huge rounded rock, having the form of a bull's head and shoulders, and hence called "The 
Bull." The mouth of the river forms the Bay of Tadoussac, said to be the finest and safest harbour in the estuary of the St. Lawrence. To my surprise, I saw quite a fleet of sailing ships and small craft in the bay, all frozen in, and waiting for the spring to load with timber, which would be floated down the river from the interior as soon as the thaw set in. Some trade in dried fish also takes place here. From Tadoussac the opposite shore of the gulf is visible, showing as blue-gray mountains, which must be of considerable height. It is only in clear weather that they can be seen; but thick weather is not of frequent occurrence in the gulf at any season of the year.

I thought it strange that ships should find it convenient to pass the whole winter here in idleness, but the explanation was that ships cannot enter the gulf in the spring until the heavy ice has cleared away, but by that time ships which have wintered here have their cargoes on board and are ready to sail on their homeward voyage. The ice on the rivers up country thaws, and permits the timber to be floated down, long before the St. Lawrence is clear of ice.

St. Catherine is quite a seaport on a small scale. Jack can get drunk there and kick up a bobbery; and I am sorry to say that here I, for the first time since I have been in the country, found Indian women who, like the sally-port sirens of Portsmouth, make a trade of robbing Jack of his hard-earned wages.

The ships engaged in the timber trade are woefully undermanned. Some of the crews make money by timber felling during their stay; others, and especially the officers, go up the river to the big towns to take it easy till the break-up of the frost recalls them to their duty.

At Tadoussac there is a big saw-mill, but the post to which my friend was bound was seventy miles off on a creek tributary of Saguenay, and it was his intention to 
cover this distance on snow-shoes. I had already come to look on a little trot of seventy miles as a mere fleabite of a journey, and determined to accompany him, and spend the remainder of the winter in learning the trade of a lumber-man.

Goose Creek, the spot to which we were bound, was not Mr. Finnock's usual post. He was going to replace the gentleman in charge there who had been brought down to Tadoussac in an apparently dying state. Poor fellow! he suffered from that most horrible of diseases, consumption, and the rough life up country had played sad havoc with him. We heard afterwards that he died before reaching Quebec.

I was most anxious before leaving the coast to go out on the water, and I persuaded some of the sailors to drag a boat over the ice, to gratify my wish. We launched it and pulled along the edge of the margin ice, if I may so call it, that next the shore to which it was attached, and which was at least a mile broad, and much more about a point of land ahead of us, probably five or six miles. Outside the margin there was a vast quantity of loose ice, some of the blocks being large enough to be very formidable to the boat's safety. I suppose that this loose ice was the result of the heaving of the waves; or perhaps the strong current of the river was the cause of its becoming detached. The danger from the swirling ice was so great that we were obliged to give it a great offing. Farther out there were still greater blocks that must have weighed many tons, and were an effectual barrier to safe navigation. We remained on the water but a very short time, as there was no object to be gained and the danger was great. I tried fishing with a hook and line, and also with a cast net, but nothing was captured. The ice barrier prevented us from landing on other parts of the coast, so we returned, dragging the boat back with us. 


\section{CHAPTER XVI}

\section{A WINTER WITH THE LUMBERERS}

FinNock having completed his business at Tadoussac, we started for Goose Creek, the journey of some seventy miles being to be performed on foot. Goose Creek is a local name given by the lumberers to the spot. The only map in my possession that appears to indicate the place is an old French one, and according to this the creek is called the Chekoutimiens River. It is a very insignificant stream, at the bottom of steep rocky banks which are, in many places, at least a hundred and fifty feet high. When the thaws of spring take place, there is sufficient water to rush the rough logs along to the Saguenay, whence they are dashed down to Tadoussac.

I use the words "rush" and "dash," for no others will properly describe the motion of the logs in the water, so powerfully are they hurried along by the furious current. It sometimes happens that the logs cross and intertwine, and form a temporary obstruction at the heads of the rapids, checking the rush of the water until sufficient weight has collected against the obstruction to force it. Then it is burst asunder with a terrific impulse, and sometimes with a report equal in intensity to that of a small cannon.

We started, as I have said, on foot, there being no other available means of travelling; the country being impossible for sleighs, and there being no means of subsistence for horses. The first day's journey was supposed to be about fifteen miles, and it took us nearly eight hours to do it on snow-shoes. These we were often 
obliged to take off to enable us to climb the rocks. The route was the most difficult of access of any I had hitherto passed over, being steep rocks alternated with deep gulches. There was no forest; only scattered spruce trees of small size, and a few bushes. No game was seen. A few ducks flying in the distance, and a few small birds were the only living things met with. Of the small birds the snowflake (snow-bunting already described) was the only one I recognised with certainty, for I had no ammunition to spare in shooting specimens; all my possessions for the winter's use being what I carried on my back in a knapsack and a bag at the waist-belt.

Towards the close of the day we turned inward toward the river, and passed the night in the hovel of some lumberers, sleeping (nine of us altogether) so closely together that there was literally no room to turn.

We started again at daybreak over similar country, but there was more wood; and near the river we saw the stumps of many thousands of felled trees. As we advanced, the timber became finer, more various, and in greater quantity. The hovels of the timber-fellers, also, were pretty numerous, and we stopped at one for the mid-day meal, consisting of ship's biscuit and salt pork.

'These lumberers' hovels are most wretched affairs. They are generally a shed of logs erected over a hollow in the ground, and are so low pitched that it is impossible to stand upright in them. They are, in fact, like great dog-kennels, and you have to stoop doubled up to enter the hole which, by courtesy, is called the door. Inside, the floor is strewn with spruce boughs which serve for seat and bed, and there is really no furniture. Some fastidious fellow may, perhaps, have a rough three-legged stool to sit on, but anything like a table I never saw. The cooking is done outside in the open air, no matter how sharp the weather is; and at night-time, if a fire is 
required, it is made opposite the entrance to the hovel; but the men depend for warmth mostly on lying close together, literally heaped in a mass under blankets and rugs.

At such hovels we spent the third and fourth nights, obtaining food and shelter; the men in each case being under Mr. Finnock's direction. We then had the worst stage of the journey to perform, an unbroken speli of twenty miles, to be covered in a short winter's day, with the certainty that we should meet nobody in the whole distance. We this day had to cross a range of hills of several hundred feet in height, the path being of the most rugged and trying description. We sometimes had to climb almost precipitous ascents, and long before the day was half over my knees were trembling under me. Finnock, sturdy Scot as he was, I could see was considerably distressed, though he would not admit it. It will be noticed that we had no guide, the river on our left hand serving the purpose of a directing line. We often lost sight of it, even for the greater part of the day; but the downward dip of the land was sufficient indication of its trend. It was impossible to keep very near it on account of the rocky and broken nature of the banks.

As we advanced the forest tracts became more and more frequent and extensive, intermingled with bare and forbidding-looking rocks. Some of the hills must, I think, have been quite two thousand feet above the level of the gulf. We passed close to a great bear this day, the first big game we had seen. I wished to shoot it, a proposal which greatly alarmed Finnock, who would not hear of its being interfered with. "Eh, mon! they're vary uncanny beasts when their bristles are up." I was vexed, as the skin would have been most useful in present circumstances. I soon found that Finnock was no sportsman; but his refusal to interfere with dangerous animals was probably due to excessive caution, as he was plucky enough on occasion. 
About two o'clock in the afternoon we ascended an eminence from which we could see a distance of many miles in nearly every direction, and from which we hoped to be able to sight our destination. To our vexation, however, no signs of the post could be discerned, and it became evident that it was still many miles off. Soon after it began to snow heavily, and it became necessary to seek shelter before darkness set in, if we did not wish to incur the risk of perishing in the storm. We cut down spruce boughs with which to form a shelter, and snow being piled over this, we soon had a tolerable covering over our heads; but all our efforts to get a fire to burn were futile, the wood being too damp to ignite. We had but a mouthful of food with us, and a small bottle of rum; and with this, and huddling close together to maintain our heat, we contrived to keep alive till the faint light of approaching day enabled us to resume our way.

It was still snowing, and as the surface snow was loose, we could not use our snow-shoes, even where the ground was tolerably level. Moreover, we met with a nasty accident soon after starting. In climbing over a steep rock a huge mass of snow gave way under Finnock. I happened to be directly under him, and he came right on to me. Down we both went, rolling thirty feet over the jagged rocks. Though my gun was at half-cock, one barrel by some means exploded, the charge passing close enough to Finnock's head to singe his hair. We were both much cut and bruised, and my friend so much lamed that it was with difficulty he could hobble along.

Under these circumstances it was nearly the close of the day before we came to the encampment; and rough as were the surroundings, I do not know that I ever beheld a blazing fire and heard the cheery shout of fellowmen with more pleasure than on this occasion. The boys were eating roast porcupine, those animals being numer- 
ous in the neighbourhood; and, hungry as I was, I thought the meat delicious.

It was a week before Finnock could get about, his ankle being much swelled. The men lived in the usual miserable huts, but there was an erection of a rath/3r better kind for the boss. As it was not equal to my idea of a comfortable lodging, however, I proceeded to build a hut of my own, I being, as the result of past experience, pretty expert at this kind of work. Moreover, I was soon on chummy terms with several of the men, who willingly lent me a hand; so in a few days I had a very comfortable hut, in which I could at least stand upright, with a raised bed-place in one corner.

There were twenty men in this camp, the majority, in about equal numbers, being Scotch and French Canadians. There was one Irishman, "Mike" O'Neill; one Englishman, two Yankee deserters from their ships, and a Norwegian. There was also a "John Chinaman" to cook for the gentlemen, and do their washing, and who was of a perpetual mud colour from the effects of the cold; and whose life, I am afraid, was rendered wretched by the tricks the "gentlemen" played with his tail. There were likewise three Indian women, squaws to some of the lumberers.

On our first arrival there seemed to have been some trouble amongst this motley company, for some of them had black eyes, and others noses that were swollen and red; and many angry looks, and a great deal too much swearing, were interchanged between certain individuals. I heard Finnock, too, complain that a proper amount of work had not been done; but even before he could get about this was remedied. Before daybreak the men were aroused by Johnny blowing a horn-the most horrid-toned horn I ever heard. Everybody was on his pins in an instant, for everybody went to bed in his clothes; and breakfast being ready before the horn was sounded, every man set to at once to consume his coffee 
and pork and damper. Johnny was an expert at preparing the latter; and nobody troubled that he licked his fingers every time that he burned them, and forgot to wipe them before he handled the food. The breakfast was eaten within the grateful warmth and red light of huge pine-branch fires, and was a wildly picturesque scene. Every man had to finish his meal before there was daylight enough for him to work by, that there might be no loss of time. By daybreak every man was wielding his heavy axe as if working against time.

I was not without a little experience, and I determined to be no idler. But behold the mighty "Irish Mike." Standing by a pine, two feet in diameter, he raises his huge felling axe, and brings it down with a thud that echoes and re-echoes through the dim glades of the forest. First a cut sloping upwards, then one sloping downwards, and the wedge-shaped chips fly about with a velocity and force that warn the on-looker to stand clear. Those long, wiry arms of Mike's never cease motion, but sway up and down with steady beat, "chip, chop, chip, chop," until the great tree nods to its fall; and then, with one powerful horizontal stroke, delivered straight into the nick, the woodman finishes his work and slays the tree that has breathed the sweet air of perfect freedom for centuries. Ah me! am I poetical and far-fetched! The fall of a tree has always seemed to me strangely like the death of some brave live creature.

Now I have a try, and the kindly Mike stands by to give "the bhoy" a word of instruction. In spite of my attempts to imitate the measured stroke and fair cut of the true lumber-man, it takes me an hour and a quarter to fell a tree that Mike would ground in ten minutes. But I improve as time goes on, and a month after my arrival in camp, I can fell the tree in twenty-five minutes, or half-an-hour at most.

Like other trades, there are tricks in that of a lum- 
berer. The choice of the axe is all-important. There is as much in the length and proper curve of the handle as there is in the selection of any other tool; and the weight of the head should be proportioned to the strength of the wielder. The heavier the axe the better, provided the woodman's strength is not overtasked. Then again, the cut, though delivered in a sloping direction, must be perfectly straight in the line of the blow, otherwise a great part of its effect is lost. Another point is to hit in the right place; the lumberer must be a marksman-must have a true eye. It takes years to make a thoroughly good lumberer. Such, however, will fell a tree two feet in diameter within ten minutes.

The tree once down must be cleared of branches, and this work I largely engaged in, as do beginners generally, for the sake of the practice. I may add that my first day's work gave me a dreadful attack of lumbago; but the benign Mike and the heathen Chinee between them, stripped me and rubbed me for an hour, before a blazing fire, with bear's grease; and in a day or two I resumed work, and ultimately could swing my axe from morn till night with the hardiest of them. But it is fearful work. The excessive labour and rough living will, and does, cripple the most vigorous in a very few years; yet, once a lumberer, always a lumberer. The men love the wild life, and few ever leave it until they leave the world.

At the present day I believe that tree-felling, both in Canada and other parts of America, is mostly performed by hand-saws. This must be on account of the scarcity of skilled axe-men. For a good lumberer will bring down his tree as speedily, at least, as two men with a saw. However the tree is felled, the branches, \&c., are always piled in great heaps and destroyed by fire. The reflection from these burning piles can sometimes be seen for nearly a hundred miles; and the odour of the burning wood can also be perceived at an immense distance. Sometimes the fire from the burning piles catches the 
standing wood, and then a deplorable waste of timber takes place, hundreds of square miles being devastated.

There was plenty of whisky and rum in the camp at the time of my arrival, which was all private property. It, and the provisions for the season, had been brought up by the Indians, and others hired for the purpose; and from time to time more was brought hither by the same means; for all through the winter there was occasional communication with St. Catherine's port. Had I been in command I should have insisted on the spirits being put under control at least. As it was, it was no unusual thing for all hands to be drunk. Even Finnock did not put that curb on himself which it is particularly desirable that a leader should.

Some of the men were very quarrelsome when tipsy. This was particularly the case with $\mathrm{M}$ 'Cullough "Fighting Jeamy M'Cullough," as he called himself. Down to this time I had thought that Scots, however stubborn and self-assertive some of them are, were all too cautious to give way to unreasoning temper. Now I discovered my mistake. I have never met with a more quarrelsome man than Fighting Jeamy. He was the author of the black eyes and broken noses before mentioned; and before a fortnight elapsed he had fought with, and beaten, every man in the camp who had the courage to stand up to him; and in consequence he became tyrant over all.

He drank immense quantities of whisky while the spirit lasted, and was seldom sober at night, though it was only by his excessive quarrelsomeness that his intoxication could be discovered. "I'm a mon o' tremendous pheesical powers, Mr. Founteen," he said to me on one occasion; and, by way of giving an illustration of his endurance, he sprang up with the suddenness of a madman, and beat his breast with appalling force. $\mathrm{He}$ must indeed have been possessed with Herculean strength.

It was not long before his relations with Finnock, the 
boss, were very much strained. They were both Highlanders, or "Hielandmen," as they termed themselves, and as such held other Scots in some contempt. To them a Lowlander was a "Southern carl " and a "loon." The Lowlanders resented this; but being in a minority, and having all felt the weight of Jeamy's fist, they had to "sing sma,", as Jeamy said. All the Scots here, three excepted, were Highlanders; and, strange to say, they seemed to think it an honour, rather than otherwise, to have been well hammered by their fellow-countryman. At all events they always sided with him against the rest of the camp, and fights among the men were of almost daily occurrence.

M'Cullough professed to doubt that Finnock was a Highlander. "Feennock's no a Hieland neem," he said. "It's mee opeenion that yeer just a tammed Edinborough laddie frae the gutter that's managed to get one foot $o$ ' the steerrup." "And I'll have ye to know that I'm master here, and I'll no permit ye or any other man to speak to me in that way. Just gang about yer business," retorted Finnock. Angry words passed, but nothing came of it on that occasion.

One day, however, when I returned from wandering in the woods, I found the whole camp in great glee. There had been a scuffle between Finnock and $\mathbf{M}^{\prime}$ Cullough, and they had agreed to fight it out; for, as Finnock said, matters had come to such a pass that he could not bide in the camp unless $\mathrm{M}^{\prime}$ Cullough was mastered. Besides, work was being neglected on account of the drinking and quarrelling bouts, and some of the men spent much of the day gambling for drink and card-playing.

Finnock told me that he had challenged $\mathrm{M}^{\prime} \mathrm{Cullough}$ to a regular set-to; "for," said he, "I must thrash him before all the men, or I'll never maintain my authority. If he is best man I'll have to quit the camp." He asked me to be his second, or backer-up, and I knew enough of camp etiquette to be assured that I could not refuse 
without incurring a charge of meanness. For I had arrived with him, and was considered his chum; and, moreover, had let out the fact that I knew something of the noble art of self-defence. In those days I could floor my man if occasion required it.

But I was much concerned for poor Finnock. I had seen enough of Jeamy to perceive that, bully or no bully, he could make himself a very ugly customer to a novice, and knew a trick or two in the gentle science. Finnock, so far from being a fighting man, I thought to be almost without spirit. He disliked the sight of fire-arms, and never used them; nor would he kill any creature, even for food, but always passed that unpleasant necessity to somebody else-not the sort of man, one might well think, to prove much of a fighter. But the unexpected often turns up; and quiet men are always dangerous when provoked.

The next day was a Sunday, and all hands were idlers. There was no respect paid to the day here, not even by the Scots; and the ecstasy of those who expected to see a pleasant spectacle is indescribable. It is no exaggeration to say that the rascals were one and all beside themselves with delight at the prospect of seeing a set-to; but not one of them believed that the boss would stand a shadow of a chance against Fighting Jeamy. It is inexplicable; for Finnock was a decent fellow, and no slave-driver, but not one of the men, except the Chinese cook, seemed at all sorry that their leader was about to be well whipped. I thought it my duty to tell my man that I thought he had not any chance against his antagonist; for I did not like to see him run the risk of being terribly mauled; but he quietly said, "Never fear, laddie. I've seen better men than him knocked out. I'll be killed before I give in; but if I'm beaten I shall have to leave the camp." That was true enough, without doubt; for with such men a beaten boss would have been a mere butt, and his daily life rendered intolerable. 
Great preparations were made: a ring roped off in the regular order, and the freshly fallen snow trod down hard and levelled; and plenty of whisky and water, and more without water, got ready for the refreshment of the combatants and spectators; and about noon the two men entered the ring, stripped to their waists, in the orthodox way. M'Cullough at once made a rush at Finnock, clearly hoping to bear him down and finish the fight off-hand; but the latter skilfully gave ground, and held himself with an easy defence that showed he was no novice, and surprised as much as it delighted me. Jeamy, seeing it necessary to mind his p's and q's, altered his tactics, and went to work more cautiously. There was considerable sparring between the men; but at length Jeamy got in with a nasty blow on the chest that knocked my man flat, and for a moment $I$ feared that he was done for. However, I got him on his pins to time, and whispered him to fight for time to recover his breath. The next round was a short one. Jeamy again got in on Finnock's left peeper (eye) and closed it, the blow being again a knock-down one. Matters began to look very bad for the boss, but the third round changed the aspect somewhat. Finnock struck his opponent a heavy blow on the chin. I heard Jeamy's teeth snap sharply, and blood ran from his mouth, showing that he was badly cut. Some of the surrounding rascals laughed, and Johnny Chinaman clapped his hands and yelled with delight: "Goee, goee, Master Finny! Dat's him; goee, goee!"

The next round was a long, roundabout one, both men fighting cautiously, and evidently afraid of punishment. Ultimately they closed, and Jeamy threw his opponent over the ropes, but was himself dragged over among the spectators. Neither man was much hurt in this round. In the next, James went down to avoid chastisement. The blow on his chin had evidently upset him. He continually mouthed and twisted his lips about; and I hinted to my man that if he could land him another in 
the same place it would settle him. However, for another half-hour the fight went on in a very lukewarm manner. Then Finnock got in with a terrific blow on his antagonist's nose, and Jeamy dropped senseless. The bully was mastered, and it took us an hour, and more, to bring him back to his senses.

All next day he lay in his hut groaning and grunting, and I had to make him a little soup myself, for the vindictive Chinaman would not do it. Jeamy had offended him past forgiveness by nailing his pigtail so firmly to his cook's block that Johnny had to sacrifice some inches of the sublime appendage to get free. As to his boon companions, like the generality of vulgar minds, they turned from the defeated tyrant, and 'were among the first to give him a bad name.

Acting on my advice, the first use Mr. Finnock made of his victory was to let the men plainly know that no more drunken idleness would be tolerated. The huts were searched, and all the whisky and rum taken possession of, and the men only allowed a small quantity when the day's work was over.

Nothing was seen of Jeamy outside his hut for a few days. Whether he was as much hurt as he seemed to be, or whether he was simply shamefaced, I cannot tell; but his face was a picture, though in this respect Finnock was almost as bad. One morning he put his head into my hut. "There's no pad plud between you and I, Measter Founteen?" "Not a drop," replied I, offering my hand. "Praps you'd pe goot enough to mak me a pair o' snoe-shoes; ye seem to be a bit dapper hand at that work?" "Certainly; with pleasure," I replied. "Are you going to take a trip in the woods?" "Yes, I theenk a walk wod be goot for me health." I offered to lend him my snow-shoes, saying that I could soon make another pair. He took them; and that is the last any of us saw of Mr. M'Cullough. When he departed no one knows; but he went. At first I feared that he might 
have met with a misadventure in the forest, but I followed his trail so far on the road to St. Catherine's as to convince me that he was making for that settlement, especially as it was soon discovered that he had taken all the provisions that he could find in the men's huts. We afterwards learned that he safely reached the coast, and departed for Quebec.

I have related this somewhat blackguardly affair, as it gives a good picture of what camp life in the backwoods often is. Kid gloves and refined manners must hold a second place in the wilds of America. The man who comes here must be able to blister his hands without a murmur, and if not exactly a fighting man, should be able to give and take a blow. The Christian precept of resisting not evil is one that $\mathrm{I}$, in common with all men who desire to do what is right, respect; but $\mathrm{I}$ take it as being purely personal in application. The man who has the safety and welfare of a party in his hands must defend their interests at any cost; and is justified, in such circumstances as those I have narrated, in defending, even at the cost of some violence, the charge committed to his care; that is my view.

The departure of $M^{\prime}$ Cullough was a good riddance. The camp became a different place at once. Drunkenness and gambling ceased, and there were no more fights. The men adinitted that they benefited by having the spirits placed under control, and served out to them in moderate quantities when their work was done, the time when they most needed a little stimulant. Men everywhere must be amused in some form, must have some relaxation, and if this is not supplied to them they will fall back on their own resources, and those resources, unfortunately, of men of toil usually take a mistaken turn. It is therefore the bounden duty of a man in charge of others, and who invariably holds his position, or ought to, on account of his superior intelligence, to provide proper amusement for those dependent on him. 
It is surprising how easily, at the expenditure of a little tactful trouble, men can be led. What is required is contrast. Light upon dark. Men whose physical powers have been greatly tried, must have mental relaxation, or the balance is lost, and either health, or morals, are destroyed. No matter how ignorant, how illiterate, men may be, healthful literature always has an attraction for them. If they cannot read, they invariably will listen to him who can, if he will only be at the trouble to put his heart into his reading. Nothing is a success that is done perfunctorily, and discretion is necessary. A man that has been studying closely all day requires outdoor amusements, as football or cricket; he who has been straining every muscle of his body from daybreak to sunset, must assist the rest of his tired frame by having his mind exercised, and that not in a laborious manner. $\mathrm{He}$ is too tired for strong mental exertion. In order to amuse him he must be interested in such a way that he entirely forgets exertion of all kinds. In providing the means of doing this the world's great writers of fiction have done a grand, a noble work, for which their fellowmen can never be too grateful to them. What they have done to prevent crime and lunacy can never be known on this side of the dark river; like all true and good work, theirs is too quiet, too unobtrusive, to be thoroughly appreciated, even by those who most benefit by it. I will prose no more on this subject, but I must record a fact that to my mind is most interesting. There were four books only in camp-the Bible, "Oliver Twist," "The Heart of Midlothian," and "Valentine Vox," and these books were re-read to the assembled toilers several times before the winter was over, for the evenings were long; and in so great reverence were they held, that any man who had ventured to tear a leaf from one of them with which to light his pipe, would have been in some danger of being lynched; he certainly would have been chastised. 


\section{A WINTER WITH THE LUMBERERS 191}

There was not much game in the vicinity of the camp. Though we saw a bear on our journey up, I could find no traces of others. The only large game I killed during the entire time of my stay here was a couple of moose-deer. There was an abundance of grouse, ptarmigan and Canadian grouse, already noticed in another part of the country, but no ducks or geese till the approach of spring, when the latter were especially abundant, as may be guessed from the name of the creek. Throughout the winter there were snow-buntings, or snow-flakes, as the Canadians invariably call them, about our neighbourhood, but I saw no other small birds till March. Then several flocks passed overhead, but I did not succeed in obtaining specimens and therefore cannot name the species. Subsequent to their appearance, there was a heavy fall of snow, and more than a month elapsed before a general thaw set in. In fact this spot proved one of the poorest, from a naturalist's point of view, that I ever stayed at for any length of time; but it should be mentioned that I never wandered more than a few miles from camp, for I suffered excessively from the cold, and was unwell during much of the time of my stay here. Also the ground had been much shot over by the men, who had doubtless thoroughly scared the game.

Once or twice we heard wolves howling at night, and saw their tracks in the snow; but I could never catch sight of any of them, or succeed in trapping them. There were porcupines here, of the species common over nearly the whole of North America, viz. Erethizon dorsatus. I have found this animal on both sides of the continent as far south as the 35 th parallel, and as far to the north as I have wandered. Strange as the fact may seem, this porcupine never hibernates, not even in the most northern part of its habitat. Though it differs much from the tree-porcupines of South America, I have, down to a recent date, considered it to be a tree-porcupine; but I now learn that it is not a true tree-porcupine. Never- 
theless, it is almost entirely arboreal in its habits, leaves of trees forming the chief parts of its food, though it also eats fruits and nuts, particularly beech mast.

It is by far the largest of American porcupines, and I suppose of those of the Old World too, the average weight being eighteen pounds, though individuals have been captured by me which weighed twenty-three. It is an uncouth-looking creature, not at all like the European porcupine, and when huddled up among the branches of a tree resembles a huge bird's nest. It is thickly covered with mingled hair and spines, the latter being short, about three inches in length, on the most exposed parts of the body. It is said that the animal can make a formidable defence against such beasts of prey as the fox and the wolf. I think this is extremely doubtful, for I know that the pole-cat frequently preys on it. It is also eaten by Indians and trappers, and I myself think the flesh superior to that of the rabbit. It is not a prolific animal, having but one at a birth, and occasionally two. It feeds and moves about mostly at night; but during the day makes no attempt to conceal itself, lying asleep in the fork of a branch of the tree where it has been feeding, and may be easily discovered by those who know how to look for it. Those that I have handled while alive never made any attempt to bite; and it seems to me that their sole attempt at defence is to erect their bristles, which makes it difficult for a four-footed animal to attack them. They do, however, fall a prey to animals and the larger birds of prey.

'The spring thaws began in April, and the men, abandoning their axes, were busily engaged dragging the logs to the banks of the stream and throwing them down to be floated to Tadoussac by the current. Tens of thousands of logs are thus sent down; and are generally sawn into planks at the mill before being shipped. Indeed the mills are at work all the winter, 
and the ships are loaded and ready to sail as soon as the ice breaks up. So the logs of this year will probably not be shipped until next season.

The throwing the logs down the steep banks is the hardest, and also the most picturesque, part of the lumberers' labour. It is not performed until the ice breaks ; otherwise the logs would jam, and form barriers in the narrow parts of the stream, an accident which does sometimes happen, and gives a lot of trouble. Though the logs have sometimes to float hundreds of miles to the place where they are formed into rafts, very few, if any, of them are lost.

In May I returned to Quebec, staying on the road a short time at the house of a hospitable Frenchman, but there is nothing in this part of my journey to record, for I was in no condition to attend to the natural history of the district, and I soon quitted Quebec for a short sojourn at home.

On my return to America I went straight to the States, being convinced that the climate of Canada was too severe for me; yet it was not until a year or two later that I became the proprietor of the prairie schooner (travelling store-waggon) so frequently alluded to in my first book. My travels in the northern part of the United States form the subject of the rest of this book; but they were not of such a nature as to admit of a connected narrative. It is rather of the manners and customs of the people that I now treat, but with an eye to the natural objects of the districts through which I passed. 


\section{CHAPTER XVII}

\section{YANKEE-DOODLE}

I HOPE that the heading of this chapter will give none offence. It ought not to, for "Yankee-Doodle" is the national air-the "Marseillaise" of America, the "God save the Stars and Stripes" of this land of liberty and equality. Every schoolboy knows - no he does not. I beg pardon. A certain select few know that the air of "Yankee-Doodle" was originally known as "Moll Rowe in the Morning." A naughty military saw-bones set the words of "YankeeDoodle" to the air of this excessively vulgar song in ridicule of the poor Yankee militia; but need I go on ? Surely everybody knows that the intended ridicule turned to honour, or was turned to honour.

Now I have a great, but not an unqualified, respect for cousin Jonathan. $\mathrm{He}$ is a brave, hospitable fellow, full of good qualities, and with plenty of (perhaps a little too much) go in him. But he has his faults. He thinks a great deal too much of his Stars and Stripes, for one thing, and is too irritable under criticism for another. Nor do I think much of his liberty and equality-not enough to become a citizen of his country, in spite of the fact that I have spent nearly two-thirds of my days there. In fact, in my opinion, an Englishman has double the personal liberty of a Yankee at home-though abroad, I admit, he takes liberty enough. But it is not the institutions of the country so much as the people that are to blame for this. While pretending to despise the pride, exclusiveness, and snobbery of the Old World, there is no country in that Old World where there is 
more slavery to custom and exclusive opinion, than in the United States. A Yank, and more particularly a Southerner, sneers at the aristocracy of birth and blood, but he is confoundedly anxious to know who was your great-grandfather. If the old gentleman was hanged for forgery, you will be an object of interest; if he was hung, drawn, and quartered for high treason, you will be a hero of the first water; but if he was the village " snip" you had better not mention the fact, even though he went to a righteous man's grave.

I shall be told by a certain American critic that I am perpetuating the usual errors against the American people. I know that beforehand. The Yankee, like the Irishman, is never satisfied. The more you concede to him, the more he wants. He thinks that no one can comprehend him and his "institutions," and is sure to quarrel with his criticiser. That I look for; but as the gospel-tenter in the backwoods said to "Kernal " Cracker : "You've got to be converted. You can take it lying down like a lamb, or you can take it standing up like a man; but converted you shall be." So I mean to treat Jonathan like a spoiled child. I am going to state my opinion of him, his ways, and his customs, with a freedom and a cheek all his own. To paraphrase what is often said of my own people, the Yankee, as a rule, knows more of Europe than he knows of his own country. He needs to learn to view himself as others see him.

To begin, the term "Yankee" is applied to the people of the five New England States only. I give it a wider range, and call all people born in the United States Yankees. I have a perfect right to do so, for the term was originally given to all white men, settlers in North America. Everybody has read that the word is supposed to be the Indian attempt to pronounce the name, English. That is an error. The term was first applied to the original Dutch settlers, and "Yanki" is the correct spelling. A yanki is a small kind of galiot, and the Dutch fur- 
traders used craft of this kind to ascend the rivers in search of their Indian customers. The latter transferred the name of the boat to its crew, and called them Yankis, or Yankees, just as Londoners speak of bargees. All Indians invariably speak of the English as Ingleese. There is no $y$ in the Red Man's languages-not in any of them that I have ever heard. If they use the syllables $y a, y e, y i, y o$ or $y u$, or any similar, you may be sure that the words in which they occur are of foreign origin, not the pure language of the Indian. He would not therefore use a $y$ in an attempt to pronounce the word "English." The Dutch word "yanki" is, I believe, now obsolete. It is used by many old writers. Its latest use by an English writer, so far as I have been able to discover, occurs in a little-known novel by Tobias Smollett, "The Modern Don Quixote."

Whence the Yankee inherited one of his most prominent characteristics, his excitability, it is difficult to imagine. $\mathrm{He}$ certainly did not derive it from his English ancestors. There is a great deal of French blood in the land, but not enough to account for the almost mad restlessness of the Yankee who can trace his ancestry, as a citizen, back for three or four or more generations. There is as much Dutch and Gernian stock in the country as French; and it would seem that a great mixture of races is accountable for the peculiarity. Be it as it may, it is certain there is not so much that is purely English left in the American character as is generally supposed on this side of the herring-pond; and though I expect to raise a hornet's-nest by saying it, I have satisfied myself that there are very few American families who can trace their descent from a purely English source.

There are not a more restless and hasty people on earth than the Americans. I soon got at loggerheads with them on the point of "grubbing," to put it straight. I decline to shovel the food into my stomach like coals into a 
cellar to please any man. Our Dickens told the plain truth when he described cousin Jonathan as feeding much like a hog. One of themselves laughingly said that it was a standing joke in his city that a man rushed into an eatingsaloon, hung up his hat, and before it had ceased to swing on the nail, had bolted his dinner, and was ready to go back to business. Now, to my thinking, eating and drinking is one of the chief businesses of life; and I willingly open this weak point to Mr. Critic. Laugh, joke, sneer as you will, I am convinced that the reason, now I am getting old and grey, after a life of excessive hardship, that I have still a hard fist and a jovial temper is, that I have paid a proper respect to the gentleman who has kept my arms and legs going. I do not allow him to be hurried over his work, or to be stinted, or abused, in any form. He has his hour to breakfast, his hour to dinner, and his hour to supper, less not one minute, on any account whatever.

Board is very cheap, or was in my time, in most parts of the States, as well it might be when the boy or girl wished to clear the table by the time I had swallowed two ounces. On this and other accounts I never could endure life in an American town, and I suppose no man ever spent so long a time in the States as I have done and knew less about its big cities. Seriously, I think that the haste with which food is eaten, the number of hot cakes and sweets, and the everlasting iced drinks, cocktails, and mint juleps, are the cause, in great measure, of the dyspepsia and bowel complaints to which Americans are so subject.

A public lecturer in London is reported to have said some time ago that gentlemen in America lived in a perfect fever of hasty business, and the ladies in-clover. $\mathrm{He}$ is quite right. The Yankee is an unqualified idiot over his womankind. The only time he idles is when he is listening, with a silly smirk on his face, to the bombastic gush of his wife. There her ladyship sits, rocking to and fro, and displaying her elaborate tucks and frills, and a 
long skinny leg, not at all like the elegant instep and ankle of a sweet English girl. She passes her opinion on all subjects, feminine or otherwise, and her husband listens to her as to an oracle. She often looks a mere child, even when she is the mother of several children, and her youthful appearance makes her assumption seem the more ridiculous. Yet, ubiquitous as she is in knowledge and self-assertion, you must be cautious in speaking freely with her. No kind of nakedness must be mentioned. I once put my foot into it most terribly by mentioning that I had met a party of German women on a religious pilgrimage, walking with naked legs and feet. Never can I forget the crimson indignation with which the lady flounced out of the room, nor the fury of the gentleman to whom she was engaged, who was fool enough to think I had put a deliberate insult on his fiancée. It seems most ridiculous and childish to an Englishman to be told that he must not refer, before ladies, to chanticleer by his ordinary vulgar cognomen. Nor is there such a thing as a bull in the States. Here he is a gentleman-cow.

But although there is so much silly squeamishness among women in America, they often do and say things that would shock the dear girls of the Old Countryparticularly, they are not at all backward in making matrimonial proposals. I have myself, on at least seven or eight occasions, been directly invited to enter the silken (!) bonds, ungracious brute as I am. Looking up some papers for purpose of reference, I have just come across a letter that I may give here. Of course I withhold name and place, but, extraordinary as the story may seem to English ears, it is perfectly true.

I received a letter from a Mrs. F. K., who some said was a widow, others a divorcee, in which she, in very neat language, proposed that we should join lots. I declined, in a note which $I$ at the time considered a masterpiece of polite diplomacy; yet I must have had some lurking un- 
easiness of mind, for I started on a round with the waggon at once. In two or three days I was caught up by one of those vagabond negroes who are always lurking about American towns, ready to take a journey to the moon or anywhere for a dime.

"'Mornen, Massa Fountain," said this rascal.

"Good morning, Smutball. What do you want?"

"I'se got somefing for you, Massa Fountain. Can I hab a whisky?"

I ordered Cookee, my black servant, to give him half a tumbler of whisky, which he swallowed at a gulp.

"Golly, dat's good! It am delicious."

"Well, what have you got for me, and where is it?"

"It am a lub-letter from Missis K."

Like a certain countryman, I " felt a great confloberation," but Cupid was not the exciting cause. Smutball pulled the lining out of his old hat, and made sundry dives among his rags in search of the missive, and finally produced it from the seat-pocket of his small-clothes. Here it is :

"Paul Fountain,-When I catch you I'll cowhide you till you scream.-Yours, \&c., F. K."

It will surprise nobody to learn that I immediately made tracks for a two thousand miles jaunt in Arizona and other (then) outlandish parts.

Another characteristic of the pure Yankee is the preposterous tales, not to say lies, which he is fond of telling. This trait seems to arise from his boastfulness; he will not be outdone in anything. Sometimes his lies are downright and impudent, often they are mere humour. An Englishman remarked that he had heard they proposed to start a service in London which should take a passenger round the world in forty days. "Bah! that ain't nothing," said a Yankee bystander. "Do you mean to say you think your country can beat it?" "I should think so. Why, there's a shoot-hole down in Alabama where they drop the passenger in and land 'um on the 
top of Fusi-yama in twenty minutes. There's side-shoots for Hong-Kong, Calcutta, and a mint o' places, and the return journey's only fifty cents."

In folly such as this the Yankee, as a rule, will take and give a joke with great good-humour; and he is far from wanting sound good sense in the daily relations of life, as all the world knows; but he is boastful, selfsufficient, and resentful to a degree. He does not cheerfully take a second place when fairly beaten. Take his rifle-shooting as an instance. There were no shots like American shots. They could snuff a candle, drive a nail, feather an "injun," and perform a thousand other impossibles. As to the British rifleman-Lord help him if ever he came before the American boys! Well, Sam sent his contingent to Wimbledon, and they were badly whipped. There were the usual excuses. They had not the pistol-grip to their rifles, were not accustomed to our poor light, \&c. Then we returned the compliment and sent a team to Rush Bottom. Here, in spite of pistolgrips and other fads, they were whipped worse than ever, and we have heard no more of American marksmanship. But we are scarcely forgiven yet for daring to be best men.

In the early part of my career rifle-clubs were very prevalent in America, having a military, or semi-military, organisation; yet a large part of the community treated the members with some ridicule, or at least cracked their little jokes at their expense, particularly in giving the clubs eccentric sobriquets. Thus, I remember, there was the Alabama Crab-feet, and the Indiana Smuttyguard, \&c. In this perhaps the vulgar in America simply resemble ourselves, for during a visit to Plymouth I noticed a street urchin waddle up behind a somewhat untidy-looking soldier and exclaim, "Quack! quack!" Inquiring why he was so rude, "that be one of the Mutley ducks" was the reply. This I found was the sobriquet of the Devon Militia, whose barracks are on Mutley plain. 
The American riflemen seldom wore a uniform, and were more ridiculous from point of numbers and appearance than any other cause that I perceived, for I have more than once seen cripples in their ranks. Often there were more bandsmen than riflemen. Thus, one body consisted of a band of four drums and a dozen brass instruments, followed by a regiment of two officers, four non-coms., and a couple of privates. Remarking on this paucity of numbers to a neighbour who was something of a wit, he said, "The company is certainly rather weak. In my regiment there were thirty generals, fifty colonels, and a hundred majors." "How about sergeants and privates?" "Oh! we did very well without them. They would have made us look too much like a nigger regiment."

Like boys in general, the Yankee boy is precocious. $\mathrm{He}$ becomes a man at a very early age, not only in his own estimation, but in that of his elders also, with the result that, like the women, he is too often spoilt. It is incomprehensible to an Englishman that urchins of twelve or fourteen should be permitted to carry firearms, and use them, threateningly, at least. On one occasion a boy of thirteen presented a loaded revolver, a heavy six-shooter, at me in resentment of a fancied injury, and threatened to let $\mathrm{G}-\mathrm{d}-$ daylight through me; and this in the public street of a town of some size. I was not slow to disarm him, and give him a sound flogging; and, will it be believed, I narrowly escaped being strung up to a lamp-post for so doing. Murders by boys, and even girls, are not unfrequently recorded in the American newspapers. It can scarcely be otherwise where the people are allowed to carry firearms indiscriminately, without either licence or registration.

In the early years of their lives many Americans retain a very youthful appearance; so that it is not unusual to meet people, who do not seem to be out 
of their teens, who are already the parents of families. As a rule, I think that Americans marry too young; and the results are often deplorable enough. A believer myself in divorce for other serious causes than the sole one admitted in England, I yet think that divorce is deplorably frequent in the States generally. It is a dreadful thing to bind a man for life to a drunken woman, and I think the husbands of such creatures fully entitled to a divorce; nor would I permit religious fanatics to bind men on this point; but there are few drunken women in America. The majority of the divorces are for incompatibility - that is, in commonsense parlance, the parties are tired of each other. This is a cause of separation that should be very cautiously admitted. It is very easy for Yankees to boast of the morality of their women when a woman can put away her husband almost at her sweet will. She is thus called a wife when, in most countries, she would be considered simply a mistress.

But apart from this, and in spite of her fantastical prudery, I doubt if the American woman is the superior in virtue to the average European woman. It is a delicate subject, and I shall confine myself here to saying that the domestic hearth in the United States is a far less enchanting place of rest than what it is in dear old England. In fact there very often is no domestic hearth at all in an American family. The wretched custom of living in hotels and lodging-houses is very prevalent in many of the towns of the States; and even in the country, when it has been my desire to live under a roof for a time, I have either kept a bachelor home of my own, or lodged with German or English emigrants who had not yet fallen in with the custom of the land.

I have made these few cursory remarks on the general manners and customs of the people of the United States by way of preface; for much of this book will from this point treat of the Yankees and their peculiar 
ways. It is one of the foibles of the Yankee that no one understands him; that no one is capable of drawing a truthful picture of him and his country but himself. This nonsense I refuse to respect. It is from outside criticism that the truth is to be gleaned; not from the self-conceited opinion of a people themselves. No incident could better illustrate what I mean than one which occurred after I had penned the bulk of this chapter.

It was announced in a London newspaper that a company would shortly be registered to provide the people of this country with American " quick luncheons." The Yankee gentleman who seems to be the founder of this scheme is reported to have said, "Londoners have no idea of what our system is. They think that a quick lunch is something that is thrown at them. But they will discover their mistake when they find how we treat them, and there are pretty well fifty new and tasty dishes which we can offer them which are almost unknown in this city."

This is the language of a man who has a concern to run, and who seems to know very well that the American mode of eating will never be tolerated in this country. The quality of the dishes is not in question. The fact remains that in his own country the average Yank feeds much like a hog-that is, his chief object seems to be to get as much into him as possible in the shortest space of time; and the picture drawn by Dickens of the offensive brute on the river-boat (in "Martin Chuzzlewit") is true to this day.

The fact is, as I have already said, that the Yankee cannot tolerate criticism. He gives no one thanks for praise, or even for flattery; and yet his vanity and self-esteem are such that he imagines himself and his institutions to be too exalted to be understood by benighted, antiquated $E_{u}$-ropeans.

I set down nothing in malice, harsh as my language may seem to those unacquainted with the bounce and 
self-assertion of the men I am writing of. As I do not withhold my admiration for that in Uncle Sam's character which is worthy of him; neither do I feel called on to conceal his faults. I wish to give none offence; but I shall speak plainly since the charge has been made that I have misrepresented lim. I write for those who have not been able to visit America and see for themselves. A stranger in the land is sure of a hospitable welcome; but that is not true which one of their poets has said, that the portals of the United States have never been closed to the "meanest child" of Adam. Apart from the fact that men have been persecuted in America, as in other countries, for mere political or religious opinion, and that Sam's treatment of the negro down to a comparatively recent date was a disgrace to his manhood, the portals of the United States have been closed, or denied, to all who could not show the almighty dollar, and are closed at this hour to those whom misfortune has deprived of the full use of their limbs. Not a month has elapsed since a man was expelled the country because he had lost one of his arms, and it was not until he had shown that he possessed much property in the country (and then with delay and difficulty) that he was permitted to enter it at all. It is to be remembered that, poet or politician, all that Sam says of himself may not be remarkable for its strict veracity. 


\section{CHAP'TER XVIII}

"BEES"

AT the time of my flying visit to my native land, referred to at the close of the sixteenth chapter, I found the country in a state of mild idiotcy regarding one of those foreign fads that, from time to time, obtain such a hold of the English people. This was the "spelling-bee," a Yankee importation; though I am bound to admit that "bees" were rife enough in Canada also. In England there was a mania for spelling-bees, especially at dissenting places of worship, and among certain classes of the swindling fraternity, who for a time reaped a rich harvest from the proceeds of bogus spelling-bees.

Now, in the States, "bees" were not confined to spelling competitions; indeed, the latter was one of the newest innovations. I have not been able to discover how, or when, " bees" originated; but they are nearly and perhaps quite as old an institution as Independence Day. A bee is an assemblage of persons to perform some industrial work for the benefit of a neighbour. That was the original meaning of the thing. An assembling to test persons in spelling is not therefore strictly a bee, as it partakes more of the definition of a competition. But a bee was designed for amusement, as well as employment.

The first "bee" that I ever saw was a husking-bee. I was invited by the lady of the house, who added, in her note, that she intended to introduce me to one of the prettiest girls in the neighbourhood. Not knowing, as yet, what a bee was, I looked with some suspicion 
at the "husking"; but the pretty girl was quite another matter. That bait took, and I went. The house was a lone farm-house in Ohio, in one of the oldest settled parts of the States. The owner was well to do, and had plenty of rich neighbours. There were more than a hundred persons present; and I noticed that the fun of the husking was left to the young unmarried people, few of the elders joining in: these, for the most part, keeping aloof and occupying themselves with the more sedate amusements provided. The hostess was one of the liveliest American ladies that I ever met; and, I may add, the freest from the humbug of prudery; but I was scarcely prepared, considering a recent experience -that of my unfortunate reference to the naked legs and feet of the German fraus-for the amount of licence which was given to the guests on this occasion, or taken by them. It was the time of the "Indian summer," a well-known, and most delightful season in North America, always eagerly looked for; and the husking took place in the open air. It frequently is performed in barns in the winter months; but there is no fixed time for this "frolic," as it is most generally termedthe word "bee" being more in use among the lower classes, as I should call them; but, in my early time at least, one had better have set a match to a barrel of gunpowder than have spoken of lower classes in America. Yet there is no country in the world where there is a class held in greater contempt than the class that is dollarless in the States. There are snobs enough in England; but the man, however poor, who makes a struggle for existence, is treated with some respect: in the States he is a "mean white," until he has made a pile; then there is little inquiry as to his past, unless that past has been notorious, which will probably redound greatly to his credit in the eyes of mammon. The Yankee is a notoriety worshipper, and he likes the notoriety, as an Englishman likes his game-a bit tainted. 
To come back to the husking. The ostensible business was to free the corn of its "cobs." You want to know what a cob is. I will save you the trouble of looking at Daniel Webster: here is what he says"Cob, n. Literally, a head; hence, a rounded mass, as in cobble-stone, cob-coal, \&c.; a thick, strong pony. In America, a spike of maize." There now! am I not a most obliging author? I dispute Daniel's definition as to the pony; but it is with the spike of maize that I have now to deal. The cobs were piled on the ground outside the barns in great heaps, and to each heap a couple of young people were assigned with instructions to "cob away."

My partner was certainly a very pretty young lady, but somewhat insipid in manner. There were rugs and mats on the ground on which we seated ourselves and commenced operations. Scarcely had we done so when some obliging friend buried us both in an armful of cobs, which knocked us into each other's arms; and other parties were subjected to the same treatment. There was much uproarious laughter, screaming, struggling, kissing, and what not; and a fine display of frilled stockings. Those that were old hands at a "frolic" of this kind were in no hurry to release themselves, and some remained buried an unconscionably long time. Indeed, some were so quiescent under the heap that I feared an accident had occurred, and was for rendering assistance, until I was politely told to mind my own business, and informed that the rule was for each couple to release themselves. I began to see the spirit of the fun, and perceived that my partner was none too pleased at the promptitude with which I removed the superincumbent cobs. However, a second load was soon over us, and the surprise with which I had previously noticed the shabby apparel of the guests vanished. The coats of some of us were soon almost in tatters, and the dresses of the ladies in no better plight. 
It should be distinctly understood that there was no person present at this scene that did not occupy a more than ordinary good position in life. For the most part they were rich farmers, or their sons and daughters-persons with, as a rule, a far better education than their compeers in the old country. The married people were those responsible for throwing the cobs over the young couples. I did not perceive that any married lady or gentleman was subjected to this very remarkable -I will not say questionable_-proceeding; but certainly nobody present was shocked at it. All was merriment and good-hurnour, and, coarse as were the proceedings, there was nothing offensive in the language of the parties engaged in them. There was not a person of inferior position present. I dwell on this point, because often as "the Britisher" is charged with snobbery, his ill-breeding in this respect fades into nothingness when compared with that of his Yankee cousin. A gentleman in England never hesitates to plainly say that he cannot afford a thing if he is too poor to indulge in it, be it a mere day's excursion, or the shooting over twenty thousand acres, or any other luxury; but the person in the States who should say he cannot afford this or that, would practically ruin himself from a social stand-point. The American is the most thoroughly purse-proud man that I have ever met; and hospitable and free as he is with his friends, he is a thorough snob to his inferiors.

There is no doubt a change, of a sort, in the manners of the States in recent years; but it is not sufficiently marked to make the above charge an unjust one. When I first set foot on American soil there was scarcely a man in the land who would wear a livery for love or gold, and the few who condescended to do so were scouted as dogs by all classes, even by their employers; for it was considered that the man had sunk himself to the level of a "nigger," the blacks usually furnishing the whole class of domestic servants, liveried or otherwise. There was 
no such thing as a white man's master in the land; and it is certain that, in the ranks of the army, there are instances on record of soldiers having punched their officers' heads, and yet escaped punishment. The word "boss" was originally a semi-contemptuous one applied to the leader of a gang or party of workers of any sort. Some substitute for the word "Inaster "-being required by those who objected to the term, the epithet "boss" was conferred on an employer. The word is said to be derived from the Dutch term baas.

The fun was kept up all night at our husking-bee, there being a somewhat liberal indulgence in wine and whisky, and more than one gentleman being "merry" long before the first grey light-streaks of dawning day warned the company that it was time to disperse. I, and others who had a long way to go to reach home, were obligingly provided with beds by our kind host, but the immediate neighbours returned to their own houses. No fewer than three of them were kind enough to invite me to frolics, otherwise bees, that were about to take place on their farms.

At these frolics there is always a good deal of drinking. I never attended one at which there was not a quantity of whisky consumed. Other drink, consisting of wine, \&c., among the well-to-do, and "ciderroyal " among the poorer farmers, is generally as plentiful as water. This cider-royal is terrible stuff, and will make a man drunk sooner than strong ale. This is said to be owing to its having been stored in spiritcasks to make it keep, but I strongly suspect that spirits are actually added to it. Strangers to the country should avoid it, as it is very apt to cause serious bowel-trouble. Cakes and sweets galore also form an important item of the feast, the Yankee being as fond of jam as a child.

I have no desire to indulge in persiflage; but the Americans themselves say that these frolics are often the source of trouble in families. Marriages are made up at, 
and take place after them; but these marriages are too often a necessity to save character. I was myself cognisant of a case in which the lady waited on her beau with a six-shooter, and informed him that if he did not at once sign a paper promising to marry her within a specified time, she would shoot him and herself. The marriage took place, but it was not a happy one. My host mentioned a similar incident, and several in which male relations of the ladies had forced, at the revolver's muzzle, erring lovers to repair their errors.

Among the most common frolics, after the huskingbee, are the apple-paring,' and the sewing- and spelling-bees. The two latter are mostly practised in meeting-houses, under the auspices of the parson and his wife; but the apple-paring is as important an event as the cornhusking. In America, as every one knows, the apples intended for storing are skinned, cored, strung upon strings, and hung up to dry. Invitations are issued to the apple-paring-bee, as to the corn-husking; and there is more real work done here than at any other kind of frolic. The apples must be pared; but, as a rule, very few cobs are husked; and at most of the other bees there is more fun and play than work.

Apart from bees and frolics, there is very little work about an American homestead that the neighbours will not willingly assemble to perform at the shortest notice for the settler who is short-handed or otherwise pressed for labour. Indeed the services are generally offered without waiting for solicitation, as I have already instanced in the erection of the log-hut. This is one of the most honourable and beneficent characteristics of the Yankee, and he deserves the greatest praise for it. No selfish consideration will induce him to withhold his hand when the stranger or his neighbour has need of his help. I have even known men willingly help neighbours with whom they were on such bad terms that they scarcely spoke together. But in the hour 
of need enmity is forgotten; and no man's crops or cattle are left to be lost because his neighbours are not on good terms with him.

These offers of services are sometimes rather embarrassing to an Englishman. For instance, I rented a small house for a few months in Ohio State, and proceeded to "do for" myself in true bachelor fashion. One night, some hours after darkness had set in, there came a gentle knock at the door. I should mention that, quite contrary to the custom of the land, I had put a lock on my door, and kept it fastened, as I did not approve of the continual intrusion of my neighbours. This subjected me to a great deal of chaff and some sarcasm.

Well, I opened the door, and there stood a bevy of five buxom lasses, the daughters of my neighbours. Without ceremony they entered, mentioned that they had come to set me straight, did my household work, took charge of my linen to wash-and in a word, did all that a troop of sisters might, or could, have done. The kindness of this will be better understood when it is considered that these girls had already done a long day's work on their own homesteads, and had come to help me at a time when they must have been tired and needed rest; for women on American farms do work to which they ought not to be subjected, and which, though often performed by countrywomen in my native land, is generally considered, and rightly, to be man's work.

The lock very soon came off my door that these dear creatures might come in and out at their pleasure, and do the work at their convenience. No American girl hesitates to enter the house of a bachelor; even women of a superior station will call alone on a gentleman at his hotel or house. No American man would misunderstand a custom so at variance with our ideas of propriety, and no American would dream of attempting to take an advantage of it. In the whole of 
my experience of the country I never so much as heard of such an attempt. In fact, a woman in America may go anywhere, and do almost anything, without the least fear of being subjected to insult or injury. Whatever I have said, or may think, of some of Uncle Sam's funny ways, I should be unworthy of the hospitality which I have received in his land if I failed to acknowledge his extreme honourableness in this matter. If ever woman is subjected to outrage or insult in the States, it may at once be concluded that the offender is either a man of colour or some recently arrived blackguard from a country that was glad to get rid of him. What Sam thinks of such human vermin is shown by the promptitude with which he strings them up to the lamp-posts-the very best thing that can be done with such wretches.

By-the-by, I may mention that my habit of speaking of the United States shortly as the States is consonant with the custom of the country. They are always, except in official documents, spoken of as the States par excellence, no other State in the world being at all comparable to them. 


\section{CHAP'TER XIX}

\section{THE OHIO DISTRICT}

IT is not part of the plan of this work to give a geographic description of Ohio or any other of the United States; but having wandered through the basin of the great lakes on the Northern or Canadian side, we have now a similar journey to describe on the Southern or States side, or rather the results of a series of wanderings in this district. It is here impossible for me to present a detailed and consecutive narrative of journeys for several reasons, the chief of which are, that I do not undertake to give a description of long settled and thickly inhabited country, but confine my attention to wilds and wildernesses only; and secondly, these observations were not all made at one time, but at several periods, with long intervals of time between them.

Roughly speaking, Ohio appears to me to have originally presented to the eye three marked descriptions of ground-prairie, mountain, and swamp. The mountains are to the eastward, being part of the northern continuation of the Alleghany range. The prairie, in my time, was a succession of forests and savannahs, differing from the prairies of the Mississippi Valley, and was, I think, before the meddlesome hand of man interfered, an unbroken forest. I am much mistaken if those openings, now called prairies, were not caused by extensive forest fires, and, if left to Nature, I am sure the forest would again gradually cover them. Beech timber predominates in these forests, and the mast is invaluable for feeding hogs, of which animal there are enormous numbers in the 
State. Many of them have escaped from captivity, and are living wild in the woods; but many also, bred wild, join the tame herds, and find their way into the pork and sausage factories of Chicago and other large towns; and in the early days of the city there were ownerless pigs wandering about the streets like pariah dogs. These were the property of anybody who could catch them; and some were made pets of by the citizens, and children inight be seen riding about on their backs. Bacon, or salt pork, is sometimes the only meat tasted by the outlying settlers and backwoodsmen from year's end to year's end, and there can be no better food for men living a rough and exposed life. Fat pork is not only a preventive, but a cure also for muscular rheumatism brought on by hard work and exposure.

The marshes and swamps in Ohio are rather extensive in places, the principal being in the neighbourhood of Lake Erie and along the River Ohio. Many of the marshes are old beaver-meadows, but the beavers have long since disappeared, for Ohio is one of the most thickly peopled of the States. The beaver-meadows contain the richest soil in the entire region.

The mountains commence abruptly on the east, and are very steep, but none of them seem to attain a great height. Judging by the eye, I should say none of them exceed twelve or thirteen hundred feet in height. Of course a reference to a gazetteer would settle the point; but I set down my impressions, whether they be right or wrong, without consulting books. The book may be right, and I wrong, or the reverse: in any case, borrowed information can be of no value.

There are portions of the plains that look to be absolutely flat. The eye cannot detect the slightest undulation. In a ride of many miles I did not see a hillock of a foot in height, nor could I perceive a hollow that would contain a bucketful of water. This district, I think, must formerly have been a portion of the bed of 
the lake. According to soundings which I have made, there are portions of Erie and the other great lakes where there are extensive areas similar to this, for not the slightest variation in the depth of the soundings could be detected.

This rough description of the country will suffice. Only the particular spots I have to describe need a more minute description. Nearly all the small birds and mammals mentioned in the account of the North-West and Canada are found in this State, some more abundantly, others much less so, than in those regions. But there is one bird of larger size that was formerly so abundant in this State, and bred here in such vast numbers, that I consider that I am justified in considering Ohio as its headquarters. That bird, so far as its general history, at all events, is concerned, is one of the most interesting of all American birds. I refer to the passenger pigeon, Ectopistes migratorius or migratoria, as American naturalists spell it. An immense amount of matter about this bird has been written, and it is famous in both history and fiction; and as may well be believed, in such circumstances, all is not correct that has been recorded of it. This is my justification for adding my mite to a subject already almost exhausted; and the fact that I cannot find a popular work on Natural History in which there is a good and correct account of this bird.

In this part of America-that is, the countries bordering on the southern shores of Lakes Erie, Huron, and Michigan; in other words, the northern parts of the States of New York, New Jersey, Pennsylvania, Ohio, \&c.- the woods consist largely, sometimes almost entirely, of beech trees, and the beech mast, as the seeds are called, attracts immense numbers of birds (as well as small mammals) which are not found so abundantly in other parts of the States. Amongst these birds the passengerpigeon holds the foremost place.

Probably no bird, large or small, not even starlings, 
or sparrows, ever multiplied so fast as these pigeons used to do. Certainly no bird ever assembled in such vast multitudes. A relative of mine, a retired naval captain, who settled in Ohio, has left it on record that in the year 1835 he saw a flock of these pigeons which was at least thirty miles long by four or five broad. No total eclipse of the sun that the captain had ever witnessed threw a deeper shadow on the earth. Daylight could not be seen through the flock anywhere except near its margin; the birds therefore must have been flying hundreds thick, one above the other. A very little calculation will show that the numbers of such a flock could only be estimated by hundreds of millions. Again in later years, 1837-38-39, and in 1843-48, the captain has left it on record that he saw immense numbers of pigeons, but remarks that each year the flocks were smaller, and accounts for that fact by saying that the wanton slaughter of the old and young birds was the cause.

The descriptions of the breeding-places of the passenger-pigeons given in modern books, and of those which I myself saw, can give no idea of what they were in former days. Many writers affirm that the great branches of the trees were broken down so extensively as to cause the death of hundreds of square miles of forest. Wilson says that the dung alone of the birds had this effect; but that is an assertion that $I$ cannot credit. Now, the nests are scattered about a certain area of forest, generally two or three per tree, with here and there a tree containing a dozen or more. Formerly the trees were crowded with nests, inasmuch that it paid to fell the trees to obtain the young birds. Those that were old enough to be eaten were put in sacks, the younger were wantonly thrown to the pigs. The old birds were slaughtered in a different way. Of that presently.

The mast, or beech nuts, lying on the ground, under the snow, all the winter, is in a swollen condition, ready to burst into shoot early in the spring - that is, generally 
about the beginning of April. It is when in this condition that it is most acceptable to the pigeons. It is not every year that there is an abundance of beech nuts. When they are scanty the birds move to another district when the first brood of young ones are reared; but when the nuts are abundant they raise two or more broods in the same nests. They always breed several times each season, and more frequently when food is abundant than when it is scarce. The number of eggs laid to each sitting is invariably two, and the eggs are a pure chalkwhite in colour. The hen sits very close, and if she loses her mate will starve to death rather than leave her eggs; but the cock, who feeds her on the nest, does not roost in the tree with her, or on trees at all. Strange to relate, the cocks go nightly to the juniper-swamps, and roost on the bushes, within a dozen or sixteen feet of the ground, breaking down the bushes by hundreds, as I have myself witnessed. This habit is a cause of tens of thousands of them being destroyed by being knocked down at night with poles. They are also netted in myriads; but the killing with poles is the favourite way with the lower classes of slaughterers, and with rough boys. Formerly the pigeon-murder was designated, like the corn-cobbing, "a frolic"; but now the pigeons are not in sufficient numbers, and wander so much from their old breeding-places that there are pigeon-frolics no more.

At these frolics the slaughter was simply awful; and it is marvellous that the Creator of these birds did not visit with a judgment the wanton murderers. Millions of the birds were killed from pure love of blood. It must have been so, for they were left to rot on the ground. The herds of pigs battened on the carcasses till, in some instances, they were too much gorged to move, and in others were driven to another part of the forest lest they should kill themselves with satiety. Every child who could handle a gun-and children of nine or ten years 
shoot in America-ran to the frolic; but on the whole there was but little shooting. The birds were not worth powder and shot, and could be killed so much more easily and cheaply, especially those that roosted in the juniper bushes, though, I should state, their roosts were not confined exclusively to junipers. For other bushes are frequently chosen, especially alders, which, for some reason or other that I have not been able to discover, invariably flourish greatly in the old beaver-meadows. Here, besides those that are killed with poles, or netted, others are suffocated with sulphur, or destroyed by equally cowardly means; in a word, formerly the people of the districts where the pigeons appeared acted as if they held a special commission to exterminate them in all haste. During the killing, which always took place at night, the birds behaved with remarkable stupidity. They never attempted to escape to the tall trees, but as fast as they were beaten down fluttered back to the bushes.

The days after the slaughter the slayers would go "pigeon-peddling," as the hawking of them about the country to those who were too idle, or lived too far off, to kill for themselves, was called. In the States all sorts of itinerant trading is termed peddling, whether performed on foot or with a waggon. One never hears of such a thing as a hawker. The birds were sold cheaply enough; but I have never heard that their flesh was held in much esteem. It is much like that of other pigeons; that is, of no particular flavour. The majority of those killed on the bushes are young of the first brood, which the old ones will not permit to roost on the breeding-trees. Most of the old cocks, which also roost on the bushes, make their escape when the attack begins.

Now, according to my experience, the birds both breed and feed in a more scattered manner than appears to have been the case in former generations. They still breed within certain areas; but they, as far as I can learn, never return to an old breeding-place-at least 
until many years have elapsed. Isolated pairs are now frequently met with: this seems never to have been the case formerly.

The passenger-pigeon comes from the south to breed in the beech woods, and returns thither when that duty is over; but the particular countries whence they come and whither they go are unknown to me. I have never seen these birds in flocks in any parts of America but the districts I have mentioned. I have met with a few in the Southern parts of the States named, but I never saw any in Canada or other parts of the British possessions. The nest is a flimsy construction of straw, scarcely substantial enough to support the eggs. The passengerpigeons are quarrelsome among themselves, like most other pigeons; and the cock bird is a great tyrant to his hen and her young. It is he who forces the young to leave the nest-often before they are strong enough to properly look after themselves. In the struggles which take place many eggs are broken or thrown out of the nest.

The migrations of the passenger-pigeons are always followed by great numbers of hawks and owls, which prey freely on them; and many also fall victims to small preying mammals, as raccoons and polecats. It is surprising that birds so much persecuted, and laying so small a number as two eggs in a clutch, should propagate in such vast numbers; and a conclusive piece of evidence that other causes than those usually surmised by men of science are at work to regulate the balance of species. It has been said that the passenger-pigeon is in no immediate danger of extinction. I hold a different opinion. It is, unfortunately, a fact that towards the conclusion of its existence a species gets wiped out very suddenly. The year before the last bison was destroyed, to my knowledge it was asserted that, though the animal required protection, it was in no immediate danger of disappearing from the prairies. Thirty years ago the passenger-pigeon was still 
abundant, though the millions of the previous thirty years were no longer to be found. Thirty years hence we shall probably have reached the last passenger, unless something is speedily done to save the race.

The forests of this region deserve a passing notice, for they are very typical American forests. In the beech woods I have been describing, as well as in all other forests in this part of North America, there is no underwood, and indeed no undergrowth of any kind, not even grass. The ground underneath the trees is composed of the decayed leaves of thousands of years, and in many parts there is a great depth of pure leaf-mould. I cannot say to what depth this mould extends in the virgin forest, but $I$ have dug into it to a depth of sixteen feet in my search for fossils. No wonder the cleared ground requires but scratching to prepare it to nourish the most luxuriant crops. The only encumbrances on the ground are the remains of trees and branches which have been torn down in storms and tornadoes. These, and the trunks of the standing trees, are often covered with moss ; but any sort of creeping plant in the depths of the forest is very rare. The seeds of the trees, as beech mast, or nuts, and acorns, of course fall to the ground every year, and these annually sprout. They are the children of a year only. The life is choked out of all except the few which happen to have fallen where there is a gap in the forest caused by the death of some ancient tree, or its destruction by a storm. At such a spot there is a struggle among the saplings, the strongest winning and occupying the vacant gap, choking in its growth the life out of its competitors.

Where any one species of tree predominates it holds its own, usually utterly excluding all others, as in the beech woods of this region for instance; but if by any chance a portion of the forest is destroyed, if only half an acre in extent, the species of tree which springs up to fill the gap will be quite different from that of the surrounding forest. This is a strange circumstance, as is the fact that 
if the ground anywhere within the limit of the forest becomes permanently swampy, the trees die and the ground falls under the dominion of alder and juniper bushes. Wherever these are found, however, in this district, there has been a beaver-dam. In other parts the cedar tree occupies the swamps, and often grows so closely together that a man cannot force his body between the trunks of adjoining trees.

On the whole, the trees here are much finer in growth than in English close woods; and beneath them the light is dim to a degree that I have never noticed in English woods. The gloom of an American forest is, indeed, intense; and there is, as in most close forests, an almost total absence of animal life.

How it may be at this day I cannot say, but at the time of which I am writing, now more than thirty years since, there were still forests of many miles in extent. I mean unbroken, primeval forest; the only kind of which I use the word forest in any of my writings. When man has violated them with "clearings" they cease to be forests in my opinion, and become mere parks or woods. In speaking of the forests generally, I am compelled to put strong control on my feelings, lest I should be betrayed into a strength of language which the reader would find it difficult to understand; for I look upon the wanton destruction of trees as a crime, as a sin, of a heinous character, as I do on the unnecessary and useless destruction of animal life. To me it is an abomination for man to consider any of the natural productions of the earth as an encumbrance thereon. Yet thousands, yea, at least tens of thousands of square miles of timber have been destroyed by fire in the States and the British possessions during the last century alone, the sole object being to clear the land. This timber, if it could have been cut, would have produced tens of millions of pounds in England and other parts of Europe; and it would have been felled for use had it not lain far from conveyance by 
water to a port. But this is no excuse for its wanton destruction; it ought to have been reserved for future generations. The prosperity of a few individuals is not to be weighed against the welfare of coming thousands. No man should be permitted to take up thousands of acres to-day because they can be spared now. There is a future to consider; and he who selfishly denudes the earth to the cost of his descendants deserves to be execrated. Enough: if any man were sentenced to the gallows for wantonly firing a forest, I, at least, would not raise a hand to save him.

The mischief was, that a man having a few acres to clear, and firing them for the purpose, often lost control of the fire; and though his neighbours assisted at "the frolic," it often happened that the flames travelled many miles in the unclaimed, and unallotted forest, and nobody cared. In such cases the fire ranged without check until it came to a watercourse of sufficient breadth to prevent its passage-that is, one of at least a hundred yards in width; for if there happened to be a wind blowing it would carry sparks, and even sheets of flame, fully that distance.

Of the trees of these northern forests I can say little but that next to beech, pine of the sort called white pine here, is most abundant; then oak, and in much less quantities, maple, larch, \&c., with cedars, alder, and juniper in the swamps. The two last cannot be called timber trees, though both grow to a size to be useful for certain purposes.

On the high grounds which bound the Ohio valley the forests assume quite a different character. They are more open, or park like, with brushwood and grass under the trees. Here there are many pretty flowers; but you will search in vain for wild flowers in the beech woods. I do not remember ever seeing the smallest flower in the depth of the gloomy forests. It is evident that neither flowers nor weeds will flourish where they are deprived of 
light. On the heights, in addition to many other trees, walnuts, chestnuts, oaks, and sycamores are conspicuous; and everywhere, even in the forests of the plains, odd pine trees are found. But it is singular that growing wild-that is, self-planted-each species of tree as a rule keeps to its own territory. Many of the pines grow in what are called pine-barrens. Here the soil is supposed to be wretchedly poor, and is always waterless; and you will look in vain for trees of other species.

Animal life in the depths of the forest is very scanty, more so even than in the northern Canadian forests, a fact for which I can advance no probable surmise. Small birds are quite absent; not a single species breeds after you have fairly entered the forest, though a few haunt the outskirts. Rattlesnakes are still found in outlying portions of the State, but neither these nor any other snakes were ever seen by me in the forests. There are a few bull-frogs in the cedar swamps; but these batrachians prefer the woodland ponds where they obtain plenty of light. They are always found in such ponds unless there are no fish in them, which sometimes happens. A few loons haunted the ponds of Ohio at the time of which I am writing, and there would probably have been more had they not been so persecuted.

Although there are no small-bird inhabitants actually in the forest, a few are occasionally seen as they pass on their way in their migrations. But they never make more than a temporary halt. The birds which I have found to frequent the interior of the great primeval forests are two species of grouse: the Canadian Canachites canadensis, here called the New England partridge; and the ruffed grouse, Bonasa umbellus. Neither of these birds seems to breed within the forest, though they do on the outskirts; and the attraction that induces them to visit the gloom of the interior is a mystery that I could not fathom. Possibly they feed on some of the wild fruits of the trees; for an odd wild plum or wild 
cherry-tree is now and then met with. Moreover these birds, like all others found in the like habitat, are very scarce. It is evidently only a few of them that penetrate beyond the outskirts of the forest.

There are also woodpeckers in the recesses of the forest; yet even these naturally wood-seeking birds do not seem to be numerous, though they are difficult to discover. You hear them tapping the trees; but though they cannot have been much disturbed by man, they are so extremely cautious that you may look for a bird that is close at hand for an hour, and then not discover it. There are at least a dozen species in these forests, some green, some grey, and some variegated; but I obtained, and therefore identified, but very few of them. Amongst the best known was the flicker, or golden-winged woodpecker, Colaptes auratus, and a bird known locally as "the marshal," and sometimes "the soldier," the specific name of which I have not, I tind, any record. It is a very gaudy woodpecker with a great deal of scarlet in the colour of its plumage.

There are also owls in these forests, the long-eared, Asio americanus, which does not, in my opinion, differ from Asio otus. It may be described as a local variety of that bird. There are several other species, or varieties, of owls; but these I cannot identify with certainty, the gloom of the forest making it exceedingly difficult to recognise a bird when seen, perhaps, but for a moment.

Among mammals the commonest are squirrels, grey and black; most of the other small animals of this region being nocturnal and therefore rarely seen. The polecat (Mustela americana) is the most conspicuous of these. There are also chipmunks (Tamias striatus), but I am not sure that I have given the absolutely correct specific name of this little animal, because the chipmunk of the Ohio forests seemed to vary somewhat from the common chipmunk found farther south; also there were clearly local varieties even in this limited district. 
Besides the chipmunks there appeared to be little for the polecats to prey on. Probably they rob the nests of the woodpeckers, and may find some small nocturnals that escaped my notice. It is almost impossible to make observations at night in these forests, for even when the moon is at the full the darkness is almost absolute. It would have escaped my notice that there were polecats had I not caught one in a trap. Then by careful watching in the early evening I discovered others in the trees. It should be observed, however, that the polecat is not a strictly nocturnal animal.

The chipmunk, which is a ground squirrel, finds an abundance of food in these forests. I found many of their stores of winter food, generally under the hollow roots of trees, and well buried to the depths of five, six, or even as much as eight feet. There were generally from two to three quarts of food in a store, but in some I found five or six quarts, consisting of acorns, hickory nuts, beech mast, and a few kinds of nuts and seeds which I could not name. There was nothing of the nature of grain, but the farmers say that these animals, in the neighbourhood of homesteads, cause them considerable loss by carrying away the corn. They are spiteful little animals, and will bite severely if they get the chance. Though I have been very successful in taming all sorts of animals and birds, I never succeeded in winning the least regard from a chipmunk. With a polecat I have been more successful, since I tamed one to the degree of noticing my approach, and climbing about my person. $\mathrm{He}$ would also utter a little, softsounding cry when he wished to attract my attention.

There were said to be a few wolves still surviving in these forests at this time, but I never saw the least sign of them, nor do I see how they could have obtained sustenance in such scantily provided woods. Had any been there they would certainly have been driven by hunger to make their appearance among the herds of 
swine in the occupied forests, especially as the wolf, like the bear, is a dear lover of pork.

I have already mentioned the beaver-meadows which abound everywhere in this country, even in the forests, where there is now no trace of running water; while along the banks of the streams the whole of the land shows traces of the handiwork of these little animals. It was also said that a few beavers still survived the persecution to which they had been subjected; but though I made a careful search I could not find a single beaver, or the recent traces of one. The fact is that had any been discovered, not many hours would have elapsed before some prowling "hunter" of the drinking-saloon type had bagged the lot. At this hour it may safely be prophesied that not a single wolf or beaver remains in any of the older States of the Union.

I spent many days wandering about these woods and the country generally, often lying on the ground at night in the awe-inspiring gloom of the never, or rarely, visited forest, but sometimes lodging at isolated farms and huts, where I was always sure of a hospitable welcome. There was nothing in this life to warrant my presenting a narrative to the reader in journal or any other form. Though I was often many miles from a habitation of any sort, I never but once met with a serious adventure. I was one evening approaching a farm where I intended to ask a night's welcome, when I perceived two stalwart fellows leave the door and come in my direction. I had had sufficient experience to perceive that they were tender-feet, or worthless characters, and I tried to avoid them by making a detour, the house being still half a mile distant, but they made straight for me.

"I say, boss, you ain't got a bit of 'bacca, have you? A bit as big as a bee 'ul do," began the first rascal.

"I don't smoke," I said shortly.

"Look here, boss," said the first fellow while the other 
gave me a wink, which I interpreted to mean, "hear him: he's a knowing one." "Look here, boss, we're a couple of poor ranchmen down on our luck. Lend us a couple of dollars."

I hesitated a moment, but I tugged out a couple of dollars, and threw them to them, for I would not give them the advantage of coming close enough to take them. "Thank you for your politeness," said the fellow as he stooped to pick them up. "Now my mate ain't got a six-shooter. Suppose you lend him yours."

This impudent proposal brought my blood up in an instant. I whipped out my six-shooter, exclaiming, "To the devil with you, you scamps! If you are not off in an instant, I will shoot the pair of you."

"Oh, I see you understand the joke," said the spokesman, and the two rascals went off laughing. I never felt more wicked in my life, and it is a wonder that I did not shoot them. Whatever the consequences, I would never have suffered myself to be disarmed by such a brace of rogues.

The American tramp is a ticklish scoundrel to deal with. A few years later a gentleman whom I knew well, residing in Spark Street, Ottawa-almost as noted a thoroughfare in that city as Regent Street in London -was stuck up by a tramp in his shop, and coerced into giving him alms. This fellow frightened several shopkeepers into "forking out," but he met his match in the outskirts of the town. There he called on a young Yankee woman who happened to be alone in the house engaged in ironing linen. She knocked Mr. Tramp down with a hot iron, and according to the policeman who arrested him, "left a remarkably good trade-mark on his back to show the devil when he went home." In plainer terms, she ironed him out.

The professional tramp is everywhere an impudent brute, but in the States he surpasses his brethren of Europe by an immeasurable amount of daring insolence. 
$\mathrm{He}$ is always armed, and though he may not draw his six-shooter at his first demand, a refusal is sure to make that weapon fly from its case. His demands are outrageous. At outlying farms he not only frequently demands food and drink of the best that the house contains, but a night's lodgings as well. I have even met with an instance where he compelled his involuntary host to supply him with a suit of clothes, and rejected the neckcloth because it was not bright enough in colour to suit his taste. Of course this sort of thing is only tried on at isolated homesteads, where the tramp's instinct informs him the boss is not made of fighting stuff. He is really as paltry a wretch here as elsewhere, and when he thinks his bounce will not frighten, he whines like a young puppy. His "firing-iron" is intended to intimidate, more than for really bloody work, even in self-defence; for your thoroughgoing tramp has a most wholesome dread of that fictitious legal gentleman, Mr. Lynch.

The farm where I had the little adventure with the two tramps happened to be the property of an Englishman, and I was so warmly received by him that I could not resist his pressing invitation to remain several days in his house. Part of his land was still covered with unbroken forest, and while I was with him he "burned off" a patch some eighty acres in extent. It was the height of summer, and the timber burnt with great fury. All the trees had previously been felled and cleared of their great limbs, and sawn into sections about twelve feet long. This had been done the previous year, and the work must have been laborious and taken much time. I was surprised that the wood had not been burned as it stood, not being experienced then; but if this is done the charred standing trunks become so hard that an axe makes scarcely any impression on them, and it becomes almost impossible to clear the ground of the débris. Hence, when the ground is wanted for agricul- 
tural purposes the trees are always cut down previously to burning. I discovered afterwards that the calcined trunks of burned trees will stand for many years. The burning off of land is supposed to add greatly to its productive qualities: I doubt if it does anything of the kind. My opinion of the proceeding has already been given.

I afterwards became more familiar with these burnings off, and also with those forest conflagrations which are the result of accident or mischievous design. The fierceness with which the fires rage is almost incredible. If there is a wind blowing at the time the rush of flame completely stops it, and the roar resembles in sound a continuous deep roll of thunder. It is so loud that the voice cannot be heard unless one shouts. The flames shoot up perpendicularly, and great sheets of fire seem to be flung off in a kind of explosion. Masses of glowing branches fly about, evidently driven by the combustion of gases; and are sometimes projected nearly a hundred yards. So the danger to houses or stock in the neighbourhood may be conceived. There are nearly always wild animals in the burning patch, and these and the birds seem to completely lose their heads with terror. Hundreds perish which ought to escape; the birds especially, wheeling round and round, and finally dropping, suffocated, into the black smoke, which hangs heavily around the base of the burning mass.

Such animals as foxes and raccoons will appear at the edge of the fiery area, and then, appearing to fear some new danger ahead, crouch paralysed until they are literally roasted alive. Not one in ten escapes, and of those which I have picked up under such circumstances several afterwards died of fright. Few, however, can be approached on account of the intense heat, which no doubt is one of the bewildering causes. I have never seen deer driven from the forests by fire, but on the prairies they run before it until its near approach causes them to become paralysed. 
These forest fires have leen known to rage for six or seven weeks at a time, and hundreds of lives have been lost in a single fire. In a country where there are no big rivers, and the forest is continuous, only a heavy rain will stop the fire; for when it has once got a fair hold on the timber, man is powerless. It travels so fast that it is often exceedingly difficult to get out of its way. 


\section{CHAPTER XX}

SHAKERS AND RELIGIOUS MUMMERS IN AMERICA.

AN account of religious fanatics may at first sight appear to be out of place in a work professing to deal with the wildernesses of a country; but the sects of religious mountebanks in North America are so numerous and so extraordinary in their antics that even a writer dealing with the wild natural scenery of the country can easily be pardoned, if not justified, in dealing with a subject so interesting, especially in the face of the interest aroused by the trouble the Doukhobors are giving in Manitoba at the present moment. Moreover, many of these sects, driven from among their fellow-men, have sought the wilderness, like wild things of the earth, and there prospered and gained their strength.

It may be objected, perhaps, that these sects did not take their rise in America. That, in some cases, may be true enough, but they all found a congenial soil there. The American is excitable in his religion as in most other things; and a novelty in religion, or in vice, is sure to attract his attention, and probably something more than his attention.

As to the Doukhobors of the present day, I know nothing of them beside what, in common with the rest of the public, I have gleaned from the newspapers. They are said to be Russians by nationality, and have probably taken root in American soil since I left this part of America. I think I have read, or heard, something of their peculiar views many years ago, as being prevalent among certain Asiatic tribes long before the 
advent of the Christian era; indeed there is nothing very new in the doctrines of any of these mummers.

That many of these fanatics, though their state of mind seems to border on insanity, are perfectly genuine, so far as their personal conviction is concerned, it would be unjust to doubt. But I think their leaders, if not what the law would denominate "incorrigible rogues and vagabonds," at least have taken advantage of their hold on their followers to serve their own private ends. It seems that even fools must have a leader, but I very much doubt if the fool who leads fools ought not properly to be considered a cunning rogue. If he can only throw a little dust in the eyes of the world he is safe, and is sure of support from Christian bodies in general; and it may be seen that the leader of a sect of ranters, even of the most outrageous class, has generally cunning enough to perceive this important fact, and act accordingly. In all these (what shall I call them?-abnormal Christian communities?) there is always one man, at least, who benefits personally more than the others. Does the society profess community of goods? No one individual, except the leader, can take what he wants from the common stock without permission of that leader or his adjutants. Where then is the community of property? I can best illustrate the impressions forced on my mind concerning the Shakers and similar sects in America by giving an account of one of their communities.

I choose that at Lebanon, in the State of Massachusetts, because it is one of the oldest, though the sect has branches in Ohio and elsewhere in the States, as well as at several places in Canada. The Shakers have been established at Lebanon about a hundred years. They came from England, where they were first established by a sort of Lancashire witch, one Mrs. Ann Lee, who, of course, like Messrs. Joe Smith and Brigham Young, " had a revelation." It is quite possible that this woman really believed that she had had a divine revelation; a certain 
class of minds have the power of persuading themselves, as well as their followers, that they are, or have been, in direct communion with the Almighty. This assumption has its birth in spiritual pride. It is often found in religiously exalted minds, but never among profound thinkers. A certain amount of selfishness, with a vulgar tone of spirit, are its invariable concomitants.

The members of the sect at Lebanon claim that Mrs. Lee brought no fewer than 4000 persons to America with her, and they came to avoid persecution. It is far more probable that they came hither because land was cheap and good, and because America has always been the dust-heap to which all that was abominable in politics and religion has found its way from the old countries of Europe. They have no objection to be called Shakers, but they term themselves the "United Society of Millennial Christians." Their doctrines, so far as I could understand them, are Christian love, community of property, strict industry of every member; with regard to the "outer world," peacefulness and lawabiding; and, in a word, precisely the same rules as those of the Mormons except on one point, for whereas the lively Brigham could not do without his forty houris, even lawful marriage is considered a deadly sin by the Shakers. I have met with people who have puffed with the lips on hearing of this rule, and said that they did not believe that any community of men and women mingling together in daily life would observe it. To persons not accustomed to control and self-denial, it may seem impossible that such a rule should be observed. I, who have been among them, am quite as convinced of their purity as I afterwards was of the gross immorality of the Mormons. Notwithstanding that the sexes mix together, to a certain extent at all events, I believe their assertion that it has very rarely happened in their history that it should become necessary to expel persons from their community for a breach of this rule. 
The sect therefore, it is needless to say, is maintained entirely by recruits, and that in face of the fact that men and women are not easily admitted to it. They guard jealously against the admission of idle and worthless characters, and there are none such among them. Their austerity is awful; it would certainly deprive some men, if subjected to it, of reason. Books, which I look upon as one of the chief delights of life, are rigorously forbidden, and their perusal accounted a sinful waste of time. The Bible, and a few religious works, are the only books to be found among them. All science, and all worldly knowledge, is counted as "sin." They do not smoke, and drink no intoxicants. It is certain that such abstinence was not always practised among them, but there has never been excess of any kind. Having admitted this much, I fear that I must to some extent discount what I have written by mentioning that it seemed to be impossible for the younger members to break any of the rules, that I should say were specially framed for their control, for want of opportunity. For instance, should a gallant young Shaker cast sheep's eyes on a buxom young Shakeress, they would have to fly the fold before they could the tale of love in sweet accents softly murmur.

But what there is of loveliness in the Shakeresses, young or old, they take care to hide under the most abominably ugly female costume that I have ever seen. Close-fitting, ungainly caps and gowns transform them into a sort of living mummies, and effectually hide any beauty of face or grace of person that they may be possessed of. The men dress much like Quakers; but they do not affect the Quaker mode of speech, though they strictly obey what they ignorantly consider the Biblical command to use no other form of asseveration or denial than "yea" or "nay."

I must not forget to say that these people take a number of orphans to train up in their peculiar tenets. 
I do not know if the number of orphans so taken is limited, but I believe that it is; and the reason is that most of these young people, when they attain a certain age, desert their benefactors; for which they cannot be blamed, for they are little better than slaves while with the community.

The estate, or settlement, or farm on which these people are established at Lebanon, and which is absolutely their own property, consists, if I remember rightly, of about 7000 acres, and is one of the most perfectly cultivated pieces of land that I have ever seen. There does not seem to be a square yard of waste on it, and the roads which intersect it, especially the main road, could not be better than they are if constructed by the best engineer in the country. The land is mostly under crops, cattle breeding not finding much favour among the Shakers; but everything that they consume, whether food or clothing, is both raised and manufactured within the limits of their settlement. The women spin, weave, knit, sew, and make, with even more than housewifely skill; and both they and the men are remarkable for the extreme cleanliness of their appearance, even when engaged on what is usually called dirty work. You see the men digging in snow-white shirt sleeves, as white as the caps and aprons of the women, which are spotless. The laundry-work is performed by the wornen and girls, as is the preparation and cooking of the meals; but the sexes eat in separate rooms, and they also sit apart in different houses when performing their evening employments. Those employments are all of an industrial character, anything in the shape of recreation or a game being condemned as sinful; even conversation, except of a strictly religious turn, is discountenanced. I say "religious"; of a canting turn would be a better term, for, however genuine the bulk of these people, they are unconscious hypocrites. In fact their existence is, in my opinion, a distinct menace to the public morality of a 
country; for their hateful austerity, combined with their hostility to one of the chief of Nature's laws, and their utterly unnatural existence in general, is far more dangerous to real religion than open immorality. Austerity causes the young to hate religion; vice often causes a disgust that drives men to virtue and piety as a welcome refuge.

Originally all the houses on the estate were what is known in America as "frame buildings," i.e. timber houses constructed of planks nailed to a beam frame-work, and roofed with shingles. The houses were painted a buff colour, with red or vermilion shingles, and consequently presented a gaudy appearance. These frame buildings are considered superior to log-houses; but in my opinion they are neither so comfortable nor so substantial as wellbuilt log-houses; and they are certainly more infested with insect and other pests, while in summer the heat in them is intolerable, and $I$, have seen them warp until they looked like huge chests which had been partly crushed. The window-frames, in particular, of a frame house, are rarely on the square after the first summer of its erection. At the time of my visit most of the erections devoted to general purposes were still of this description; but there were also some built of brick and stone. The bricks, I was told, had been made by the saints, as they seemed to have made everything else which they use.

None of the men and women seemed to be living alone. A number of men, or a number of women, lived together; and a certain band of women waited on a certain band of men. This was a common, but not a general, arrangement. To my surprise I found certain houses tenanted by a man, his wife and, sometimes, a large family-all born before their parents were "converted." Though they live together the sinful intercourse of the "worldly married" ceases-they are now simply "brothers" and "sisters." That this most singular arrangement should 
lay them open to all sorts of evil surmises on the part of men whose chief guide in life is unlimited self-indulgence, is not surprising. I believe those evil surmises to be groundless: these people really live celibate lives. But there is something wrong somewhere in the community. The women are a wretched-looking lot of creatures. I spoke just now of a possible buxom Shakeress. There is no such thing among them. They are as ugly, without exception, as their dresses are unbecoming. Moreover, they all have the look of being out of health. The men, on the contrary, and the children, are ruddy, well fed, and cheerful-looking to a high degree. The impression strongly stamped on my mind was, that if I were compelled to live among these creatures I should certainly fall into most of their habits until my reason failed. I could not possibly fall in love with, or desire to marry any of these most repulsive specimens of womanhood, if indeed they deserve to have the revered name of womanhood applied to them in any form. There is something picturesque in Macbeth's hags : there is nothing picturesque in a female Shaker.

Among the Doukhobors of this day (more than thirty years later than the time of which I have been writing) it is recorded that no garment made of the wool or hair of animals or the feathers of birds is used. I do not think that the Shakers paid any such silly, but pitiful, respect to the animal creation; but I remember running my eye along the clothes-lines (my impudence is boundless), and noticing that there were no articles of flannel suspended to dry, though the time was late autumn, when the weather was something more than chilly.

Another circumstance that struck me much was that there were stores on this remarkable estate, stuffed with goods which had all been made by this more than remarkable community, and which were worth many thousands of dollars. The stock was so extensive that not a fifth of it could possibly have been consumed by the com- 
munity; and on inquiry I found that the trading transactions of these people were so extensive that they were positively rich; and that in no small degree. It was asserted by outsiders likely to know, and of position not likely to indulge in idle chatter, that the Lebanon settlement alone was worth more than half a million dollars in hard cash, besides their land, stock, and cattle. The saints keep a banking account; but I did not happen to be inquisitive enough to find out whether it was kept in the narne of an individual or was a joint-stock affair.

The community is governed by two classes of officers, the religious and the secular; and both may be of either sex, though at the time of my visit there was no female preacher - at least actively engaged as such. The religious teachers are termed elders, the secular governors, deacons, or deaconesses if females. There are always deaconesses in direct charge of the women and girls; and even in the families living together I noticed that there was usually, perhaps always, an old crone of viperish aspect presentto see that the rules are respected, probably.

There did not appear to be any desire, on the part of the saints, to raise mystery, or conceal any of their ideas and doctrines, from inquirers; at the same time there was no eagerness to give information; and the answers were sometimes short, if not off-hand. I thought there was an intention on the part of my informant to insinuate that he thought me too inquisitive; and this acted as a deterrent to much questioning on some subjects on which I should have liked more information. Any person is at liberty to pass over the ground of these people and examine their works; but they certainly do not care to have many visitors. Their principles resemble those of Quakers in several respects, though, in my opinion, they lack the religious genuineness of Quakers. Like the latter people, they are enemies to warfare and all strivings; and I think that it is for this reason, because they will not resist evil even in trifles, that they tolerate visitors. I may be wrong, 
but the impression was left on my mind that they would much rather be left to themselves; that they dislike having strangers approach them, but would never say so for fear of giving offence. They certainly are careful to "give offence to none."

The women avoided coming in contact with me as much as they could, and in this they were aided by the men, who drew my attention to other things. I could not therefore learn much of the daily life of the women, although I was permitted to look into a building used as a laundry, and a room where a number of young girls were busy sewing and making garments. All work seemed to be going on with the regularity and silence usually observed in prisons; and these two rooms reminded me of pictures I have seen of Dutch industrial schools. There was no conversation or singing, even of hymns. Two or three horrible old ogresses seemed to be watching the young workers, whose ages ranged from about seven to twenty years; and I supposed that this acted as a spell on them. The "brother" who showed me round uttered a word or two of explanation to me about the work, but did not address or salute any of the women. Only one of them looked up as we stood on the threshold of the door (we did not pass beyond), and she was instantly observed by one of the ogresses, who uttered the single word, "Martha!" in a tone so awful that it shocked me more than a torrent of blasphemy would have done. Mentally I exclaimed, "For God's sake, let us go !" and scarcely could refrain from uttering the words aloud. Certainly it does not require flarnes to make a hell. Perhaps the remark can scarcely be understood by a person who has not visited a place of this kind, perhaps I am too imaginative; but the horrible constraint of this place, with the cool, fiend-like nature of the discipline, made me feel, long before my inspection was finished, that it was a sin to live- - a wickedness to have a being; and so far was the scene from provoking a single holy 
thought in my mind that I caught myself almost blaspheming; for I could not shake off the thought that if God wanted, or took pleasure in such service as this, $\mathrm{He}$ must be a monster.

It was the same among the men. Into their workshops I passed more freely. There were carpenters, shoemakers, tailors, tin workers, and most other trades at work; but all was performed with the silence of a penitential establishment. Scarcely an eye glanced toward me on my entrance, not a word was addressed me, and when I made an inquiry or two from a man or a boy, my guide took it upon him to reply, and the person addressed moved away, or turned his back on me with an air that could not be mistaken. He did not want to be bothered. Yet one lad spoke to me unbidden.

It was at the blacksmith's forge; and I shall have more to say about this youth a page or two farther on. He. was not older than fifteen or sixteen years; a thin, sharp-featured lad, with an enormous nose, and the straight, black hair so frequently found on the head of the religious fanatic-perhaps because affected by him; but I am inclined to think as a peculiarity of his constitution. The youth, who was called John (surnames are not used, and I think not acknowledged, among the Shakers), had a habit of scratching or tickling his nose with his little finger, in a manner so peculiar that it could not escape observation. When I first saw him he was swaying a heavy sledge-hammer, while a man of three times his bulk held the red-hot iron on the anvil; for John, if slight in build, was strong of arm, as I soon discovered.

As I approached the forge he dropped the hammer, rushed to me and seized my arms, pinning them to my sides, and screamed, "Come, dear brother, come and be saved. Leave the sin, and come home to Jesus. Come, thou dearly beloved of the Lord, come and be saved." The poor fellow was undoubtedly mad. He continued to 
yell, in every sentence uttering the request to come to the Lord, till he fell to the ground in an ecstatic fit, foaming at the mouth, and screaming appallingly. The bystanders, who seemed to worship the poor wretch, said that he was "in the spirit"; and I was informed that he had "wonderful gifts from the Lord," of which "the gift of tongues" was not the least. His flying at me was described as a special .Providence, which I was entreated not to neglect. It was "a call" which I should commit awful sin in refusing to obey.

I got away from this blasphemous mummery as quickly as I could.

Of the skill of the workmen engaged in the shops there could be no question. They were admittedly the most skilful mechanics in this district of Massachusetts, and the farmers for many miles round sent all their ironwork to be done by the saints. They could do anything - shoe horses, forge a ploughshare, turn out a dozen miles of iron palings, or make a handsome pair of entrance-gates. Other work was also done for outsiders, all at the most fair prices, for a saint takes advantage of no man. Only the work must be brought to them. They will not fetch it, nor will they go off their own land to work. The stockings and jerseys knitted by the women are in great demand among the unredeemed outsiders.

It is not to be supposed from what I have said of the industry of these people that they suffer themselves to be overworked. That is not the case. All of them have plenty of spare time, which they seem to idle away or devote to religious mummery. Everything about the settlement is kept in such apple-pie order, is always so neat, prim, clean, that it is child's-play to keep it continually so. As to outside works, the saints say, truly enough, that they are under no need to perform them, but they do not wish to be idle. They have a superabundance of everything; and they look on it as a favour done to the outsider if they accept his work-which, as a 
matter of fact, it is ; for many of the farmers of this part (remember that I am writing of a period long past) would be put to great straits if the saints refused their work.

With regard to outside charity, I do not think the saints ever refuse it. They obey all the precepts of Christ in a literal sense. "Give to him that asketh of thee, and from him that would borrow of thee turn not away." I am sure that a Shaker would carry out that command in a thoroughly literal way. But there are no beggars in America, except those of the six-shooter, tender-foot type; and these gentlemen, I ascertained, never by any chance show their face on the settlement. Why they do not I cannot tell, but I can guess. A tender-foot has as much dread of a sermon as he has of the gallows. ${ }^{1}$

I did not come to Lebanon in the first place out of idle curiosity, but was brought here by an eccentric friend who took a great interest in the community and ultimately joined it. Perhaps owing to this circumstance we were entertained by an elder, who was living with other officers, in a house that was certainly much too large for their requirements. The place was well but plainly furnished; and though its chief occupant was one of the principal leaders and preachers of this society, there was no bookcase, nor more than half-adozen religious books and Bibles in the house. In reply to my inquiry if he ever read any of the masterpieces of

1 A tramp whom I met not many miles from Lebanon Springs told the following anecdote: "I went up to an old slab-sides [Quaker] and told him that if he didn't give me a new shirt I'd raise bell among his stacks. He brought me out two good shirts and a pair of breeches, 'for,' said he, 'I see you want them. Come in and have some food; and here is a trifle for your future wants.' While I was eating the dinner his old woman gave me, he said: 'Friend, when thou wast a boy, did thy mother teach thee to pray?' I didn't like that, somehow, and so didn't answer; and he continued: 'If she did, try to remember her prayer, and the Lord have pity on thee.' What he said made me feel so bad that I couldn't take them things; and when I was leaving, and he said, 'God bless thee, friend,' I would have given all I'm worth if he had changed it to 'G$\mathrm{d}-$ thee.' I never was so near six-shootering myself as I was that night." 
the world's great intellects, he replied that "They that cultivate the vain rovings of the mind, like those that handle the harp and organ, indulge a lust; and, like the lusters of old, are swept into hell." On my remarking that I heard that they themselves indulged in music at their worship, he answered, "Yea! even as Miriam sounded a timbrel over the enemies of the Lord, but not to gratify the lust of sweet sounds."

We were fed here with boiled mutton, bread, and potatoes, followed by a plain rice pudding. Good wholesome food, and I quite agreed with our host's remark that those who desired better deserved to have none, though I thought the rernark out of place, as I am sure that neither of his guests failed to partake of the fare with thankfulness to him and to our common Master.

We had intimated that we intended to attend their public worship the next day, which was a Sunday, but we were not invited to pass the night in the settlement, which I could see vexed my friend. We had consequently to ride six miles the following morning to the Shaker meeting-house. It was a building without ornament, and without a pulpit; and the men sat separate on one side of the building with the women on the other. The music was furnished by that most abominable of all musical instruments, a harmonium, which, we may justly surmise, was invented by the father of evil for the special behoof of such orgies as that I now narrate.

The presiding elder called on "some brother to open with prayer," and immediately up jumped my young friend, the blacksmith. Prayer! I hope I shall never hear another such; and the only point in favour of him that offered the horribly blasphemous incantation-for such it was-that I can say, is that I am sure he was raving mad. I shall not attempt to repeat anything that he said; but his manner was enough to convince any impartial observer that he was insane. $\mathrm{He}$ jumped up from the floor, he stood on a bench, then down again; 
he threw his arms and legs about as if trying to throw them from him. He screamed and yelled in his piercing sharp tones till my ears quivered with the horrible noise, while his brethren and sisters groaned and "amened" in an agony of ecstasy. Finally he went "into the spirit," otherwise a foaming fit, on the floor, where he lay while a hymn was being sung, by which time he had recovered and resumed his seat. When the hymn was finished he sang a verse by himself, snapping out the time with his fingers with a noise like castanets.

Then followed prayers by the elder and a woman, and another hymn, after which the sermon was delivered. There was much twaddle in this discourse, but nothing particularly outrageous, and a few of the remarks were sensible enough; but needless to say that the speaker revealed himself a vulgar, ill-informed man, or that the sermon was unconnected and without point. It certainly could not have made any impression on the mind of an ordinary commonplace man possessed of a grain of common sense, but it seemed to give immense gratification to the brethren, for they groaned themselves-I was going to write, into a fury of enthusiasm. I do not know how otherwise to put it.

The sermon over, there was sung another hymn, and then followed the proceeding to witness which I had been induced to be present at this orgie. It was commenced by the young blacksmith. Stretching his legs out stiffly before him, and throwing his body back so that he could look straight up to the ceiling, he commenced a series of the most horribly blasphemous invocations to the Holy One of God to come down. His language, even his gestures, are quite indescribable.

While this awful invocation was going on, a woman arose, quietly enough, and began to shuffle round a space in front of the platform where the speaker had stood. She was followed by others in quick succession, till about a dozen were shuffling around, the benches being pulled 
out of the way to give them room. It was not a dance, but rather a gliding motion, accompanied by ridiculous gestures of the arms and hands. The feet were raised so little from the floor that the toes were but rarely visible. The women uttered a few cries, and worked their features convulsively; but the most noise was made by the men, and the uproar was simply brutal. They shouted and stamped as badly as the rabble in a low theatre, and several lashed themselves into a state bordering on furious madness. The appeals to the Deity or His Son to " come down" were incessant, and couched in terms that cannot be repeated.

Meanwhile the women, with one or two girls among them, continued to glide round in a steady way, not very fast, and with but little motion except with the hands. I noticed that all the very old women took part in this mummery; and several kept their eyes closed, finally falling motionless to the floor, where they lay for some time. The time occupied in this ceremony was about a quarter of an hour, and the whole proceeding was inexplicable. I never learned the meaning of it, if it had one; and in reply to my inquiries I was told that these women were under the influence of the Spirit, or rather "in communion with Him," was, I think, the phrase used. None of the men took part in this dance, or whatever they call it; but I quite expected to see them stamp in the boards of the floor. I should have noted that while the women were shuffling about, the harmonium continued to play an indistinguishable tune, resembling a dirge to my ears, but there was no singing.

By the conclusion of this extraordinary manœuvre, John the blacksmith had quieted down, and was tickling his nose with his little finger, in the ludicrous manner before mentioned; an eccentricity constantly indulged in by him when he had nothing better to do. Unfortunately his eye caught mine as I was observing him, and instantly he flew towards me, and seized me with such 
fierceness that I was nearly dragged off the bench. "Come to glory," he yelled. "Come to salvation. Come to the blessed of the Lord, and learn the Way." I am anything but a weak man, and at this time was in the zenith of my strength, weighing over thirteen stone; but I was nearly powerless in the clutches of this wiry youth. He clung to me like a cat, and I could not shake him off. Pity withheld me from throwing him roughly, for I was convinced that only insanity could show the superhuman strength of this miserable stripling. At length my friend and some of the brethren interfered on my behalf; but it took the united strength of three or four powerful men to compel the young fanatic to relinquish his hold of me. Some years afterwards, being in that neighbourhood, I made inquiries after John, and learned that he died suddenly in one of his fits of "communion" when he was about eighteen years of age-not a surprising fate. Few, I think, will disagree with me when I describe his end as a case of death from religious excitement.

I have devoted more space to this strange community than I intended to do when I commenced the chapter, and I cannot therefore describe several other strange religious sects as I had intended to do. As is well known, nearly all denominations in America have "big tents " in the woods and wastes during the summer months; and perhaps it is as well that I do not describe some of the disgraceful scenes that take place in these religious picnics, especially in the "coon" tents.

It can well be imagined that where people camp promiscuously together in the woods for perhaps six or seven weeks at a time, strange, not to say indecorous, scenes take place, especially as Uncle Sam is fond of novelty in his religion as well as in other things.

I have described New Lebanon as being situated in the State of Massachusetts. It seems, however, to be in New York. I cannot now say how the mistake 


\section{SHAKERS AND RELIGIOUS MUMMERS 247}

occurred; but I have not seen fit to alter my notes, because I have a clear recollection of the Shakers describing their estate as being in Massachusetts; and they were punningly described, by people living near, as being "Mercy-choose-sites"; an allusion to their general shrewdness in choosing the best of everything, and a play on the name of the State. 


\section{CHAPTER XXI}

\section{MICHIGAN}

Perhaps it is not generally known to average Englishmen that Michigan State is divided into two separate portions. Michigan proper is the peninsula enclosed by Lakes Michigan, Huron, and Erie; but it also includes a second, and much smaller peninsula, wedged between the north of Lake Michigan and the south of Lake Superior. At the time of which I am writing, this last portion contained very extensive forests, and possibly still does, for this is not a favourite settling portion of the State, intending settlers preferring to cross over into the British dominions; for what reason I cannot tell; but so it is. These forests are as solitary, regarding animal life, as other densely wooded districts in this region of America; but there are spots, particularly in the swamps near the coasts of the lakes, which abound with water-fowl, for the most part of the same species as those described as found in the northern portion of this great lake region. See the account of the Red River Colony, \&c.

I need not repeat my description of those birds here, except when I have something new to say about their habits; but I think there are more small birds in Michigan during summer than in Red River and adjacent parts. I noticed great numbers of ground sparrows, as they are called here, and swamp sparrows; and I found many of their nests, including that of the common swamp sparrow. This bird greatly resembles Melospiza georgiana, but I am not quite sure that it is the same bird. A confusing circumstance is that the eggs of 
nearly all these ground sparrows, including the celebrated song sparrow, are so much alike that unless the bird is actually caught on the nest it is often very difficult to identify them. I formed a complete gradation of these eggs, showing that in a dozen species any two adjoining were so much alike that it could not -be positively said that they were not the eggs of the same bird. Generally the ground colour is bluish,speckled and blotched with dull red and purplish brown. The eggs of all these so-called sparrows (they are not true sparrows) are very small and delicate shelled, approximating those of the English linnet in size. I did not find those of the song sparrow in Northern Michigan; but the bird is plentiful enough a little farther south in Ohio and Massachusetts, \&c. Probably the northern breeding limit of the song sparrow does not extend beyond the south of Michigan. I never found the nest farther north, though odd individuals of all these sparrows sometimes stray very far from their normal habitat. The nests of all the ground sparrows are cunningly hid, and all avoid their nests if they have the slightest suspicion that they are being watched.

Among the animals noted in Northern Michigan was the Canadian lynx. I saw a fine specimen of this animal in the forest, but failed to shoot it, it was so quick in its movements, and lost not a moment in making its escape. By-the-by, I heard this lynx plunge into a stream in making its escape. It could not have got away without doing so, and it must have swum very quickly, for it had crossed a distance of fifty yards and disappeared before I could get up, though I did so promptly.

In this same stream and in the adjacent swamps, some of which were close to the shores of Superior, the large rats called musquashes, Fiber zibethicus, were very abundant, insomuch that I sometimes obtained forty or fifty of an evening for the sake of the skins, which are of great use for making rugs, fur coats, \&c., though the skin itself is not much esteemed by the trader's. About here 
the musquashes were living amicably in swamps which swarmed with bull-frogs.

Musquash seems to be an Indian corruption of the words musk rat. The animal is about the size of a small rabbit, with a long tail compressed at the sides, and is aquatic in its habits. It makes lodges under the water with the entrance above the surface-at least one entrance, for there are usually several, one or more of which may be under water. They also burrow in the banks of streams and ponds to a great depth. The musquash is capable of being tamed, and shows more affection for its master than most pet rats ; though, as is well known, there are several of the family that are capable of evincing a considerable degree of affection towards those who are kind to them. Those captured in traps should be handled cautiously, as they will bite very sharply.

Another animal common in some spots where the forest was thin, or on the outskirts, near small open plains, was the North American skunk, Mephitis mephitica. This animal is also about the size of a rabbit. It is notorious for its offensive odour, but I think the offensiveness of the smell has been much exaggerated. For instance, I have heard of people being made ill in their houses when the skunk was a quarter of a mile away. This is nonsense. Nor do I believe that the odour could have dangerous effects on the human subject, as is often asserted. As a matter of fact the stench of several of the South American species is far more abominable than that of the North American skunk. It is bad enough, however, especially if the animal is old. If the beastly fluid is squirted on your clothes they must be destroyed, for the odour cannot be got rid of. It is an indescribable stench-a compound of putrid-sore odour with the extreme essence of tom-cat, and of great intensity. There is no doubt but that it often makes people with weak stomachs very ill, but that it is so very offensive to the animal creation at large I strongly doubt. We are told by the professional naturalist 
that the horrid odour is given to the animal by Nature as a protection, and they strive to make the general habits of the creature fit in with this view. A protection against what? Other beasts of prey? Carnivorous animals do not devour each other. I will not go the length of saying that a preying animal never, under any circumstances, devours another predatory creature, but I am not sure that I should be going too far if I did. I will say positively that no preying mammal or bird habitually does so; and unless it was a common practice, it will be palpable to any real naturalist that Nature would not make a special guard against it. Besides, why protect a skunk more than a stoat or a weasel? But, says the advocate of the pet theory, the abominable odour must be given for some special purpose. I fail to see that. For some inscrutable reason all created beings are more or less offensive-man among them, as those who have sniffed an unwashed nigger are well aware. That they are so offensive for protective reasons is simply nonsense. For what reason does a carcass stink? To frighten the vultures from it, perhaps! The horrid odour of many kinds of deer is only second in offensiveness to that of the North American skunk.

As a matter of fact most carnivores are possessed of highly offensive odours. The same applies to birds of prey, and even to reptiles. No one who has dissected a serpent can be ignorant of the filthy odour of its intestines, nor have failed to note that this stench is often powerfully given off by the living animal, especially when terrified. That, however, does not save them from destruction.

Regarding the skunk, a great deal has been said as to whether the odour is offensive or not to the animal itself. It is not, as might be expected. For it is ridiculous to suppose that the Creator would make any of His creatures an abomination to itself. The skunk, in common with such creatures as stoats, weasels, and polecats, to say nothing of foxes and the larger carnivores as well as other 
classes of animals, probably are gifted with the malodours that distinguish them for sexual reasons. I am very strongly of that opinion, but I do not see how I can more than hint at the evidence on which I base it in a book that will fall into the hands of all sorts and ages of persons. Moreovier, in animal physiology there is almost always more than one reason for a particular circumstance. This makes the subject too intricate to be discussed in one or two paragraphs.

The habits of the skunk are rather sluggish. He is not timid, and is in no hurry to get out of your way unless you are accompanied by a dog. The assertion that dogs will not attack a North American skunk is not correct. Dogs can be trained to attack anything, a remarkable circumstance, since wild dogs, like other preying animals, only attack those creatures on which they feed. Carnivorous animals sometimes quarrel, and the stronger will slay the weaker; but the conqueror never devours the vanquished, whether of his own species or some other. If there are any exceptions to this rule, the meal has been made under pressure of extreme hunger or in captivity, when the tastes of the confined animals are often abnormal. Even men and herbivorous animals have been known to devour each other under stress of starvation.

The skunk moves about slowly; but if put to it, he can cover the ground at a tolerably quick pace. I have never seen them climb trees. The trappers say that they will do so when driven to bay; and also to rob birds' nests. I strongly doubt the latter part of the assertion. They rob the nests of birds of the grouse and partridge family; and, no doubt, those of smaller birds when built near the ground. The general food of the skunk consists of any sort of animal food it can find-rats, mice, chipmunks, young birds, young hares, every sort of small animal that it can surprise; and snakes, lizards, frogs, and even beetles, \&c. It is to be understood that the expression, "every sort of small 
animal," does not include those of its own or allied families. As I have just said, no beast of prey devours those of its own kind, except under abnormal circumstances.

The fur of the skunk is by no means to be despised. It is superior to that of many animals which find a ready market. The skin is not tainted with the fetid odour of the fundamental glands. The old school of trappers would not strip a skunk; but their brethren of the present day are wiser, and at a time when all sorts of furs are growing scarce, have found that it pays to collect skunk skins. I have met with old trappers who always kill and bury these animals when they meet with them, alleging that if they get into their traps, no other animal can afterwards be caught in them. I have, over and over again, proved that this is an error, or perhaps a superstition.

The fact that the skunk can, and often does, eject its offensive fluid when dogs or men seize them, is a strong point in favour of those who believe in the defensive theory. Many animals emit their urine when captured. The badger, to which the skunk is closely allied (it is a badger, in my opinion), does so, and so do many stoats, polecats, \&c.; and I have noticed the same thing when handling bull-frogs and other batrachians. The subject of anal secretions is a difficult one, but I cannot get away from the opinion that sex is the only reasonable explanation. For instance, why are certain species of deer, civets, \&c., furnished with musk glands, if not for purely sexual reasons? No one has ever yet suggested that the odour of musk is a defence to the animal possessing it; yet musk, which is a pleasant odour to man, is most offensive to some other animals.

I come now to treat of the American tree-squirrels. No man can penetrate the American forests far without noticing the squirrels. They are abundant in many parts of Canada and the North-West, but I bave thought 
fit to wait till I reached this chapter before giving a detailed account of them.

The trappers say that there are three species of squirrel-the red, the grey, and the black; the naturalists acknowledge two-the red, Sciurus hudsonianus, and the grey, Sciurus carolinensis. The black is an abnormal, or erratic, colouration of individuals. All these are met with in the forests of Michigan, but there is great uncertainty as to where and in what numbers. There used to be a great migration of these elegant little mammals, or perhaps it would be better to say a great invasion, occurring every few years, with an uncertain interval. A district in which there were very few squirrels would be invaded by countless thousands, and the farmers would assemble in defence of their barns and granaries, and have a week's squirrel-shooting. I have heard of a party of a dozen guns shooting as many as 20,000 squirrels in a week. These were of the species termed grey by the people of the locality; but they seem to have been the $S$. hudsonianus of the naturalists; for they were the variety known as the chickaree, the most abundant in the northern districts. Personally I doubt if there is more than one distinct species; $I$ am quite sure that there are more than half-a-dozen local varieties. Books and naturalists cannot supersede my eyesight.

It would be interesting to know from whence these great hordes came. They always brought many enemies, as owls, buzzards, and kites, in their train; and in the following years there would be a scarcity of squirrels in the invested district. Man, and birds of prey, rapacious as they were, could not account for the disappearance of hundreds of thousands, perhaps of millions; and my opinion is, that the bulk of the horde failed to find sufficient food to lay up a store for the winter, and consequently were starved to death. But, apart from this, great migrations of squirrels frequently took place to my knowledge, for no discoverable cause; but I 
noticed, after one or two such migrations, which almost denuded an extensive district of squirrels, that the following year was a bad one for nuts and beech mast. It looks, therefore, as if the little animals, by some remarkable instinct or train of reasoning, were forewarned that a season of scarcity was approaching. I do not say that squirrels are the only animals in the American forests which make these remarkable migrations. Other mammals and many species of birds do so ; but the habit is more marked in the squirrel than in any other animal found here. It is the vast number in these migrations that is so remarkable; so that it looks as if the horde had deliberately started on a journey, like a body of emigrants, to find a new country, the old being no longer able to supply their wants.

The squirrels hibernate, but I do not consider their retirement for the winter a true hibernation; for they lay up a store of food for use during the winter, which such animals as bears, which fall into a profound sleep, resembling death, during the season of winter, do not. This food is taken to their store-holes in their cheekpouches, which are capable of holding an acorn. Many of those which I shot had acorns in their pouches, but more often it was beech mast, nuts, and, where there were barns in the neighbourhood, grain of several sorts; for these squirrels visit the outhouses of farms, and have been known to nearly empty corn-bins of their contents.

The grey squirrel, S. carolinensis, is said in books to be distinguished by its superior size, and the absence of tufts of hair on the ears; but none of the American squirrels have such large ear-tufts as the European species, and size depends on locality, or the supply of food, in great degree. It is individuals of the grey variety, however, that are most frequently of a black colour; and this black colouration is of varying degrees of intensity. Sometimes it is a dark brown, sometimes 
almost a chestnut, and occasionally the fur is mottled, brown, black, and grey. In any case, it is absolutely certain that these abnormally coloured specimens are not a distinct variety. The numbers in which they occur are alone a proof of that; though formerly they seem to have been much more numerous than at present, if the accounts I have heard of late years are to be relied on, of which I have no doubt. At this time they were so numerous that I obtained a sufficient number to make an overcoat of. Coats formed of the skins of animals of small size, or lined with them, seem to be warmer than those made of the pelts of larger mammals. Such articles of clothing are very desirable possessions to a man exposed to a North American winter.

No matter how numerous squirrels were in a district, I never succeeded in finding many of their storehouses, probably because they seem to choose holes far up the trunks of trees, often very near the tops, for this purpose. Of those I did discover I can record that they did not contain anything like the quantity of food which $I$ found in the stores of the chipmunks; and whereas the chipmunk's store generally consisted largely of grain, those of the chickarees consisted mainly of wild-grown nuts, \&c., and rarely any sort of grain unless the place of storage was near a farm or barn. It is curious that I never found wild rice in the winter store of any species of rodent, though several of them, including the chipmunk, feed off this grain in marshy districts. Wild rice, I should mention, grows abundantly in the head-waters of the Ohio and other streams of the district, and forms a principal food, in the season, of several small animals, and especially of birds. I have raised flocks of ducks numbering thousands from a patch of wild rice. Small birds are much attracted by it, clinging to the straw to pick out the grain; but the larger birds, such as ducks and other water-fowl, swim among it, and pull the straws down to get at the head. The rodents nibble the straws 
through, or attack those which are beaten down by the weather, often venturing into the water after it. Among the animals to which the rice is a boon is the musquash, which nibbles the straw as well as the grain.

It is a singular circumstance that among the small mammals which lay up a store of food for winter use, those that keep to the ground collect much greater stores than those with an arboreal habitat. The chipmunk, for instance, often lays up a food-depôt, if I may use the term, which is at least fifty times its own weight; while I have never found the store of a chickaree (tree-squirrel) to exceed above twelve times its weight.

The native rats and mice of North America belong to different families from those of the Old World. The species which struck me most was the common jumping mouse. It is a very small animal, not exceeding the size of a small English mouse, but the tail is much longer, as are the hind legs; otherwise the little creature has a strong superficial, at all events, likeness to the common housemouse, which is the terror and torment of our careful English housewives. When disturbed it attempts to escape by a series of leaps of about six feet each; but it is easily run down, appearing to become partially paralysed with fear when closely pursued, as its leaps then degenerate into little hops. It trembles violently when captured, and makes no attempt to bite. Many of those that I have handled uttered a little squeak of joy or satisfaction on being released; and, I may remark, I have frequently known birds utter cries of joy under similar circumstances.

The jumping mouse, Zapus hudsonianus, does not associate in large numbers, but its habitat has an enormous range, extending, practically, to the whole of the northern half of the continent. According to books it is found far within the limit of the 60th parallel, if not as far as the Arctic circle; and within my own knowledge it extends southward as far as the north of Mexico. It 
shuns hot plains and valleys, however, in the southern portions of its habitat, and is evidently fitted for life in a cold climate. In the north it hibernates; in the south it does not, or only partially so. I enter the last clause by way of caution, as I am not quite sure. I believe, however, that it is beyond doubt that the little animal only hibernates when the cold is severe. Its hibernation, like that of all animals whose diet is of an omnivorous character, is a true hibernation. It does not lay up a store of food for the winter, but it makes a nest of hay in which it buries itself. Like the squirrels, it has cheek-pouches, which are of considerable size; but in spite of this indication that its natural food is of a granivorous kind, it feeds very largely on insects, especially ants and beetles.

Another little rodent, of omnivorous diet, and true hibernation habit, is the American flying squirrel. This animal, in my opinion, approaches very nearly to the mouse tribe; and I think that it would be just as correct to call it a flying rat. Its enormous eye indicates that its habits are nocturnal; and it has a bushy tail which is flattened horizontally to assist its spurious flight. Notwithstanding its large eye, it is about much in broad daylight, going, like the red and grey squirrels, in large parties. It is found in the profound depths of the torests, which the jumping mouse is not, although the latter animal is found on almost all descriptions of ground, except, as I have said, hot plains.

I am not sure that the flying squirrel, Sciuropterus volucella, inhabits the northern portion of Michigan. $\mathrm{My}$ notes, I find, do not make particular mention of that; but it was abundant in Michigan proper, Ohio, Pennsylvania, and other parts which I consider to come within the basin of the Great Lakes. Though described as a "flying" squirrel, it is, like all other flying mammals, bats excepted, simply furnished with a natural parachute, enabling it to drop great distances without developing a dangerous 
momentum. The skin of the flanks is loose and dilatable, and when stretched by means of the limbs enables the animal to drop slowly and gracefully, from branch to branch, in a slanting direction. The distance of these so-called flights is sometimes very great when passing from tree to tree. I have seen them take leaps which appeared to exceed a hundred feet in actual length, passing from the top of one tall tree to the centre of another that stood thirty feet from it. They alight on the branch for which they are making with unerring certainty and unsurpassable grace, undulating the body and tail with elegant motion in mid-flight. In passing from branch to branch in a perfectly horizontal, or slightly ascending, direction, they cannot leap farther, or better, than ordinary squirrels.

They are omnivorous, devouring greedily all kinds of coleopterous insects and larvæ. They also devour birds' eggs, which, probably, all squirrels do; but I suspect them of destroying the young birds as well. I found some unfledged young under trees inhabited by these squirrels, which had the skulls bitten open and the brains sucked out. The marks of the teeth showed that the depredator was a very small animal; and it seems certain that the flying squirrel was that depredator, for different species of small rodents never occupy the same tree, or in any case only very temporarily. In this they resemble the monkeys of South America; and generally it seems that mammals, and most birds, having selected a tree for their special habitation, resent the intrusion of other species; and when they are not strong enough to drive away the intruder, themselves forsake the tree and seek another.

The large black eye, which is surrounded by a narrow white, or light-coloured ring, is a very beautiful feature of these pretty little squirrels.

Of other rodents I shall say nothing more than this, that the common rats and mice of Europe, such as Mus 
decumanus, Mus musculus, and Mus rattus, have established themselves in several parts of Canada and the States; not only in coast towns, but also in the interior. In some places they are more abundant than the native species. Of course they have come to America concealed in the cargoes of ships; and several interesting problems have now to be solved. Will the new species oust the old? Will the brown rat drive its black brother out of the land, or prevent its obtaining a permanent footing here? Or will this vast continent find room for all ? Time only can answer these questions; meanwhile it is certain that the three species I have mentioned, and some others from both Europe and Asia, are propagating fast, though as yet only locally. I was a little surprised to find both black and brown rats here; because, as far as my experience goes, the brown rat is the only rat found on shipboard. $\mathrm{He}$ is master, and seems to have frightened the black species from maritime adventure. Certainly the two kinds are never, by any chance, found on the same ship. 


\section{CHAPTER XXII}

\section{THE WILD BEES OF AMERICAN FORESTS}

THE insect life of the American backwoods is not very striking though a portion of it (the mosquito portion, to wit) is decidedly piercing. The butterfly and moth population of Canada and the States is not more curious or brilliantly coloured than that of England. Indeed some of the butterflies so closely resemble those of England as to suggest that they have been transplanted here, which it is quite possible that they have. I think I have already referred to a small blue butterfly, and remarked that this appears to be a very common colour for butterflies in all parts of the world. There are several blue butterflies in Europe, in India, and I have heard, in Africa, and there is a very large and handsome one in South America.

But I have nothing worth recording concerning the North American butterflies and moths, and but little about other insects of this region, with one exception.

During my stay in Michigan I associated for some time with two professional hunters and trappers, a race even at that time fast dying out; for the miserable shack and whisky-bar loafer that now passes by that name is no more like the old backwoodsman than a kite is like an eagle.

The two men I refer to had been trappers from boyhood and were splendid types of their class. Long, the elder, by a transposition of his names familiarly called "Long Jake," was a man in the prime of life, six feet four inches in height, broad, and loose-limbed, but of 
herculean strength and a power of endurance that seemed to be untirable. Brown was also over six feet in height, and of muscular power scarcely inferior to that of his companion. He was known as "Splits"; where or how he obtained that inelegant sobriquet I could not learn. If I questioned either of them on the subject there would be a hearty laugh, and a sly look pass between them, but I got no answer. Probably the nickname had been conferred during one of those boisterous orgies in which all backwoodsmen occasionally indulge.

Long Jake was a taciturn, quiet sort of man, as so many other trappers are. It would seem that the solitary life they lead, often absolutely alone, seldom with more than a single companion during the greater part of the year, has a tendency to teach these men to speak seldom, and as shortly as they can. Splits, however, was a strong contrast to his companion. He was a very lively man, full of joke and fun, and whiling the time away when he was perforce alone with songs comic, songs jovial, songs of love, and songs of questionable sentiment. $\mathrm{He}$ was full of anecdote too, and used to tell some funny as well as some strange tales, for he had seen not only a great deal of frontier fighting with the Red Men, but had fought also through the Civil War, in one of Kilpatrick's cavalry regiments.

With these two men I spent several weeks in the forests of Northern Michigan, living in a temporary hut, and spending the days in shooting, fishing, and watching the habits of the animals. There were still plenty of foxes and wolves, with deer, at this time in this region, but the bears had nearly or quite disappeared. The pelts obtained by my companions, with the exceptions named above, were all those of small mammals; and they both complained that of late years their earnings had decreased by more than one-half in amount.

Our hut was about three miles from the shore of the lake, and about thirteen, as far as we knew, from the 
nearest farm. Occasionally visits were paid to this farm to dispose of venison, \&c., and obtain in return eggs, pork, and flour. These visits were paid by Splits more frequently than was strictly necessary, for there was a pretty girl or two there that—he made no secret-took his fancy. One of these young ladies suggested that he should get her some honey. I thought this was a joke at the time, but a day or two after I noticed Splits gazing upward towards the sky like a daft man; then he began to run to the forest, dodging about in a most eccentric manner. I went after him to learn what was the matter, not a little alarmed, fearing he had been suddenly smitten with an attack of dementia. "It's a bee, boy; don't you see?" said he ; and looking carefully I did indeed see a bee high up, sailing about in that seemingly lumbering, aimless manner to which bees are often given, but I could see nothing remarkable about the insect, and asked why it so interested him. Instead of answering, he rushed on into the interior of the forest, and I followed him, his sole anxiety being apparently to avoid losing sight of this solitary insect. Soon we saw others, and after a chase of nearly a mile, came to a tree, far up the trunk of which many bees were flying in and out of a small hole. "That's a bee-stock. Now for a frolic," said Splits.

This was delayed for the time being, till we should have Jake with us, and the spot being carefully marked we went in search of him. It was not until the next day that the nest was taken. The usual way of getting at the honey is to fell the tree, and then smoke out the bees, but this is a clumsy way, much, and sometimes all the honey being spoilt in the fall of the tree, and as the honey in this case was the principal object, it was decided to endeavour to get rid of the bees without running this risk. To effect this Jake ascended the tree, and bundles of dry grass being passed up to him by means of a string, he fixed them to a forked stick, 
and setting fire to them forced them into the entrance of the hole. The bees were soon all suffocated or driven away, and the honey-comb cleared out and sent down by the string. In this way about thirty pounds of honeycomb was secured, besides some that was spoilt by being burned, or flavoured with the smoke.

This honey was much prized by the farmer's wife, and we rose so much in her favour and that of her daughters that I am afraid we received much more than ten times the value of the honey during our stay ; for notwithstanding the distance of our camp from the farm, a boy was frequently sent over with eggs, butter, pork, jam, and flour. On nearly every farm in the New England States, to say nothing of other parts of the country, bees are kept and carefully attended to; but in North Michigan we learned that bee-keeping was not gererally successful. At this particular farm and others where I made inquiry they had failed to rear bees in spite of repeated trials. The wild swarms had been taken, often at great trouble and expenditure of time, and though they sometimes stopped in the hives for one season, they always forsook their new quarters before the second arrived. Sometimes, from some undiscoverable cause, a great number of the bees died. They never, under any circumstances, made an attempt to lay up a store of honey for the second winter. On some farms, however, bees that had been brought from a distance succeeded tolerably well, but I heard of no cases of such heavy hives as are the rule in Ohio, New Jersey, Pennsylvania, \&c., where bees prosper exceedingly.

The climate of all these States in winter is exceedingly severe, Michigan particularly so; yet the wild bees are numerous. The insect therefore must be very hardy. With many poor people-mean whites, as they are termed here - and with negros, bee-hunting is a source of living, to some extent at least. It is not the honey, however, but the wax which is the chief object of the search. 
This wax always commands a sale at a remunerative price; in fact the supply is less than the demand for it, or was at the time of which I am writing. I did not satisfactorily ascertain the reason of this, or whether the consumption was entirely a home one; but beeswax seemed to be used for many other purposes than those to which it is usually applied in England.

The means of collecting it by the bee-hunter is invariably to fell the tree in which they have found a nest, as the colony of wild bees is termed. The bees are then suffocated with thick smoke raised by burning grass, \&c. The weight of comb found in a nest varies from four or five pounds to as much as forty. I have met a negro carrying a ball of wax weighing at least half a hundredweight, the produce of a single day's labour, and representing the spoils of half-a-dozen nests.

The discovery of the nests is often a work of some difficulty, as they are generally placed high up the tree, and the time of hunting being the summer, when the trees are in full foliage, they cannot be seen from the ground. The favourite mode of hunting is to follow a bee. The little creature is sure to make for its home as soon as it has obtained a sufficient load of nectar. In following a single bee many ludicrous scenes often occur. The insect is so small, and flies so high when making for its nest, that the eye must be kept constantly fixed on it, or it will be lost sight of, and as it flies at a goodly rate, it is not an easy task to keep it in view. The hunter often has to run like a inad fellow, dodging and turning with the movements of the bee, and every now and then stumbling over fallen tree-trunks or clumps of brambles. At length the bee disappears amid the foliage of a tree, perhaps sixty or eighty feet above the ground, but it is by no means certain that the nest is there. The bee may simply have passed among the branches and flown out unseen on the opposite side, and the hunter have had his long and tiring run for nothing; or the nest may be 
a very small one, not worth the trouble of cutting down the tree for. To ascertain, if possible, the certainty of the nest being there, the hunter knocks or kicks the trunk. This will often cause the bees to swarm out. If this expedient fails, he watches to see if many bees return to the nest at nightfall, which they invariably do before sunset. If this should be the case, or if the nest-hole is visible, he at once fells the tree. Nearly all the bees fly out on the fall of the tree; and this is a moment of great danger, for the bees are furious and apt to attack any one standing near. Heaps of grass are at once lighted and placed before the nest-hole, and this generally confuses them and prevents an attack on the hunter. Most of the bees are destroyed, for they fly into the smoke in their endeavours to reach their home, and are suffocated. The comb is scraped out, the honey expelled by rough pressure, and the wax carried away to be refined at home.

The wild bees sometimes make their nests in the fissures of rocks, but holes in decayed broad-leaved trees are the favourite sites. I cannot say positively that they never select holes in trees of the pine class; but I have never seen a nest in a pine-trunk, and some of the hunters say that few trees but oaks and maples are ever selected. There are cases of nests being found in holes in the ground and under roots. The nesting-holes of woodpeckers and owls are favourite resorts of the wild bees. The birds are compelled to abandon their homes, and, once established, the swarm never forsakes its nest.

Bears are very fond of wild honey, and habitually rob the nests. The bees do not seem to be able to hurt the robber, whose shaggy hide is impenetrable to their short stings. A bear which I saw rob a nest in another part of the country repeatedly clapped his paw over his nose, evidently to dislodge his assailants, but his work was not interrupted for an instant. The hole in the trunk was too small to admit his paw; but he soon enlarged it, 
and scooped out the comb with great coolness, eating it as he did so, and finally coming down with a great piece in his jaws, which be carried away with him, an angry crowd of bees following and buzzing about his ears. Every now and then he stopped to free himself from these enemies, but they evidently could give him no serious annoyance. The scene was a most amusing one, for the bear, unconscious of my presence among the bushes, moved most leisurely, stopping to lick the honey from his paws and the ground, as if loth to lose a single drop of the luscious fluid. I, being unarmed, felt anything but happy with the huge brute within thirty yards of me, grunting his satisfaction to himself; for though I have now grown to have little or no apprehension of an unprovoked bear, I had not so much confidence then, and seized the first opportunity to try and get away. Bruin saw me, and stared in astonishment. Recovering himself, he went off with the air and gait of a thieving dog, not forgetting to take his honey-comb with him. I did not laugh at the time, but I have laughed heartily at the remembrance of the scene.

At the time I made no very minute examination of the American wild bee; but I certainly never noticed any difference between it and the common hive-bee, Apis melifica, of England; there is often a peculiar and not very pleasant flavour with the honey. This applies also to honey obtained at American farms, and depends, no doubt, on the source from which the nectar is gathered. On some farms, with the view of remedying this defect, large numbers of stocks are grown, this being a favourite flower with the bees.

When the bees have taken possession of a cavity in a tree-trunk, they give off no swarms until they have completely filled it and there is no room for fresh inhabitants. The swarms are therefore often of enormous numbers, in some cases amounting to hundreds of thousands. The age of a nest may approximately be told by the number 
of inhabitants. A freshly formed swarm is always very small, numbering, perhaps, no more than a few hundred bees; but their instinct must inform them of their probable increase, for they never take possession of a cavity that will not accommodate many thousands. If disturbed in their home, but only partially destroyed, the survivors will return again and again with indomitable perseverance. 


\section{CHAPTER XXIII}

\section{LIFE IN THE WOODS OF NORTH MICHIGAN}

THE anecdote of a bear in the last chapter is not the only instance of a similar nature that I have experienced. On several occasions I have been face to face, or nearly so, with a bear, under more or less ludicrous circumstances; notably in Canada, and in the Sierra Nevada some years later, and I have always noted that the astonishment of the bear at being suddenly confronted with man was very great. There are instances, however, in which bears suddenly surprised have at once attacked the intruder; it should therefore be remembered that no wild animal of a ferocious nature is to be trifled with, and I should always deprecate anything approaching foolhardiness. The point is this: that neither bears nor jaguars, nor pumas, as a rule, voluntarily attack man unless they think themselves threatened; but one of the surest means of provoking an attack is to show signs of fear, or a desire to get away. It is best to stand your ground until the animal has retired some distance. If it finds that you do not move, or interfere with it, it will presently make off as fast as it can. Attempt to run yourself, and it is twenty to one that it will immediately spring upon you. It is best, in the backwoods, never to move about without your firearms, for you can never tell when you are likely to want them. After a few years' experience in the wildernesses of America I adopted this rule myself, and it is a strange circumstance that on the very few occasions on which I broke it, and 
went abroad without my gun, I nearly always had cause to regret it.

But bears are not the only animals that I have surprised, and that have shown an overwhelmed astonishment at my sudden appearance. My habit of moving cautiously about, and lying concealed in the woods that I might watch the habits of the birds, has brought me into some strange adventures and revealed some curious sights, for animals, like men, behave very differently when watched from what they do when they think no eye is upon them. And if it is objected that animals indulge in ways and habits in the presence of man that show a carelessness of his opinion, or a lack of bashfulness before him, I have simply to say that I have seen savage men, and some who do not consider themselves savages, behave with quite as little sense of decency as any brute. But to get back to the surprise of animals at suddenly encountering man.

While we were staying in these woods I one day came right on a wolf. I had moved so softly that it is evident that the animal did not wake from its sleep until I almost trode upon it. It sprang up with a savage growl, but then stood quite still, gazing on me with a dazed look. While I remained motionless the wolf did the same, and thus we stood for fully a minute, staring at each other. The instant, however, that I attempted to bring my gun to the shoulder it dashed off, uttering a snappy cry. Not quickly enough, however. I shot it before it had gone twenty paces. It was a very old and lanky animal, quite grey about the muzzle, and was probably a sort of outcast from its horde. I have found other old wolves, living solitarily, and I feel sure that they are individuals which have been expelled from the common herd. It seems to be a habit of all gregarious mammals to expel certain members from their society, sometimes on account of age, but more frequently it would seem because they are "rogues" or ".black sheep." 
Every student of natural history has heard of "rogue elephants," for instance, and knows that hunters consider them the most dangerous to meet or attack.

There were wolves in the Michigan woods at this time, but not in great numbers, and they had been so harassed by the trappers that it was difficult to find the few that remained. They evidently scented us miles before we came up to them, for on one occasion we followed a wolf trail for three days in succession, and for the whole of that time they compelled us to follow them before the wind so that our scent was sure to reach them. All our skilful endeavours to alter this were of no avail. In Europe the fox is the type of cunning: he is not one whit more crafty than the wolf. Indeed I should award the wolf the palm for sly craftiness, and I may say that in following wolves for three days we showed ourselves very poor foresters; for this animal is very rarely tracked down. The only way to shoot him openly is either to surround a tract of forest with a large circle of hunters, and gradually close in towards the centre; or to lie in wait near a bait, the said bait being a pig. For the wolf, like the bear, would risk his soul, if he had one, for pork.

But we had this excuse for following the wolves mentioned above, that we knew, from the state of the tracks, that they were not very far ahead, and every night we set traps hoping to catch some of them. The traps were of two kinds-large, steel spring-traps, and a cage-trap, constructed on the principle of a mouse-trap, but of course of huge size. It seems incredible, but remarkable as the statement may seem, these ferocious brutes, while cunningly refusing to enter the traps, actually tore the back out of one of them, though made of steel ribbons, breaking the metal, apparently, with the teeth, and so obtained the bait. It was the opinion of all of us that the trap was broken from the outside; certainly it was done by the wolves as the marks of their teeth 
plainly showed; and Jake could tell a story of a wolf breaking a gun-barrel by a sudden snap of the jaws.

The spring-traps, made like a huge rat-trap, must be concealed, and very craftily too; indeed the cage-traps were also covered with grass and small branches, but without avail, as I have shown. The spring-traps were disposed around the others in the hopes that the wolves would step into them while prowling about. This only happened in a single instance. We found the fore-paw of a wolf in one of the traps. The spring was very strong, and it having cut through the bone, the animal had either gnawed or dragged itself free-not at all an uncommon occurrence with foxes and wolves. After a short search we found the body of the wolf not far off among some bushes. It had bled to death.

Afterwards I lay in wait several nights near the traps hoping to get a shot, but in this I was disappointed. We ascertained that these cunning brutes always came up against the wind, and consequently scented the presence of an enemy. My own opinion is that dogs are necessary to make wolf-stalking successful; but it is only really good dogs that will face a wolf; and the old school of trappers have a prejudice against dogs, holding that they often do more harm than good in tracking the majority of wild animals; as, indeed, I believe they do. In deer and moose stalking profound silence is necessary; and it is only with highly trained dogs that this can be ensured; while the scent of dogs causes the smaller mammals to be very shy and cautious of showing themselves.

Of the pack of wolves we really never got a sight, though we were often quite close to them. They numbered about twenty; and though it is no longer a mystery how savages and hunters follow the trails of wild animals and men, I may mention that it was quite easy to perceive when the wolves had recently passed, not only by the disturbance of the dead leaves on the ground, but also by many other little circumstances, particularly the drop- 
ping of their dung, \&c. Wolves, like dogs, are incessantly shedding their urine, and it is often easy to follow them by the rank odour alone. In the pure air of the woods and prairies, every sense is fully developed and has fair play. There are not such a number of cross-scents and confusing odours as mislead the nose in cities and populous places, and any unusual scent is noticed at once. There is nothing that the hunter has to more carefully guard against than letting his scent be borne on the wind to his prey. The wolves we had been tracking became thoroughly alarmed and soon forsook the neighbourhood, apparently making for the shores of Lake Superior.

About this time a strange and painful incident occurred. While I was wandering in the forest according to iny usual custom I one day met a man running through a narrow ravine. At sight of me he drew his six-shooter, which naturally induced me to place myself behind a tree and demand what he wanted. $\mathrm{He}$ said he had made a mistake, and begged if I had any food about me for the love of God to give it to him, for he was starving. No one could resist such an appeal as that, and I gave him the small quantity of bread and pork I had brought for my lunch. He devoured it ravenously and drained my whisky flask, listening attentively while he was thus engaged, and holding up his hand for silence when I attempted to question him. I took him for a tender-foot, or tramp, who had been guilty of some depredation; especially when, as he went away, he said the sharks were after him, and begged me if they came up not to tell them which direction he had taken. Shortly afterwards I met several members of a sheriff's posse, and of course told them this little incident as the man was evidently a fugitive from justice. Half-an-hour later I heard several distant shots, and curiosity induced me and my companions, who were now with me, to make for the spot whence the sound came. 
We soon met the posse carrying the unfortunate fugitive in a dying state, for they had shot him through the body. Two of the posse were also wounded, but not very severely. It seems the man, who was quite young, had offered resistance when overtaken, and the officers of justice had not been slow to return his fire. He was heaving fearfully for breath, could not speak, and died at our camp less than an hour afterwards. He was buried then and there, under a tree in the forest; and his captors were somewhat reticent about his crimes. We learned, however, that he had taken part in the Fenian irruption into Canada some time before, and since the failure of that ridiculous enterprise, had been living as a prowling depredator on the farmers in this part of America. He had been guilty of violence towards some of them, and had actually killed a negro.

At this time the Northern States were full of doubtful characters, most of whom had taken part in the Fenian raid referred to, and were lurking about in the hopes of further troubles in the British dominions. I have already mentioned that Yankee agitators were fomenting disturbance in the Red River Colony, and it was mostly Irish Americans or Fenians who were engaged in that dastardly work. I have only made cursory reference to this matter, or to the Fenian raid, because I kept far from the points of agitation, and I do not consider it my business, in a book of this class, to deal with the political state of the countries through which I passed. I may, however, mention, that I had certain evidence that small gangs of Fenians were at this time lurking in the woods of North Michigan and. elsewhere, drilling, collecting ammunition, and evidently preparing for the anticipated trouble in Red River (now Manitoba) which broke out a year or two later. For though that attempted rebellion had nothing to do with the Fenian movement, the Fenians hoped to make capital out of it; and it is my opinion that but for their interference and encouragement there would never have 
been any attempt at open resistance to colonial authority in that settlement.

Most of these vagabond Fenians were men who had committed crimes in both Canada and the States, and were therefore obliged to keep on the outskirts of civilisation, living by begging, stealing, intimidationanything except work. It is also pretty certain that they were being supplied with funds from both the States and England. They committed several murders in this district; and some of them were shot by the farmers in retaliation. I met several of them myself. They were mostly American Irish, blackguards of a revolting type, whose whole conversation was of blood and rapine. According to many of them any violence, even the destruction of women and children, was justifiable to obtain their ends - the humiliation of the "damned Saxon" and the independence of Ireland. There were some foreigners, and a few native Irish among them; and many of these had the gaol-taint on them when they arrived in this country. I am writing from memory only, now; but I believe these men were convicted felons, who had been granted their liberty on condition of "leaving their country for their country's good."

I am sorry to have sullied my pages with a reference to this subject at all. It is quite foreign to the matter of the book; but I feared that an absolute silence on a matter that was greatly agitating America and Canada, as well as the Old Country, at this time would be misunderstood, and perhaps excite comment. Personally I was more than once put to inconvenience in Canada, as all strangers were more or less objects of suspicion. However, I had friends in the country, and I have not thought fit to more than cursorily mention these incidents.

Now and then I spent a day or two on the farm before mentioned, where I was always most kindly 
entertained, as were also my companions. We made it a rule, however, for not more than one of us to stay with Mr. Dunford, as the farmer was called, at a time; for his family was large, and as he always insisted that we should have a bed in the house, though we would have been very well content with a shakedown in one of the barns, the presence of more than one guest must necessarily have upset the family arrangements. However, I was so heartily pressed to take up my abode at the farm that, on the whole, I spent as much time there as with my trapper friends.

There was a great deal to interest one about the farm, which was what, I believe, agriculturists in England call a mixed one; that is, part was devoted to raising cattle and poultry, and part to crops. There were some very fine meadows which had been made of artificial grasses at great cost and trouble; but these meadows were much infested with grasshoppers which, in some seasons, did so much damage as almost to ruin the grass, the larvæ injuring the roots, while the fully developed insect devoured the grass. In very wet seasons there were but few grasshoppers, but in dry ones, as this summer was, the swarm anounted to a plague.

There were several species of this insect, but unfortunately I cannot give the specific name of any of them. The first was so like the common English grasshopper, that I could discover no difference, except that it was at least twice the size. This was by far the most numerous and destructive; but another, and much larger species, runs it very close in the latter respect. This is, perhaps, a locust, for its wings are more developed than in the first-mentioned grasshopper, and it flies powerfully. It grows to a very great size, fine specimens being nearly two and a half inches long. 
My attention was first attracted to these grasshoppers by their larvæ. Seeing a vast number of some minute, jumping insects among the grass, I at first thought that they were a kind of flea, or jigger. That was just their size and superficial appearance. I soon discovered, however, that they were young grasshoppers, and on calling my host's attention to them, his countenance fell, and he exclaimed, "The varmints have appeared at length!" According to him they were very late, notwithstanding the favourableness of the season; but the multitude of them was greater than he had ever seen before, and he anticipated a heavy loss of his hay-crop.

A patch of grass that has been devastated by grasshoppers presents a rather singular appearance. The fastidious insects do not devour the bents, or hard stems, but only the tender sprigs or leaves. The bents therefore stick up like the short straws in a stubble-field. The work of destruction goes on steadily, but fast enough to enable you to mark a change in the field every morning; while the chirping, stridulation, or whatever you like to call it, of the insects is kept up all night long, and affords one of the best means of judging of their immense numbers. It is not a loud or an unpleasant noise; on the contrary, it is a cheerful sound; but it seems to come from every square inch of the ground, giving the idea of millions of tiny chirpers, which is probably not an incorrect one. Indeed, on this farm alone there must have been hundreds of millions. By passing the hand quickly over the grass I could capture hundreds of the larvæ in a single grasp; but it is not while the insects are in this stage that a serious attempt can be made to lessen their numbers- to exterminate them is impossible; and, strange to say, few birds, in this part of the country at all events, seem to prey on them to any great extent. Domestic fowls, ducks, and turkeys like them; but the ducks, at least, prefer 
to have them killed, and the wings and legs shaken off before feeding on them. Later in the summer the younger members of my host's family used to gather a peck or two for the ducks. These were mostly of the larger sort, which represent a very respectable beakful for a duck. The bodies are round, plump, more than two inches long, and of a dirty-brownish buff colour, greatly resembling those of the locusts of the south of Europe.

When such a plague as that I have described comes upon the farmers, they are compelled to adopt some means to diminish its evil effects, or they would be ruined. The only effectual defence is to destroy as many of the grasshoppers as possible. The commonest way of effecting this is to dig a long and pretty deep trench. A quantity of dried grass and rough herbage is placed along the outer edge of the trench, and the farm hands are then turned out, great and small, master and man alike, and drawn up in a line, as close together as their numbers will admit of. They start on the side of the meadow farthest from the trench, and advance towards it slowly, gently sweeping the grass with leafy boughs of trees. This drives the grasshoppers towards the trench, into which they fall by thousands. The dried grass, brush, \&c., is then quickly thrown into the trench on top of them, and set fire to. In this way vast numbers are destroyed.

The meadow is then left at rest for a day, and afterwards passed over a second, and perhaps a third time, which generally destroys the greater part of the grasshoppers. In moving across the field, and in making the sweeping motions with the tree-branches, the quieter the men go to work the better, so that the grasshoppers may be induced to keep in front of the line; for the insects never leap in a direct line, but always at an angle to the last leap. That is, their course is a sort of zig-zag one; and if they are too much frightened they will leap 
wildly, many of them breaking back through the line of sweepers.

In the sweeping of Mr. Dunford's farm about twenty bushels of grasshoppers were roasted, in addition to a large number destroyed by other means. They were given to the poultry and hogs, which devoured them greedily. In spite of this great slaughter, his grass suffered severely, his hay-crop being reduced, he calculated, by at least one-half.

Just before I left this district, Brown, otherwise "Splits," married Miss Lillie Dunford, and there was the greatest frolic on the occasion that I ever witnessed, and that is saying a great deal; for "frolics" in the States are a serious business, and never carried out in a half-hearted way. If a man is well enough off to give a frolic at all, he does so in a liberal way. It is understood that a frolic, whether a hunting, corn-husking, or a strictly pleasure frolic, is intended for enjoyment, and-well, in a word, they do not spoil the ship for lack of a ha'porth of paint.

At first there had been some opposition on the part of Miss Lillie's parents to the intended marriage; but it seems that Splits, who was a steady old file, had a comfortable nest-egg by him; and having convinced Mr. Dunford that he had the wherewithal to stock a small farm, ultimately "all went merry as a wedding bell."

To give the reader some idea of a backwoods wedding, and the wide area that a man's neighbours are sometimes scattered over in these thinly-peopled districts, I may mention that there were over a hundred guests at the wedding, some of them coming from distances of over a hundred miles to be present. The reverend gentleman who performed the ceremony came from AnnArbor, nearly three hundred miles away (Mrs. Dunford's native town), performing the journey, both in coming and going, by canoe, through Lakes Huron and Michigan. 
And yet he was over seventy years of age! There were pastors nearer, but this gentleman had married Mrs. Dunford and many of her relatives-was the family pastor, in fact-and he came, not only cheerfully, but no man present enjoyed the frolic better than he.

The actual wedding took place in the dining-room of the farm-house, which was a wooden frame-building, at eight o'clock in the evening, quite a usual time for weddings in Canada and the States; and I should think that, among people of the moderately well-to-do, or middle class, at least, fully two-thirds of the weddings take place in the private houses of the bride's, or bridegroom's, relatives. It is the custom of the land. Of course the festivities had commenced earlier in the day; immediately after breakfast indeed, a barn-dance opening the fun. Wine there was none, but anybody was at liberty to swim in cider-royal and whisky; and some did swim, pretty soon too. Here, as is too often the case in the Old Country among the bulk of the people, a wedding is made an excuse for excessive drinking; and as American whisky is, as a rule, most abominable stuff, the results are often deplorable. On the present occasion, I am happy to say, there was no quarrelling, but some of the guests made themselves very ill.

So many guests, most of whom remained two or three days, and some a week, required a large quantity of food, and there were slaughtered on the farm for their entertainment half-a-dozen oxen, a few sheep, and I do not know how many hogs and poultry. All the female servants, and most members of the family, were engaged all day long making bread and cakes; and a hard time they had of it to keep us supplied with those muchdemanded articles. Like the guests at a certain Welsh wedding, each man had largely to depend on his own efforts as cook, for the staff at the farm was not large enough to provide all the cooked meat that was needed. And I hope it will not be thought that I am emulating 
the boastfulness of the Welshman in question when I record that we had no fewer than seven fiddlers, two flautists, and two sets of bagpipes, to say nothing of a gentleman who did wonders with a drum, which he asserted had been captured at Yorktown when Burgoyne surrendered, but which bore the number of the $47 \mathrm{th}$ regiment. This, I think, was Wolfe's regiment; and it is not at all unlikely that this wonderful drum really had a history. By-the-by, let me remark that all our musicians were whites-not a black fiddler among them, I assure you.

Where did so many people sleep? The most of them on the floors of the barns, wrapped in blankets, rugs, and greatcoats; and lying on sacks, bundles of straw, \&c. One gentleman was placed in a rack by the lively youths of the party; and as he was too tipsy to get down, he passed the night there, comfortably enough if we may judge from the regularity of his snoring. In the house, I believe, they were sleeping five or six in a bed, placed "heads and tails, like sardines in a box," according to one gentleman, who had undergone the experience. The bride and bridegroom, I presume, were accommodated in a garret; for when I turned out, the bagpipes and drums, reinforced by sundry tin-kettles and old pots, were busy serenading a lofty window; and I was just in time to see friend Splits reward their kind attention with the contents of the water-jug.

The farm our friend had purchased was situated about nine miles from his father-in-law's place, and on the third day the bride and bridegroom were carried the whole distance on the shoulders of their friends, and after a day's orgies there, they were left in peace, and we returned to finish the rejoicings at the father's house.

I have thus been minute in an account of this wedding, because I believe that the proceedings were typical of backwoods marriages in general among the respectable farmers. For if the scenes here may seem 
a little rough and vulgar to some English readers, I can assure them that they were remarkably quiet and orderly compared with those that often take place on similar occasions in the outlying settlements.

Mr. Furgesson, of Scottish descent, the pastor who united the happy couple, was, I believe, a Baptist by denomination, and undoubtedly a very good man. Unfortunately he discovered one or two of my little weaknesses, and it seemed to afford him pleasure to give me pain thereon. Possibly I was foolishly susceptible; but the fact is, that confounded drum of the gallant $47 \mathrm{th}$ led up to a discussion, in the course of which Mr. Furgesson made such abominable charges against British soldiers and sailors, that I could not help feeling angry at him. I should not mention so puerile a matter if it were not for the fact that the dispute which arose between us ended in Mr. Furgesson claiming a superiority for Americans in everything they did or said, particularly for the purity of the English they speak. "Excuse me, Mr. Fountain," said the reverend gentleman, "but you used the word clark for clurk. 'Clerk,' pronounced 'clark' means a priestly man. You should say 'clurk' when you mean a commercial accountant."

I ventured to think there was so such distinction, and that the word might be pronounced indifferently either way. "Nay!" replied Mr. F., "I have had a collegiate education, and in that I have the advantage of you. In common with other Britishers I notice that you mis-pronounce many words. Now we have, singularly enough, kept the English language remarkably pure. American-English is the purest in the universe, \&c. \&c."

American-English! I hope it will interest most Englishmen not acquainted with the States to learn a little of how the Yankees abuse what ought to be their mothertongue. As I desire to be perfectly fair, I admit, before going farther, that the bulk of Americans, even the negroes, are on the whole better educated than Englishmen. But 
they are responsible for a great deal of bad English. I took up my paper yesterday. The first paragraph that met my eye was to the effect that a club of bachelor girls had been started in New York. This is a distinct and a gross abuse of the English language. Girls may be spinsters: they never can be bachelors-unless they reverse the sexes as they do with regard to the gentlemen cows, i.e. bulls.

I have said that Americans are, as a rule, better educated than Englishmen, but this statement requires some modification. In what I term the $\mathrm{A}, \mathrm{B}$, C's of education, the bulk of the American people are, undoubtedly, better grounded than the bulk of the English nation, but you do not often meet with a really well-read American gentleman. I consider extensive reading the most important part of an education, as it is undoubtedly the most mind-expanding. Yet you often meet with Americans who, while they are very fair classical scholars, are ludicrously ignorant of modern history. Science, again, is an American's strong point in his own estimation, but as a matter of fact he holds, generally, a very inferior place in any branch of science. In philological learning, again, he considers himself a past-master, and as Mr. Furgesson claimed, declares that a Yankee is the only man on earth who speaks pure English in general conversation.

Any gentleman who has spent some time in the States, however, knows better than this. Not only do the Yankees interlard their discourse with many foreign words (which is the greatest corruption of a language that can be committed) and much slang, but they also misuse hundreds of words, giving them quite a new meaning. It is no use pointing out these inaccuracies to an American. $\mathrm{He}$ will obstinately persist that he is right and you are wrong, and will appeal to any obscure American lexicographer rather than to Johnson or Walker, at whom he scoffs.

But it is to the introduction of slang and foreign 
words that I take the greatest exception. In many parts of the States there are, and have been for more than a hundred years past, isolated colonies of foreigners who cannot speak a word of English. These people, who are principally pure bred Dutch and Germans, live and keep to themselves, forming isolated communities in the land. So far, so good. These interfere not with the English language, but there are other Germans, and Dutch and Russians, Jews principally, with riff-raff and scoundrels from every part of the world, none of whom speak their mother-tongue correctly. These people have imported a large number of continental slang words among a community which delights in slang, and many of these have, during the last half century, been retransported to England to the no small corruption of the language. Take an example. The East End coster no longer has a girl. She has become "My dōnar," or donah, an evident corruption of the Italian donna, or lady.

But a far worse abuse is the use of words of a profane nature. When I first went to the States I have often heard American gentlemen use abominable language, even in the presence of ladies, without arousing the least symptom of disgust or even surprise; while to describe the land as "Well! this is an infernal country," or, "Well! I'm jiggered! this is a h- of a track," was a common figure of speech : truck, by-the-by, being used for "tract"; and this not in the mouths of vulgar cowboys, but the everyday language of men of position. The word infernal is to this day in common use in the sense of bad; as, "This timber is infernally rotted," "This is an infernal path," "The roads are infernal," "He is infernally ill;" the thought of the infernal regions probably never entering the speaker's mind. This abuse of the word is becoming common among the lower and middle classes in England; while, on the other hand, the superior classes in America have during the last twenty years or so greatly improved and 
have dropped the use of many objectionable words and phrases.

Of such words as "skedaddle" for "run away," and "varmish the ranch " for "abandon a position," and a host of others which came into use during the Civil War, I need say nothing, because they were never used by educated people, except, perhaps, playfully; and the remembrance of them is gradually dying out, even in the country of their birth. Like many vulgar sayings and words in our own country, they, like some noxious insect, flutter out their little day, then fall and die.

What I have said applies to the vernacular and not to the written language. The American classics with few exceptions are couched in language as pure and elegant as the average of our own, though I think, considering her vast population, that the good writers of the United States are singularly few. There are at least five hundred English words that are used in a false sense by Americans.

In commercial language it struck me as having an unpleasant sound to address a firm with the abbreviation "gents." instead of "gentlemen," or the more cordial "Dear sirs." 


\section{CHAPTER XXIV}

ANIMAL LIFE ABOUT MR. DUNFORD'S FARM, WITH AN ACCOUNT OF “MAJOR" SHADLEY, AND TITLES IN THE UNI'LED STATES

ONE afternoon when I returned from a ramble I found Mr. Dunford chastising one of his younger sons, a boy of fourteen. The young rascal, it seems, had been out with a gun without permission, and had not only blazed away a pound of powder (a very valuable article in the backwoods), but had shot thirteen robins, a most heinous offence, and one which I was surprised to find an American boy committing; for the American robin is as much revered in this part of America as the English robin in the Old Country. About Boston, however, Chicago, and many parts of New York State, I have seen boys and men shooting them, as Cockney sportsmen used to do the sparrows in my own country. Few farmers will permit them to be destroyed on their farms, as they say that this bird is a most useful devourer of noxious insects. My experience is that, like a thrush, which its habits exactly resemble, it is omnivorous, with a preference for fruit, of which it is passionately fond, in this matter emulating the fieldfare and common song-thrush of Europe, which all observers must have noticed clustering in hawthorn bushes, mountain-ash, and apple or pear trees in which, by chance, a few fruit have been left.

Robin is a misnomer; the bird so called is really a thrush, Turdus migratorius of the Americans, Turdus canadensis of Europeans. But I have this to say, with all due deference to the professional naturalists, that superficially, at least, and size apart, the English robin is 
not only remarkably like a thrush in shape, but has also many of the peculiar habits and contortions of one. The common song-thrush has a peculiar trick of twisting and fluttering in the bottom of a hedge which is indescribable on paper. The robin of England has a precisely similar trick. The object of the bird in either case I have not been able to discover. Perhaps it is a case of mimicry. At all events there is, in my opinion, some excuse for the vulgar but popular name of $T$. canadensis; for it is as much like a robin, size set aside, as a thrush.

The American robin, as we will call it, is about the size of a blackbird. The upper parts are a bluish grey colour, the under a sort of orange, or rust colour, which, no doubt, was the chief reason for bestowing its popular name upon it. The primaries and head, neck, and tail are blackish brown; and the breast and belly of the female are buffish brown instead of orange. The plumage of the bird varies in some degree in different localities, and there is also a seasonal change. I first saw the bird in Red River Colony (Manitoba) and other parts of the Great North-West; and afterwards odd birds, or small flocks, in nearly every part of Canada visited by me. In the United States it is very extensively distributed. I saw it in all the Northern States east of the Rocky Mountains, but it is not found in any of the Southern States.

It is a sociable bird, often seen about the farms, homesteads, and villages; and there were several nests in Mr. Dunford's orchard, built in fruit-trees close to the house. Bushes and fruit-trees are its favourite nesting places, and the nest is usually placed ten or twelve feet from the ground. It breeds rather early in the spring, and when I arrived here the nestlings had already taken wing and were often seen, together with the old birds, hopping about the farm-yard; and on one occasion I even saw a robin in the dairy picking up the crumbs that lay in the sink. Robins are held in as much favour and awe by American country-people as redbreasts are by the peasantry of England; yet in towns, as in Boston, Trenton, 
Providence, Philadelphia, \&c., as well as in many smaller places, they are often exposed for sale as food, the price being a dollar for two or three dozen, according to their abundance. Like many other small birds they are delicious eating.

The robin is much given to squabbling with its companions, and attacks other small birds, in this respect again resembling the English redbreast, which is a fierce little tyrant. "Who killed cock-robin ?" says the nursery rhyme. It should be Who killed cock-sparrow? for I have actually seen a redbreast slay a sparrow. I do not know that the American robin is equally fierce, but it will not permit other small birds to feed near it.

The robin is gregarious, to some extent at least. Where you find one, you may be certain there are others close at hand. It is rare to see single birds; occasionally six or eight go together; but when the breeding season is over, you will find them often in flocks of eighty or a hundred, and, more rarely, perhaps two or three hundred will be seen together. It is when they are in flocks that they fall victims to the netter.

The robin is one of the few birds which seem to prey on the kitty-dads or grasshoppers, though cuckoos and mocking-birds do so also where they are found. Before swallowing the grasshoppers all these birds nip off the legs and wings of the victim. The robins also devour all sorts of insects, and are as fond of snails and slugs as the European thrush. They, however, are still more fond of fruits, and they may, like fieldfares, be shot down in great numbers by a gunner concealed near any fruit or berrybearing tree. The fruits I have most frequently seen them devouring, in flocks or parties, were the blackcherry, Cerasus nigra; sand-cherry, C. depressa; elderberry, Sambucus canadensis; gum-berry, Nyssa sylvatica; and a bright scarlet berry resembling a hawthorn-berry, the specific name of which I have failed to learn; also blackberries and wild raspberries, and all sorts of cultivated fruits. They even peck the apples and pears, and 
I have seen them in American apple-trees, comparatively hard and tasteless as that fruit is. I am puzzled about these apples-whence came they? They are small and elongated in shape, something like a tiny sausage. They are not worth the picking, though they are made into jam by the Yankees, as is everything else that is not as hard as a cannon-ball. All the fruits mentioned above are found abundantly in the Michigan forests.

At the risk of being tedious, I must yet say a few words about the song of the robin. $\mathrm{He}$ is not to be compared to our own beautiful song-thrush, yet his few notes are sweet and plaintive; and I have never met the backwoodsman or hunter who would not stop to listen to him, as, perched on the top of a tree or bush, he uttered at intervals his few charming combinations of sweet sounds-a sort of mellow whistle, not at all like the song of our thrush. The robin is something of a mocking-bird too. He imitates the songs of other birds, but not at all so well as the mocking-bird, and I have heard them evidently striving to repeat the whistle of man. In captivity they will learn a few notes from the flute, and they are agreeable cage-birds, becoming very tame, and recognising their owner. My host had two, one of which he had in a cage for twenty years. It was so tame that it would come onto his finger at his call.

The robin leaves Canada and the north of the States in September and October, though I have seen odd ones in Michigan as late as the first half of November. They do not go very far south to winter, certainly not as far south as Florida, and they are the very first birds to return in spring, beginning to reappear in.March. Their advent is always joyfully noticed by the farmers and others as an indication of the return of fine weather.

I will not describe any other bird here; but nearly all those noticed in the British territory to the north - that is, Red River, \&c., \&c.--are found in this part of the State. Wild ducks of all sorts are extremely abundant in the marshes near the shores of the lake, but I did not see 
any swans, though I heard that a few had been shot within a few miles of the farm.

Bats were very plentiful about the barns and the house itself, passing to and fro to the trees of the forest. There were at least five species, of which I can name with certainty the long-eared bat, Plecotus macrotis, which does not seem to differ materially from the long-eared bat of the British Isles, $P$. auritus; the silver-haired bat, $V e s-$ perugo noctivagans; and the brown bat, Vespertilio subulatus. The last, which is a very small animal, was by far the most numerous, but the silver-haired bat was the one about which I learned most. It is brown in colour, but the longer hairs towards the base of the back are tipped with white, hence the name. But it is a misnomer, as the creature cannot be truly called silver haired, and the name is probably only applied as a distinction. There are a couple of white spots at the sides of the head, and a portion of the membrane by which it flies is hairy, a rather unusual circumstance. It is, on the whole, a handsome bat, and tolerably plentiful in this region.

I was attracted to it by seeing it hawking over the meadows, which were infested by the kitty-dads, where it appeared before sunset, skimming close to the ground. I have noticed in other parts of the continent that the silver-haired bat comes forth very early in the evening if prey is abundant. I have no doubt that on this occasion it was the grasshoppers that the bat was in pursuit of, but I could not verify the supposition. I traced the bats to a hollow tree, just within a clump of forest that bordered on the farm, less than half a mile from the house, and, going thither with a ladder in the middle of the day, found their colony about forty feet above the ground. The number of bats was considerable; but as the hollow was extensive, running up and down the tree, I could only see and disturb a portion of them. Probably there were from two to three hundred in this one colony.

The cries they uttered on being disturbed were very faint, as they are when the bat is on the wing. It is a 
sort of a sharp metallic click, very high pitched, but not loud. Probably it would not be heard or noticed by a person standing under the bats when they were flying high, though I have often heard it while watching them. Some of those which I handled attempted to bite, but though the teeth are sharp they are small, and the jaws weak, and I do not think the little animal could inflict a very sharp nip-not so sharp as that of a mouse. I was anxious to learn something of the breeding habits of this bat, but I could not find any traces of young ones. There were certainly none at this time of year, the end of August.

Often when quietly watching the birds in the orchard I noticed some exceedingly small creature rush over the ground so quickly that it appeared as a mere shadow, scarcely larger than a marble. It always started from a lurking place under a bramble, tuft of grass or treetrunk, and disappeared into a similar refuge, so that I could never get a clear view of it at rest. Its motions were so sudden and peculiar that I thought it must be a large ground-spider. After much trouble and many attempts I caught this little animal in a butterfly net, and found it to be a shrew-mouse, Sorex cooperi. So exceedingly minute is this animal that I feel sure it is much less in size than our English harvest-mouse, and is therefore the smallest mammal living. It is a most beautiful and graceful little thing, and that which I captured was so overcome with terror that I feared it would die with fright, and released it before I had fully examined it. I soon found others, however, under the guidance of an old negro, who knew where to look for them. Their favourite haunt is in rotten timber lying on the ground. They eat hollows into it, and there form their nests, seeming to have sometimes as many as seven or eight young. In every trunk where we found them, however, there was always a colony, fifty or sixty at least, which made their escape instantly, seeming to roll over the ground, leaving their young 
behind. Many of the latter were not nearly so big as humble-bees. The multitude of insects and larvæ which swarm in rotten wood is probably the attraction to these little animals. The same cause induced them to harbour in the orchard, for I noticed that a multitude of small birds frequented the ground under the fruit-trees to pick up the grubs, \&c., which fell from the branches. I could not discover that these shrew-mice ever touch other food than insects and their larvæ, and I should think that they are valuable friends to the farmer.

By-the-by, in the southern part of Michigan I found a much larger shrew, which is certainly the same as Sorex vulgaris of England. It does not seem even to be a variety. Is it indigenous? or has it been transplanted like the rats, mice, and sparrows from the Old Country?

A few evenings before I left the hospitable and kindhearted Dunford family we were visited by "a major." The major was dressed in a pair of green trousers (he had been in the rifles, perhaps!) which were extensively patched with brown cloth on that part which was hid from sight when the major assumed a recumbent position. He had no coat, and his red Garibaldi shirt, like his what-ye-may-call-'ums, had undergone many repairs with materials of a different colour and texture from the original. As he, without being invited, took a seat at the log fire, and complacently crossed one leg over the other, I noticed that his shoe was nearly soleless. If one of his eyes had not been knocked entirely out, it was, at least, out of line with the other. There. were also sundry scars about his face and nose, the marks of bygone fights during the war, perhaps, or during drinking-saloon rows. His face and hands were of such a colour that he might have been any breed, red, black, grey or brown; but a glimpse or two of the most exposed parts of his person obtained through the rents in his shirt showed that, at all events, he had been born white. From these signs I concluded that the major had lighted on hard times. I should certainly have taken him for 
a tramp, and a very dilapidated tramp, but his air of cool self-possession would have graced a king. It was afternoon, and Mr. Dunford and I happened to be alone in the house, Mrs. D. and the girls having gone to visit the recently-married daughter, and all the males being still at their work. My host and I were having a quiet chat and smoke together, the last we thought to enjoy previously to my departure. Had the lady of the house been at home, I fancy Major Cornelius K. Shadley would have had a different reception from that he received from the quiet and amiable Mr. Dunford.

Cornelius had probably reconnoitred the house and thought that there were no men about; for he impudently entered without knocking. Seeing us he was somewhat taken aback, but only for an instant. "How do, boss? How do, younker?" he said, nodding to us with the familiarity of an old acquaintance, and without more ado he drew a chair near the fire and sat down. As he had all the appearance of a professional tramp, I expected that Dunford would order him out, but after glancing at the two formidable six-shooters in the intruder's belt and at his own gun hanging over the fireplace not within immediate reach, he simply asked what he wanted.

It is to be noted that all the tramps and tender-feet, at this period at least, carried valuable six-shooters that could not have cost less than twenty-five or thirty dollars apiece. This fellow had two splendid weapons, bright and in good order, in addition to a bowie-knife.

In answer to Dunford's inquiry he said that he was "prospecting for land," an assertion that caused me to laugh; though, by-the-bye, it is not safe in the States to judge of a man's means by his personal appearance. I have met men who looked as if they had been pulled out of a chimney who, nevertheless, possessed a very respectable banking account, and it did not escape our notice that as yet the major had made no appeal for charity. As to his abrupt manner and free conduct, it is very usual in the States. Our host gravely asked 
if he was wanting a big block (the land is sold in "blocks"), and mentioned some good land that he knew of. Cornelius said he was game for anything between thirty and sixty thousand acres. I could not repress a grunt of astonishment, which drew his eyes on me with a sharp look. "You was never riz in the States," he said. "Are you a —— Britisher?" I admitted that I was one of that much-abused yet long-suffering race. "I thought so," said the major. "You know, I suppose, what a _- whipping our Washington gave you a hundred years ago?" I replied that I had heard something about it. "Well, I guess that ain't nothin' to the whipping you'll get within these next ten years." I was, of course, sorry to hear this, but ventured to think that a flag that had braved the battle and the breeze for a thousand years might still be found floating over its unhumbled sons for a longer period than ten years. "You've got to clear out of Canada; that's what you've got to do." I thought this notice to quit, like a great many more, might be disregarded, and remarked that possession was something more than nine points of the law when backed by an armed force. "I tell you, you are going to lose Canada, and you're going to lose Ireland," reiterated Major Shadley. "I say, boss, have you got any cold pork, and a hollow-toothful of whisky?"

Dunford got up and began to lay the table; meanwhile the major talked incessantly to $\mathrm{me}$, and in spite of his brag and big assertions, to say nothing of his downright lies, the fellow was most amusing, and of imperturbable good-temper. His mouth was the most pleasant of his features, for the good-natured smile never left it; and I wondered if he ever used the formidable six-shooters. I ventured to ask. "There's twelve lives there," he said, "for I never miss a shot. I'm none of your bloodletters; but, by golly, when I'm riz, I shoot free." "You are a dead shot?" I inquired. "Dead shot! Why, I've clicked a flea off a dog's nose and never grazed the 
dog." I thought it unnecessary to inquire further particulars of Major Shadley's skill as a marksman.

Of his skill as a trencher-man I was soon left in no doubt whatever. He was a long, lanky, thin fellow, and where on earth he found stowage for his food I could not conjecture. He put junks of pork two inches square into his capacious mouth, and seemed to swallow them, like pills, without chewing, helping himself liberally to whisky; but he was not greedy in the latter respect and knew when he had taken sufficient. The entrance of Tom, Mr. Dunford's eldest son, upset his equanimity; for Tom took after his mother, who was a lady born to rule; and as he surveyed the major from head to foot, and foot to head, in no very friendly glances, the latter shuffled about in his seat in a way that reminded me of a lobster in a lobster-pot. I perceived, at once, that the major's sixshooters were simply the lion's skin with which the ass had tried to make himself appear formidable.

"I 'spose we've got to find you a shakedown," said Tom. "Jest you come along to one of the barns, and leave your pipe and lights here. You ain't going to smoke us out o' our homestead. Come along," and the major went with the meekness of a sheep to the slaughter, and with an appealing look towards Mr. Dunford and the fire, as much as to say, "I should like to sit a little longer." The weather was chilly, I should say: for autumn was well advanced, and the cold in north Michigan sets in early.

Next morning I heard Tom at the major again. "You can have a breakfast before you go. Then just you varmish - you understand? Clear off. I ain't a-going to have you loafing about the farm." The major promised that he would make himself scarce without delay; but he took advantage of Tom's departure for a distant part of the farm to induce Mr. Dunford to let him remain till the midday meal. In the afternoon Mrs. Dunford returned from her visit, and not a quarter of an hour elapsed before the major told me that he saw how the wind blew. "I think I had better be off", he said. 
I agreed with him, as if he lurked about till Tom came home he would "probably have a flea "clicked off his nose," and I would not undertake to promise that the bark would not be raised in the process. The major looked at me askance, but smiled. He still lingered. "Britain's a rich country ?" he inquired. "I believe so." "Plenty of money there?" "Yes." "Lend me half-a-dollar for a month or two." Such a trifling favour could not of course be refused, but the major insisted on making a note of the transaction with a view to future repayment. Diving into one of his side pockets, he produced a pocketbook nearly as dilapidated as himself, and strongly perfumed with stale tobacco. As I did not care to give a business address to such a character, I said I had no fixed address at present. "Like me," said he; "but we shall meet again;" and, truly enough, we did meet again.

I have given this sketch of an individual of a race of creatures that are rapidly being stamped out in the modern United States. Like the swagsman of Australia, he cannot long survive when the law against rogues and vagabonds can lay hold of him without over-exerting itself. I hope the sketch will be of some interest as the correctly recorded picture of an incident that gave me much amusement at the time; though the humour of the major was so very broad, and disfigured by such strange and terrible profanity, that it was only in the wild surroundings of the time and place that it could give amusement, and could not by any means be too minutely recorded on paper without giving disgust.

As to the man's title to major, reference may be made to what I have said in a former chapter on military titles in America. (See the Index.) But I may add a few words on titles in general among this strange people; for while they profess such a dislike to titles and distinction that they would not admit the words " master " and "servant" into their daily life, but substituted " boss" (Dutch foreman) for the former, and " help" for the latter, there are really no greater quality worshippers on earth-not even 
in Spain or in Germany. A lord!! That is a thing to be scoffed and sneered at while he remains in England, but let one come out here, and the announcement of his arrival appear in the papers, and immediately every lady in the land will have palpitation of the heart, and before he is fairly settled in his hotel a full description of him, from the colour of his teeth to the fit of his boots, will have had a prominent place on the front page of every journal published in Uncle Sam's territory.

I have said enough about military titles in the States, especially as it is a hackneyed subject which has long been a favourite skit of the humorist; but it is certainly not so well known generally to Englishmen that every class in America abounds in titles of honour, to which, for the most part, they have not the slightest legal claim.

To commence with the legal profession. I knew a judge who was a slaughterman in a village near Chicago, and who when work was slack travelled the country as an itinerant pig-sticker. His honour used to swear and get drunk; and I have seen him with a black eye on more than one occasion. I do not know if he ever sat on the bench; but I am quite sure that he could not adjudicate in grammatical language. Who is, or who is not, a judge in this country it would be difficult to say, for many members of the learned professions do not think it beneath their dignity to follow very humble manual occupations in daily life. For the emoluments of a professional man in an outlying and sparsely populated district are not sufficient to support him; indeed it seems to be the honour, rather than the profit, of official position that is sought after. This remark applies chiefly, if not solely, to obscure appointments in obscure places. I am not writing of the great officers of State.

To resume, I knew two other judges who really acted as such, one of whom was a barber and the other kept a very small store, equal perhaps to a huckster's shop in an English hamlet. I heard one of these gentlemen, in delivering judgment, tell a defendant that he believed 
he was a b-y rascal, and if he did not get out of court pretty quick he would kick the tails of his coat. I am putting it as politely as I can.

But the title of judge is so common that certainly many men must assume it without authority to do so. For instance, in a township of seven hundred inhabitants there were five men addressed by this style, the omission of which in the superscription of a letter, or bill, or even in colloquial speech, would have given great offence, as it actually did in one case in which I was personally concerned. Yet the most respectable of these five was a man who ran a small store, quite a twopenny-ha'penny affair, while another was a disreputable loafer and drunkard, who lived I do not know how. A third was a blacksmith, and the other two were farmers, not so well off as average English market-gardeners, and certainly not one whit better educated. I may add that I have known a duly appointed judge to be drunk when he took his seat on the bench, and several who threatened principals and witnesses with personal violence.

"Professor" is not so common a title as judge; but there are few districts in which at least one gentleman bearing this exalted designation may not be found. A boy of sixteen, hearing I was making a collection, brought me some rare eggs. I spoke to him with the familiarity I might display to any boy, but he soon brought me up with a round turn, by informing me that he was a professor, and expected to be addressed by his title. "A professor of what?" I inquired. "A professor of Greek," was the reply. He kept a school in a district where there were about eight persons to the square mile, had about a dozen scholars, and eked out a miserable living by turning his hand to anything it could find to do. He seized with avidity the few dimes I gave him for his specimens. I do not remember to have ever met a professor of law - they are always judges; but there are a great many attorneys who are not in practice, never have been, and never will be. But then every American 
who has the slightest pretension to learning has studied the law-so he will tell you. As to general professors, in some parts of the country I could scarcely find a schoolmaster who did not lay claim to that title, though not one of them had been to a university or received a learned degree of any kind. There were professors of languages, general and specific; of the latter, Latin, Greek, and Hebrew in particular; professors of history, of mathematics, of ethics (spelt "etthics" in one case), of medicine (with three boxes of pills and half-a-dozen vials in the window of his hut); of writing; of phrenology, and of mystery and spiritualism. These were not mere trade designations; but the bearers of the titles would, one and all, have looked upon it as a gross insult if they were not habitually, and on all occasions, addressed as "Professor."

Perhaps the most general of all civil titles is that of "doctor." A diploma, of a sort, can be picked up for a song in the States; but, quite apart from that, the number of doctors is simply enormous, amounting in some places I was afterwards in the habit of visiting with my waggon to twelve per cent. of the population. Of all these, I am sure, not one was a qualified medical man, probably not one was other than an unqualified quack, though some pretended to bave studied medicine in Europe and the States, one man exhibiting a full-grown skeleton in his house, and claiming to be a professor of anatomy as well as an M.D. Hundreds of persons, however, use the title of doctor without pretending to practise the medical, or any other profession, desiring merely to raise their name above that of the general rag-tag and bobtail of humanity.

Another numerous class of titled personages in the States are those who have held office of some sort, and whose official designation clings to them for life. Thus there are no end of Mr. Commissioners, Mr. Sheriffs, Mr. Deputies, Mr. Senators, and Governors. A man who has been a deputy, if but for a week, is Deputy Silas P. Johnston, 01 whatever his name may be, to the end of his days. 


\section{CHAPTER XXV}

\section{JOURNEY FROM MR. DUNFORD'S FARM TO MARQUETTE}

I THINK I have mentioned that the number of small mammals in the forest near Mr. Dunford's farm was considerable both in numbers and species. In addition to rodents and insectivores, there were also many foxes and skunks, and these last gave some trouble to my host by visiting his hen-roosts and killing his poultry, for the skunks have just the same habits as the foxes in this respect. To guard himself from these depredators it was his custom to leave a fierce dog, of mongrel breed, loose in the yard all night. The dog killed one skunk by nipping it across the loins, thus affording some refutation of the opinion that dogs are scared away by the abominable stench of this animal. Some dogs will not attack skunks; a good dog will do so. It would seem, therefore, that fear rather than the offensive smell is the deterring cause. The skunk is a very fierce animal when put on its defence, and is a match for a bigger animal than itself; but it is so rarely attacked that this fact seems to have escaped observers. I cannot find a single reference to the pluck of the skunk in any work on natural history within my reach; on the contrary, it seems to be the opinion that it is a mean and cowardly creature, dependent on its abominable habit for safety. This is quite wrong. It is quite as plucky as an average dog; and is, moreover, a cleanly animal. It is quite as easy to tame a skunk as a badger, and if taken when young it can be taught to follow its master like a dog; but nothing will cure it of offending, from time to time, with its abominable nuisance. 
Notwithstanding that my friend's dog kept the foxes out of the farm-yard, these cunning animals contrived to form a burrow under the boards seven feet long, and coming up through the floor of the hen-roost sometimes killed as many as a dozen fowls and ducks in a night, carrying away one or two, and simply eating the heads off the others. A concealed trap was placed in this burrow. It caught one fox, and then these remarkable animals formed a new burrow, avoiding the old one. In a short time they had destroyed half the poultry on the farm; and it became necessary to try other means of driving them away; for few could be trapped, even in the forest, and only a few shot without organising an extensive drive.

The plough was therefore brought out, and four or five deep furrows ploughed across the ground, converging on the hen-roost. In these furrows steel spring-traps were placed covered with earth. Now foxes when abroad, and especially when foraging round farms or habitations, will always take advantage of the ground for concealment. They will run along ditches, the bottom of hedges, and behind walls, well knowing what excellent protection from the sight of enemies these afford. Ploughed furrows are particularly used by them. They will go much out of their way to avoid open meadows, and approach a farm in the furrows of a ploughed field.

It was a knowledge of this trait of the fox that induced Mr. Dunford to adopt these trenches as a means of protecting his fowls. The first night after they were formed, three foxes-two red and a grey-were taken. They were all caught by the fore-leg, and two of them simulated death when discovered. The third howled dreadfully, and made frantic efforts to escape. None of them attempted to bite. Two nights later another red fox was caught; but after this none approached the farm. They were fairly alarmed, and kept away. The intelligence of these animals must, consequently, be very great. The men on the farm asserted that after such a lesson as 
had been taught them their fright would be so great that they would not attempt to renew their depredations for many months.

The time had now come for me to leave my kind friend and host. The winter was not far off, and I had determined to pass it in a town previously to leaving the northern parts of the States permanently. I came to this resolution reluctantly, and in spite of a lingering desire to keep near the British frontier. My heart's desire was to settle in Canada, or failing that, in one of the northern States; but by this time I had become convinced that, in spite of a strong constitution, I could never weather the severe winters of the North.

After some chilly winds, accompanied by storms of rain and hail, the weather suddenly cleared up, and the latter half of October in this year was remarkably fine, bright, and clear, though with sharp frosts every night. I had purchased an old horse at this time with a covered cart (not the waggon in which I afterwards for many years traversed the Mississippi States), and in this I determined to proceed to Marquette, where I intended to pass the winter. Long Jake wished me to go with him by canoe to Chicago, where he had a market for his pelts, and proposed that I should take the place of "Splits," the benedick, as his chum and partner, so good an opinion had he of my skill and energy as a trapper. But though I had discovered that there was a market for "specimens" in England, my opinion was that fur-hunting, even at this time, had seen its palmy days go by for ever. Pelts then, as now, fetched their price, but really good furs had to be sought for so far distant in the wilds, and the time and trouble of bringing them in was so great, that it was impossible for a trapper to earn more than the wages of a mechanic; and he was fortunate who could do that. So I declined Jake's offer, and we parted with a hearty shake of the hand and mutual regret, for we had been excellent comrades. 
The distance to Marquette from Mr. Dunford's farm was about eighty miles as the crow flies, but a route was mapped out for me which, though it increased the length of the journey by thirty miles, I was assured I should find an immense advantage in taking, not only on account of its being a better road, but because I should also have a succession of farms and other places of call where I could obtain food and shelter. Mr. Dunford kindly offered to send either one of his sons or a man with me to show me the road; but considering the trouble he would have, and that he must return alone, I would not agree to it. My self-confidence at this period was illimitable, and I would have set out on a thousand miles journey alone without hesitation. A mere hundred then, I laughed at; but I soon found, as all youngsters do, that to resolve and to execute are two very different things, however closely they are allied.

The road lay through forests nearly the whole distance. The first two nights I stopped at hamlets of small size; and the third at a large farm, getting rough but most hearty hospitality at each place. But the roads between them were execrable; in fact there were no roads. Near the hamlets, for a mile or two, there was a cart track, but it was in such a bad state from the passage of heavy wains that I found it better to pick my way through the forest by the side of it. This road had originally been made by laying logs side by side; but these, of course, had soon rotted, and being repaired piece by piece had left it in a most treacherous condition. For while a portion of the road seemed firm and good, and induced me to urge my old mare into about the best trot she had ever done in her old age, we suddenly floundered on to rotten logs that gave way beneath us, and the cart sank in up to the axletrees, as did the hind-quarters of the mare till she was half hid from sight. Finding herself in chancery, she did a very wise thing-remained quite passive; but of all the comical figures she cut! - there it was no joke to me. 
Scrambling out of the cart, I did my best to get her out of her uncomfortable scrape. I could not get at all the buckles to release her, and had to cut some of the harness; but at length her struggles, and my tuggings and pullings, got her out of the hole, and she walked to the side of the road unhurt, I was glad to see, and began to nibble such leaves and herbage as she could get at, quite indifferent to my predicament and the efforts I was making to get the cart up. In vain I unloaded it of all my effects and strove with all my might: it was firmly wedged in between the logs, and I could not stir it an inch.

I was in despair. It would take me quite two hours to walk back to the hamlet; and though the forest was so solitary that I supposed there was not a human being nearer than eight miles away, I did not like to leave the horse and my goods, especially as it would probably be dark before I could get back; for I had wasted three hours in trying to move the cart.

While I was pondering on what would be my wisest course, I heard voices approaching, roaring out a song of anything but delicate sentiment, and presently three very scabby-looking scamps came up. Of course they were armed with the inevitable six-shooter, which takes the place of the walking-stick in this country; and I marvelled how much, for brightness and size, two of these weapons resembled those of the redoubtable Cornelius K. Shadley, whilom major in the United States army. These men, however, though undoubtedly tramps, were better dressed than the major, and appeared better fed. As they came up, one of them exclaimed, "What the L have we here?"

I explained what had happened and begged their help in getting the cart out of the hole. They laughed, and were in no hurry to help me; and one of them facetiously offered me a thousand dollars for the mare, saying that he had been looking for a bit of blood for breeding purposes for a long time. This bit of pleasantry 
afforded them immense amusement. I put the best face on the matter I could, and laughed and joked with them in the hope that that would prove the best way of winning their good will, for I could see that they were three very nasty fellows.

They began to throw my goods about, and to appropriate whatever took their fancy. Some cakes and jam, which Mrs. Dunford had kindly given me for use on the road, they ate, or wantonly threw away; and each of them donned one of my clean shirts, which they certainly wanted badly enough. Having discovered that I was an Englishman, they destroyed everything I possessed except my arms. One scoundrel tried to take my rifle from me, but I threw him off so vigorously that he fell into the hole out of which the mare had scrambled. For a moment it looked as if there would be murder, for I was determined to die rather than suffer myself to be disarmed, though I would not shed blood for the sake of a little personal property; but it ended in a laugh at the ridiculous figure their mate cut, with his head in the hole and his legs sticking up.

When they had satisfied themselves, and plundered me of all that they could carry, they began to walk away, but I asking them again to help me pull the cart up they turned back and did so, assisted me to mend the harness, and then insisted in riding on to the hamlet in the cart. Arriving there, I, of course, told the people what had happened; but though there were twenty able-bodied men in the place, they were so awed by these three scoundrels that nobody dared lay a finger on them. They remained in the place all night, eating and drinking of the best, and treated as hail-fellow-well-met by the majority of the inhabitants; and in the morning would have taken my horse and cart from me, but that by this time my blood was up, and I threatened to blow the brains out of the first fellow that touched them. I was therefore permitted to depart, shorn as I was, but for- 
tunately with some three hundred dollars in gold safely stowed away in my pockets. I left these rascally tenderfeet in the hamlet, half drunk, although it was scarcely daylight. All day long I was apprehensive that they would come after me, but I never saw them again.

My mare not having much go in her, the road, where road there was, being so bad, and I several times mistaking side tracks for the main one, caused so much delay that I was eight days doing the hundred and ten miles I was supposed to have to cover. During this long week I was continually meeting with trifling but vexatious accidents; and though the adventure I have just narrated was one of the most troublesome I ever met with in all my experience in the States, it was not the only accident I met with during this journey; for on the fifth night I mistook the road to the wood-feller's hut where I expected to find accommodation, and becoming quite bewildered passed the night in the depths of the forest.

It was bitterly cold, and the snow fell in slight showers all night, so that all my efforts to make a fire failed, though perhaps the recent rains which had made both wood and ground thoroughly damp had as much to do with this failure as the snow. Fortunately I was not without food, for I had already become experienced enough in wild life to know the wisdom of always providing for a day or two ahead. At my last resting-place I had procured bread, cold boiled pork, and a bottle of whisky, and some jam. Jam is always procurable in a Yankee homestead, for if there is nothing better to make it of, pumpkins, or even turnips, are used for this purpose.

I gave the most of the bread to the old horse ; and to her and the whisky bottle I consider that I owe my life on this occasion. My friends the teetotalers, I hope, will not judge me harshly. I have a profound respect for them, and believe that they mean well, though I cannot subscribe to all that they teach. The Maine liquor laws, which are downright wicked, and the ladies' whisky war, 
which was downright comical, established my opinion about teetotalism long before I had ceased to be a legal infant; and I have a confirmed habit, not of getting drunk, but of sticking to my opinion in spite of evolutionists and social reformers; and so I drank so much of the whisky that I doubled the trees, and doubled the horse, and doubled the cart, and finally doubled myself up against the old mare. She found a hollow amongst the trees and lay down, and I huddled up close to her, and neither reason nor revelation will persuade me that she did not know full well that our only chance of life was the mutual warmth which we communicated to each other. She curled herself up like a dog, with her nose pressed close to me, and never moved till morning. I had a rug or two, which the scoundrelly robbers could not carry off (they had so well loaded themselves), and these I spread over myself and her; and so we managed to survive the night.

And yet it was not a hard frost, for before midday the following morning there was scarcely a trace of the snow left on the ground. But I can say from experience that it is not degrees of cold which cause suffering and danger, but the kind of cold. For a damp cold will kill when three times the degrees of frost can easily be endured.

It was some time before I could get the mare to move when daylight came back-she was so stiff. I was in a miserable plight myself, but the remains of the whisky pulled me together, and about the middle of the day we reached the timber-fellers' domicile - a small log-hut, with a shed or two erected round it. There I got some hot coffee for myself, and some flour-gruel (in lieu of a bran mash) for the old horse. This was the last bit of hard work she ever did, for there never was much go in her; and the next spring I took her back to Dunford from whom I had her, and there left her under a solemn promise that in consideration of her splendid behaviour 
on this occasion she should be permitted to live in clover the rest of her days, and shuffle off this mortal coil in her own time and way.

The following day I got on to a track that had more pretensions to a road than any I had hitherto travelled over. I met a few of my fellow-men on horseback, one of whom was polite enough to offer me a cigar. I am not a habitual smoker, but I can enjoy an occasional weed just to make myself sociable. This gentleman being free of speech and opinion like myself, criticised my horseflesh and general turn-out with a confident unreserve that made us friends on the instant. He soon got tired of my jog-trot pace and went off at a canter, but he gave me an address near Marquette where I could find him, and during the following winter I spent many happy hours with him and his charming daughters-his lady lying under the trees in Marquette Churchyard.

That night I stopped at a wayside inn-such an inn! An Irishman would have looked twice before he put a cow or a pig in such a hovel, and all the world knows that Pat is not particular about lodgings, either for himself or his beast. When I drew up there seemed to be no waking soul about, though I could hear the stentorian snoring of a sleeper through the half-open door. Knowing the style of such cribs as this, and that I should have to do everything for myself, I put the mare in the best shed I could find, and gave her the whole of a small rick of hay - corn I could find none.

I should explain that there is a custom in parts of America of piling a small quantity of hay round a stick driven into the earth, or round the trunk of a fruit-tree. Such a pile, which is rarely more than a small load in quantity, often a mere armful, is called a rick. There may be scores of such ricks on a single farm. The hay is supposed to dry better in this form of storing; it also is supposed to afford a beneficial protection to the tree trunks. It is a very common method of storing hay in 
the Southern States; but this was the first occasion on which I had noticed its adoption in this district.

While I was engaged about the horse, the boss (landlord, as we should call him) came up with an axe in his hand and a huge pile of wood on his back. "Wal!" he exclaimed, "I guess you are making yourself at home." I reminded him of the old proverb that tells us that our friends will love us the better for helping ourselves, and asked if I could sleep there, and have a meal. A bed, I saw at a glance, it would be preposterous to ask for in such a place, and I was doubtful about the meal. The man was good-humoured enough, which Yankees almost invariably are, in spite of a plain spokenness which seems rather offensive to a newcomer, and said I could have a bench and blanket before the fire, and that he had the never-failing cold pork and pumpkin-pie. He had also plenty of stuff he called ale, which much resembled the waters of the Missouri-that is, yellow mud-and cider and whisky, the latter the most horrible stuff ever concocted. How its consumers survived its consumption is a mystery.

The hut consisted of two compartments, a partition of thin boards having been erected, cutting off a third from the general apartment, where the chance customers sat, drank, spat, and swore to their hearts' content. Fortunately for my comfort there was but one customer here at present, and he it was I had heard snoring, for he was asleep on three chairs in front of the Dutch-stove, his body being on one, and his two long legs spread wide apart on others.

Surely I had previously seen those green small-clothes patched with brown, and that dirty red shirt, mended with still dirtier grey flannel. It actually was Major Shadley, sponge and tender-foot, tramp and rogue, all, or each by turns. $\mathrm{He}$ had evidently been sampling the poisonous "Scotch" (a placard hung on the wall described it as "Best Scotch whisky, direct from the 
Highlands, imported by Sam Rankin, wine and spirit merchant"!), for he was so firmly asleep that shouting and back-slapping would not rouse him. The sort of comments Sam Rankin made on this unconscious guest must be imagined by the reader. I cannot repeat any two consecutive words of it.

I have said that the major was perched on three chairs, but the only one of them that retained its back was the one which supported Mr. Shadley's spinal column. As mine host wanted that particular chair for my accommodation, and failed to convey that circumstance to the deadened brain of the sleeper, he at last forcibly pulled it from under him. Down went the major in a heap on the floor, and the shock having aroused him, he gathered himself up, swearing horribly. At sight of me he fairly staggered against the wall. "Wal, I'm jiggered!" he exclaimed.

"Why, major, what is the meaning of this? I thought you meant to make for the south," I said.

Without a word the major dropped on one of the backless chairs and sobbed aloud. Hardly knowing what to make of this conduct, I supposed he was cryingdrunk, and begged the host to bring some strong coffee.

"If you only knowed what I've been through since I saw you," howled the major. "You remember them six-shooters? Two of the loveliest barkers that was ever belted!"

"To be sure I do," I replied, noticing now that the major was no longer armed; " the splendid weapons with which you flicked the dog's nose."

"Oh! cheese that; don't joke on a poor varmint in distress. They're gone,Mr. Fountain; gone by —— to three of the dirtiest, sneaking cut-throats that ever went unlynched," and the major swore till he exhausted himself.

It flashed on me in an instant that the three rascals who had overtaken and robbed me four days previously had a brace of six-shooters in their possession that at the 
time reminded me of the major's dandy firing-irons, and I had no doubt that these rogues had also interviewed this poor tramp. A very few inquiries put it beyond doubt that this was the case; and six-shooters, bowie-knife, and the few cents in possession of this wretched fellow had all been taken from him by these heartless thieves.

"But, major, you used to boast that you had twelve lives in your belt (referring to the twelve charges of his two weapons), how came it then that you permitted only three men to despoil you?" I could not help asking.

"That's all very well; but with two fellows holding you behind and raising —-, and another in front spitting blue sulphur down your throat, there ain't much chance for fancy shooting, I can tell you," continued the poor major, blubbering afresh. "I had a hard job to save my skin. They kicked me till I could scarcely stand, and then strapped me to a tree and left me, and there I was for eight or nine hours, till a couple of travelling farriers came by and released me."

Host Sam Rankin seemed to have but little sympathy with the sufferer; but the poor man had, no doubt, not only been robbed of the very little he possessed, but subjected to brutal usage, and was much unnerved. He had been begging his way from door to door, but without the moral support of his shining six-shooters, he had found that but a poor business. However, he plucked up a little energy when the cold pork and pumpkin-pie were put on the board; and after he and I had spent a very uncomfortable night, sitting in corners near the stove, he forestalled me, and, without saying a word, neatly curried the mare, harnessed her to the cart, and brought her round to the door, a kindness which I took as partaking strongly of the broad hint.

We had a better breakfast than supper, for a young woman, Sam's wife, appeared from the inner apartment, where we had heard her all night long coughing and trying to comfort a sick child whose restless whining, 
poor little creature, gave me the heartache. The woman was in the last stage of consumption; but she tried to serve up a comfortable meal, having heard our stories of the robbers, and being sorry for us.

These rascals committed several other outrages in the district, as we afterwards heard; but they never showed themselves at Marquette or any of the larger hamlets in the district; and after the posse turned out to look for them they were heard no more of, having probably realised that it was time to transfer their wicked persons to some other and safer district.

From the hostelry of Mr. Sam Rankin we reached Marquette without further adventure. The roads were bad to the last; and when we reached the township, which is little better or bigger than a village, it was snowing heavily. The last mile or two of road was along the shores of Lake Superior; and the water was running in and breaking in furious waves on the beach, like the sea during a storm; while thousands of gulls were hovering over the land, evidently driven in by stress of weather. The number of gulls always to be found on the Great Lakes is, to me, who have always considered these birds as purely marine forms, a strange circumstance. I should like to know if gulls frequent, spend their whole lives, or breed, on large inland bodies of fresh water in other parts of the world. They do all three here; for there are some gulls which breed about the lakes and never leave the fresh water except for those exceptional inland visits which all gulls make in bad weather, but these gulls are found on the coasts of America also. And there are other species which make annual migrations to the sea-some to the Atlantic, some to the Pacific. At least one species makes journeys right across the continent, from ocean to ocean.

I said we arrived at Marquette. That means that the major had climbed into the cart at Sam Rankin's, and duly attached himself to me. At Marquette we had 
to come to an understanding. I could have no doubtful characters about me while I was lodging in a respectable house; and though I am rather given to employing what may be called "waifs and strays," as I have often found these men, under proper treatment, far better servants than your smoothed-speeched, kid-gloved gentry, I had yet never engaged a major as "a help"; and though I gave Cornelius a trial, I will take remarkable good care to never again have to do with disbanded military gentlemen of phantom corps, or Massachusetts Rangers, as C. K. S. styled his late regiment when pressed to name it.

As I needed a servant, and the major made a pitiful appeal for "another chance," thereby tacitly admitting that he had lost a chance or two in the past, I engaged him, on the understanding that he gave up spitting, swearing, pig-tail smoking, and shiny-six-shootering. All this he faithfully promised to do, and promised only; for as soon as he received his first dollars he got drunk, bought a fearful-looking weapon at second hand, killed a neighbour's dog in trying "to flea him," and frightened my landlady half out of her wits. His general beastly conduct, and the trouble I had to get rid of him, I say nothing about, for it would not be pleasant reading.

I think I ought to record that the occasion narrated above was the only one on which I was actually robbed during the whole time of my sojourn in the States. As I mentioned in my first book, I have frequently been "rounded up" by rascally cowboys and tenderfeet, and eased of a few bottles of whisky; but anything like a deliberate and cruel robbery, such as that I have just told about, happened on this one occasion only. Nevertheless it is certain that there is a class of mean train-wreckers and cunning thieves prowling about the outlying districts of the States; and this class seems of late years to be greatly on the increase. As the land becomes more thickly populated, and to obtain an easy living becomes more difficult, certain classes of men take to dishonest courses. 


\section{CHAPTER XXVI}

\section{THE SOUTHERN SHORES OF LAKE SUPERIOR}

IN America the terms city, town, \&c., have no very definite meaning. In the early part of my career in the States I knew many cities that had not a hundred inhabitants; when I left it one or two of these places could count its people by tens of thousands. It seems that the founder of a new settlement, often anticipating great prosperity for his venture, gives it, prospectively, the name of a city. If the place fails to attract many residents, it yet still retains the title originally bestowed upon it. There are seldom other designations in the States than towns and cities for collections of buildings. What we should call a village or a hamlet is a "township" in America. Places rarely have the name of village; and I do not remember to have ever heard of hamlets or boroughs in any part of the United States.

Marquette, though the chief place in all this region of North Michigan, was really a small township, but seemed to do a considerable trade, its situation on the shore of Superior being much to its advantage. A large proportion, if not the whole, of the trade was coastwise; and fish-catching and curing was one of the chief employments of the inhabitants - that is, of course, apart from its mining operations; for Marquette owes its existence entirely to its proximity to enormous mineral wealth.

It was here, or near here, that the murder of Father Marquette took place in the early years of the eighteenth century. Some local antiquarians showed me the exact spot, as they supposed, where the cruel deed was com- 
mitted; but I strongly doubt the correctness of this information, though it is asserted that tradition has handed down full particulars of the affair. The accounts which I heard are somewhat confused and contradictory; and though $\mathrm{I}$ am acquainted with some of the writings of Father Marquette, I have not been able to find an authentic account of his death. This much is certain, that the French look upon him as a martyr, and the English and Americans as a meddlesome politician who provoked his fate.

He was a French priest who, leaving Canada, then a French colony, established himself alone in the forest, soinewhere in the immediate neighbourhood of the town which now bears his name. He acquired an extraordinary influence over the Indians, many of whom he converted to the Roman Catholic faith. He certainly had no particular right to establish a mission on English territory, as it then was; but considering that the country was a wilderness inhabited by the Red Men only, it is difficult to believe that the father had any political motive for his action. Nor is it usual to forbid men of the Cross from propagating their views among savages, or to require them to obtain the permission of the executive authorities to establish their missions in a wilderness. At least that has never been the policy of the British people. But Father Marquette aroused the jealousy of the local authorities, and his mission was suddenly attacked and himself and his converts butchered on the spot. I believe that American militia were the actual murderers, and that the father was killed by a thrust from a sergeant's halberd. $\mathrm{He}$ is represented as being so killed in an old French print, and there is a tradition among the Roman Catholics at many places in Lower Canada that such was his fate. But other accounts record that he met with a very different fate. Some of English or American origin assert that he was slain by Indians, and some that he was not murdered at all. 
Apart from traditions, which may or may not be erroneous, it is certain that there were Catholic Missions in this neighbourhood at a very early period in the history of the country, and that many murders of priests and converts took place, sometimes by hostile Indians, who seem to have been instigated to commit the crimes by whites, and sometimes by the Europeans themselves. All through the northern countries bordering the Great Lakes and along the Canadian frontier, the loss of life among the early white settlers was simply appalling, amounting in Maine, it is on record, to five or six per cent. of the total population. Often when no Indians were thought to be near, and the settlers were quietly going, unarmed, about their business, villages and isolated settlements were suddenly attacked, and every soul, man, woman, and child, butchered and scalped. Occasionally women were made prisoners of, but as a rule the Red Men seem to have had little inclination for the society of European women. There are but very few instances of their having been kept for squaws or wives; there are even fewer instances of children being taken into captivity. Men were sometimes taken away to be afterwards put to death with exquisite torture, but the rule was to slay all at the moment of attack.

That the Red Man when on the war-path is a brutal savage is a fact that cannot be gainsaid, but I have my own opinion about the amount of provocation he received. I have not been able to discover that he ever commenced hostilities without provocation, though there is no doubt that his reprisals were often visited on innocent victims. I am sorry to add that there is also no doubt his attacks were often instigated by both French and English, one against the other. On the whole, the French got on much better with the Red Man than any other European settlers. This seems to have been the result of careful policy; and it is also most certain that those founders of English settlements who behaved justly to the Indians 
very seldom, if ever, had any serious trouble with them. And frightful as it may seem to read of wholesale slaughtering of women and children, this fiendish crime was not confined to red savages; it would be interesting to know if it originated with them. If so, the early settlers retaliated in kind, and with no slack hand. A great many of these men were fellows whom their native land must have been mighty glad to get rid of. They resembled those bandits who, three thousand years ago, joined themselves to King David the Hebrew. He who had a creditor whom he could not pay, he who had committed an offence against the laws of his country and feared the consequences, and he who was naturally of a discontented temperament, became "a pilgrim father," and went to America for liberty of conscience, and liberty to steal and murder and burn witches, as they termed several poor imbecile women whom they sent to the stake after torturing them into a confession of witcheraft.

I do not wish it to be supposed that I do not think that many of the founders of America were great and good men, but it has always been the misfortune of that country, down to quite modern times, to be a city of refuge for political agitators, religious impostors, and all sorts of scamps and reprobates who had made their own countries too hot to hold them.

Only a few days after my arrival at Marquette the winter set in with great vigour, and I was thus prevented from making any long excursions about the neighbourhood as I had wished to do. The country seemed, as far as I had yet seen it, to be far less desolate than that on the north side of the lake, but the winter was quite as severe; indeed, I think I felt the cold more than I did north of the Red River Settlement. The Great Lakes never freeze over, as I have already said, but there was a broad fringe of ice right along the coast, on which people sleighed to their heart's content all through the winter; and though channels were on several occasions 
cut to enable boats to come up to the town, they were always frozen over again within a few hours, and towards the end of the winter ice to a great thickness was piled up along the coast. All the small rivers were hard frozen, but the number of streams that empty themselves into the lake on this side is very inconsiderable, and they are all of small size, being mere brooks.

It is singular, or at least worthy of note, that it was late in the history of the United States that large towns began to spring up on the shores of the Great Lakes. Some of those towns promise to rank with the greatest cities of the New World, and perhaps Marquette will one day be a second Chicago. At present it has not come up to expectation. The first settlers established the "city," as they called it, much farther eastward, and gave it an Indian name-Munesing. The mineral wealth of this neighbourhood seems to have been the attraction which caused the change of site, and the reason for the change of name I have already given. At this time the country was certainly not opened up to any great extent. I am ignorant of the present state of matters, but of the future I prophesy without hesitation. This is not only one of the most picturesque but also one of the richest, from a mineralogical point of view, districts of North America. Iron, copper, silver, and coal, seem to abound at many points, though "I am not prepared to speak of the quality of the latter. The iron is probably responsible for the red, crimson, and purple colour of many of the cliffs on this side of the lake, and also for the remarkable coloured cascades which I found on some parts of the coast. The water in these cascades was coloured a deep vinous shade, so that it seemed to be wine rather than water which was rushing over the rocks. The lake was tinted by the coloured water poured into it, but not to any great distance from the foot of the falls. These claret-coloured cascades are far more numerous on the north side of the lake. 
The cliffs seemed to be far more rugged and elevated than those opposite on the Canadian side, but I did not examine the latter so closely as those east and west of Marquette. The variety of rock shapes and forms in this district is simply marvellous, and in fantastic variety is not to be compared with anything I have seen in North America, excepting only the Sierra Nevada and the Yosemite Valley.

The elevation of the rocks is in some cases very considerable, and they often rise sheer from the water, so that it is impossible to land for a distance of many miles. There is no beach, not even a ledge broad enough to give a cat foothold. Of course when the ascent is so steep there is no vegetation; the rocks are bare. At the top there are generally trees, sometimes broad-leaved and sometimes pines; and there are places where the rocks shelve down with a sufficient slope to permit trees and other vegetation to grow quite down to the water's edge. At such places there is usually a narrow strip of beach; at others there is a broader beach, but it is nowhere of any great breadth. The nomenclature of these cliffs and the mountains is of the usual idiotic kind found throughout the States, and which gives one the idea that some individual has travelled through the land with a certain list of names and no power of invention. Everywhere we have Lovers' Leaps, Phantom Rocks, Painted Rocks, and Old Men's Faces galore, and these designations are repeated with a confusing frequency.

I commenced my inspection of these remarkable cliffs to the eastward of Munesing. They there bear the title of "Picture Rocks," and there is not a mammal, bird, or inanimate object that some one or other of them is not thought to represent-sometimes with truth, though it too often happens that different persons' ideas on the supposed resemblance greatly vary; what one declares to be an elephant's head, another thinks more nearly approximates a pig's snout, and so on. My own 
opinion is that the variety of forms and shapes of these rocks is in the highest degree remarkable, and resembles, or rather repeats on a small scale, those that so much excited my wonder in the Sierra Nevada, and which I have fully described in "The Great Deserts and Forests of North America"; but for appalling grandeur and sublimity of scenery the Sierra is not to be compared to anything to be found in other parts of the north of the continent.

With regard to the nomenclature of the Superior Lake cliffs, one difficulty in recognising the "Lions, Eagles, Panthers," \&c., of the popular parlance, arises from the very remarkable way in which a slight change of the spectator's position alters the apparent shape of the viewed rock. That which looks like a rampant horse from one spot, is changed into something more nearly resembling a coffin, or long chest, by a move of a few yards to the left or right. Some few of the popularly named spots are worthy of their designations, and some of these I will proceed to mention in rotation, premising that the great majority of them are not marked on my map; and that I have often had to rely on Indians and uneducated persons for such information as I give. I have, however, carefully avoided making any statement which I thought to be unlikely as regards truth, or careless in fact.

My explorations were mostly made in an Indian canoe. Sometimes I took an Indian or two to paddle for me, and sometimes I went alone. It depended on the weather, and, consequently, on the distance I could venture, and the time I might be absent from Marquette; for the navigation of all the great lakes is dangerous for small boats, and particularly for canoes. The storms are frequent, and come on with surprising suddenness, so that on a coast where there is often no landing-place for several miles, it is imperative for the humble voyageur to keep his eye constantly on the watch for impending 
changes of the weather. I have seen the weather apparently most promising only half-an-hour before a fierce squall rushed over the surface of the lake, and on several occasions we have had to literally race the wind to the nearest landing-place. Two or three times we have only escaped by the skin of our teeth. With a considerable experience of the open sea, $\mathrm{I}$ am of opinion that it is far less dangerous to small craft in bad weather than the waters of these lakes. During storms the waves seemed to me to be at least as high as those of the ocean, while they are much shorter, or more choppy. A seaman will understand, therefore, why they are so dangerous to small craft. On a long, running swell, a boat may do very well, however deep the trough of the sea, but it is a different matter with a short choppy sea, especially as in these lakes, where there is either no defined current, or a meeting of aberrant currents, particularly near the shore, where the danger is greatest. There is also very deep water, right inshore in many places, the rocks rising abruptly from the surface. The average depth is variously stated, but it is nowhere as great as might be thought, considering the extent of the lake. My measurements did not always agree with the chart of the lakes which I used, although as a rule it seemed to be very correct. I appeared to find some holes, or narrow gullies, at the bottom of Superior, and other lakes. The average depth of Superior is about eight hundred feet, and the water is generally so beautifully clear that objects can be seen lying on the bottom where the depth is two or three hundred feet. This is not the case where streams or falls bring mud or sediment into it, though, as a rule, the pollution extends to but a very short distance from the shore.

Near Munesing, according to my measurements, some of the cliffs exceed, by a few feet, seventy yards in height, rising so straight from the water that they seemed to be absolutely verticle, and the measurement was taken by 
dropping a line over the edge. Some of the cliffs were undermined, and others sloped under water; but at places, from a boat lying only a few yards from the rocks, depths of two to four hundred feet were obtained. Sometimes the bottom was very rough and irregular, seeming to be a mass of piled-up rocks which had fallen from the cliffs above.

None of the Picture Rocks showed a red colour, but almost every other imaginable tint was found in strange combination, such as a person acquainted only with the dull-coloured rocks of Europe can have no idea of. Bright blues and greens were very conspicuous, due probably to the presence of copper in some form; and these various tints have much to do with the fanciful shapes the cliffs seem to assume. From a distance many of the bare rocks appear to be covered with luxuriant forest, among which nestle towns, castles, forts, and picturesque cottages. As you approach nearer all these forms change in a wonderfully grotesque way, like the ever-recurring alterations in a kaleidoscope, often assuming the figures of gigantic men and animals. The resemblance was often perfect from a certain point of view, but half-a-dozen strokes of the paddle were enough to dispel the illusion, or transform it into a greater. The best, and most grotesque views, perhaps, are obtained at about a mile from the shore; but the atmosphere is usually so beautifully clear that good views are obtained at much greater distances.

"Chimney-rocks" are very common on this part of the coast, but none of the pinnacles struck me as being very extraordinary. I was far more interested in the caverns and perforations. A remarkable projection, called the Sail Rock, cannot be passed without notice. This is one of the least changeable of the rock-objects. It is such a faithful likeness of a sloop-rigged boat that strangers have repeatedly believed it to be such. A short distance beyond is a very remarkable natural per- 
foration of the rock between two cliffs, named by the Canadian voyageurs Le Grande Portail. It is a hundred and four feet in height, and a hundred and seventy broad, and forms a kind of entrance to a large cavern, with curiously rugged sides and roof, the result of the sea's furious action. The cavern is not otherwise remarkable in appearance, but during storms the waves rush in through Le Portail with tremendous force and fury. I had the gratification of witnessing a tempest at this spot. The waves came on much quicker than those of a salt sea, and, rushing straight through the Portals, seemed to actually fill the cave, breaking with a force that made the rock perceptibly tremble, and with a noise that cannot be compared to that of a cannon, for it was far more deep and sullen in tone. This tremendous sound has been heard by passing vessels ten miles out on the lake. The sight of the water bursting into the cave left an impression on the mind of the first degree of intensityone of those impressions which return in moments of quiet thought with the freshness and reality of yesterday. The quantity of water which entered the cave it would be vain to attempt to calculate. It was immense, but it seemed to be all dashed to foam and spray. The spray rushed into the air in a million jets, and, though we stood on rocks nearly two hundred feet high, we were drenched at each burst. There was very little of that undersuck, or under-current, which is so prominent a feature of waves bursting on the shores of a salt sea. In fact, though a careless observer might not have noticed much difference, I perceived that in several points the action of storms on these lakes differed from similar conditions on the ocean. The tempest seemed fiercer, the wind was so boisterous that we crouched down, fearful of being blown over the cliffs. The action of the waves was certainly quicker, and seemingly more powerful than those of salt water, and never have I seen spray thrown so high on a sea-coast. There is always a strong 
odour from the sea during a storm, an odour of Neptune that cannot have escaped the notice of any person who has seen the ocean. From the lake there was no perceptible smell, though the air had a peculiar freshness about it, and, being winter time, was piercingly cold. Neither was there any weed thrown up, or clinging about the rocks, as would be the case on the sea-coast. Marine creatures were absent also, except gulls, which hovered overhead in myriads, screaming loudly. No such flocks of gulls are ever seen on the British coasts. There are some insignificant crustaceans and molluses on the shores of the lakes, but of these I will defer speaking till I have done with the cliffs.

At the time of the storm referred to there was no sign of ice forming on any part of the lake, but the spray froze on the rocks, making them exceedingly slippery. Subsequently there was ice on parts of the coast, extending out some distance from the shore, of sufficient width to enable people to walk and sleigh on it, until it packed. This ice was mostly in small sheltered bays. Where the waves had full action on it, it either was washed away during storms, or never found at all. The great lakes are never frozen over. I do not deny that the reason given by scientific men, the great depth of the water, is the true one, but I want evidence of it.

It is sad; but I often find myself doubtful of the accuracy of much that is called science. It is quite likely that I am sinning myself as a writer, that I am provoking punishment by presuming to differ from "established opinions." Well, I must die in the breach. I never turn. back until I am quite convinced. I do not say that I think that many of the theories and doctrines of the modern naturalist and scientist are mere delusions of fantastic brains. I know it. That goes miles beyond thinking.

To get back to the ice. A depth of eight hundred feet may be the reason that Lake Superior never freezes. 
I think (and I do no more) that the extreme restlessness of its waters may have something to do with the fact that there is never more than a narrow fringe of ice on its unargin. All the Great Lakes-that is, Superior, Huron, Michigan, Erie, and Ontario-are extremely restless bodies of water. I doubt if some part of their surface, more or less, is ever free from tempest in some degree, in the winter season especially. It is certain that a motionless body of water will freeze much more readily than that which is agitated. The great lakes farther north, the Slave Lake, Bear Lake, \&c., freeze entirely in the winter; but I know nothing of them, whether their waters are deep or shallow, though I think I have heard that they are of no great depth. I have certainly heard from trappers that they are not so subject to storms in summer as Superior and its companions. But the Great Bear Lake and other northern sheets of water are, nevertheless, subject to very fierce and dangerous storms.

Continuing our canoe voyage still farther east, past the Organ and the Cathedral Rocks, which resemble the objects after which they are named just as much, and no more, than a thousand other rocks in the neighbourhood, we come to the Ghost, a most striking representation of a human figure clothed in a long flowing garment, the hand appearing to point outwards, the lower part of the face enveloped in a bandage, but the eye and nose visible. Though this figure is of a yellow colour, it looks from a distance, when the sunlight is strong upon it, as if it were enveloped in a phosphorescent light, and the whole object seemed to me to be one of the most notable on this line of coast. Nine or ten miles farther on we came to the Chapel, another cave, not situated at the surface of the water, but between forty and fifty feet above it. It is reached by a rugged climb among broken rocks, trailing creepers and brambles, and sapling trees, which find just enough soil to support them, but when they grow to any size lose their roothold, and tumble into the lake beneath. 
The cave has just the same rough, broken appearance which is remarked at Le Portail. Rugged rocks and huge stones project from the sides and hang from the roof; and to two of these masses are given the names of the Altar and the Pulpit. The gulls breed in this cave, and the bottom was covered with their droppings; but the Indians say that the place is beginning to be so frequently visited by holiday-makers from Marquette, Munesing, and other places, that the birds are forsaking it. Most of them, however, breed before boats can venture to navigate the lake. With the exception of gulls, I saw no birds about here.

There are a few smaller caves near the Chapel, and some of the rocks look like the balustrades of a terrace, surmounted by a forest growth of tall trees. There is a rapid near the Chapel, coming over the rocks in a series of short falls, beautifully overhung and half-hid with foliage. The many cascades cannot be enumerated. Only one or two of them can be dignified with the term, falls. As I have said, there are no rivers of size emptying into the lake on the south side; and the rivulets and brooks, which are shallow, all rush over the cliffs in babbling cascades, which, though sometimes falling more than a hundred feet, are mere ribbons of water. Superior is completely surrounded with a wall of cliffs and mountains; and is, I am convinced, now some two hundred feet shallower than it was a few thousand years ago. For I am convinced that at no great distance of time the surface of the water was level with the present tops of the cliffs. My opinion also is that the waters of all the Great Lakes are slowly, but most surely, decreasing in depth, though, as there is deep water close inshore, there is but small perceptible contraction of area as yet.

The Indians look at Chapel Cave with superstitious fear. It is, they say, the residence of an evil manitou, or spirit, and my paddle-men would not enter it with me. They crossed themselves and told their beads while I was 
examining it; for they were Roman converts. The spirit of Father Marquette, whom I believe to have been a good man, lives all over the lake; and hundreds of the few Indians that still remain on its shores revere his memory, and are ardent Catholics. There are several other places on the lake, mostly caves and dangerous headlands, that are accredited with bad manitous, who raise the storms and cast the poor fishermen and sailors away. The whole coast hereabout, and for many miles east and west, is a most dangerous one. The craft that is caught with a gale blowing inshore (and it is sure to blow inshore in seven cases out of ten) is lost; for there is no landing-place when a thundering surf is beating right on to the rocks. The lake navigators therefore give the Picture Rocks a wide berth: the reason that a great part of this coast is nearly, or quite, a terra incognita. That is, it was thirty years ago.

Not much farther on are the Silver Falls, the largest, I believe, on the lake. They drop, in an unbroken line, a distance of about one hundred and eighty feet. This height alone makes the fall an imposing one; but the volume of water is not great, especially in the middle of summer, when many of the smaller cascades dry up altogether. The Silver Fall rushes out above from a dense forest, and some of the rocks overhang in a threatening way. All along this coast, and, indeed, every part of the borders of Superior, the rocks are mostly bare of vegetation. Often there is forest on the top, even overhanging the cliffs on the south side; but, on the face of the rocks, a clump of bushes, an odd tree or two, perhaps a mass of creepers or clinging festoons of moss, is the only vegetation I observed on those parts I visited.

At Chapel Cave, Silver Falls, and other points, there is what is called "a beach." It is only a few feet wide, but affords a convenient landing-place. At such points there are also huge masses of sunken rocks lying at the bases of the cliffs, and other rocks show above the 
surface of the lake; but there is deep water close inshore. Fish abound here, as in every other part of the lake, notwithstanding the enormous numbers that are caught; and many wrecks, and a lamentable loss of life, annually occur at this point during the fishing season.

A great number of the cliffs show the outline of the human form, both male and female. Those which struck me as being most happily named, were, The Trapper, The Voyageur, The Rifleman (a remarkable presentment of a hunter taking aim), The Belle, The Sleeping Beauty, and The Empress. All these well represented the figures they were named after ; the females especially were charming presentments of beauty. The Empress has a coronet formed of trees; but, in each case, a near approach dispels the illusions their forms occasion at a distance.

The Picture Rocks were the most eastwardly part of the south coast that I visited. There are but few islands above the size of rocks lying off the Pictures; the biggest of them being miscalled Great Island. There are a dozen islands in the lake that exceed it in size, one or two of them having twenty times its area. Seventy or eighty per cent. of the names of places on the lake are French, having been bestowed by the voyageurs, who were the first white men to navigate its waters. In the winter all navigation has to cease, at least by sailing craft and boats, on account of the quantity of floating ice, as well as the impossibility of approaching the shore, in most places, on account of the frozen field. Returning to Marquette, I continued my exploration westward during the winter, with some intervals when the weather was too severe to permit travelling.

Marquette harbour is a picturesque spot, but not more so than Munesing, and both are, no doubt, destined to be greatly disfigured by the useful, but beauty murdering, works of man. At the first-named place these have already made sad havoc with the natural scenery. Most persons can realise what "mining-works" mean to 
scenery; and wharves are certainly no improvement to rocks. At both Marquette and Munesing there are strips of beach, with forest-clad hills overlooking it. At Munesing the forest comes down to the water's edge, and here the water is comparatively shallow. The few inhabitants who still remain here are mostly engaged in fishing-the principal fish, as in all the lakes, being bass, lake trout, and the celebrated white fish. These are cured and sent to all parts of Canada and the States.

Eleven or twelve miles from Marquette, and fully in view from all parts of the district, is the Iron Mountain, which the Marquette miners declare to contain the richest iron ore in the world. It may be so; it is certainly immensely rich in the most useful of all the metals; and huge quantities of it are yearly shipped to the great manufacturing centres of the States. At least three hundred small vessels (1869) arrive here every summer to carry cargoes of ore to Cleveland, Ohio, whence it is sent by land carriage to various places of manufacture. Now, in December 1902 , it is announced that orders have been placed with British shipbuilders for three steamers, of between 3000 and 4000 tons each, for the Great Lakes trade. It is mostly iron ore that goes from Marquette, but the whole district abounds in several metals, in a profusion that I can quite believe, as is asserted here, is unknown in any other part of the world. In Marquette harbour there is a small island of the same formation as Iron Mountain. Some specimens, which I afterwards brought to England, from the rocks of this island were pronounced by a Dudley ironmaster to be nearly pure-metal; while some samples of copper ore were declared to contain more than 90 per cent. metal. This copper was obtained on the peninsula of Keweenaw, about a hundred miles west of Marquette.

Keweenaw, as it is pronounced, is spelled in old maps Kioueounan. It is a Huron Indian word, and means a short cut or passage; so named because the 
Indian hunters used to pass across the base of the peninsula where the Kioueounan Lake (the Portage Lake of the voyageurs), enabled them to save two days' canoe journeying in coasting along the south of Superior. Kioueounan, or Keweenaw, is a solid mass of copper ore, and could, I should think, supply the whole world, even on a wasteful scale, for tens of thousands of years to come. Much of the peninsula, which is, roughly, ninety miles long by more than a hundred broad, seems to be nearly pure copper, judging from the specimens which I brought away, and the reports of the miners. If the accounts of the latter are to be relied on, masses of pure copper have been found containing six or seven hundred tons' weight. I saw, myself, great jagged masses peeping through the soil, which seemed to be pure copper, but which, as I have mentioned, prove to contain about one-tenth of dross.

Keweenaw has been frequented for copper by the Red Men from time immemorial. Many vestiges of their old mines still remain, and they came from immense distances to obtain the metal for making knives, heads to their spears, and a hundred different purposes. They, of course, worked only the masses which they found at the surface of the ground, but the traces of ancient smelting works of rude construction still remain, showing that the Indians had probably arrived at some degree of skill in working the metal. Yet the peninsula was a place of superstitious dread to them, as they believed it, like innumerable other points round the lakes, to be the haunt of an evil spirit. The Indians who resided nearest to the peninsula were a tribe of Chippeways, while on the opposite coast were Iroquois, a fierce and quarrelsome race, and so many different tribes coming for copper, it naturally came to pass that fierce fights took place frequently, and perhaps this had something to do with the superstitious dread in which Keweenaw was held by all the Red Men. Certainly none ever permanently 
inhabited the peninsula, and there are traditions of thousands having been massacred on the coasts near it. These things are never forgotten among the Red Men, and the account of them is handed down by tradition from generation to generation. The medicine men are the particular custodians of tribal tradition, and their traditions, I have proved, are quite as reliable as the white man's histories; perhaps a little more so sometimes.

Portage Lake is not the only body of water on Keweenaw Point. There are several other lakes and ponds, notwithstanding that the land is hilly and drained by a great number of brooks and runnels. Several of them are enchantingly beautiful: so much so that one has actually been named by the voyageurs the Beautiful Lake. Unfortunately I could not spare sufficient time to thoroughly explore either lakes or peninsula, and so cannot give that minute description of either that I should like to: neither was my visit paid at a time of the year favourable to a sight of the full enchantment of the spot. Most of these small lakes are embosomed amidst grandly wooded hills, and are very irregular in shape, having many winding arms, which adds greatly to their picturesqueness.

The coastline of Keweenaw is, generally, rocky, rising into abrupt hills several hundred feet high, enclosing fairy-like coves, many of which afforded safe hidingplaces to Indian canoes in former perilous times. In some places the rocks are pierced with cares, but none of these, though some were rugged and picturesque, were of great size, or otherwise remarkable. As there was ice on the water at the time of my visit, I could walk into some of the caves on it, and so explore them. There were also arches, or perforated rocks, but only on a small scale, and these were not at all to be compared to some of those on the sea-coast of America.

Moving westward the cliffs were not so remarkable, and 
were oftener broken by beach spaces, while the country inland rapidly grew more mountainous. I cannot, however, say much of the country, except on the immediate edge of the lake; for time pressed, and much of my journey on this occasion was a mere scamper over the ground. I could only stop to examine some of the more interesting objects. Contenting myself therefore with a distant view of the Porcupine Mountains, I hurried on to the Twelve Apostles, as a group of beautiful islands in the south-western corner of the lake are called. I do not know when, or by whom, this name was conferred upon them, but they are so named on maps which are two hundred years old, so they must have borne it from the date of their discovery; for Lake Superior was almost unknown two hundred years ago. At the time of my visit, half the coastline was still imperfectly charted, and the other half to a great extent inaccurately so. The Apostles are in duplicate here; for there are twenty-four islands, without reckoning a number of rocks.

The Apostles were the headquarters of the Father Marquette mission, and to this day there is a Roman Catholic church and school on St. Madeline. The Roman Catholics have always met with great support from the Indians; all of whom, in this district, profess to belong to that body. This is the more remarkable as Protestant missionaries have met with but very little success in their endeavours to make converts of the Red Men. The Indians throughout the northern half of the continent, as a rule, reject Christianity with disdain and unanswerable argument, not seeming to be able to comprehend the mystery and regenerating influence of faith.

The Apostles are also the headquarters of the remnants of the Indian tribes, mostly Chippeways, and the United States Government maintain an Indian agency on the shore immediately opposite, at the township of Bayfield. This agency is similar to those established in Canada, 
and the Indians receive an annual gratuity of blankets, ammunition, flour, \&c., and their welfare, and protection generally, are supposed to be looked after, but I have reason to believe that a great deal of peculation is committed by the officials in charge of the agency. That offence, however, is one common to every department of the American Government.

This is about all of interest that I have to relate of the southern shore of Lake Superior. A few words descriptive of the north shore I give in another chapter, as this has been spun out to an unusual length. On the whole the coastline of the lake more resembles the shore of a sea than that of a body of fresh water, and, indeed, the Americans frequently speak of the Great Lakes as inland seas.

I have deferred to the end of this chapter the few remarks I wish to make concerning the natural history of the south coast, as it is more convenient to say, once for all, that every bird mentioned in an early chapter, when I made my first journey on these lakes, was found here, and also many of the ducks, geese, grouse, \&c., spoken of as being common in the Red River (or Manitoba) region. Small birds there were none seen until the early spring, when the first of the migrants began to return to their summer haunts, but I left Marquette too soon to permit me to pay much attention to them. I observed nothing to call for notice, those few species I saw being the same as those found in other parts of the lake district. The pine grosbeak and the Lapland bunting (see Index) being among the earliest arrivals, the first being seen March 28, the latter April 4.

Among water birds on the lake there was a grebe not seen on the north side. I did not get this bird satisfactorily identified; but it appeared to be the horned grebe of the Americans, Colymbus auritus. I was shown some egg-shells which were said to be those of this bird. 
They were of a pale grey colour (not white as grebe's eggs are said to be), and with both ends the same shape; that is, they much resembled heron's eggs.

Among the gulls collected I shot a long-tailed skua, Stercorarius parasiticus. It was one of a small flock; but I cannot say whether or not this bird is an habitual frequenter of the lake. I have no record of its having been seen on the north shore.

There are a number of small crustaceans in the waters of the lake, but here again I can give no clear description of species. I caught a shrimp, or prawn, exceeding an inch in length, on the north shore, but it being winter when I examined the south, animals of this class were probably buried in the sand. None were seen. The shells of many small molluses were found on all the shores, and the class of water-snails is evidently well represented, though of the species I can say nothing.

The lake is very free of weeds and aquatic plants, perhaps because there is not much shallow water; but in places the sandy mud was covered with them. These spots seemed to be more abundant on the north than on the south side. In places free of other growths I could see what seemed to be a fresh-water sponge; the little masses, of a dark colour, varied in size from that of a fist to that of a marble. They were growing in depths which I found to be thirty to a hundred feet. Beyond that depth I could not see objects distinctly. 


\section{CHAPTER XXVII}

\section{THE NORTH SHORE OF LAKE SUPERIOR}

I HAVE already said something of the northern part of Lake Superior. To make my account of the lake as complete as possible I add some more particulars gathered on different occasions, previously, or subsequent, to my. visit to Marquette.

The lake is full of islands, the four largest of which are Royal, Maurepas, Pontchartrain, and Pheltpaux. All, large and small, appear to be very beautiful spots of earth, but as I have only landed on a few of the smallest I cannot give a description of them. Many of them present a striking contrast to the rocky shores, having low beaches with grass as green as that of English meadows, a sight not to be seen every day in the northern part of the continent, where the plains are often covered with a coarse, reedy grass, of a brown or dingy colour. Isle Royal and Pheltpaux, which I have coasted, appear to be quite thirty miles long and fifteen broad. I saw several Indian encampments on the shores, but otherwise they appear to be uninhabited. There was, however, a deserted lighthouse on Isle Royal; and to my intense surprise I afterwards learned that this island, which is close to the British side of the lake, is claimed by the United States, and forms part of Michigan!

The north shore of Superior is considered by Americans to commence at the St. Louis River, which enters the lake at its extreme western corner. It is not nearly so well known as the south coast, though not a fourth of the latter had been even cursorily explored at 
this time. I do not think I shall be going too far if I say that six-sevenths of the north line of the lake was known only to trappers and voyageurs, and, of course, Indians. Many spots have no record of ever having been visited by a white man, and others, well known to the voyageurs and other children of the wilds, have never had their names jotted on a map.

Commencing at the town of Superior, at the mouth of the St. Louis, formerly, I believe, called Duluth, after a voyageur who established himself here (I am writing this from remembrance - all the guide I have), the coastline is of the boldest character to be found on the lake. I may add that my acquaintance with this part is not complete. I know but certain spots, as I made a somewhat hurried canoe voyage along this part.

The Great Palisade is the first striking object. It is a projecting headland almost detached from the shore, and was, I should think, when the lake was fuller, a mighty rock standing out of the water, completely isolated from the shore. This is the appearance it has viewed from a canoe; but I had not the opportunity to land here. It is nine hundred or a thousand feet high, and crowned with trees; but the rock is columnar, and of a bright red colour, encrusted with a kind of crystal which causes it to sparkle in the bright sunlight in a way that is sometimes painfully dazzling to the eye. I was at first, on account of its remarkable formation, inclined to think it a kind of basalt; as a matter of fact I was not geologist enough to satisfactorily fix the actual formation, but I have heard it stated to be a kind of porphyritic greenstone. The same formation extends for a great distance; in fact, with intervals, where other rocks intrude, it may possibly extend right round the lake.

Continuing a north-eastward course, wonder follows on wonder and beauty crowds on beauty so fast that the eye becomes confused and fails to note the multitude of objects that deserve attention. Even at this day-thirty 
years and more since that of which I am writing-the marvels of Superior are but little known to civilised man; and there are vast tracts of both the lake and the adjoining country that are wholly unexplored. At this time those tracts were far more numerous and extensive than they are at the present day, but Lake Superior lies wide of all established routes, and is a troublesome spot to reach from any of the great cities of either Canada or the States. Were it otherwise, it would undoubtedly be far more frequently visited by travellers for pleasure.

For many miles beyond the Palisade the coast is exceedingly rugged and broken, rendered enchanting by patches of beautiful forest trees clinging to the rocks, and sometimes coming quite down to the water's edge. Considering the latitude, and the nature of the country, I expected to see a far greater profusion of firs and pines. These trees were often conspicuous by their entire absence. The great majority of the trees were of broad-leaved species, sometimes intermingled with firs, and occasionally the latter held the sway. It is unusual for the two classes of trees to be much mixed together in American forests. Even among broad-leaved kinds, one species generally predominates, ousting and destroying all others.

Here and there torrents rush furiously through channels in the rocks. Sometimes vistas are obtainable up these channels, showing a long series of bounding cataracts, overhung, or entirely arched, by splendid trees; and not infrequently huge uprooted trees are whirled down into the lake. These become a floating danger, and have been the cause of disaster to small craft when run foul of in the dark. The largest cascade in this part is that formed by Beaver River, which, especially in winter, throws a considerable body of water into the lake. There is a recess here called Beaver Bay, which is one of the safest harbours of refuge on all the shores of Superior.

I have already said that no considerable river empties itself into Superior. The rivers scarcely deserve 
to be considered as more than brooks, or, at most, rivulets, and $I$ do not know of one of them that can be navigated from the lake, even by so shallow draft a craft as a canoe. They one and all, as far as I know, enter the lake as falls or fierce rapids. I am, of course, exempting from this description the rivers at Fort William, already described, and the channels which connect the great lakes. These latter are scarcely correctly described as rivers. They are simply straits joining the various lakes. The Alemipigon River, also, leading to the lake of the same name, can be navigated by canoes. This lake has been made a great mystery of in the past, and its size greatly exaggerated. Thirty years ago even its correct name was not known to the Canadian Government, if it is now-a matter on which I presume to have my doubts. It seems to be officially known as Nipigon or Neepigon; the Indians, who, I think, should know best, pronounce it Al-e'-nip'-i-gon, which means the "lake of the myriad rocks."

I thought Alemipigon to be about fifty by forty miles in area; but a Government survey made since I visited it gives the dimensions as seventy miles long by fifty broad, a size that alone would make it a remarkable natural object in any country, but this is the native land of great lakes. It has bold rocky shores like Superior, and is crowded with rocky islets. It will, some day, be the centre of great mining operations; for silver abounds in every rock, and the copper ore is perhaps as rich as that of the Kioueounan peninsula on the south side of Superior, while, for scenery, it can hold its own with any lake of this vast region. Alemipigon is about thirty-five miles, as the crow flies, from the most northerly shore of Superior.

Continuing along the coast of Superior, the next point of interest is Pigeon River, which is the boundary between the United States and the British possessions, and is remarkable for but little else. Continuing, we 
soon come to the three rivers and Fort William, already described, and immediately afterward to Thunder Bay only cursorily noticed. Thunder Cape is held in extreme awe by the Indians, and they do not care to paddle too near it. When I mention that it is but a few feet short of fourteen hundred in height, or nearly three times that of Beachy Head, rising a sheer cliff from the water, it will easily be comprehended what an imposing sight it presents to the traveller passing below in his frail bark canoe. The formation of the rock is undoubtedly basaltic, and according to my measurements about here is the deepest part of the lake. It is from this majestic cliff, or rather mountain, that the furious storm-demon hurls his blasts across the lake-so say the Indians; and they never pass near it without making offerings to propitiate the good-will of this uncertain-tempered, irascible manitou.

Red is the prevailing tint of the rocks in the neighbourhood of Thunder Cape, and many of the cliffs have irregular masses of detached, or semi-detached rocks at their bases. As we proceed, hundreds of cascades are seen leaping over the rocks, many of them dyed, by the soil over which the streams have run, the colour of claret or port-wine; others looking like muddy, discoloured blood. These cliffs abound in several metals, of which, so far as is yet known, copper and silver are the most valuable. The latter metal has been extensively worked, especially at Silver Island off this coast, which is simply a solid mass of the precious ore, said, by the miners, to be yielding a thousand pounds' worth of silver to every ton. No wonder the island is guarded with jealous care and every precaution taken to prevent waste by the restless waters chafing its shores.

Of the multitudinous small islands of this lake the greater number have no name, and others only the vernacular names of the Indians and voyageurs. Others again have no certain name; some have map names not 
recognised by the few men who visit or pass them, and some bearing a different name from every canoe-crew which glides by. Most of them are rocky, many rising in abrupt cliffs sheer from the water, and the action of the waves is very perceptible on some of them. They are gradually disappearing, though often there is five or six hundred feet of water ten or twelve yards from the shore. On several of these islands I found great caves into which it was possible to paddle the canoe, though this was sometimes dangerous, as the waves came in with a rather strong wash, causing strange and mournful sounds, which are a source of superstitious terror to the Indians. There were also rocks just awash, or looming close up to the surface, and these had to be carefully watched for, as the canoe is a craft which is soon upset or pierced by a sharp projection. In some of the caves, however, I found, on heaving the lead, more than four hundred feet of water. Most of the islands had trees upon them, some being quite covered with forest growth. Rocks of only a few square yards surface would yet support a tree or two.

Other of the islands were perforated by the action of the waves, forming natural arches such as are found on most rocky coasts, and all these islands, if inaccessible, and especially those with caves, were frequented by the gulls for the purposes of breeding. Some of the rocks were white, as if covered with snow, from the dung of the multitude of birds which frequented them. There were also purple martins breeding in the caves, their nests being far out of reach, and only just discernible in the faint light which reached the interior.

In order to check my account of this important lake and make it as correct as possible (though it is to be understood that throughout the book, as in this particular place, I state no fact at second hand, and it is my own observations, or actual gleanings only that are recorded), I have been looking up the remarks of other 
observers. So far as I can discover there is very little recorded of Superior, and some of that little does not quite agree with my experience. For instance, an American writer says that the navigation of Superior is not so dangerous as that of the other great lakes, and says that there is more "sea-room" here than in the other lakes. I can say, from my own experience, that this is not correct. Superior is certainly by far the largest of the five great lakes, but its larger islands are so placed that there is less actual sea-room, as understood by sailors, than in either Michigan or Huron. As to storms, they are as violent, but I think not more so, as in any of the other lakes: that they are more frequent I am sure. As I have already said, I do not think that dangerous gales are ever absent, in winter time, from some part of the lake.

The northern, or British, shore of Superior is more elevated, on the whole, than the southern, and not inferior to it in beauty and grandeur. Thunder Cape is not the only point which rises to an elevation exceeding a thousand feet, while cliffs and hills of several hundred feet in height are very numerous. The bays, or harbours, are not numerous. Nipigon Bay (or Alemipigon, as it should be called), or the Bay of Clear Waters, as the Indians name it, is about 500 square miles in extent, and as it is full of small islands it affords excellent shelter from winds from every quarter.

The country inland is almost invariably written of as a desert. I know less of the country to the north-west than of other parts of the district-too little to venture on a description of it. I can only say, briefly, that it is not a forest region, has a barren aspect for many miles in some places; in others is remarkable for the numbers of shallow reedy ponds, which swarm with swans, geese, and ducks, and on the whole may be described as a rough, broken, and often rocky prairie. I doubt strongly that it is such a desert region as some represent it. On the 
immediate borders of Lake Superior there is a sufficient growth of trees to make the scenery thoroughly picturesque.

The hour has come in which I must lay down my pen. I do so with regret, as this is probably the last of my books on America. Though I could say something on Mexico and other parts of the north not referred to here, or in my first volume, my remaining notes could scarcely be extended to form yet another work. From what I have recorded in my three volumes, the reader will learn that I have been a very great wanderer. This, my last book, contains my first experiences in point of time; and, after the travels here recorded, I went south to Tennessee, and commenced my business as a peddler, or "boss of a prairie schooner," and perhaps it will be of some interest if I give a few particulars of the business of peddling in the States in a final chapter.

But let me write a caution. The palmy days of peddling are over for ever. As the country is opened up, the character of the trade completely changes, and the facility for obtaining goods of all kinds is such that there is now no chance of making three or four hundred per cent. on a "cargo of notions," while the gentlemen with the wooden nutmegs have long since ceased to be in it. 


\section{CHAPTER XXVIII}

\section{PEDDLING IN THE UNITED STATES}

THE word peddler is one of those which Yankees misuse and abuse. It is applied to any person who hawks goods in any way or form, and not restricted to a travelling foot-trader, as it should be. A Yankee talks of peddler and peddling, where an Englishman would say a hawker, and hawking. The word peddling is but little used in England, while hawking is rarely spoken of in the States. The peddler in both countries is rapidly dying out. Railways and quick transition have made it no longer profitable for a man to wander from place to place with a small quantity of goods. The prairie schooner, however, is not yet a thing of the past, and will not be for years to come, though the expense of running one is great. A prairie schooner is a waggon furnished with all sorts of stores likely to be required in outlying stations and farms, such as medicines, tea, coffee, sugar, medicaments for marking sheep, cattle washes, and unguents, tin and iron ware, cutlery, gunpowder and shot, cartridges, firearms, all sorts of drapery and wearing apparel, pins, needles, threads, \&c., \&c., in a word, any and everything that there is a demand for in a household. But the articles which I have purposely enumerated were those that I had the greatest call for, and therefore those that formed the bulk of my stock. The stock of a prairie schooner is always spoken of as "a cargo of notions," because most traders carry, on speculation, a large number of articles of doubtful utility, on the chance of doing a brisk trade at a large profit, a chance that seldom failed. 
For instance, I knew a fellow who took into the wilderness a large stock of Birmingham toys, specially brought out for him, and smuggled into the country. The total cost to him, as he himself told ine, was under seven dollars a gross, but he sold them like wild-fire for a dollar per trinket, and in three days got rid of his entire stock of a hundred gross. That means that for an outlay of 700 dollars he made 13,700 dollars clear profit. His customers for these articles were nearly entirely cowboys and women, and the mischief he made can never be known, for many of these silly fools spent large sums on this trash, hoping to make a profit in turn among their acquaintances, for they swallowed all G__ said about the value of the articles. By-and-by there were angry husbands and fathers, furious at the waste of dollars by their female kind, and the next time I went that round many were the inquiries by irate cowboys after $\mathrm{G}-$ -

It was a Yankee peddler who invented the painted wooden nutmegs, now forgotten, but which caused a great commotion in the Eastern States at the beginning of the century just closed. He sold thousands of them at twenty-five cents apiece, wandering from district to district, and always carefully changing his quarters as soon as he had done a good trade; but I might write chapter after chapter narrating the trickery of these rogues, who were exceptions of their class. For the genuine peddler was a man much looked and longed for, as will easily be realised when it is remembered that thirty or forty years ago many of his customers could not visit a store (shop) of the meanest class without riding a hundred miles or more. Such journeys were often taken, even by women, for the purpose of shopping, so the visit of a genuine prairie schooner to an outlying ranch or farm was an event that the news of spread over the adjacent country with simply marvellous rapidity. "P. F. is at Smith's ranch. Have you heard the news?" must have flown over the country with almost the rapidity of a telegraph, 
for next day there would be cowboys and farmers riding in from fifty miles around, and even from such articles as I carried I would sometimes make more than a thousand dollars in a day's sales. This may seem a large sum to take in so short a time, but it is to be remembered that there is five or six days' travelling for one of trading, and that the expenses are heavy. I always had at least two men to assist me, and ten or twelve horses and mules; and though the latter sometimes picked up a good deal of forage at the camping place, they had to be kept in good condition to enable them to perform their heavy work, often dragging eight or ten tons over trackless wildernesses.

My headquarters, in the latter part of my career, was at Memphis, on the lower Mississippi, but often the round of trading calls I made extended to quite a thousand miles, which distance, including stoppages, generally occupied a little more than four months in performing.

During these wanderings I led a very regular life, inconsistent as that may seem with, I had nearly written, perpetual motion. But the waggon was really my home. I had everything fitted for my comfort as far as that could be done in such a very limited space, and though, I must confess, rather cramped till the sale of the greater part of the goods made room, I contrived to eat, sleep, and follow my favourite occupations of reading and writing quite as freely and comfortably as I ever did in lodgings.

Of course the waggon and its contents were of considerable value, and, naturally enough, might have been thought to offer a great temptation to dishonest wanderers or roving Indians, of which there were not a few lurking about the wilds when I first commenced this life; but, as I have already said several times, I never suffered a disaster of this kind, though, looking back at the many risks I ran, I wonder that I came of' so well. The danger was often 
great, but from the first I never was troubled with any fears on this account, nor went out of my way to avoid it. The Indians I contrived to overawe; the whites never attempted to do me harm when on my ordinary travels.

Most men engaged in this peddling trade, if well enough off to own a waggon, carry a large quantity of whisky and rum with them, off which they make a great protit. For the rough cowboys and ranchmen will give anything that they possess to obtain the horrible spirit that such traders carry, and which deserves not the name of whisky. So infatuated with strong drink are these miserable men that the most abominable concoctions are often sold to them without raising a protest, and double and treble the price of good spirit charged. If they are in possession of money, they will have drink at any price, and without regard to quality. Personally, I have an objection to selling drink, though, as the reader knows by this time, anything but a teetotal fanatic, and I never carried whisky with me except for my own use; yet the quality of my brand was so well known that, over and over again, the rogues of cowboys would pilfer from $\mathrm{my}$ waggon all that they could find. Often, however, I would afterwards receive compensation in some form from the marauders.

Payment for goods sold was made in a great variety of ways-by cheques and bills on bankers and merchants, by note, and largely in kind, but very seldom in hard cash. There was very little gold or silver in circulation in the wilds; but many of the outlying farmers and ranchmen were rich men, and I would often part with coin to them at a small discount, taking bills in exchange. This was an advantage to both parties, the coin being much needed for circulation among themselves and their servants, and being a source of danger to me; for if by chance I had been "stuck up" by Indians or other thieves the money would have been irretrievably lost, but the paper would be absolutely useless to them, not being payable at sight. 
Indeed, Indians will not touch paper money. From some cause, probably through some of them having been brought to justice through attempting to pass paper, they have an amusing awe of any kind of bill or note. They will not accept it in payment for anything they have for sale, and if they find it in the possession of any traveller they are plundering they will drop it like a hot brick. I do not know if superstition has anything to do with this trait, but probably it has; for I call to mind three cases of robbery and murder committed by them in which paper money was concerned. In two instances they had killed the men and left notes to a large amount on the ground beside the corpses, pegging them down to prevent the wind scattering them; in the other, fortunately for the victim, they proceeded to plunder him before slaying and scalping him. Finding a small bundle of notes, they hastily thrust them into his hand, and rode off in evident trepidation, not even taking his arms from him. There must have been superstition in the last case, at least, otherwise they would certainly not have abandoned a scalp, an article quite as precious as gold to an Apache.

Very large fortunes have been made by peddlers in the United States - that is, by the class who run waggons. But even foot-peddlers, men with no more stock than they could carry on their back or across their shoulders, often did fairly well for their class - that is, they made more money than they could have done as labourers or mechanics.

The expense of a waggon and team of horses is, of course, great; but my plan was to sell the horses or mules when winter set in and travelling was no longer safe or possible. Some peddlers harness a team of oxen to their waggons, but I found mules the best and cheapest of any draught cattle. Occasionally I have met peddlers who travelled with a one-horse van or cart, but these men never took long journeys, and generally dealt in one or two kinds of goods only. Sometimes a peddler would 
have a partner; and I knew one man who was proprietor of nearly a dozen waggons which took different routes; and this man amassed a very large fortune, notwithstanding that he was frequently robbed by his "deputy-bosses," who sometimes not only sold his goods but his horses and waggons as well, and skedaddled with the dollars. The man I refer to was one of the meanest skinflints I ever met, and used to cry and howl aloud when he suffered such a loss as that I have referred to; yet he told me himself that he was worth half a million dollars besides the value of his stock and waggons. When he was nearly sixty he married a very pretty girl of twenty, and a year or two afterwards she obtained a divorce from him on the ground of his meanness. This is really so, and the judge, in pronouncing the decree, told the defendant that, though he had plenty of money, "he wasn't worth a carrot." The beauty and force of this simile need not be pointed out.

The defendant, or respondent as he would be called in England, then went to live in a mean house, did his own cooking - I cannot say blacked his own boots, for I do not think they were ever subjected to that process at all-and used to threaten any intruders near his door with a gun. In this miserable way he lived for many years, and was still alive when I last heard of him, being then over eighty.

If this is all the happiness that is to be gleaned from "a pile," I have no cause to reproach myself for having made one and spent it. For I have at least seen much of a most beautiful world, and enjoyed more days of unalloyed happiness than a certain class of moralists seem to allow, on the average, to what they call " miserable man." 


\section{GLOSSARY}

Name. Pronunciation. Meaning.

Аввітіввк, river. . . . ab-be'-tib'-by.

Alkmipigos . . . . . . a'l-e'mip'-i-gon . . Million islands.

Anticostr, island . . . anti'- $\cos ^{\prime}-$ ti.

Assixibolne, river . . . as-sin'-i-boi-ne'.

Cariboo, reindeer . . . . car'-i-boo'.

Chккоotminns, river . . . check-oo'-tee-mee'-ens.

Chicago, city ${ }^{1}$. . . . . she-cau'-go . . . . Roaring current.

ChомгеL, Indian woman . . tshom'-pel . . . . Sweet voice.

Chоскоонilghgan, Indian . . tshuk'-o-tshil-ge-gau . . Cunning polecat.

Erie, lake . . . . . . ee'-ry.

Huron, lake . . . . . . hū'-ron.

KrсKIBECKI, falls . . . . . kek'-i-bek'-i . . . Roaring demon.

Kkwkexaw, peninsula . . . ke-wee'-naw.

Mal BaIk, village . . . . $\mathrm{mal}^{\prime}-\mathrm{ba}^{\prime}$. . . . False bay.

Manitoba, district . . . . ma-nit'-o-bar'.

Maxitoulin, island . . . . man-i-too'-lin . . . Storm spirit.

MARQUETTk, village, \&c. . . . mar-ket'.

Michigax, lake . . . . . mish'-i-gan.

Monchuapigaxon, Indian . . mon'-choo-a-pig'-a-non . Deep water.

Moosk, deer . . . . . mōōse (soft).

Natanyan, Indian . . . . nat'-a-nī-an ${ }^{2}$. . . Slow creeper.

Nipissing, lake . . . . ne-piss'-ing.

Онго, river and State . . . . o-hi'-o.

Otmasquloton, Indian . . ot-mas'-kwil-o-ton . . Young rogue.

Prerra, rivulet . . . . . pe'-er-ra . . . . . Lily brook.

Skautraux, Indians . . . sō-tó-sō-tō' . . . : Leapers.

TADotssac, village and bay. . ta-doo-sack'.

Temiscaming, lake . . . . Te-mis'-ca-ming'.

WiPITI, deer . . . . . we-pee'-te.

1 Correct Indian sound is shak-a-kwan'.

2 No Indian word has sound of " $y$ " as in "yacht," "year," \&c. 



\section{NDEX}

AвbitibBe River, 154

Abies canadensis, 29

Acadian owl, 144

Agialitis semipalmata, 133

Albany River, 146

Alder tree, 221

Alemipigon Lake, 338

River, 338

American apple, 289

" English, 282-285

A " "mill" in the backwoods, 186188

Anas boscas, 79

" obscura, 79,158

, strepera, 79

Anticosti Island, 168

Apple-paring frolic, 210

Aquila chrysaëtus, 145

Arctic fox, 38

Asio americanus, 145

,, otus, 145

Assiniboine, 79

Avocet, 153

BACKWOODSMEN, 262

Badger, 39-40

Bass, 3

Bats, 152, 290

Bay of Clear Waters, 341

Bear, 97-100, 120, 138, 154, 158$159,168,179$

Bear and honey, 266

Beaver, 156-158

Beaver-meadows, 157, 214

Beaver Bay, 337

Beaver River, 337

Bee, wild, 263-268

", hunting, 265

"Bee," husking, 205-209

$$
\text { ", spelling, } 205
$$

Beech woods, 215

Bernicla brenta, var., glaucogaster, 132

Bernicla canadensis, 83, 132

Black cherry, 288
Block-house, 14

Blood-drinking, 35

Bonasa umbellus, 52, 223

Boss, origin of the word, 209

Brent goose, 132

Brown bat, 290

Bull, the, 175

Bull-frogs, 223

"Burning off," 228-230

Butcheries by Indians, 316

Calcarius lapponicus, 5

Canachites canadensis, 52, 223

Canadian goose, 132

, independence, 17

, partridge, 52

Canis lagopus, 38

Canoes, 64

, north, 65

Canotes de maitre, 64

Caprimulgus virginianus, 95

Cariboo, 45, 48, 119, 122

Castor, 157

Caverns on Superior, 323, 325

Cedar swamp, 221

Celibacy, 233

Cerasus depressa, 288 ," nigra, 288

Chekoutimiens River, 177

Chickaree, 146, 254

Chipmunk, 224-225

Chippy, 68

Chompel, 10

Chordeiles virginianus, 95

Chrysomitris tristis, 105

Chuckochilgegan, 10

Cider-royal, 209

Cities and towns, terms, 314

Clangula islandica, 133

Cliffs at James Bay, 150

Clothes moth, 128

Colaptus auratus, 224

Coloured rocks, 322

$$
\text { " waterfalls, } 339
$$

Colymbus auritus, 333 
Colymbus glacialis, 6

Colymous glacialis, 6

Copper ore, $329-330$

Curlew, 66

Cygnus buccinator, 82

Dafila acuta, 79, 158

Dead in the wilderness, 111, 115-116

Death of a tree, 182

Deer-shooting, 34, 45

Dendragopus canadensis, 52

Diminutive hay-ricks, 308

"Doctors" in the States, 299

Dogs, Indian, 160

Drawing lots, 44

Drum, historical, 281

Ducks, 79, 81, 132-133, 158 black, 158

Dunford, Mr., kindness of, 276

EAGLE, golden, 145

, white-headed, 145

Ectopistes miyratorius, 215

Eggs, birds', 6, 8, 23, 52, 68, 69, $133,149,217,249,334$

Elderberry, 288

Emma, 10, 155, 163, 166

Empress rock, 328

Erethizon dorsatus, 191-192

Ermine, 103

Esquimaux whimbrel, 153

Extinction of game, 142-143

Falco candicans, 125

Fenian incidents, 273-275

Fiber zibethicus, 249

Fighting Jeamy $M^{4}$ Cullough, 184, 188

Finnock, Mr., 168, 179

Fish, 3, 19

Fishing, 3, 20, 55

Fish-spearing, 55, 68

Fog, 25

Forest fires, 222, 228-230

Forests in Ohio, 220-223

Fort Alexander, 75

, Frances, 73

, Severn, 131 .

,, Stone, 80

"William, 62

Fox, 38-39, 301 modern, 65

,varieties of, 38

Frame houses, 236

Frost, 25, 55, 117

Fulmar petrel, 149

Pulmarus glacialis, 149
GeEse, 82

Ghost rock, 325

Glutton, 100-102, 120

Golden eagle, 145

Golden-winged woodpecker, 224

Goose creek, 176, 177

Grasshoppers, 276-279

Grease, deadly poison to flies, 70

Great Palisade, 336

Grebe, 333

Grosbeak, 68, 106

$$
\text { " pine, 106, } 123
$$

Ground sparrows, 133

Guelle, Achil, 83

Gulf of St. Lawrence, 172, 173, 176

Guillemots, rock, 148-149

Gulls, 66, 75, 86, 158

Gulo luscus, 102

Gum berry, 288

Guns and rifles, 27-28

Habia ludoviciana, 69, 106

Harelda glacialis, 133

Hares, 158

Hedymcles virginianus, 68, 106

Hemlock spruce, 29

Hibernation, 104, 120-121, 255, 258

Hogs at Chicago, 213-214

Hospitality, American, 5ij

House spider, 127

French, 171

Hudson Bay Company's policy, 9092

Hudson Bay Company's employees, 73

Hudson Bay, coast-line, 148 , shores of, 132

ICE, 25, 55, 175, 176, 317, 324

Icicles, 40

Indian character, 21, 22

, habits, $20,21,22,24,43,47$, $87,106,131,160-161,162$

Indian companions, 10

Indians, Red, 11, 26, 315, 316, 326$327,330,332,339,347$

Interior of a fort or depôt, 89

Iron mountain, 329

, ore, 329

Island of Anticosti, 168

," in Superior, 335,340

Ivory gull, 158

JACK River, 88

James Bay, 151

Judge with a black eye, 297 
Jumping-mouse, 257

Juniper bush, 221

KEWEEN $A$ w peninsula, 229, 331

Kittiwake gull, 66, 149

Kittydads, 276-279, 288

LADYBIRDS, 127

Lake Abbitibbe, 162

" Play-green, 93

", Superior, cliff of, 319

" " coast-line, 333, 337

"Temiscaming, 1

"Winnipeg, 85

" of the Woods, 74

Lapland bunting, 5, 114, 333

Larus argentatus, 149

" glaucescens, 158

" canus, 66, 86

Lee, Mrs. Ann, 232

Lepus americanus, 28

, campestris, 158

", polarius, 158

Le Grande Portail, 323

Log-felling, 182-184

," floating, 177, 192, 193

, -huts, 12, 13-17

Long-eared bat, 290

Long 'Jake, 261

$$
\text { owl, } 145
$$

Long-tailed skua, 334

Loon, 6

Lumberers' camp, 181

", hovels, 178

Lutra canadensis, 105

Lynx, 163-165, 249

"MAjoR" Shadley, 293-296, 309, 313

Mal Baie, 170

Mareca americana, 79

Marquette, 312, 318, 328

Marquette, Father, 315,327

Marriage frolic, 279-282

Marten, 103, 225

," fish, 104-105

Maternal love, 50

Meat, 46

Melospiza georgiana, 248

Mephitis mephitica, 250-253

Migration of birds, $8,18,25,69$, $106,114,123-124,289$

Military titles and humour, 200-201

Mink, 102

Model farm, a, 235

"Moll Rowe in the Morning," 194

Monchuapiganon, 10
Money in the wilderness, 346

Montmorenci Falls, 168

Montreal, 167

Moose deer, 48-50, 141

Moose Factory, 150

Mosquitoes, 127

Mountain Fall, 66

Mus decumanus, 260

", musculus, 260

"rattus, 260

Muskinongi, 19-20

Musquash, 87-88, 249-150, 257

Mustela americana, 103

" penanti, 104

Muzzle-loaders $v$. breech-loaders, 27-28

Navigation, canoe, 68

Neighbourly kindness, 210-211

Nests, birds', 6, 8, 12, 13, 52, 68, 113,287

New Lebanon, 232

Norway House, 88-89, 93

"Not worth a carrot," 348

Numenius borealis, 66, 153

Nyctala acadica, 144

Nyctea scandiaca, 124

Nyssa sylvatica, 288

OFFENSIVE odour of animals, 251

Old mare, anecdote of, 307

Osprey, 8

Ottawa River, 1

Otter, 105

Owls, 53

" acadian, 144

" great grey, 53, 144

"long-eared, 145

, saw-whet, 144

," screech, 144

"snowy, 54

Pagophila eburnea, 75, 158

Passenger-pigeon, 215-220

," disgraceful slanghter of, $217-218$

Peerra, brook of, 139

Phalarope, grey, 153

Phenomenon, curious, 169

Pickerel, 2

Picture rocks, 319, 327

Pigeon River, 338

Pine grosbeak, 123, 126, 333

Pinicola enucleator, 106, 123, 333

Pintail duck, 79 
Plecotus macrotis, 290

Plectrophenax nivalis, 123

Plover, 133, 153

$$
\text { Norfolk, } 153
$$

Polar bear, 154

Pond, Wolf, 2

Ponds in America, 1

Porcupine, 191-192

Portage Lake, 331

Prairie, 81 schooner, 343

Professional jargon, 134

Professor of Greek, a, 298

Progne purpurea, 13, 340

Ptarmigan, 51

Quebec, 169

"RabBits," 158

Rat.Portage House, 74

Recurvirostra americana, 153

Red River Settlement, 77

Red spruce, 29

Reedy ponds, 341

Regulus calendula, 106

Remarkable phenomenon, 126

Rifleman rock, 328

Rifles and guns, 27-28

River Abbitibbe, 154

River Ottawa, 1

Roads, Canadian, 170

Robin, American, 286-288

" $\quad$ "song of, 289

Ruby-crest, 106

Ruffed grouse, 52

SABINE's gull, 150

Saguenay River, 174, 179

Sail rock, 322

St. Catherine, village of, 174

Salt, 48

Salt-licks, 47

Sambucus canadensis, 288

Sand cherry, 288

Saw-whet owl, 144

Scared game, 141

Seiuropterus volucella, 258-259

Sciurus carolinensis, 254

Scops asio, 145

Screech owl, 144

Severn River, 130

Shakers, 232-247

Shrew-mouse, 291

Shooting, deer, 34

Silver Falls, 327

" .haired bat, 290
Silver island, 339

, ore, 338

Silvery bat, 152

Skunk, 250-253, 300 " malodour of, greatly exag. gerated, 250

Sledge or sleigh ? 137, 169

Sleeping Beauty rock, 328

Smart trade, 344

Snow, 25, 57

" bunting, 54, 123, 191

" deer in, 42,125

" -drifts, 45

", -shoes, 41,117

Snowy owl, 54, 124, 140, 144

Song of American robin, 289

Song sparrow, 249

Sorex cooperi, 291

,, vulgarus, 292

Spiritual pride, 233

Spizella domestica, 68

" monticola, 106

"Splits" Brown, 262

Squirrel, 146, 253-256

„ flying, 258-259

Stercorarius parasiticus, 334

Sternäfluviatilis, 66 pomatorhinus, 149

", hirundo, 66

Strepsilas interpres, 153

Swamp sparrow, 248

Swan, S2

Syrnium cincreum, 53, 144

TADOUSSAC Bay, 175 " village, 174

Tamias striatus, 224

Taxidea americana, 39

Temiscaming Lake, 1

Tenderfeet and tramps, 226-228, 292, 304

Three Rivers, 65

Thunder Bay, and Cape, 339

Titles in the States, 296-299

Tom, the Indian, 10

Tracking, 36

Trapping, 36, 88, 103, 271, 301

Tree-sparrow, 106

Turdus canadensis, 286

" migratorius, 286

Twelve apostles, 332

UGLY female costume, 234

Unconscious hypocrites, 235

"United Society of Millennial Christians," 233

Uria grylle, 148 
Uria troile, 148

Urinator imber, 6

Ursus americana, 97

Vexisos, American, 46

Vespertilic noctivagans, 290 " subulatus, 290

Vesperugo noctivagans, 152

Voyageurs, 93

WARM current, 126

WVayside inn, 308

Wbales, size of, 152

Whip-poor-will, 95

Whisky-jack, 6, 96

White falcon, 125

White fish, 19

White-headed eagle, 145

Widgeon, 79

Wild animals reluctant to attack man, 269

Wild flowers, 154

, fruits, 5, 96
Wilson's snipe, 86, 153

Wipiti, 48-50, 119

Wolf, 36-37, 271

„, ferocity of, 37

Wolf Pond, 2

Women, Indian and half-breed, 20

Woodpeckers, 224

Xema sabinei, 150

“ YANKEE-DOODLE," 194

Yankee, boastfulness, 200

, exaggeration, 199

, excitability, 196

" mode of feeding, 197, 203

, offer of marriage, 198

" origin of the word, 195-196

," precocity, 201

, self-conceit, 195

" squeamish women, 198

Zapus hudsonianus, 257

THE END 



\title{
THE GREAT
}

\section{DESERTS AND FORESTS OF NORTH AMERICA}

\section{By PAUL FOUNTAIN}

\author{
With a PreFace by W. H. HUdSON \\ Author of "The Naturalist in La Plata," \&c.
}

Speaker.- "A Natural History abounding in freshness such as this book, is not often met with."

Yorkshire Weekly Post. - "One of the best books of American exploration published for many years."

Land and Water. - "The book is most readable, some of it containing observations fresh and original. We must congratulate the author on his spirited treatment of much hackneyed ground."

Field. - "We have a wealth of common-sense, simply told descriptions of rude unspoiled nature in waste and desert places. In short, it is a book of real value to the naturalist and sportsman."

Manchester Guardian.- "We commend the volume to the happy few-or many-who care for the life of the open air and the lore of wild things, and who desire to know how they act in every part of their lives."

Bristol Daily Mercury.- "One of the most fascinating volumes that the press has put forth for many a day. . . Mr. Fountain has met with many strange adventures and encountered strange animals, and whether he writes from notes or memory he invariably enlists the interest of his readers."

Academy.- "If you want fine local colour without the embarrassment of a screech-advertised story in the foreground, just ask at your library for Mr. Paul Fountain's 'The Great Deserts and Forests of North America.' A book of reality and America, thoroughly worth reading."

Dally Chronicle. - "In this volume the author sets forth his experiences of men and cities as well as of wild beasts in North America. There is more about the latter, and the solitudes which they inhabit, than about the humau beings of the continent and their ways. . . We have never read a more fascinating work of the kind."

Geographical Journal. - "Though dealing with regions well known both to the geographer and naturalist, this work stands distinctly above the general level of books of travel. The author possesses in a high degree the power, too often wanting in travellers, of presenting vivid pictures of nature and wild life which enable the reader, to wlom the pleasure of actual travel is denied, to realise the true conditions of countries remote from his own. The book supplies an illustration of the fact that good work may be done without passing the limit of the unknown."

$$
\begin{gathered}
\text { L O NGMANS, GREEN, A N D C O. } \\
\text { LONDON, NEW YORK, AND BOMBAY }
\end{gathered}
$$




\section{THE GREAT MOUNTAINS AND FORESTS OF SOUTH AMERICA}

\section{By PAUL FOUNTAIN}

\section{CONTENTS}

CHAP.

INTRODUCTION.

I. A TRIP UP THE TROMBRTAS.

II. The River Purus.

III. Continuation OF the VOFage ON THE PURUS.

IV. Conclusion of the Votage oN THE PURUS.

V. Raybling Days in a Central Brazilian Forest.

VI. The District of THE SEveN LAKES.
CHAP.

VII. The POISONED ARrow.

VIII. The EcUador ANdes.

IX. The Highlands and Llanos of NEW Granada.

X. Mountain aND VALLEY IN Chili and Peru.

XI. A Miscellaneous ChapterBolivia - THE RIO JANEIRO DISTRICT-CONCLUDING ODDS AND ENDS.

INDEX.

Yorkshire Weekly Post. - "As a romance of strange travel, adventures, and as a solid contribution to natural science, this is even a more fascinating and instructive book than the author's first."

Morning Post.- "This book is so full of marvellous stories that the reader might doubt whether there was not some confusion between memory and imagination if he did not find much intrinsic evidence of its general credibility."

Aberdeen Free Press._- "A delightful record of unconventional travel, and the reader concludes it in pleasurable anticipation of Mr. Fountain's next book, in which he promises to describe his wanderings in Canada."

St. James's Gazette. - "Mr. Paul Fountain is one of those rave writers on travel who can make their readers live in the scenes described. . . Mr. Fountain promises another instalment of these valuable accounts of his wanderings should the public show sufficient interest in this book under notice; and if it be read as widely as it deserves to be, we shall soon welcome more of this explorer's tales of adventure by flood and field."

speaker. - "It reads like a romance."

Pall Mall Gazette. - "Mr. Fountain's new book, "The Great Mountains and Forests of South America,' fairly surpasses its predecessor in interest, for during two-thirds of its length the author deals with territories practically unexplored. ... If anxious mothers do not wish their boys to acquire a yearning for pathless forests and cayman-haunted streams, it were well to keep those interesting youngsters from a knowledge of Mr. Paul Fountain's South American adventures."

I. ONGMANS, GREEN, AND CO. LONDON, NEW YORK, AND BOMBAY 




\section{A Classífíed Catalogue}

OF WORKS IN

\section{GENERAL LITERA T URE PUBulseb BX LONGMANS, GREEN, \& CO.}

39 PATERNOSTER ROW, LONDON, E.C. 9I AND 93 FIFTH AVENUE, NEW YORK, AND 32 HORNBY ROAD, BOMBAY

\section{CONTENTS.}

PAGE

BADMINTON LIBRARY (THE) - - 12 BIOGRAPHY, PERSONAL MEMOIRS, \&C.

CHILDREN'S BOOKS

CLASSICAL LITERATURE, TRANS: LATIONS, ETC.

COOKERY, DOMESTIC MANAGEMENT, \&C.

EVOLUTION, ANTHROPOLOGY, \&c.

FICTION, HUMOUR, \&c. -

FINE ARTS (THE) AND MUSIC FUR, FEATHER AND FIN SERIES HISTORY, POLITICS, POLITY, POLITICAL MEMOIRS, \&C.

L A N G UAGE, H ISTOR Y A D SCIENCE OF

LOGIC, RHETORIC, PSYCHOLOGY, \&c. -
MENTAL, MORAL, AND POLITICAL PHILOSOPHY .

MISCELLANEOUS AND CRITICAL WORKS

POETRY AND THE DRAMA

POLITICAL ECONOMY AND ECO. NOMICS

POPULAR SCIENCE .

RELIGION, THE SCIENCE OF - 2 I

SILVER LIBRARY (THE) - - 33

SPORT AND PASTIME - • - 12

STONYHURST PHILOSOPHICAL SERIES

TRAVEL AND ADVENTURE, THE COLONIES, \&C.

17 WORKS OF REFERENCE.

\section{INDEX OF AUTHORS AND EDITORS.}

\section{\begin{tabular}{rr|rr} 
& Page & & Page \\
Abbott (Evelyn) & $3,19,22$ & Balfour (A. J.) & - 13,21
\end{tabular}}

$=\left(\right.$ (r. K. ..) ${ }^{-}$

Acland (A. H. D.)

Acton (Eliza) -

Adelborg (O.)

Eschylus

Albemarle (Earl of)

Alcock (C. W.)

Allen (Grant)

Allgood (G.)

Alverstone (Lord)

Angwin (M. C.)

Annandale (N.)

Anstey (F.)

Aristophanes

Aristotle

Arnold (Sir Edwin) - II, 23

- (Dr. T.)

Ashbourne (Lord)

Ashby (H.)

Ashley (W. J.).

Atkinson ( 3 . J.)

A vebury (Lord)

Ayre (Rev. J.) .

Bacon

Bagehot (W.) -

Bagwell (R.)

Bailey (H. C.) -

Baillie (A. F.)

Bain (Alexander)

Baker (J. H.)

(Sir S. W.)

Baldwin (C. S.)
Ball (John)

Banks (M. M.) -

17 Baring-Gould (Rev.

(3) S.)

Barnett (S. A. and $\mathrm{H}_{\text {. }}$ )

Baynes (T. S.) -

Beaconsfield (Earl of)

Beaufort (Duke of)

Becker (W. A.)

Beesly (A. H.) -

Bell (Mrs. Hugh)

Bent (U. Theodore) -

Besant (Sir Walter)-

Bickerdyke (J.)

Bird (G.)

Blackburne (J. H.)

Bland (Mrs. Hubert)

Blount (Sir E.)

Boase (Rev. C. W.) -

Boedder (Rev. B.) -

3, 20 Bonnell (H. H.)

Booth (A. J.) :

Bottome (P.)

Brassey (Lidy)

$\begin{array}{rll}-9,17 & \text { Brassey (Lady) } \\ \text { 9, 20, } 38 & \text { Brighe (Rev. J. F.) }\end{array}$

Broadfoot (Major W.

Brooks (H. J.) -

Brough (J.)

Brown (A. F.) -

Bruce (R. I.)

12 Buckland (Jas.)

I7 Buckland (Jas.)

13.

Page

Bull (T.)

I Burke (U. R.)

Burne-Jones (Sir E.)

Burns (C. L.)

Burrows (Montagu)

Campbell (Rev. Lewis) 2

38

25

Chesney (Sir G.)

Childe-Pemberton (W.

S.)

Chisholm (G. C)

Cholmondeley-Pennell

(H.)

Christie (R. C.

Churchill (Winston S.) 4,25

Cicero - - - 22

Clarke (Rev, R. F.) -

Climenson (E. J.)

Clodd (Edward) 213

Clutterbuck (W. J.) - 12

Cochrane (A.)

Cockerell (C. R.)

Colenso (R. J.)

Conybeare (Rev. W. J.)

\& Howson (Dean)

Coolidge (W. A. B.)

Corbert (Julian S.)

Coutts (W.)

Cox (Harding)

Crake (Rev. A. D.) .

Crawford (J.H.)

Creed (S.)

Creighton (Bishop) - 4, 6, 9

Cross (A. L.) -

\section{Crozier (J. B.)}

- 9.17

(1)

Dabney (J. P.) - - 23

Dale (L.)

Dallinger ( $F$. W.)

Dauglish (M. G.)

Davenport (A.)

22

(W. L.) - 17, 20,21

Davies (J. F.) - 22

Dent (C. T.) - - 14

De Salis (Mrs.) - 36

De Tocqueville (A.) -

Devas (C. S.) - 19,20

Dewey (D. R.) - - 20

Dickinson (W. H.) - 38

Dougall (L.) - - 25

Dowden (E.) - - 40

Doyle (Sir A. Conan) 25

Du Bois (W. E. B.) - 5

Dunbar (Mary F.) - 25

Dyson (E.) - - 26

Ellis (J. H.) - : 15

(R. L.) - : I7

$-9$

Falkiner (C. L.) :

Farrar (Dean). $\quad$ 20, 26

Fite (W.).

Firzmaurice (Lord E.)

Folkard (H. C.) - Is

Ford (H.) - - - 16

Fountain ( $P$

Fowler (Edith H.) - 26 


\section{INDEX OF}

Page

Francis (M. E.

Freeman (Edward A.)

Fremantle (T. F.)

Frost (G.)-

Froude (Iames A.) $4,9,3^{8}$

Fuller (F. W. )

Furneaux (W.)

Gardiner (Samuel R.)

Gathorne-Hardy (Hon. A. E.)

Geikie (Rev. Cunning-

ham)

Gibson (C. H.)

Gilkes (A. H.)

Gleig (Rev. G. R.)

Graham (A.)

- (P. A.)

Granby (Marquess of

Grant (Sir A.) -

Graves (R. P.)

(A. F.)

Green ( $T$. Hill)

Greene (E. B.) -

Greville (C. C. F.)

Grose (T. H.)

Gross (C.)

Grove (Lady) (Mrs. Lilly)

Gurnhill (J.)

Gwilt (I.)

Haggard (H. Rider)

I $1,26,27,3^{8}$

Halliwell-Phillipps (J.) Io

Hamilton (Col. H. B.)

Hamlin (A. D. F.)

Harding (S. B.)

Hardwick (A. A.)

Harmsworth (A, C)

Harte (Bret)

Harting (J. E.) -

Hartwig (G.)

Hassall (A.)

Haweis (H. R.)

Head (Mrs.)

Heath (D. D.)

Heathcote (J.M.) (C. G.)

- (N.)

Helmholtz (Hermann von)

Henderson (LieutCol. G. F. R.) -

Henry (W.)

Henty (G. A.) -

Higgins (Mrs, N.)

Hill (Mabel)

- (S, C.)

Hillier (G. Lacy)

Hime (H. W. L.)

Hodgson (Shadworth)

Hoenig ( $F$.)

Hoffmann (J)

Hogan (J. F.)

Holmes (R. R.)

Homer

Hope (Anthony)

Horace

Houston (D. F.)

Howard (Lady Mabel)

Howitt (W.)

Hudson (W. H.)

Huish (M. B.)

Hullah (J.)

Hume (David) (M. A. S.)

Hunt (Rev. W)

Hunter (Sir W.)

Hutchinson (Horace G.)

Ingelow (Jean)

Ingram (T. D.)

James (W.)

Jameson (Mrs. Anna)

Jefferies (Richard)

Jekyll (Gertrude)

10

5

20

I7

9
23
18

5
5
18
5

30

37.

17

14

II

II

$3 \circ$ 23 8,21

\section{AUTHORS}

Page

Jerome (Jerome K.) -

Johnson (J.\& J. H.)

ones (H. Bence)

Joyce (P. W.)

$6,27,3$

Kant (I.) -

Kaye (Sir ]. W.)

Keary (C. F.) -

Kelly (E.) -

Kielmansegge (F.)

Killick (Rev, A. H.)

38 Kitchin (Dr. G. W.)

Knight (E. F.) -

8 Köstlin (J.)

1 Lilie (A.)

18 Locock (C. D.)

Lodge (H. C.)

Loftie (Rev. W. J.) -

Longman (C. J.) - I2, 16

5
6
5 F. W. (G. H.)

- (Mrs. C. J.)

Lowell (A. L.) -

Lucian

Lutoslawski (W.)

27 Lyall (Edna)

I5 Lynch (G.)

\section{I}

Lytton (Earl of)

9

Maher (Rev. M.)

2 Mallet (B.)

Malleson (Col. G. B.)

Marbot (Baron de)

Marchment (A. W.)

Marshman (J.C.)

Maryon (M.)

Mason (A. E. W.)

Maskelyne (J. N.)

Matthews (B.)

Maunder (S.)

Max Müller (F.)

$\mathrm{IO}_{2} 18,20,21,22,27,39$

May (Sir T. Erskine)

Meade (L. T.) - - 32

Melville (G.J. Whyte) 27

Merivale (Dean)

Merriman ' $H$. S.)

Mill (John Stuart) - 18,20

Millais (J. G.) - - 16,30

Milner (G.)

Monck (W. H. S.)

Montague (F. C.)

Moore ( $T$.)

(Rev. Edward)

$\begin{array}{lr}\text { Moran (T. F.) - } & 7 \\ \text { Morgan (C. Lloyd) - } & 2 \mathrm{I}\end{array}$ Morris (W.) $\begin{array}{r}-22,23,24 \\ 27,28,37,40\end{array}$

Mulhall (M. G.)

37 Murray (Hilda)
38 Myers (F. W. H.

38 Nansen (F.)
AND

EDITORS

Nash (V.) -

Nesbit (E.)

Nettleship (R. L.)

Newman (Cardinal) -

Nichols (F. M.)

Oakesmith (U.) -

Ogilvie (R.)

Oldfield (Hon. Mrs.)

Osbourne (L.)

Packard (A. S.)

Paget (Sir J.) -

Park (W.)

Parker (B.)

Payne-Gallwey(Sir R) 40

Pears (E.)

Pearse (H. H. S.)

Peek (Hedley) -

Pemberton (W. S

Childe-)

Penrose (H. H.)

Phillipps-Wolley (C.) 12, 28

Pierce (A. H.) -

Pole (W.)

Pollock (W. H.) - $\quad 13,40$

Poole (W. H. and Mrs.) 36

Poore (G. V.) - : $\quad 40$

Portman (I.)

Powys (Mrs. P. L.) -

Praeger (S. Rosamond) 33

Pritchett (R. T.) - $\mathrm{I}_{4}$

Proctor (R. A.) 16, 30, 35

Raine (Rev. James) -

Ramal (W.)

Randolph (C. F.)

Rankin (R.)

Ransome (Cyril)

Reid (S. J.)

Rhoades (J.)

Rice (S. P.)

Rich (A.)

Richmond (Ennis) -

Rickaby (Rev. John)

(Rev.Joseph)

Riley (J. W.)

Roberts (E. P.)

Robertson (W. G.)

Robinson (H. C.)

Roget (Peter M.) - 20, 31

Romanes (G.J.) I0, 19,21,24 (Mrs. G. J.)

Ronalds (A.)

Roosevelt ( $T$.) -

Ross (Martin)

Rossetti(Maria Fran-

cesca)

Rotheram (M. A.)

Rowe (R. P. P.)

Russell (Lady) -

Sandars ( $T$. C.)

Sanders (E, K.)

Savage-Armstrong(G.P.

Scott (F. J.)

Seebohm (F.)

Selous (F.C.) -

Senior (W.)

Seton-Karr (Sir H.).

Sewell (Elizabeth M.)

Shadwell (A.)

Shakespeare

Shaw (W. A.) -

Shearman (M.)

Sheehan (P. A.)

40 Sheppard (E.) -

Sinclair (A.)

Skrine (F. H.) -

Smith (C. Fell)

(R. Bosworth) -

( $T$, C.)

- (W.P. Hasket $t$ )

Somerville (E.)

Sophocles

20 Soulsby (Lucy H.)

Southey (R.)

Spedding (J.)

(W.) -

Tait (J.)

Todd (A.) -

\begin{tabular}{r|l}
7 & Stanlev (Bishop) \\
24 & Stebbing (W.) -
\end{tabular}

I7 Steel (A. G.)

28 Stephen (Leslie)

Stephens (H. Morse)

Sternberg (Count Adalber $t)$

Stevens (R. W.)

- 40

Stevenson (R. L.) 25, 28, 33

Stuart-Wortley (A. J.) 14, I5

Stubbs (J. W.) -

Suffolk \& Berkshire

(Earl o1)

Sullivan (Sir E.)

Sully (James)

Sutherland (A and G.)

-(Alex.) - $\quad$ - 9,40

Suttner (B, von)

Swinburne (A. J.)

Symes (J. E.)

Tallentyre (S. G.)

Tappan (E. M.)

Taylor (Col. Meadows)

Theophrastus

Thomas (J. W.)

Thomson (H. C.)

Thornhill (W. I.)

Thornton ( $T, \mathrm{H}_{\mathrm{S}}$ ) 


\section{History, Polities, Polity, Political Memoirs, \&e.}

Abbott.-A HISTORY OF GREECE. By Evely ABвotT, M.A., LL.D.

Part I.-From the Earliest Times to the Ionian Revolt. Crown 8vo., Ios. $6 d$.

Part II. - 500-445 B.C. Crown 8vo., ros. $6 d$. Part III.-From the Peace of 445 B.c. to the Fall of the Thirty at Athens in 403 B.c. Crown 8vo., Ios. $6 d$.

Abbott.-TOMMY CORNSTALK : being Some Account of the Less Notable Features of the South African War from the Point of View of the Australian Ranks. By J. H. M. Аввотт. Crown 8vo., 5s. net.

Acland and Ransome.-A HANDBOOK IN OUTLINE OF THE POLITICAL HISTORY OF ENGLAND TO I8g6. Chronologically Arranged. By the Right Hon. A. H. Dyke Acland, and Cyril Ransome, M.A. Crown 8 vo., $6 s$.

Allgood. - CHINA WAR, 1860: LETTERS AND FOURNALS. By MajorGeneral G. Allgood, C.B., formerly Lieut. G. Allgood, Ist Division China Field Force. With Maps, Plans, and Illustrations. Demy 4 to. 12s. $6 d$. net.

Annual Register (The). A Review of Public Events at Home and Abroad, for the year Igo2. 8vo., I $8 \mathrm{~s}$.

Volumes of the ANNUAL REGISTER for the years $1863-1901$ can still be had. I8s. each.

Arnold.-INTRODUCTORY LECTURES ON MODERN HISTORY. BY THOMAS ARNOLD, D.D., formerly Head Master of Rugby School. 8vo., 7s. 6d.

Ashbourne.-P:TT: SOME CHAPTERS ON HIS LIFE AND TIMES. By the Right Hon. Edward Gibson, Lord Ashbourne, Lord Chancellor of Ireland. With I I Por. traits. 8vo., gilt top, 2 Is.

\section{Ashley (W. J.).}

\section{ENGLISH ECONOMIC HISTORY AND THBORY. Crown 8vo., Part I., 5s. Part II., IOS. $6 d$.}

\section{SURVEYS, HISTORIC AND ECONOMIC. Crown Svo., 9s. net.}

Bagwell.-IRELAND UNDER THE TUDORS. BY RICHARD BAgWELl, JLL.D. (3 vols.) Vols. I. and II. From the first invasion of the Northmen to the year 1578 . 8 vo., 32s. Vol. III. I578-1603. 8vo., I8s.
Baillie.-THE ORIENTAL CLUB, AND HANOVER SQUARE. BY ALEXANDER F. Batllie. With 6 Photogravure Portraits and 8 Full-page Illustrations. Crown 4to., 25s. net.

Besant. - THE HISTORY OF LONDON. By Sir Walter Besant. With 74 Illus. trations. Crown 8vo., is. $9 d$. Or bound as a School Prize Book, gilt edges, 2s. $6 d$.

Bright.-A HISTORY OF ENGLAND. By the Rev. J. Franck Bright, D.D.

Period I. MEDIEVAL MONARCHY: A.D. 449-1485. Crown 8vo., 4s. $6 d$.

Period II. PERSONAL MONARCHY. I485. I688. Crown 8vo., 5 s.

Period III. ConstituTIONAL MONARCHY. I689-1837. Crown 8vo., 7s. $6 d$.

Period IV. THE GROWTH OF DEMOCRACY. I837-1880. Crown 8vo., 6 s.

Bruce.-THE FORWARD POLICY AND ITS RESULTS; or, Thirty-five Years' Work amongst the Tribes on our North-Western Frontier of India. By RICHARD ISAAC BRUCE, C.I.E. With 28 Illustrations and a Map. 8 vo., I5s, net.

Buckle.-History OF CIVILISATION IN ENGLAND. By HeNRY ThOMas Buckle. Cabinet Edition. 3 vols. Crown 8vo., 24s. 'Silver Library' Edition. 3 vols. Crown 8 vo., Ios. $6 d$.

Burke.-A History OF SPAIN, FROM THE EARLIEST TIMES TO THE DEATH OF FERDINAND THE CATHOLIC. By Ulick Ralph BURKE, M.A. Edited by Martin A. S. Hume. With 6 Maps. 2 vols. Crown 8vo., I6s. net.

Caroline, Queen.-CAROLINE THE ILLUSTRIOUS, QUEEN-CONSORT OF GEORGE II. AND SOMETIME QUEEN REGENT: a Study of Her Life and Time. By W. H. WiLkins, M.A., F.S.A., Author of 'The Love of an Uncrowned Queen'. 2 vols., 8 vo., $36 s$.

Casserly. - THE LAND OF THE BOXERS; or, China under the Allies. By Captain Gordon Casserly. With 15 Illustrations and a Plan. 8vo., Ios. $6 d$. net.

Chesney.-INDIAN POLITY: a View of the System of Administration in India. By General Sir George Chesney, K.C.B. With Map showing all the Administrative Divisions of British India. Svo., 21 s. 


\section{History, Polities, Polity, Political Memoirs, \&c._continued.}

Churchill (Winston Spencer, M.P.).

THE RIVER WAR : an Historical Account of the Reconquest of the Soudan. Edited by Colonel F. RHODES, D.S.O. With Photogravure Portrait of Viscount Kitchener of Khartoum, and 22 Maps and Plans. 8vo., Ios. $6 d$. net.

THE STORY OF THE MALAKAND FIRLD FORCE, 1897. With 6 Maps and Plans. Crown 8vo., 3s. $6 d$.

LONDON TO LADYSMITH VIÂ PRETORIA. Crown 8vo., 6s.

IAN HAMILTON'S MARCH. With Portrait of Major-General Sir Ian Hamilton, and Io Maps and Plans. Crown 8vo., 6s.

\section{Corbett (Julian S.).}

DRAKE AND THE TUDOR NAVY, with a History of the Rise of England as a Maritime Power. With Portraits, Illustrations and Maps. 2 vols. Crown 8 vo., I6s.

THE SUCCESSORS OF DRAKE. With 4 Portraits (2 Photogravures) and 12 Maps and Plans. 8vo., 2Is.

Creighton (M., D.D., Late Lord Bishop of London).

A History OF the PAPACY fRom THE GREAT SCHISM TO THR SACK OF ROME, 1378-1527. 6 vols. Cr. 8vo., 5s. net each.

QUEEN ELIZABETH. With Portrait. Crown 8vo., 5s, net.

HISTORICAL ESSAYS AND REVIEWS. Edited by Louise Creighton. Crown 8 vo., 5s. net.

Dale.-ThE PRINCIPLES OF ENGLISH CONSTITUTIONAL HISTORY. By LUCY DALE, late Scholar of Somerville College, Oxford. Crown 8vo., $6 s$.

\section{De Tocqueville.-DEMOCRACY IN} A MrRica. By Alexis de Tocqueville. Translated by HENRY REEvE, C.B., D.C.L. 2 vols. Crown 8 vo., I6s.

Falkiner.-STUDIES IN IRISH HISTORY AND BIOGRAPHY, Mainly of the Eighteenth Century. By C. LitToN FALKINER. 8vo., I2s, $6 d$. net.
Fitzmaurice. - CHARLES WILLIAM FRRDINAND, DUKE OF BRUNSWICK: an Historical Study. By Lord EDMund Fitzmaurice. With Map and 2 Portraits. 8 vo., 6s. net.

Froude (James A.).

THE HISTORY OF ENGLAND, from the Fall of Wolsey to the Defeat of the Spanish Armada. I2 vols. Crown 8vo., 3s. $6 d$. each.

THE DiVORCE OF CATHERINE OF ARAGON. Crown 8vo., 3s. 6 d.

THE SPANish StoRY OF THE AR$M A D A$, and other Essays. Cr. 8vo., 3s. $6 d$.

THE ENGLISH IN IRELAND IN THE EIGHTEENTH CENTURY. 3 vols. Cr. 8 vo., Ios. $6 d$.

ENGLISH SEAMEN IN THE SIXTEENTH CENTURY.

Cabinet Edition. Crown 8vo., 6s.

Illustrated Edition. With 5 Photogravure Plates and $\mathrm{I} 6$ other Illustrations. Large Cr. 8 vo., gilt top, $6 s$. net. 'Silver Library' Edition. Cr. 8vo., 3s. 6d. THE CouncIL of TRENT. Crown 8vo., 3s. $6 d$.

SHort Studies on GREAT SUbJECTS. Cabinet Edition. 4 vols. 24s.

'Silver Library' Edition. 4 vols. Crown 8 vo., 3s. $6 d$. each.

CESSAR : a Sketch. Cr. 8vo, 3s. $6 d$. SELECTIONS FROM THE WRITINGS OF F $A M E S$ ANTHONY FROUDE. Edited by P. S. Allen, M.A. Crown 8vo., 3s. $6 d$.

Fuller.-EGYPT AND THE HINTERLAND. By Frederic W. Fuller. With Frontispiece and Map of Egypt and the Sudan. Crown 8 vo., 6s. net.

Gardiner (Samuel Rawson, D.C.L., LL.D.).

HISTORY OF ENGLAND, from the Accession of James I. to the Outbreak of the Civil War, I603-1642. With 7 Maps. Io vols. Crown 8vo., 5s. net each.

A History OF THE GREAT CIVIL WAR, 1642-1649. With 54 Maps and Plans. 4 vols. Cr. 8 voo., 5 s. net each. 


\section{History, Polities, Polity, Political Memoirs, \&e.-continued.}

Gardiner (Samuel Rawson, D.C.L., LL.D.)-continued.

A History OF THE COMMONWEALTH AND THE PROTECTORATE. 1649-1656. 4 vols. Crown 8 vo., 55. net each.

THE STUDENT'S HISTORY OF ENGLAND. With 378 Illustrations. Crown $8 \mathrm{vo}$., gilt top, r2s.

Also in Three Volumes, price 4s, each.

WHAT GUNPOWDER PLOT WAS. With 8 Illustrations. Crown 8vo., $5 s$.

CROMWELL'S PLACE IN HISTORY. Founded on Six Lectures delivered in the University of Oxford. Cr. 8vo., 3s. $6 d$.

OLIVER CROMWELL. With Frontispiece. Crown 8vo., 5s. net.

German Empire (The) of To-day: Outlines of its Formation and Development. By 'Veritas'. Crown 8vo., 6s. net.

Graham.-ROMAN AFRICA : an Outline of the History of the Roman Occupa. tion of North Africa, based chiefly upon Inscriptions and Monumental Remains in that Country. By Alexander Graham, F.S.A., F.R.I.B.A. With 30 reproductions of Original Drawings by the Author, and 2 Maps. 8vo., I6s. net.

Greville.-A TOURNAL OF THE REIGNS OF KING GEORGB IV., KING WILLIAM IV., aND QueEn Victoria. By Charles C. F. GREvilLe, formerly Clerk of the Council. 8 vols. Crown 8 vo., 3 s. $6 d$. each.

Gross.-THE SOURCES AND LITERATURE OF ENGLISH HISTORY, FROM THB EARLIEST TIMES TO ABOUT I485. By Charles Gross, Ph.D. 8vo., I8s, net.

Hamilton.-HISTORICAL RECORD OF THB I4TH (KING'S) HUSSARS, from A.D. 1715 to A.D. 1900. By Colonel HENRY BLACKburne Hamilton, M.A., Christ Church, Oxford; late Commanding the Regiment. With 15 Coloured Plates, 35 Portraits, etc., in Photogravure, and ro Maps and Plans. Crown 4 to., gilt edges, 425 , net.

\section{Hill.-LIBERTY DocUmeNTS.}

With Contemporary Exposition and Critical Comments drawn from various Writers. Selected and Prepared by Mabel HiLl. Edited with an Introduction byALBERT BUSHNELL HART, Ph.D. Large Crown 8vo., $7 s .6 d$. net.

\section{HARYARD HISTORICAL STUDIES.}

THE SUPPRESSION OF THE AFRICAN SLAVE TRADE TO THE UNITED STATES OF AMERICA, 1638-1870. By W. E. B. Du BoIs, Ph.D. 8vo., 75. 6d.

THE CONTEST OVER THE RATIFICATO OF THE FEDERAL CONSTITUTION IN MASSA CHUSETTS. BY S. B. HARDING, A.M. 8vo.,6s

A CRitical Study of Nullification IN SOUTH CAROLINA. By D. F. Houston, A.M. 8 vo., $6 s$.

NOMINATIONS FOR ELECTIVE OFFICE IN THE UNITED STATES. By FrEDERICK W. Dallinger, A.M. 8vo., 7s. $6 d$.

A BIBLIOGRAPHY OF BRITISH MUNICIPAL HISTORY, INCLUDING GILDS AND PARLIAMENTARY REPRESENTATION. By Charles Gross, Ph.D. 8vo., izs.

THE LIBERTY AND FREE SOIL PARTIES IN THE NORTH WEST. By Theodore C. Sмiтн, Ph.D. 8vo, 7s. 6d.

The Provincial Governor in the E NGLISH COLONIES OF NORTH AMERICA. By Evarts Boutell Greene. 8vo., 7s. 6d.

The County Palatine of DURham: a Study in Constitutional History. By GaIL. LARD Thomas Lapsley, Ph.D. 8vo., Ios. $6 d$.

THE ANGLICAN EPISCOPATE AND THE AmERICAN Colonies. By Arthur Lyon Cross, Ph.D., Instructor in History in the University of Michigan. 8vo., Ios. $6 d$,

Hill.-THREE FRENCHMEN IN BENGAL; or, The Loss of the French Settlements. By S. C. Hill, B.A., B.Sc., Officer in charge of the Records of the Government of India. With 4 Maps. 8vo.

Historic Towns.-Edited by E. A. Freeman, D.C.L., and Rev. William Hunt, M.A. With Maps and Plans. Crown 8vo., 35. $6 d$. each.

Bristol. By Rev. W. Hunt. Oxford. By Rev. C. W. Carlisle. By Mandell
Creighton, D.D.

Cinque Ports. By Montagu Burrows.

Colchester. By Rev. E. L. Cutts.

Exeter. By E. A. Freeman.

London. By Rev. W. J. Boston (U.S.) By Heary
Loftie.
Winchester. By G. W. Kitchin, D.D.

York. By Rev, James Raine.

New York. By Theodore Roosevelt. 


\section{History, Polities, Polity, Political Memoirs, \&c.-continued.}

\section{Hunter (Sir William Willon).}

A History OF BRITISH INDIA. Vol. I. - Introductory to the Overthrow of the English in the Spice Archipelago, 1623. With 4 Maps. 8vo., I8s. Vol. II. - To the Union of the Old and New Companies under the Earl of Godolphin's Award, 1708. 8vo., I6s.

THE INDIA OF THE QUEEN, and other Essays. Edited by Lady Hunter. With an Introduction by FRANCIS HENRY Skrine, Indian Civil Service (Retired). 8 vo., 9s. net.

Ingram. - $A$ CRITICAL EXAMINATION OF IRISH HISTORY. From the Elizabethan Conquest to the Legislative Union of 1800 . By T. Dunbar Ingram, LL.D. 2 vols. 8 vo., $24 s$.

Joyce.-- 4 SHORT HISTORY OF IRE$L A N D$, from the Earliest Times to 1603 . By P. W. Joyce, LL.D. Crown 8vo., ios, $6 d$.

Kaye and Malleson.-HistorY OF THE INDIAN MUTINY, I857-1858. By Sir JoHn W. Kaye and Colonel G. B. MALleson. With Analytical Index and Maps and Plans. 6 vols. Crown 8vo., 3s. $6 d$. each.

\section{Lang (ANDREW).}

THE MYSTERY OF MARY StUART. With 6 Photogravure Plates (4 Portraits) and 5 other Illustrations. 8 vo., I8s. net.

JAMES THE SIXTH AND THE GOWRIE MYSTERY. With Gowrie's Coat of Arms in colour, 2 Photogravure Portraits and other Illustrations.- 8 vo., I2s. $6 d$. net.

PRINCE CHARLES EDWARD STUART, THE YOUNG CHEVALIER. With Photogravure Frontispiece. $\mathrm{Cr}$. 8vo., 7s. $6 d$. net.

Laurie.-HISTORICAL SURVEY OF PRE-CHRISTIAN EDUCATION. BY S. S. Laurie, A.M., LL.D. Crown 8vo., $7 s .6 d$.

Lecky (The Rt. Hon. William E. H.) HISTORY OF ENGLAND IN THE EIGHTEENTH CENTURY.

Library Edition. 8 vols. 8 vo. Vols. I. and II., I $700-1760,36 s . ;$ Vols. III. and IV., $1760-1784,36 s$.; Vols. V. and VI., 1784-I 793, 36s.; Vols. VII. and VIII., I793-1800, 36s.

Cabinet Edition. ENGLAND. 7 vols. Crown 8 vo., 5s. net each. IRELAND. 5 vols. Crown 8vo., 5s. net each.
Lecky ('The Rt. Hon. William E. H.) -continued.

LEADERS OF PUBLIC OPINION IN IRELAND: FLOOD-GRATTAN-O'CONNELL. 2 vols. 8 vo., 25s, net.

\section{HISTORY OF EUROPEAN MORALS} FROM AUGUSTUS TO CHARLEMAGNE. 2 vols. Crown 8 vo., Ios. net.

A SURVEY OF ENGLISH ETHICS: Being the First Chapter of the 'History of European Morals'. Edited, with Introduction and Notes, by W.A. Hirst. Crown 8 vo., 3s. $6 d$.

HISTORY OF THE RISE AND INFLUENCE OF THE SPIRIT OF RATIONALISM IN EUROPE. 2 vols. Crown 8vo., Ios. net.

DEMOCRACY AND LIBERTY.

Library Edition. 2 vols. 8 vo., $36 s$.

Cabinet Edition. 2 vols. Cr. 8 vo., Ios. net.

Lieven. - LETTERS OF DOROTHEA, PRINCESS LIEVEN, DURING HER RESIDENCE IN LONDON, 1812-1834. Edited by LiONEL G. Robinson. With 2 Photogravure Portraits. 8 vo., I 4 s, net.

Lowell.-GOVERNMENTS AND PARTIES IN CONTINENTAL EUROPE. By A. LAWRENCE LOWELL. 2 vols. 8Vo., 2 Is.

Lumsden's Horse, Records of.Edited by H. H. S. PEarse. With a Map, and numerous Portraits and Illustrations in the Text. 4to., 2Is. net.

Lynch.-THE WAR OF THE CIVILISATIONS : BEING A RECORD OF'A FOREIGN DEVIL'S' EXPPERIENCES WITH THE ALLIES IN ChiNA. By George Lynch, Special Correspondent of the 'Sphere,' etc. With Portrait and 2I Illustrations. Crown 8vo., $6 s$. net.

Macaulay (Lord).

THE LIFE AND WORKS OF LORD MACAULAY.

'Edinburgh' Edition, ro vols. 8vo,,6s,each. Vols. I.-IV. HISTORY OF ENGLAND.

Vols. V.-VII. ESSAYS, BIOGRAPHIES, INDIAN PENAL CODE, CONTRIBUTIONS TO KNIGHT'S 'QUARTERLY MAGAZINE'.

Vol. VIII. SPEECHES, LAYS OF ANCIENT ROME, MISCELLANEOUS POEMS.

Vols. IX. and X. THE LIFE AND LETTERS OF LORD MACAULAY. BY Sir G. O. Trevelyan, Bart, 
History, Polities, Polity, Political Memoirs, \&e.-continued.

Macaulay (Lord)-continued.

THE WORKS.

'Albany' Edition. With 12 Portraits. I 2 vols. Large Crown 8vo., $35.6 d$. each.

Vols. I.-VI. HISTORY OF ENGLAND, FROM THE ACCESSION OF F AMES THE SECOND.

Vols. VII.-X. ESSAYS AND BIOGRAPHIES.

Vols, XI.-XII. SPEECHES, LAYS OF ANCIENT ROME, ETC., AND INDEX.

Cabinet Edition. 16 vols. Post 8vo., $£ 4$ I6s.

Library Edition. 5 vols. 8vo., $£ 4$.

HISTORY OF ENGLAND FROM THE ACCESSION OF ҰAMES THE SECOND.

Popular Edition. 2 vols. Cr. 8vo., 5 s.

Student's Edition. 2 vols. Cr. 8vo., 125.

People's Edition. 4 vols. Cr. 8vo., I6s.

'Albany' Edition. With 6 Portraits. 6 vols. Large Crown 8vo., 3s. 6d. each.

Cabinet Edition. 8 vols. Post 8 vo., 48 s.

'Edinburgh'Edition. 4 vols. 8vo., 6 s. each.

CRITICAL AND HISTORICAL ESSAYS, WITH LAYS OF ANCIENT ROME, etc., in I volume.

Popular Edition. Crown 8vo., 2s. 6d.

'Silver Library' Edition. With Portrait and 4 Illustrations to the 'Lays'. $\mathrm{Cr}$. 8vo., 3s. $6 d$.

CRITICAL AND HISTORICAL ESSAYS.

Student's Edition. I vol. Cr. 8vo., 6 s.

'Trevelyan' Edition. 2 vols. Cr.8vo., 9s.

Cabinet Edition. 4 vols. Post 8 vo., 24 s.

'Edinburgh' Edition. 3 vols. 8vo., 6 s. each.

Library Edition. 3 vols. 8vo., 36 s.

ESSAYS, which may be had separately, sewed, $6 d$. each ; clotli, Is. each.

Addison and Walpole.

Croker's Boswell's Johnson. Ranke and Gladstone.

Hallam's Constitutional Lord Bacon.

History.

Warren Hastings.

The Earl of Chatham (Two

Essays).

Lord Clive.

Lord Byron, and The Comic Dramatists of the Restoration.

\section{MISCELL.4NEOUS}

WRITINGS, SPEECHES AND POEMS.

Popular Edition. Crown 8vo., 2s. $6 d$.

Cabinet Edition. 4 vol\%. Post 8vo., 24s.

SELECTIONS FROM THE WRITINGS OF LORD MACAULAY. Edited, with Occasional Notes, by the Right Hon. Sir G. O. Trevelyan, Bart. Crown 8vo., 6s.
Mackinnon (James, Ph.D.).

THE HISTORI OF EDWARD THE

THIRD. 8vo., 18 s.

THE GROWTH AND DECLINE OF THE FRENCH MONARCHY. 8vo., 2is. net.

Mallet.-MALLET DU PAN AND THE FRENCH REVOLUTION. By BERNARD MALlet. With Photogravure Portrait. 8 vo., 12s. $6 d$. net.

May.-The Constitutional HisTORY OF ENGLAND since the Accession of George III. I760-1870. By Sir Tномаs Erskine MaY, K.C.B. (Lord Farnborough). 3 vols. Cr. 8vo., I 8 s.

Merivale (Charles, D.D.).

HISTORYOF THE ROMANS UNDER THE EMPIRE. 8 vols. Crown 8 vo., 3s. 6 d. each.

THE FALL OF THE ROMAN REPUBLIC: a Short History of the Last Century of the Commonwealth. 12mo., 75. $6 d$.

GENERAL HISTORY OF ROME, from the Foundation of the City to the Fall of Augustulus, B.C. $753 \cdot$ A.D. 476 . With 5 Maps. Crown 8vo., 7s. $6 d$.

Montague. - THE ELEMENTS OF ENGLISH Co.vstituTIONAL HISTORY. By F. C. Montague, M.A. Crown 8vo., 3s. 6d.

Moran.-THE THEORY AND PRACTICE OF THE ENGLISH GOVERNMENT. By Thomas Francis Moran, Ph.D., Professor of History and Economics in Purdue University, U.S. Crown 8vo., 5s. net.

Nash.-THE GREAT FAMINE AND its Causes. By Vaughan Nash. With 8 Illustrations from Photographs by the Author, and a Map of India showing the Famine Area. Crown 8vo., $6 s$.

Owens College Essays.-Edited by T. F. Tout, M.A., Professor of History in the Owens College, Victoria University, and James TAIT, M.A., Assistant Lecturer in History. With 4 Maps. 8vo., I2s. $6 d$. net.

Pears. - ThE DEstRuction OF THE GREEK E MPPIRE AND THE STORY OF THE CAPTURE OF CONSTANTINOPLE BY THE TURKS. By EDwin PEars, LL.B. With 3 Maps and 4 Illustrations. 8vo., 18s. net. 


\section{History, Polities, Polity, Political Memoirs, \&c.-continued.}

\section{Powell and Trevelyan. - THE}

PEASANTS' RISING AND THE LOLLARDS: a Collection of Unpublished Documents. Edited by Edgar Powell and G. M. TrEvelyan. 8vo., 6s. net.

Randolph.-THE LAW AND POLICY OF ANNEXATION, with Special Reference to the Philippines; together with Observations on the Status of Cuba. By CARMan F. RANDOLPH. 8vo., gs. net.

Rankin (REGINALD).

THE MARQUIS D'ARGENSON; AND RICHARD THE SECOND. 8vo., IOs. 6d. net. A Subaltern's Letters to His WIFE. (The Boer War.) Crown 8vo., 3s. 6 d.

Ransome.-THE RISE OF CONSTITUTIONAL GOVERNMENT IN ENGLAND. By Cyril Ransome, M.A. Crown 8vo., 6 s.

Scott.-PORTRaitures of JULIUS C ESAR: a Monograph. By FrANK JESUP ScotT. With 38 Plates and 49 Figures in the Text. Imperial 8vo., 2is. net.

Seebohm (FrEdFric, LL.D., F.S.A.). THE ENGLISH VILLAGE COMMUNITY. With 13 Maps and Plates. 8vo., I6s.

TRIBAL CUSTOM IN ANGLO-SAXON $L_{A W}$ : being an Essay supplemental to (1) 'The English Village Community,' (2) 'The Tribal System in Wales'. 8 vo., I6s.

Seton-Karr.-THE CALL TO ARMS, Igoo-IgoI; or a Review of the Imperial Yeomanry Movement, and some subjects connected therewith. By Sir Henry SetonKARR, M.P. With a Frontispiece by R. Caton-Woodville. Crown 8vo., 5s, net.

Shaw.-A HISTORY OF THE ENGLISH CHURCH DURING THE CIVIL WARS AND UNDER THE COMMONWEALTH, I6 40 -1660. By William A. Shaw, Litt.D. 2 vols. 8 vo., $36 s$.

Sheppard. - THE OLD ROYAL PALACE OF WHITEHALL. By EDGAR SHEPPARD, D.D., Sub-Dean of H.M. Chapels Royal, Sub-Almoner to the King. With 6 Photogravure Plates and 33 other Illustrations. Medium 8vo., 21s. net.

Smith.-CARTHAGE AND THE CARTHAGINIANS. By R. Bosworth SMith, M.A. With Maps, Plans, etc. Cr. 8vo., 3s. 6 d.

Stephens. - $A$ History OF THE FRENCH REVOLUTION. By H. Morse STEPHENS. 8vo. Vols. I. and II. I 8 s. each.
Sternberg.- MY EXPERIENCES OF THE BOER WAR. By Adalbert Count Sternberg. With Preface by Lieut.-Col. G. F. R. Henderson. Crown 8vo., 5s, net.

Stubbs.-HISTORY OF THE UNIVERSITY OF DUbLiN. By J. W. StubBs. 8vo., I2s. $6 d$.

Stubbs. - HISTORICAL INTRODUCTIONS TO THE 'ROLLS SERIES'. By William Stubis, D.D., formerly Bishop of Oxford, Regius Professor of Modern History in the University. Collected and Edited by Arthur Hassall, M.A. 8vo., I2s. $6 d$. net.

Sutherland.--THE HISTORY OF AUSTRALIA AND NEW ZEALAND, from 1606. I900. By Alexander Sutherland, M.A. and George Sutherland, M.A. Crown 8 vo., 2s, $6 d$.

Taylor.-A STUDENT'S MANUAL OF THE HISTORY OF INDIA. By Colonel MEADows Taylor, C.S.I. Cr. 8vo., 7s. $6 d$.

Thomson.-CHINA AND THE POWERS: a Narrative of the Outbreak of 1900. By H. C. Thомson. With 2 Maps and 29 Illustrations. 8vo, ros. $6 d$. net.

Todd. - PARLIAMENTARY GOVERNMENT IN THE BRITISH COLONIES. BY Alpheus Todd, LL.D. 8vo., 3os. net.

Trevelyan.-THE AMERICAN REVOLUTION. Part I. I766-I776. By Sir G. O. Trevelyan, Bart. 8vo., i6s.

Trevelyan.-ENGLAND IN THE AGE of W YCLIFFe. By George Macaulay Trevelyan. 8vo., I5s.

Wakeman and Hassall.-EssAYS INTRODUCTORY TO THE STUDY OF E NGLISH CONSTITUTIONAL HISTORY. Edited by Henry OfFley Wakeman, M.A., and Arthur Hassall, M.A. Crown 8vo., $6 s$.

Walpole.-HISTORY OF ENGLAND FROM THE CONCLUSION OF THE GREAT WAR IN I8I5 TO I858. By Sir SPENCER Walpole, K.C.B. 6 vols. Cr. 8 vo., 6s, each.

Wylie (James Hamilton, M.A.).

HISTORY OF ENGLAND UNDER HENRY IV. 4 vols. Crown 8vo. Vol. I., 1399-1404, 1os. 6d. Vol. II., I405I406, I5s. (out of print). Vol. III., I 407 . I4II, I5s. Vol. IV., I4II-I4I3, 21 s.

The Council of Constance to the DEATH OF ҰOHN HUS. Cr, 8vo., 6s. net. 


\section{Biography, Personal Memoirs, \&c.}

Bacon.-TIE LETTERS AND LIFE OF FRANCIS BACON, INCLUDING ALL HIS OCCASIONAL WORKS. Edited by JAMES SPED. DING. 7 vols. 8vo., $£ 445$.

Bagehot.-BIOGRAPHICAL STUDIES. By Walter Bagehot. Crown 8vo., 3s. $6 d$.

Blount. - THE MEMOIRS OF SIR EDWARD BLOUNT, K.C.B., ETC. Edited by Stuart J. Reid, Author of 'The Life and Times of Sydney Smith,' etc. With 3 Photogravure Plates. 8 vo., ros. $6 d$. net.

Bowen.-EDWARD BOWEN: A MEMOIR. By the Rev, the Hon. W. E. Bowen. With Appendices, 3 Photogravure Portraits and 2 other Illustrations. 8vo., I2s. $6 d$. net.

Carlyle.-Thomas CARLYLE: A History of his Life. By JaMes ANTHony FroUdE.

I795-1835. 2 vols. Crown 8vo., 7s.

1834-188r. 2 vols. Crown 8vo., 7 s.

Crozier.-MY INNER LIFE : being a Chapter in Personal Evolution and Autobiography. By John Beattie Crozier, LL.D. 8vo., I4s.

Dante.-THE LIFE AND WORKS OF DANTE A LLIGHIERI : being an Introduction to the Study of the 'Divina Commedia'. By the Rev. J. F. Hogan, D.D. With Portrait. 8vo., I2s. $6 d$.

Danton.-LIFE OF DANTON. By A. H. BeEsly. With Portraits. Cr. 8vo., 6s.

De Bode.-THE BARONESS DE BODE, I775-I803. By William S. Childe-PemBERToN. With 4 Photogravure Portraits and other Illustrations. 8vo., gilt top, I2s. $6 d$, net.

\section{Erasmus.}

LIFE AND LETTERS OF ERASMUS. By James Anthony Froude. Crown 8vo., 3 s. $6 d$.

THE EPISTLES of ERASMUS, from his Earliest Letters to his Fifty-first Year, arranged in Order of Time. English Translations, with a Commentary. By Francis Morgan Nichols. 8vo., i8s, net.

Faraday.-FARADAY AS A DISCOVERER. By John Tyndall. Crown 8 vo., 3 s. $6 d$.

Fénelon: his Friends and his Enemies, I65I-1715. By E. K. SANDERS. With Portrait. 8vo., ros. $6 d$.
FOX. - THE E ERLY HISTORY OF CHARLES f AMES FOX. By the Right Hon. Sir G. O. TRevelyan, Bart. Crown 8vo., 3s. $6 d$.

Froude. - MY RELATIONS IVITH CARLYLE. By James Anthony Froude. Together with a Letter from the late Sir James Stephen, Bart., K.C.S.I., dated December, I 886. 8vo., 2s. net.

Granville.-SOME RECORDS OF THE LATER LIFE OF HARRIET, COUNTESS GRANVILLE. By her Granddaughter, the Hon. Mrs. Oldfield. With 17 Portraits. 8 vo., gilt top, I6s. net.

Grey. - MEMOIR OF SIR GEORGE GREY, BART., G.C.B., I799-1882. By Mandell Creighton, D.D., late Lord Bishop of London. With 3 - Portraits. Crown 8vo., 6s. net.

Hamilton.-LIFE OF SIR WILLIAM HaMiLTON. By R. P. Graves. 8vo. 3 vols. I5s. each. ADDENDLM. 8vo., 6d. sewed.

\section{Harrow School Register (The),} I80I-1900. Second Edition, r9or. Edited by M. G. Dauglish, Barrister-at-Law. 8 vo. Ios. net.

Havelock.-MEMOIRS OF SIR HENRY HAVELOCK, K.C.B. BY JOHN ClaRK Marshman. Crown 8vo., 3s. $6 d$.

Haweis.-MY MUSICAL LIFE. By the Rev.H.R.HAwEIS. With Portrait of Richard Wagner and 3 Illustrations. Cr. 8 vo., 6 s. net.

Higgins. - THE BERNARDS OF ABING TON AND NETHER WINCIIENDON: A Family History. By Mrs. Napier Higgins. 2 Vols. 8vo., 2Is, net.

Hunter.-THE LIFE OF SIR WILLIAM WILSON HUNTER, K.C.S.I., M.A., LL.D. Author of 'A History of British India,' etc. By Francis Henry Skrine, F.S.S. With 6 Portraits (2 Photogravures) and 4 other Illustrations. 8vo., I6s, net.

Jackson.-STONEWALL JACKSON AND THE AMERICAN CIVIL WAR. By Lieut.-Col. G. F. R. Henderson. With 2 Portraits and 33 Maps and Plans. 2 vols. Cr. 8vo., I6s. net.

Kielmansegge.-DIARY OF A JOURNEY TO ENGLAND IN THE YEARS I76II762. By Count Frederick KIELMANSEGGE. With 4 Illustrations. Crown 8 vo. 5s. net.

Luther. - LIFE OF LUTHER. By JuLius KösTLIN. With 62 Illustrations and 4 Facsimilies of MSS. Cr. 8vo., 3s. $6 d$. 


\section{Biography, Personal Memoirs, \&c.-continued.}

Macaulay.-THE LIFE AND LETTERS OF LORD MACAULAY. By the Right Hon. Sir G. O. Trevelyan, Bart.

Pupular Edition. I vol. Cr. 8vo., 25. 6d. Student's Edition I vol. Cr. 8vo., 6s.

Cabinet Edition. 2 vols. Post 8vo., i2s. 'Edinburgh' Edition. 2 vols. 8 vo.,6s. each. Library Edition. 2 vols. 8 vo., $36 s$.

Marbot. - THE MEMOIRS OF THE BARON DE MARBOT. 2 vols. Cr. 8vo., 7s.

\section{Max Miller (F.)}

THE LIFE AND LETTERS OF THE KIGHT HON. FRIEDRICH MAA MÜLLER. Edited by his Wife. With Photogravure Portraits and other Illustrations. 2 vols., 8 vo., 32s. net.

MY AUtOBIOGRAPHY: a Fragment. With 6 Portraits. 8vo., i2s. 6d.

AULD LANG SYNE. Second Series. 8 vo., IOs. 6 d.

CHIPS FROM A GERMAN WORK'SHOP. Vol. II. Biographical Essays. Cr. 8vo., 5s.

Meade.-GENERAL SIR RICHARD MEADE AND THE FEUDATORY STATES OF CENTRAL AND SOUTHERN INDIA. By Thomas Henry Thornton. With Portrait, Map and Illustrations. 8vo., Ios. $6 d$. net.

Morris. - THE LIFE OF WILLIAM MorRIS. By J. W. MackaIl. With 2 Portraits and 8 other Illustrations by E. H. NEw, etc. 2 vols. Large Crown 8 vo., Ios. net.

On the Banks of the Seine.

A. M. F., Author of 'Foreign Courts and Foreign Homes'. Crown 8vo., 6s.

Paget.-MEAIOIRS AND LETTERS OF SIR F AMES PAGET. Edited by STEPHEN PAGET, one of his sons. With Portrait. 8 vo., 6s. net.

Place. - THE LIFE OF FRANCIS PLACE, I77I-1854. By Graham Wallas, M.A. With 2 Portraits. 8vo., I2s.

Powys.-PASSAGESFROM THEDIARIES OF MRS. PHILIP LYBBE POWYS, OF HARDWICK HOUSE, OXON. 1756-1808. Edited by Emily J. Climenson. 8vo., gilt top, i6s.

Râmakrishna : HIS LIFE AND SAYINGS. By the Right Hon. F. MAX MÜLLER. Crown 8vo., 5 s.

Rich.-MARY RICH, COUNTESS OF WARWICK (1625-1678): Her Family and Friends. By C. Fell Smith. With 7 Photogravure Portraits and 9 other Illustra. tions. 8vo., gilt top, $18 s$. net.
Rochester, and other Literary Rakes of the Court of Charles II., with some Account of their Surroundings. By the Author of 'The Life of Sir Kenelm Digby,' The Life of a Prig,' etc. With 15 Portraits. 8vo., I6s.

Romanes.-THE LIFE AND LETTERS OF GEORGE FOHN ROMANES, M.A., LL.D., F.R.S. Written and Edited by his WiFE. With Portrait and 2 Illustrations. Cr. 8vo., 5s. net.

Russell. - SWALLOWFIELD AND ITS OWNERS. By Constance Lady Russell, of Swallowfield Park. With 15 Photogravure Portraits and 36 other Illustrations. 4to., gilt edges, 425 . net.

Seebohm.-THEOXFORD REFORMERS - FOHN COLET, ERASMUS, AND THOMAS MORE : a History of their Fellow-Work. By Frederic Seebohm. 8vo., i 4 s.

Shakespeare. - OUTLINES OF THE LIFE OF SHAKESPEARE. By J. O. HALLIWELL-PHILLIPPS. With Illustrations and Facsimiles. 2 vols. Royal 8vo., 2 Is.

Tales of my Father.-By A. M. F. Crown 8vo., $6 s$.

Tallentyre.-THE WOMEN OF THE SALONS, and other French Portraits. By S. G. TAllentyre. With II Photogravure Portraits. 8 vo., Ios. $6 d$. net.

Victoria, Queen, I819-1901. By Richard R. Holmes, M.V.O., F.S.A. With Photogravure Portrait. Crown 8vo., gilt top, 5s. net.

Walpole.-SOME UNPUBLISHED LETTERS OF HORACE WALPOLE. Edited by Sir Spencer Walpole, K.C.B. With 2 Portraits. Crown 8vo., 4s. $6 d$. net.

Wellington.-LIFE OF THE DUKE OF WELLINGTON. By the Rev. G. R. Gleig, M.A. Crown 8vo., 3s. $6 d$.

\section{Wilkins (W. H.).}

CAROLINE THE ILLUSTRIOUS, QUEENCONSORT OF GEORGE II. AND SOMETIME QUEEN-REGENT: a Study of Her Life and Time. 2 vols. 8 vo., $36 s$.

THE . LOVE OF 'AN UNCROWNED QUEEN: Sophie Dorothea, Consort of George I., and her Correspondence with Philip Christopher, Count Königsmarck. With Portraits and Illustrations. 8 vo., I2s. $6 d$. net. 


\section{Travel and Adventure, the Colonies, \&c.}

Arnold.-SEAS AND LANDS. By Sir EDWIN ARNOLD. With 7 I Illustrations. Crown 8vo., 3s. $6 d$.

\section{Baker (Sir S. W.).}

EIGHT YEARS IN CEYLON. With 6 Illustrations. Crown 8vo., 3s. $6 d$.

THE RIFLE AND THE HOUND IN CEYLON. With 6 Illusts. Cr.8vo., 3s. $6 d$.

\section{Ball (ЈонN).}

THE ALPINE GUIDE. Reconstructed and Revised on behalf of the Alpine Club, by W. A. B. COOLIDGE.

Vol, I., THE WESTERN ALPS : the Alpine Region, South of the Rhone Valley, from the Col de Tenda to the Simplon Pass. With 9 New and Revised Maps. Crown 8vo., 12s. net.

HINTS AND NOTES, PRACTICAL AND SCIENTIFIC, FOR TRAVELLERS IN THE ALPS: being a Revision of the General Introduction to the 'Alpine Guide'. Crown 8vo., 3s. net.

Bent.-THE RUINED CITIES OF MA. SHONALAND : being a Record of Excavation and Exploration in $189 \mathrm{r}$. By J. THEODORE BENT. With II7 Illustrations. Crown 8vo., 3s. $6 d$.

\section{Brassey (The Late Lady).}

A VOYAGE IN THE' 'SUNBEAM'; OUR HOMB ON THB OCEAN FOR ELEVEN MONTHS.

Cabinet Edition. With Map and 66 Illustrations. Cr. 8vo., gilt edges, 75. $6 d$.

'Silver Library' Edition. With 66 Illus. trations. Crown 8vo., 3s. $6 d$.

Popular Edition. With 6o Illustrations. 4 to., $6 d$. sewed, is. cloth.

School Edition. With 37 Illustrations. Fcp., 2s. cloth, or 3s. white parchment.

SUNSHINE AND STORM IN TIIE EAST.

Popular Edition. With 103 Illustrations. 4to., 6d. sewed, Is. cloth.

IN THE TRADES, THE TROPICS, AND THE' ROARING FORTIES'.

Cabinet Edition. With Map and 220 Illustrations. Cr. 8vo., gilt edges, 7s. $6 d$.

Cockerell.-TRAVELS IN SOUTHERN EUROPE AND THE LEVANT, 1810-1817. By C. R. Cockerell, Architect, R.A. Edited by his Son, Samuel Pepys Cockerell. With Portrait. 8vo., ros. $6 d$. net.
Fountain (PAUL).

THE GREAT DESERTS AND FORESTS OF NORTH AMRRICA. With a Preface by W. H. Hunson, Author of 'The Naturalist in La Plata,' etc. 8vo., 9s. $6 d$. net.

THE GREAT MOUNTAINS AND FORESTS OF SOUTH AMBRICA. With Portrait and 7 Illustrations. 8 vo., ros. $6 d$. net.

Froude (James A.).

OCEANA : or England and her Col. onies. With 9 Illustrations. Cr. 8vo., 3s. $6 d$.

THE ENGLISIT IN THE WEST INDIES : or, the Bow of Ulysses. With g Illustra. tions. Crown 8vo., 2s. boards, 2s. $6 d$. cloth.

Grove.-SEVENTY-ONE DAYS' CAMPING IN MoRocco. By Lady Grove. With Photogravure Portrait and 32 Illustrations from Photographs. 8vo., 7s. 6d. net.

Haggard.-A Winter PII.grimage: Being an Account of Travels through Palestine, Italy and the Island of Cyprus, undertaken in the year 1900. By H. RIDER HAGGARD. With 3 I Illustrations from Photographs. Cr. 8 voo, gilt top, I2s. $6 d$. net.

Hardwick. - AN IVORY TRADER IN NORTH KENIA: the Record of an Expedition to the Country North of Mount Kenia in East Equatorial Africa, with an account of the Nomads of Galla-Land. By A. Arkell-Hardwick, F.R.G.S. With 23 Illustrations from Photographs, and a Map. 8 vo., 12s. $6 d$. net.

Heathcote.-ST. KIIDDA. By NoRman Heathcote. With 80 Illustrations from Sketches and Photographs of the People, Scenery and Birds by the Author. 8 vo., ros. $6 d$. net.

Howitt. -VISITS. TO REMARKABLE PLACES. Old Halls, Battle-Fields, Scenes, illustrative of Striking Passages in English History and Poetry. By William HowitT. With 8o Illustrations. Crown 8vo., 35. 6d.

Knight (E. F.).

WITH THE ROYAL TOUR : a Narrative of the Recent Tour of the Duke and Duchess of Cornwall and York through Greater Britain. With 16 Illustrations and a Map. Crown 8vo., 5s. net.

THE CRUISE OF THE 'ALERTE' : the Narrative of a Search for Treasure on the Desert Island of Trinidad. With 2 Maps and 23 Illustrations. Crown 8vo., 3s. $6 d$. 


\section{Travel and Adventure, the Colonies, \&c.-continued.}

\section{Knight (E. F.)-continued.}

WHERE THREE EMPIRES MEET: a Narrative of Recent Travel in Kashmir, Western Tibet, Baltistan, Ladak, Gilgit, and the adjoining Countries. With a Map and 54 Illustrations. Cr. 8vo., 3s. $6 d$. THE 'FALCON' ON THE BALTIC: a Voyage from London to Copenhagen in a Three-Tonner. With ro Full-page Illustrations. Crown 8vo., 3s. $6 d$.

Lees.-PEAKS AND PINES: another Norway Book. By J. A. LeEs. With 63 Illustrations and Photographs. Cr. 8vo., 6s.

\section{Lees and Clutterbuck.-B.C. I 887 :} A RAMBLEIN BRITISH COLUMBIA. By J. A. Lees and W. J. CluTterbuck. With Map and 75 Illustrations. Crown 8vo., 3s. $6 d$.

Lynch. - ARMENIA : Travels and Studies. By H. F. B. Lynch. With I97 Illustrations (some in tints) reproduced from Photographs and Sketches by the Author, I6 Maps and Plans, a Bibliography, and a Map of Armenia and adjacent countries. 2 vols. Medium 8vo., gilt top, 42s. net.

\section{Nansen.-THE FIRST CROSSING OF} GREENLAND. By FridTJof NANSEN. With I 43 Illustrations and a Map. Crown 8vo., 3s. $6 d$.
Rice.-OCCASIONAL ESSAYS ON $N_{A}$ TIVE SOUTH INDIAN LIFE. By STANLEY P. Rice, Indian Civil Šervice. 8vo., ros. $6 d$.

Smith-CLIMBING IN THE BRITISH IsLES. By W. P. HasketT SMITh. With Illustrations and Numerous Plans.

Part I. ENGLAND. I6mo., 3s. net.

Part II. WALES AND IRELAND. $16 \mathrm{mo}$, 3s. net.

Spender.-TWO WINTERS IN NORWAY : being an Account of Two Holidays spent on Snow-shoes and in Sleigh Driving, and including an Expedition to the Lapps. By A. Edmund Spender. With 40 Illustrations from Photographs. 8 vo., Ios. $6 d$. net.

Stephen. - THE PLAY-GROUND OF EUROPE (The Alps). By Sir LesLie STEPHEN, K.C.B. With 4 Illustrations. Crown 8vo., 3s. $6 d$.

Three in Norway. By Two of Them. With a Map and 59 Illustrations. Crown 8vo., 2s. boards, $2 s$. $6 d$. cloth.

\section{Tyndall.-( ЈоHN).}

THE GLACIERS OF THE ALPS. With 6I Illustrations. Crown 8vo., 6s. $6 d$. net. HOURS OF EXERCISE IN THE ALPS. With 7 Illustrations. Cr. 8 vo., $6 s .6 d$. net.

\section{Sport and Pastime.}

\section{THE BADMINTON LIBRARY.}

Edited by HIS GRACE THE (EIGHTH) DUKE OF BEAUFORT, K.G., and A. E. T. WATSON.

$A R C H E R Y$. By C. J. LONGMAN and Col. H. Walrond. With Contributions by Miss LEgH, Viscount DilloN, etc. With 2 Maps, 23 Plates and 172 Illustrations in the Text. Crown 8 vo., cloth, $6 s$. net; halfbound, with gilt top, $9 s$. net.

\section{ATHLETICS. By Montague} Shearman. With Chapters on Athletics at School by W. Beacher Thomas; Athletic Sports in America by C. H. Sherrill; a Contribution on Paper-chasing by W. RYE, and an Introduction by Sir RICHARD WEB. Ster (Lord Alverstone). With I2 Plates and 37 Illustrations in the Text. Cr. 8vo., cloth, $6 s$. net; half-bound, with gilt top, 9 s.net.
BIG GAME SHOOTING. By Clive Phillipps-Wolley.

Vol. I. AFRICA AND AMERICA. With Contributions by Sir SAMUEL W. Baker, W. C. Oswell, F. C. Selous, etc. With 20 Plates and 57 Illustrations in the Text. Crown 8vo., cloth, 6s. net; half-bound, with gilt top, 9 s. net.

Vol. II. EUROPE, ASIA, AND THE ARCTIC REGIONS. With Contributions by Lieut.-Colonel R. HEBER Percy, Major Algernon C. Heber Percy, etc. With 17 Plates and 56 Illustrations in the Text. Crown 8vo., cloth $6 s$. net; half-bound, with gilt top, $9 s$. net. 


\title{
Sport and Pastime-continued.
}

\section{THE BADMINTON LIBRARY-continued.}

\author{
Edited by HIS GRACE THE (EIGHTH) DUKE OF BEAUFORT, K.G.,
} and A. E. T. WATSON.

BILLIARDS. By Major W. BROADFoot, R.E. With Contributions by A. H. Boyd, Sydenham Dixon, W. J. Ford, etc. With II Plates, Ig Illustrations in the Text, and numerous Diagrams. Crown 8 vo., cloth, $6 s$. net; half-bound, with gilt top, gs. net.

\section{COURSING AND FALCONRY.}

By Harding Cox, Charles Richardson, and the Hon. Gerald Lascelles. With 20 Plates and 55 Illustrations in the Text. Crown 8 vo., cloth, $6 s$. net; half-bound, with gilt top, gs. net.

CRICKET. By A. G. STEEL and the Hon. R. H. LytreltoN. With Contributions by ANDREW LANG, W. G. GRACE, F. Gale, etc. With 13 Plates and 52 Illustrations in the Text. Crown $8 v o$., cloth, $6 s$. net; half-bound, with gilt top, gs. net.

CYCLING. By the EARL of AlbeMARLE and G. Lacy Hillier. With Ig Plates and 44 Illustrations in the Text. Crown $8 v o .$, cloth, $6 s$. net; half-bound, with gilt top, gs. net.

\section{$D A N C I N G$. By Mrs. Lilly Grove.} With Contributions by Miss Midpleton, The Hon. Mrs. Armytage, etc. With Musical Examples, and $3^{8}$ Full-page Plates and 93 Illustrations in the Text. Crown 8 vo., cloth, $6 s$. net; half-bound, with gilt top, 9 s. net.

DRIVING. By His Grace the (Eighth) DUKe of BEaufort, K.G. With Contributions by A. E. T. Watson the EARL of OnsLow, etc. With 12 Plates and 54 Illustrations in the Text. Crown 8vo., cloth, $6 s$. net; half-bound, with gilt top, gs. net.

\section{FENCING, BOXING, AND}

WRESTLING. By Walter H. Pollock, F. C. Grove, C. Prevost, E. B. Mitchell, and Walter Armstrong. With 18 Plates and 24 Illustrations in the Text. Crown $8 v 0 .$, cloth, $6 s$. net; half-bound, with gilt top, $9 s$. net.

\section{FISHING. By H. Cholmondeley-} PenNell.

Vol. I. SALMON AND TROUT. With Contributions by H. R. Francis, Major John P. Traherne, etc. With 9 Plates and numerous Illustrations of Tackle, etc. Crown 8vo., cloth, $6 s$. net; half-bound, with gilt top, $9 s$. net.

Vol. II. PIKE AND OTHER COARSE FISH. With Contributions by the Marquis of Exeter, William Senior, G. Christopher Davis, etc. With 7 Plates and numerous Illustrations or Tackle, etc. Crown 8 vo., cloth, $6 s$. net ; half-bound, with gilt top, $9 s$. net.

FOOTBALL. HISTORY, by MONtague Shearman; THE ASSOCIation GAME, by W. J. OAKLEY and G. O. SMITH; THE RUGBY UNION GAME, by FRANK Mrtchell. With other Contributions by R. E. Machaghten, M. C. Kemp, J. E. Vincent, Walter Camp and A. SutherLAND. With Ig Plates and 35 Illustrations in the Text. Crown 8vo., cloth, 6s. net; half-bound, with gilt top, gs. net.

GOLF. By Horace G. Hutchinson. With Contributions by the Rt. Hon. A. J. Balfour, M.P., Sir WALTER Simpson, Bart., ANDREW LANG, etc. With 34 Plates and 56 Illustrations in the Text. Crown 8 vo., cloth, $6 s$. net; half-bound, with gilt top, $9 s$. net.

HUNTING. By His Grace the (Eighth) DUKe of BEAufoRT, K.G., and MOWBRAY MORRIS. With Contributions by the EARL of Suffolk and BERKShire, Rev. E. W. L. Davies, G. H. Longman, etc. With 5 Plates and 54 Illustrations in the Text. Crown 8 vo., cloth, $6 s$. net ; halfbound, with gilt top, gs. net.

MOTORS AND MOTOR-DRIVING. By Alfred C. Harmsworth, the Marquis de Chasseloup-laubat, the Hon. John Scott-Montagu, R. J. ME. CREDY, the Hon. C. S. Rolls, Sir David Salomons, Bart., etc. With 13 Plates and 136 Illustrations in the Text. Crown 8vo., cloth, 9s. net; half-bound, 12s. net.

A Cloth Box for use when Motoring, 2s. net. 


\section{Sport and Pastime-continued.}

\section{THE BADMINTON LIBRARY-continued.}

\section{Edited by HIS GRACE THE (EIGHTH) DUKE OF BEAUFORT, K.G.,} and A. E. T. WATSON.

\section{MOUNTAINEERING. By C. T.} DENT. With Contributions by the Right Hon. J. Bryce, M.P., Sir Martin Conway, D. W. Freshfield, C. E. MatThews, etc. With 13 Plates and 91 Illustrations in the Text. Crown 8vo., cloth, $6 s$. net; halfbound, with gilt top, $9 s$. net.

\section{POETRY OF SPORT (THE).-} Selected by Hedley Peek. With a Chapter on Classical Allusions to Sport by ANDREW LANG, and a Special Preface to the BADMINTON LIBRARY by A. E. T. Watson. With 32 Plates and 74 Illustrations in the Text. Crown 8vo., cloth, 6s. net; half-bound, with gilt top, $9 s$. net.

\section{RACING AND STEEPLE-CHAS-} ING. By the EARL OF SUFFOLK AND Berkshire, W. G. Craven, the Hon. F. Lawley, Arthur Coventry, and A. E. T. Watson. With Frontispiece and 56 Illustrations in the Text. Crown 8vo., cloth, $6 s$. net; half-bound, with gilt top, $9 s$. net.

RIDING AND POLO. By Captain Robert Weir, J. Moray Brown, T. F. Dale, The Late Duke of Beaufort, The EARL of Suffolk and Berkshire, etc. With 18 Plates and 4 I Illusts. in the Text. Crown 8vo., cloth, 6s. net; half-bound, with gilt top, 9 s. net.

ROWING. By R. P. P. Rowe and C. M. PItMan. With Chapters on Steering by C. P. SERocold and F. C. BegG ; Metropolitan Rowing by S. LE BLANC SMITH; and on PUNTING by P. W. SQUIRE. With 75 Illustrations. Crown 8 vo., cloth, 6s. net ; half-bound, with gilt top, $9 s$. net.

\section{SHOOTING.}

Vol. I. FIELD AND COVERT. By LORD Walsingham and Sir Ralph Payne. Gallwey, Bart. With Contributions by the Hon. Gerald Lascelles and A. J. Stuart-Wortley. With II Plates and 95 Illustrations in the Text. Crown 8vo., cloth, 6s. net; half-bound, with gilt top, 9s. net.

Vol. II. MOOR AND MARSH. By Lord Walsingham and Sir Ralph PayneGallwey, Bart. With Contributions by LORD Lovat and Lord CharLes LENnox KERR. With 8 Plates and 57 Illustrations in the Text. Crown 8vo., cloth, 6 s. net; half-bound, with gilt top, $9 s$. net.
SEA FISHING. By JoHN BickeRDYKe, Sir H. W. Gore-BooTh, AlFred C. HaRmsworth, and W. SEnIOR. With 22 Full-page Plates and 175 Illusts. in the Text. Crown 8vo., cloth, 6s. net; half-bound, with gilt top, 9 s. net.

SKATING, CURLING, TOBOG. GANING. By J. M. HeAthcote, C. G. Tebbutt, T. Maxwell Witham, Rev, JOHN KERR, ORMOND HAKE, HENRY A. Buck, etc. With I2 Plates and 272 Illustrations in the Text. Crown 8vo., cloth, $6 s$. net; half-bound, with gilt top, 9 s. net.

SWIMMING. By Archibald SinCLAIR and William HENRY, Hon. Secs. of the Life-Saving Society. With 13 Plates and I I2 Illustrations in the Text. Crown 8vo., cloth, $6 s$. net; half-bound, with gilt top, $9 s$. net.

TENNIS, LAWN TENNIS, RACKETS AND FIVES. By J.M. and C. G. Heathcote, E. O. Pleydell-BouVERIE, and A. C. AINGER. With Contributions by the Hon. A. Lyttelton, W. C. Marshall, Miss L. DoD, etc. With $\mathrm{I}_{4}$ Plates and 65 Illustrations in the Text. Crown 8vo., cloth, 6s. net; half-bound, with gilt top, 9s. net.

\section{YACHTING.}

Vol. I. CRUISING, CONSTRUCTION OF YACHTS, YACHT RACING RULES, FITTING-OUT, etc. By Sir Edward Sullivan, Bart., The Earl of Pembroke, Lord Brassey, K.C.B., C. E. Seth-Smith, C.B., G. L. Watson, R. T. Pritchet', E. F. KNIght, etc. With 2 I Plates and 93 Illustrations in the Text. Crown 8vo., cloth, $6 s$. net; halfbound, with gilt top, 9 s. net.

Vol. II. YACHT CLUBS, YACHT. ING IN AMFRICA AND THE COLONIES, YACHT RACING, etc. By R. T. Pritchett, The Marquis of Dufferin and Ava, K.P., The EARL of Onslow, James McFerRan, etc. With 35 Plates and I6o Illustrations in the Text. Crown 8vo., cloth, 9s. net; half. bound, with gilt top, 9 s. net. 


\section{Sport and Pastime-continued. FUR, FEATHER, AND FIN SERIES.}

Edited by A. E. T. Watson.

Crown 8vo., price 5 s. each Volume, cloth.

* The Volumes are also issued half-bound in Leather, with gilt top. Price 7s. 6 d. net each.

THE PARTRIDGE. Natural History, by the Rev. H. A. Macpherson; Shooting, by A. J. STUarT-WORTLEY; Cookery, by George Saintsbury. With II Illustrations and various Diagrams. Crown 8vo., 5 s.

THE GROUSE. Natural History, by the Rev. H. A. Macpherson; Shooting, by A. J. Stuart.Wortley; Cookery, by George Saintsbury. With $x_{3}$ Illustrations and various Diagrams. Crown 8 vo., 55 .

THE PHE ASANT. Natural History, by the Rev. H. A. MACPHERSon; Shooting, by A. J. Stuart-WortLey; Cookery, by Alexander Innes Shand. With Io Illustrations and various Diagrams. Crown 8 vo., 5 s.

THE HARE. Natural History, by the Rev. H. A. Macpherson; Shooting, by the Hon. Gerald Lascelles; Coursing, by Charles Richardson; Hunting, by J. S. Gibbons and G. H. Longman ; Cookery, by Col. Kenney Herbert. With 9 Illustrations. Crown 8vo., 5 s.

Alverstone and Alcock.-SURREY CRICKET: its History and Associations. Edited by the Right Hon. Lord Alverstone, L.C.J., President, and C.W. Alcock, Secretary, of the Surrey County Cricket Club. With 48 Illustrations. 8vo., r6s. net.

Bickerdyke.-DAYS OF MY LIFE ON WATER, FRESH AND $S_{A L T}$; and other Papers. By JoHN Bickerdyke. With Photo-etching Frontispiece and 8 Full-page Illustrations. Crown 8vo., 3s. $6 d$.

Blackburne. - $M_{R}$. BLACKBURNE'S GAMES AT CHESS. Selected, Annotated and Arranged by Himself. Edited, with a Biographical Sketch and a brief History of Blindfold Chess, by P. Anderson Graham. With Portrait of Mr. Blackburne. 8vo., 75. $6 d$. net.

Dead Shot (The): or, Sportsman's Complete Guide. Being a Treatise on the Use of the Gun, with Rudimentary and Finishing Lessons in the Art of Shooting Game of all kinds. Also Game-driving, Wildfowl and Pigeon-shooting, Dog-breaking, etc. By MARKSMAN. With numerous Illustrations. Crown 8vo., tos. $6 d$.
RED DEER.-Natural History, by the Rev. H. A. Macpherson; Deer Stalking, -by Cameron of Lochiel; Stag Hunting, by Viscount EBRINGTON; Cookery, by Alexander InNes Shand. With Io Illustrations. Crown 8vo., 5 s.

THE SALMON. By the Hon. A. E. Gathorne-HaRdy. With Chapters on the Law of Salmon Fishing by Claud Douglas Pennant; Cookery, by Alexander Innes Shand. With 8 Illustrations. Cr.8vo., $5^{s}$.

THE TROUT. By the Marquess of Granby. With Chapters on the Breeding of Trout by Col. H. Custance; and Cookery, by Alexander InNes Shand. With I2 Illustrations. Crown 8vo., 5 s.

THE RABBIT. By James Edund Harting. Cookery, by Alexander InNes Shand. With ro Illustrations. Cr.8vo., 5 s.

PIKE AND PERCH. By William SENIOR ('Redspinner,' Editor of the 'Field'). With Chapters by John BickerDYKE and W. H. POPE; Cookery, by Alexander Innes Shand. With I2 II. lustrations. Crown 8vo., $5^{5}$.

Ellis.-CHESS SPARKS; or, Short and Bright Games of Chess. Collected and Arranged by J. H. Ellis, M.A. 8vo., 4s. $6 d$.

Folkard.-THE WILD-FOWLER : A Treatise on Fowling, Ancient and Modern, descriptive also of Decoys and Flight-ponds, Wild-fowl Shooting, Gunning-punts, Shooting-yachts, etc. Also Fowling in the Fens and in Foreign Countries, Rock-fowling, etc., etc., by H. C. Folkard. With $x_{3}$ Engravings on Steel, and several Woodcuts. 8vo., i2s. $6 d$.

Ford.-THE THEORY AND PRACTICE oF ARCHERY. By Horace Ford. New Edition, thoroughly Revised and Re-written by W. Butr, M.A. With a Preface by C. J. Longman, M.A. 8vo., I4s.

Francis.- $A B O O K$ oN ANGLING : or, Treatise on the Art of Fishing in every Branch ; including full Illustrated List of Salmon Flies. By Francis Francis. With Portrait and Coloured Plates. Crown 8vo., I5s.

Fremantle. - THE BOOK OF THE RIFLE. By the Hon. T. F. Fremantle, V.D., Major, Ist Bucks V.R.C. With 54 Plates and ro7 Diagrams in the Text. 8vo., I2s. $6 d$. net. 


\section{Sport and Pastime-continued.}

\section{Gathorne - Hardy. - AUTUMNS IN} ARGYLESHIRE WITH ROD AND GUN. By the Hon. A. E. Gathorne-Hardy. With 8 Illustrations by ARCHIBALD THORBURN. Evo., 6s. net.

Graham.-COUNTRY PASTIMES FOR Boys. By P. Anderson Graham. With 252 Illustrations from Drawings and Photographs. Cr. 8vo., gilt edges, $3 s$. net.

Hutchinson.-THE BOOK OF GOLF AND GOLFERS. By Horace G. Hutchinson. With Contributions by Miss AMY Pascoe, H. H. Hilton, J. H. Taylor, H. J. Whigham, and Messrs. Sutton \& Sons. With 7 I Portraits from Photographs. Large crown 8 vo., gilt top, $7 s$. $6 d$. net.

Lang.-ANGLING SKETCHES. By ANDREW LANG. With 20 Illustrations. Crown 8vo., 3s. $6 d$.

Lillie.-CROQUET UP TO DATE. Containing the Ideas and Teachings of the Leading Players and Champions. By ArTHUR LILlie. With Contributions by Lieut.-Col. the Hon. H. NeEdham, C. D. Locock, etc. With Ig Illustrations (I5 Portraits), and numerous Diagrams. 8vo., ros. $6 d$, net.

Locock.-SIDE AND SCREW: being Notes on the Theory and Practice of the Game of Billiards. By C. D. Locock. With Diagrams. Crown 8vo., 5s. net.

Longman.-CHESS OPENINGS. By FREDERICK W. Longman. Fcp. 8vo., 2s. 6 d.

Mackenzie.-NOTES FOR HUNTING $M R N$. By Captain Cortlandt Gordon Mackenzie. Crown 8vo., 2s. $6 d$. net.

Madden.-THE DIARY OF MASTER WILLIAM SILENCE : a Study of Shakespeare and of Elizabethan Sport. By the Right Hon. D. H. MADDEN, Vice-Chancellor of the University of Dublin. 8vo.; gilt top, I6s.

Maskelyne.-SHARPS AND FLATS : a Complete Revelation of the Secrets of Cheating at Games of Chance and Skill. By John Nevil Maskelyne, of the Egyptian Hall. With 62 Illustrations. Crown 8vo., $6 s$.

\section{Millais (John Guille).}

THE WILD-FOWLER IN SCOTLAND. With a Frontispiece in Photogravure by Sir J. E. Millais, Bart., P.R.A., 8 Photogravure Plates, 2 Coloured Plates and 50 Illustrations from the Author's Drawings and from Photographs. Royal 4to., gilt top, 3os, net.
Millais (John GuILle) - continued. THE NATURAL HISTORY CF THE BRITISH SURFACE-FEEDING DUCKS. With 6 Photogravures and 66 Plates (4r in Colours) from Drawings by the Author, ARCHibald THorburn, and from Photographs. Royal 4to.,cloth, gilt top, $£^{6} 6 s$.net.

Modern Bridge.-By 'Slam'. With a Reprint of the Laws of Bridge, as adopted by the Portland and Turf Clubs. I8mo., gilt edges, $3 s .6 d$. net.

Park.-THE GAME OF GOLF. By William Park, Jun., Champion Golfer, 1887-89. With 17 Plates and 26 Illustrations in the Text. Crown 8vo., 7s. 6d.

Payne-Gallwey (Sir RalPH, Bart.). THE CROSS-BOW: Mediæval and Modern; Military and Sporting; its Construction, History and Management, with a Treatise on the Balista and Catapult of the Ancients. With 220 Illustrations. Royal 4 to., $£ 33$ s. net.

LETTERS TO YOUNG SHOOTERS (First Series). On the Choice and use of a Gun. With 4 I Illustrations. Crown 8 vo., $7 s .6 d$.

LetTers to Young Shooters (Second Series). On the Production, Preservation, and Killing of Game. With Directions in Shooting Wood-Pigeons and Breakingin Retrievers. With Portrait and I03 Illustrations. Crown 8vo., I2s. $6 d$.

LETTERS TO YOUNG SHOOTERS. (Third Series.) Comprising a Short Natural History of the Wildfowl that are Rare or Common to the British Islands, with complete directions in Shooting Wildfowl on the Coast and Inland. With 200 Illustrations. Crown 8 vo., $18 s$.

Pole.-THE THEORY OF THE MODERN SCIRNTIFIC GAME OF WHIST. By William PoLE, F.R.S. Fcp. 8vo., gilt edges, 2s. net. Proctor.-How to PLAY WHIST: WITH THE LAWS AND ETIQUETTE OF Whist. By Richard A. Proctor. Crown 8 vo., gilt edges, 3 s. net.

Ronalds. - I HE FLY-FISHER'S ENTOMOLOGY. By Alfred Ronalds. With 20 coloured Plates. 8vo., I 4 s.

Selous.-SPORT AND TRAVEL, EAST AND WEST. By Frederick Courteney SELous. With 18 Plates and 35 Illustrations in the Text. Medium 8vo., I2s. $6 d$. net.

Warner.-CRICKET ACROSS THE SEAS: being an Account of the Tour of Lord Hawke's Team in New Zealand and Australia. By P. F. WARner. With 32 Illustrations from Photographs. Crown 8 vo., 5s. net. 


\section{Mental, Moral, and Political Philosophy.}

LOGIC, RHETORIC, PSYCHOLOGY, ETHICS, EC.

Abbott. - THE ELEMENTS OF LOGIC. Bу T. K. Аввотт, B.D. I2mo., $3^{\text {s. }}$

\section{Aristotle.}

THE ETHICS: Greek Text, Illustrated with Essay and Notes. By Sir AlexanDER Grant, Bart. 2 vols. 8 vo., 325.

An INTRODUCtion to ARISTOTLE'S ETHICS. Books I.-IV. (Book X.c.vi.-ix. in an Appendix). With a continuous Analysis and Notes. By the Rev. E. MOORE, D.D. Crown 8vo., Ios. $6 d$.

\section{Bacon (Francis).}

COMPLETE WORKS. Edited by R. L. Ellis, James Spedding and D. D. Heath. 7 vols. 8vo., $£ 3$ I3s. 6 d.

LETTERS AND LIFE, including all his occasional Works. Edited by JAmes SPEDDING. 7 vols. 8 vo., $£ 44$ s.

THE ESSAYS: with Annotations. By Richard Whately, D.D. 8vo., ios. $6 \dot{d}$.

THE ESSAYS: with Notes. By F. Storr and C. H. Gibson. Cr. 8vo., 3s. $6 d$.

THE ESSAYS: with Introduction, Notes, and Index. By E. A. AввотT, D.D. 2 Vols. Fcp. 8vo., 6s. The Text and Index only, without Introduction and Notes, in One Volume. Fcp. 8vo., 2s. 6d.

\section{Bain (Alexander).}

MENTAL AND MORAL SCIENCE: a Compendium of Psychology and Ethics. Crown 8vo., 10s. $6 d$.

\section{Or separately,}

Part I. PSYCHOLOGY AND HISTORY OF PHILOSOPHY. Crown 8vo., 6s. 6d.

Part II. THEORY OFE THICS AND ETHICAL Systems. Crown 8vo., 4s. $6 d$.

Logic. Part I. Deduction. Cr. 8vo., 4s. Part II. InduCtion. Cr. 8vo., 6s. 6d.

THE SENSES AND THE INTELLECT. 8 vo., I5s.

THE EMOTIONS AND THE WILL 8vo., 15s.

Practical Essays. Cr. 8vo., 2s.

Dissertations on LEAdING PHILOSOPHICAL TOPICS. $8 \mathrm{vo}$., 7s. $6 d$. net.
Baldwin.-A College MaNuAL of Rhetoric. By Charles Sears Baldwin. A.M., Ph.D. Crown 8 vo., 4 s. $6 d$.

Brooks.-THE ELEMENTS OF MIND : being an Examination into the Nature of the First Division of the Elementary Sub: stances of Life. By H. JAMYN Brooks. 8 vo., Ios. $6 d$. net.

Brough.-THE STUDY OF MENTAL SCIENCE: Five Lectures on the Uses and Characteristics of Logic and Psychology. By J. Brough, LL.D. Crown 8vo, 2s. net.

\section{Crozier (John Beattie).}

CIVILISATION AND PROGRESS: being the Outlines of a New System of Political, Religious and Social Philosophy. 8vo., I 4 s.

HISTORY OF INTELLECTUAL DEVELOPMENT: on theLines of ModernEvolution.

Vol. I. 8vo., I4s.

Vol. II. (In preparation.)

Vol. III. 8vo., Ios. $6 d$.

Davidson. - THE LOGIC OF DEFINITION, Explained and Applied. By William L. Davidson, M.A. Crown 8vo., 6s.

Fite.-AN INTRODUCTORY STUDY OF E Thics. By Warner Fite. Cr. 8vo., 6s.6d.

Green ('Thomas Hill). - The Works or. Edited by R. L. NetTLESHIP.

Vols. I. and II. Philosophical Works. 8vo. I6s. each.

Vol. III. Miscellanies. With Index to the three Volumes, and Memoir. 8vo., 2Is.

LECTURES ON THE PRINCIPLES OF Political OBLIGATION. With Preface by BERNARD Bosanquet. 8vo., 5 s.

Gurnhill.-THE MORALS OF SUICIDE. By the Rev. J. Gurnhill. B.A. Vol. I., Crown 8 vo., 5s. net. Vol, II., Crown 8vo., 5s. net. 


\title{
Mental, Moral and Political Philosophy-continued.
}

\author{
LOGIC, RHETORIC, PSYCHOLOGY, ETHICS, EC.
}

Hodgson (ShadWorth H.).

TIME AND SPACE: A Metaphysical Essay. 8vo., r6s.

THE THEORY OF PRACTICE: an Ethical Inquiry. 2 vols. 8 vo., 245 .

The Philosophy of Reflection. 2 vols. 8 vo., 2 Is.

THE METAPHYSIC OF EXPERIENCE.

Book I. General Analysis of Experience;

Book II. Positive Science; Book III. Ana ysis of Conscious Action; Book IV. The Real Universe. 4 vols. 8 vo., 36 s. net.

Hume. - THE PHILOSOPHICAL WORKS oF DAVID HUME. Edited by T. H. GREen and T. H. Grose. 4 vols. 8vo., 28s. Or separately, Essays. 2 vols. I4s. Treatise of Human Nature. 2 vols. I4s.

James (William, M.D., LL.D.).

THE WILL TO BELIEVE, and Other Essays in Popular Philosophy. Crown 8 vo., $75.6 d$.

THE VARIETIES of RELigious $E_{X}$ PERIENCE : a Study in Human Nature. Being the Gifford Lectures on Natural Religion delivered at Edinburgh in rgor1902. 8 vo., I2s, net.

TALKS TO TEACHERS ON PSYCHOLOGY, AND TO STUDENTS ON SOME OF LIFE'S IDEALS. Crown 8vo., $4 s .6 d$.

Justinian.-THE INSTITUTES OF FUSTINIAN : Latin Text, chiefly that of Huschke, with English Introduction, Translation, Notes, and Summary. By Thomas C. Sandars, M.A. 8vo., I8s.

Kant (Immanuel).

CRITIQUe OF Practical REASON, AND OTHER WORKS ON THE THEORY OP ETHICS. 'Translated by T. K. Aввotr, B.D. With Memoir. 8vo., I2s. $6 d$.

FUNDAMENTAL PRINCIPLES OF THE METAPHYSIC OF E THICS. 'Translated by T. K. Aввотt, B.D. Crown 8 vo, $3^{s}$.

INTRODUCTION TO LOGIC, AND HIS ESSAY ON THE MISTAKEN SUBTILTY OF THE FOUR FIGURES. Translated by T. K. Аввотт. 8vo., $6 \mathrm{~s}$

Kelly.-GOVERNMENT OR HUMAN EVOLUTION. By EDMOND KELLY, M.A., F.G.S. Vol. I. Justice. Crown 8 vo., $75,6 d$. net. Vol. II. Collectivism and Individualism. Crown 8vo., Ios. $6 d$. net.

Killick.-HANDBOOK TO MILL'S SYSTEM OF LOGIC. By Rev. A. H. KILLICK, M.A. CCrọwṇ 8vo., 3s. $6 d$.
Ladd (George Trumbull).

PHILOSOPHY OF CONDUCT: a Treatise of the Facts, Principles and Ideals of Ethics. 8vo., 21s.

Elements of Physiological PSY. CHOLOGY. 8vo., 2Is.

OUTLINES OF DESCRIPTIVE PSYCHOLOGY: a Text-Book of Mental Science for Colleges and Normal Schools. 8vo., r2s.

Outlines of Physiological PsyCHOLOGY. 8vo., I2S.

PRIMER OF PSYCHOLOGY. Cr. 8vo., 5s. $6 d$.

Lecky(William Edward Hartpole).

THE MAP OF LIFE: Conduct and Character. Crown 8vo., 5s, net.

HISTORY OF EUROPEAN MORALS FROM AUGUSTUS TO CHARLEMAGNE. 2 vols. Crown 8 vo., Ios. net.

A SURIEY of ENGLISH ETHICS: being the First Chapter of W. E. H. Lecky's 'History of European Morals'. Edited, with Introduction and Notes, by W. A. Hirst. Crown 8vo., 3s. $6 d$.

HISTORY OF THE RISE AND INFIUENCE OF THE SPIRIT OF RATIONALISM IN EUROPE. 2 vols. Cr. 8 vo., IOs. net.

DEMOCRACY AND LIBERTY.

Library Edition. 2 vols. 8vo., 36 s.

Cabinet Edition. 2 vols. Cr. 8vo., Ios. net.

Lutoslawski.-THE ORIGIN AND GROWTH OF PLATO'S LOGIC. With an Account of Plato's Style and of the Chronology of his Writings. By WINCENTY LUTOSLAWSKI. 8vo., 2 Is.

Max Müller (F.).

THESCIENCEOF THOUGHT. 8vo., 2 Is.

THE SIX Systems of INDIAN PHILOSOPHY. 8vo., I8s.

THREE LECTURES ON THE VEDANTA PHILOSOPHY. Crown 8vo., 5 s.

Mill (John Stuart).

A SYSTEM OF LOGIC. Cr. 8vo., 3s. $6 d$. ON LIBERTY. Crown 8vo., Is. $4 d$.

CONSIDERATIONS ON REPRESENTATIVE GoverNMENT. Crown 8vo., 25.

UTILITARIANISM. 8vo., 2s. 6d.

EXAMINATION OF SIR WILLIAM HAMILTON'S PHILOSOPHY. 8vo., I6s.

NATURE, THE UTILITY OF RELIGION, $A N D$ THEISM. Three Essays. 8vo., 5 s. 


\title{
Mental, Moral, and Political Philosophy-continued.
}

\author{
LOGIC, RHETORIC, PSYCHOLOGY, ETHICS, E.C.
}

Monck. - AN INTRODUCTION TO Logic. Ry William Henry S. Monck, M.A. Crown 8vo., 5 s.

Myers.-HUMAN PERSONALITY AND ITS SURVIVAL OF BODILY DEATH. BY Frederic W. H. MYers. 2 vols. 8vo., 42s. net.

Pierce.-STUdIES IN AUDITORY AND VISUAL SPACE PERCEPTION: Essays on Experimental Psychology. By A. H. Pierce. Crown 8vo., 6s. $6 d$. net.

Richmond.-THE MIND OF A CHILD. By EnNis Richmond. Cr. 8vo., 3s. 6d. net.

Romanes.-MIND AND MOTION AND Monism. By George John Romanes, Cr. 8vo., 4s. $6 d$.

\section{Sully (James).}

AN ESSAY ON LAUGHTER : its Forms, its Cause, its Development and its Value. 8vo., I2s. $6 d$. net.

THE HUMAN MIND : a Text-book of Psychology. 2 vols. 8vo., 2 Is.

Outlines of PSyChology. Crown 8 vo., 9 s.

THE TEACHER'S HANDBOOK OF PSYCHOLOGY. Crown 8vo., 6s. 6 d.

StUdies OF CHILDHOOD. 8vo., ros.6d. CHILDREN'S WAYS : being Selections from the Author's 'Studies of Childhood'. With 25 Illustrations. Crown 8vo., $4 s .6 d$.

Sutherland. - THE ORIGIN AND GROWTH OF 7 HE MORAL INSTINCT. By Alexander Sutherland, M.A. 2 vols. 8vo., 28s.

Swinburne. - PICTURE LOGIC: an Attempt to Popularise the Science of Reasoning. By Alfred James Swinburne, M.A. With 23 Woodcuts. Cr. 8vo., 2s. $6 d$.
Thomas. - INTUITIVE SUgGestion. By J. W. Thomas, Author of 'Spiritual Law in the Natural World,' etc. Crown 8 vo., 3s. $6 d$. net.

Webb.-THE VEIL of ISIS : a Series of Essays on Idealism. By Tномаs E. WEBB, LL.D., Q.C. 8vo., Ios. $6 d$.

Weber.-HISTORY OF PHILOSOPHY By Alfred Weber, Professor in the University of Strasburg. Translated by FRANK Thilly, Ph.D. 8vo., I6s.

Whately (Archbishop).

BACON'S ESSAYS. With Annotations. $8 \mathrm{vo}$., I0s. $6 d$.

ELEMENTS OF LoGIC. Cr. 8vo., 4 s. $6 d$. ELEMENTS OF RHETORIC. Cr. 8vo., 4s. $6 d$.

Zeller (Dr. Edward).

THE STOICS, EPICUREANS, AND SCEPTICS. Translated by the Rev. O. J. REICHEL, M.A. Crown 8vo., I5s.

OUTLINES OF THE HISTORY OF GRERK PHILOSOPHY. Translated by Sarah F. Alleyne and Evelyn AbBott, M.A., LL.D. Crown 8vo., Ios. $6 d$.

PLATO AND THE OLDER ACADEMY. Translated by Sarah F. Alleyne and ALFRED Goodwin, B.A. Crown 8vo., i8s.

SOCRATES AND THE SOCRATIC. SCHOOLS. Translated by the Rev. O. J. Reichel, M.A. Crown 8vo., ios. $6 d$. ARIStotle AND THE EARLIER PERIPATETICS. Translated by B. F. C. CosTELLOE, M.A., and J. H. MUIRHEAD, M.A. 2 vols. Crown 8vo., 24 s.

\section{STONYHURST PHILOSOPHICAL SERIES.}

a manual of Political econumy. By C. S. Devas, M.A. Crown 8vo., 7s. $6 d$.

FiRST PRINCIPLES OF KNOWLEDGE. By John Rickaby, S.J. Crown 8vo., 5 s.

GENERAL METAPHYSICS. By JoHN Rickaby, S.J. Crown 8vo., 5 s.

Logic. By Richard F. Clarke, S.J. Crown 8vo., 5 s.
Moral Philosophy (Ethics aND NATURAL LAW). BY JOSEPH RICKaBy, S.J. Crown 8vo., 5 s.

NATURAL THEOLOGY. By Bernard Boedder, S.J. Crown 8vo., $6 s .6 d$.

Psychology. By Michael Maher, S.J., D.Litt., M.A. (Lond.). Cr. 8vo., 6s. $6 d$. 


\section{History and Seience of Language, \&e.}

\section{Davidson.- LEADING AND IMPORT-} $A N T \cdot$ ENGLISH WORDS : Explained and Exemplified. By William L. Davidson, M.A. Fcp. 8vo., 3s. $6 d$.

Farrar.-LANGUAGE AND LANGUAGES. By F. W. FARrar, D.D., late Dean of Canterbury. Crown 8vo., $6 s$.

Graham. - ENGLISH SYNONYMS, Classified and Explained: with Practical Exercises. By G. F. Graham. Fcp. 8vo., $6 s$.

\section{Max Müller (F.).}

THE SCIENCE OF LANGITAGE. 2 vols. Crown 8vo., Ios.
Max Müller (F.)-continued.

BIOGRAPHIES OF WORDS, AND THE HOME OF THE ARYAS. Crown 8vo., 5 s. CHIPS FROM A GERMAN WORKSHOP. Vol. III. ESSAYS ON LANGUAGE AND LITERATURE. Crown 8vo., 5 s.

LAST ESSAYS. First Series. Essays on Language, Folk-lore and other Subjects. Crown 8 vo., 5 s.

Roget.-THESAURUS OF ENGLISH WORDS AND PHRASES. Classified and Arranged so as to Facilitate the Expression of Ideas and assist in Literary Composition. By Peter Mark Roget, M.D., F.R.S. With full Index. Crown 8vo., 9s. net.

\section{Political Economy and Economies.}

Ashley (W. J.).

ENGLISH ECONOMIC HISTORY AND THEORY. Crown 8vo., Part I., 5s. Part II., IOS. $6 d$.

SURVEYS, HistoriC AND ECONOMIC. Crown 8vo., 9s. net.

The ADJUSTMENT OF WAGES: a Study on the Coal and Iron Industries of Great Britain and the United States. With 4 Maps. 8vo., I2s. 6d. net.

Bagehot.-Economic Studies. By Walter Bagehot. Crown 8vo., 3s. $6 d$.

Barnett.-PRACTICABLE SOCIALISM : Essays on Social Reform. By Samuel A. and Henrietta Barnett. Crown 8vo., $6 s$.

Devas.-A Manual uF POLItical Economy. By C. S. Devas, M.A. Cr. 8vo., 7s. 6d. (Stonyhurst Philosophical Series.)

Dewey.-FinANCIAL HISTORY OF THE UNITED STATES. By Davis Rich Dewey. Crown 8vo., 7s. $6 d$. net.

Lawrence.-LUCAL VARIATIONS IN WAGES. By F. W. LAWRENCE, M.A. With Index and x8 Maps and Diagrams. 4to.,8s.6d.

Leslie.-Essays on Political EcoNomy. By T. E. Cliffe Leslie, Hon. LL.D., Dubl. 8 vo., ros. $6 d$.

\section{Macleod (Henry Dunning).}

BIMETALLISM. 8vo., 5s, net.

$T_{\text {HE ELEMENTS OF }}$ BANKING. $\mathrm{Cr}$. 8vo., 3 s. $6 d$.
Macleod (Henry Dunning)-contd.

THE THEORY AND PRACTICE OF BANKING. Vol. I. 8vo., I2s. Vol. II. I4s.

THE THEORY OF CREDIT. 8vo. In I Vol., 3os. net; or separately, Vol. I., Ios. net. Vol. II., Part.I., Ios. net. Vol II., Part II. ros. net.

INDIAN CURRENCY. 8vo., 2s.6d.net.

Mill.-Political ECONomy. By John Stuart Mill. Popular Edition. Cr. 8vo.,3s.6d. Library Edition. 2 vols. 8vo.,3os.

Mulhall.-INDUSTRIES AND WEALTH of Nations. By Michael G. Mulhall, F.S.S. With 32 Diagrams. Cr. 8vo., $8 s, 6 d$.

Symes. - PoLitical ECONOMY : a Short Text-book of Political Economy. With Problems for Solution, Hints for Supplementary Reading, and a Supplementary Chapter on Socialism. By J. E. Symes, M.A. Crown 8 vo., $2 s .6 d$.

Toynbee.-LECTURES ON THE INDUSTRIAL REVOLUTION OF THE $18 T H$ CEN. TURY IN ENGLAND. By ARnold Toynbee. 8 vo., xos. $6 d$.

Webb (Sidney and Beatrice).

THE HISTORY OF TRADE UNIONISM. With Map and Bibliography. 8vo., $7 s .6 d$. net.

INDUSTRIAL DEMOCRACY: a Study in Trade Unionism. 2 vols. 8vo., x2s. net.

PROBLEMS OF MODERN INDUSTRY. 8 vo., 5s. net. 


\section{Evolution, Anthropology, \&e.}

Annandale and Robinson.-F $F_{A S}$ CICULS M ALAYENSES : Anthropological and Zoological Results of an Expedition to Perak and the Siamese Malay States, Igor-2. Undertaken by NELSON ANNANDALE and HERBERT C. ROBINSON. With 17 Plates and I5 Illustrations in the Text. Part I. 4to., I5s, net.

Avebury. - THE ORIGIN OF CIVILISATION, and the Primitive Condition of Man. By the Right Hon. LORD AvEBuRy. With 6 Plates and 20 Illustrations. 8vo., I8s.

Clodd (EDWARD).

THE StORY OF CREATION: a Plain Account of Evolution. With 77 Illustrations. Crown 8vo., 3s. 6d.

A PRIMER OF EVOLUTION: being a

Popular Abridged Edition of 'The Story of Creation'. With Illustrations. Fcp. 8vo., Is. $6 d$.

Lang and Atkinson. - SOCIAL OrIGINS. By Andrew LANG, M.A., LL.D. ; and PRIMAL LAW. By J. J. ATKINSON. 8 vo.,. Ios. $6 d$. net.

\section{The Science of Religion, \&e.}

Balfour. - THE FOUNDATIONS OF $B E L I E F$ : being Notes Introductory to the Study of Theology. By the Right Hon. Arthur James Balfour. Cr. 8vo., 6s. net.

Baring-Gould. -THE ORIGIN AND DEVELOPMENT OF RELIGIOUS BELIEF. By the Rev. S. BARING-Gould, 2 vols. Crown 8vo., 3s. 6 d. each.

Campbell.-RELIGION IN GREEK LITERATURE. By the Rev. Lewis CAMPBELL, M.A., LL.D. 8vo., I5s.

Davidson.-THEISM, as Grounded in Human Nature, Historically and Critically Handled. Being the Burnett Lectures for 1892 and 1893 , delivered at Aberdeen. By W. L. Davidson, M.A., LL.D. 8vo., I5s.

James.-THE VARIETIES OF RELIGIOUS EXPERIENCE: a Study in Human Nature. Being the Gifford Lectures on Natural Religion delivered at Edinburgh in IgOI-Ig02. By WiLliaM JAMES, LL.D., etc. 8vo., I2s. net.

\section{Lang (ANDREW).}

MAGIC AND RELIGION. 8vo., ios. 6 d.

CUSTOM AND MYTH: Studies of Early Usage and Belief. With 15 Illustrations. Crown 8vo., 3s. $6 d$.

MYTH, RITUAL, AND RELIGION, 2 vols. Crown 8 vo., 75 .
Packard.-LAMARCK, THE FOUNDER of EVOLUTION: his Life and Work, with Translations of his Writings on Organic Evolution. By Alpheus S. PACKard, M.D., LL.D. With. Io Portrait and other Illustrations. Large Crown 8vo., gs, net.

Romanes (GEORGE JoHN).

ESSAYS. Ed. by C. LLOYD MORGAN. Crown 8vo., 5s. net.

AN EXAMINATION OF WEISMANNISM. Crown 8vo., $6 s$.

DARWIN, AND AFTER DARWIN: an Exposition of the Darwinian Theory, and a Discussion on Post-Darwinian Questions. Part I. The Darwinian Theory. With Portrait of Darwin and 125 Illustrations. Crown 8vo., Ios. $6 d$.

Part II. Post-Darwinian Questions: Heredity and Utility. With Portrait of the Author and 5 Illustrations. Cr. 8vo., Ios. $6 d$.

Part III. Post-Darwinian Questions : Isolation and Physiological Selection. Crown 8vo., 5 s.

Lang (ANDREW)-continued. MODERN MYTHOLOGY : a Reply to Professor Max Müller. 8vo., gs.

TIIE MAKING OF RELIGION. Cr. 8vo., 5s. net.

Leighton.-TYPICAL MODERN CONCEPTIONS OF GOD; or, The Absolute of German Romantic Idealism and of English Evolutionary Agnosticism. By JosePH Alexander Leighton, Professor of Philosophy in Hobart College, U.S. Crown 8vo., 3s. $6 d$. net.

Max Müller (The Right Hon. F.). THE SILESIAN HORSEHERD (DAS PFERDEBÜRLA'): Questions of the Day answered by F. MAX Müller. Translated by Oscar A. Fechter, Mayor of North Jakima, U.S.A. With a Preface by J. EstLIN CARPENTER.

CHIPS FROM A GERMAN WORKSHOP. Vol. IV. Essays on Mythology and Folklore. Crown 8vo., 5s. .

THE SIX SYSTEMS OF INDIAN PHILOSOPHY. 8vo., I8s.

Contributions to THE SCIENCE OF $M Y T H O L O G Y .2$ vols. 8 vo., 32 s.

THE ORIGIN AND GROWTH OF RELIGION, as illustrated by the Religions of India. The Hibbert Lectures, delivered at the Chapter House, Westminster Abbey, in 1878 . Crown 8vo., $5 s$. 


\section{The Science of Religion, \&e.-continued.}

Max Müller (The Right Hon. F.)continued.

INTRODUCTION TO THE SCIENCE OF RELIGION: Four Lectures delivered at the Royal Institution. Crown 8vo., 5 s.

NATURAL RELIGION. The Gifford Lectures, delivered before the University of Glasgow in $\mathrm{I} 888$. Crown 8vo., 5 s.

Physical Religion. The Gifford Lectures, delivered before the University of Glasgow in 1890. Crown 8vo., 5 s.

Anthropological Religion. The Gifford Lectures, delivered before the University of Glasgow in I891. Cr. 8vo., $5^{5}$.

Theosophy, oR Psychological RELIGION. The Gifford Lectures, delivered before the University of Glasgow in 1892 . Crown 8 vo., $5 s$.
Max Müller (The Right Hon. F.)continued.

THREE LECTURES ON THE VEDÂNTA PHILOSOPHY, delivered at the Royal Institution in March, I894. Cr. 8vo., 5 s. LAST ESSAYS. Second SeriesEssays on the Science of Religion. Crown 8vo., 5 s.

Oakesmith. - THE RELIGION OF PLUTARCH: a Pagan Creed of Apostolic Times. An Essay. By John OAkesmith, D,Litt., M.A. Crown 8vo., 5s. net.

Wood-Martin (W. G.).

TRACES OF THE ELDER FAITHS OF

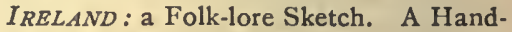
book of Irish Pre-Christian Traditions. With I92 Illustrations, 2 vols. 8vo., 3os. net.

PAGAN IRELAND: an Archæological Sketch. A Handbook of Irish PreChristian Antiquities. With 512 Illustrations. 8vo., I5s.

\section{Classical Literature, Translations, \&c.}

Abbott.-HELLENICA. A Collection of Essays on Greek Poetry, Philosophy, History, and Religion. Edited by EvELYN Aввотт, M.A., LL.D. Crown 8vo., 7s. $6 d$.

Aschylus.-EUMENIDES OF ASCHYLUS. With Metrical English Translation. By J. F. Davies. 8vo., $7 s$.

Aristophanes. - THE ACHARNIANS OF ARISTOPHANES, translated into English Verse. By R. Y. TYRRELL. Crown 8vo., Is.

Becker (W. A.), Translated by the Rev. F, Metcalfe, B.D.

GALLUS: or, Roman Scenes in the Time of Augustus. With Notes and Excursuses. With 26 Illustrations. Crown 8vo., 3s. $6 d$.

CHARICLES: or, Illustrations of the Private Life of the Ancient Greeks. With Notes and Excursuses. With 26 Illustrations. Crown 8vo., 3s. $6 d$.

Campbell.-RELIGION IN GREEK LITERATURE. By the Rev. LEwIS CAMPBELL, M.A., LL.D., Emeritus Professor of Greek, University of St. Andrews. 8vo., 15 s.

Cicero.-CiCERo's CORRESPONDENCE. BY R. Y. TYRRELL. Vols. I., II., III., 8vo., each I2s. Vol. IV., I5s. Vol. V., I4s. Vol. VI., I2s. Vol. VII. Index, 75. $6 d$.
Harvard Studies in Classical Philology. Edited by a Committee of the Classical Instructors of Harvard University. Vols. XI., I900 ; XII., I90I ; XIII., I902. 8 vo., 6s. 6d. net each.

Hime.-LUCIAN, THE SYRIAN SATIRIST. By Lieut.-Col. HenRy W. L. Hime, (late) Royal Artillery. 8vo., 5s, net.

Homer. - THE ODYSSEY OF HOMER. Done into English Verse. By William MORRIs. Crown 8 vo., 5s, net.

Horace.-THE WORKS OF HORACE, RENDERED INTO ENGLISH PROSE. With Life, Introduction and Notes. By William Coutrs, M.A. Crown 8vo., 5s. net.

Lang.-HOMER AND THE EPIC. By ANDREW LANG. Crown 8vo., 9s. net.

Lucian. - TRANSLATIONS FROM Lucian. By Augusta M. Campbell Davidson, M.A. Edin. Crown 8vo., 5s. net.

Ogilvie.-HORAE LATINAE : Studies in Synonyms and Syntax. By the late Robert Ogilvie, M.A., LL.D., H.M. Chief Inspector of Schools for Scotland. Edited by Alexander Souter, M.A. With a Memoir by Joseph OgILvie, M.A., LL.D. 8 vo., I2s. $\bar{\delta} d$. net. 


\section{Classical Literature, Translations, \&c.-continued.}

Rich.-A DictionaRY OF ROMAN AND GREEK ANTIQUTTIES. By A. Rich, B.A. With 2000 Woodcuts. Crown 8 vo., 6s. net.

Sophocles. - Translated into English Verse. By Robert Whitelaw, M.A., Assistant Master in Rugby School. Cr. 8vo., 8 s. $6 d$.

Theophrastus. - THE CHARACTERS OF THEOPHRASTUS: a Translation, with Introduction. By Charles E. BennetT and William A. Hammond, Professors in Cornell University. Fcp. 8vo., 2s. 6d. net.

Tyrrell. - DUBLIN TRANSLATIONS INTO GREEK AND LATIN VERSE. Edited by R. Y. TYRRELL. 8vo., $6 s$.

\section{Virgil.}

The POEMS of VIRGIL. Translated into English Prose by John Conington. Crown 8vo., 6s.
Virgil-continued.

THE $E_{N E I D}$ OF VIRGIL. Translated into English Verse by JoHn Conington. Crown 8vo., 6s.

THE ENEIDS OF VIRGIL. Done into English Verse. By William Morris. Crown 8vo., 5s. net.

THE AENEID OF VIRGIL, freely translated into English Blank Verse. By W. J. Thornhill. Crown 8 vo., 6 s. net.

THE AENEID OF VIRGIL. Translated into English Verse by James Rhoades. Books I.-VI. Crown 8vo., 5 s. Books VII.-XII. Crown 8vo., 5 s.

The Eclogues and Georgics of VIRGIL. Translated into English Prose by J. W. MackaIL, Fellow of Balliol College, Oxford. I6mo., 5 s.

Wilkins.-THE GROWTH OF THE Homeric Poems. By G. Wilkins. 8vo.,6s.

\section{Poetry and the Drama.}

Arnold.-THE LIGHT OF THE WORLD: or, The Great Consummation. By Sir EDWIN ARNOLD. With I4 Illustrations after Holman Hunt. Crown 8vo., 5s. net.

Bell (Mrs. Hugh).

CHAMBER COMEDIES: a Collection of Plays and Monologues for the Drawing Room. Crown 8 vo., 5s. net.

FaIRY TaLE Plays, and How to ACT THEM. With 9I Diagrams and 52 Illustrations. Crown 8vo., 3s. net.

RUMPELSTILTZKIN : a Fairy Play in Five Scenes (Characters, 7 Male; I Female). From 'Fairy Tale Plays and How to Act Them'. With Illustrations, Diagrams and Music. Cr. 8 vo., sewed, $6 d$.

Bird.-RONALD'S FAREWELL, and other Verses. By Grorge Bird, M.A., Vicar of Bradwell, Derbyshire. Fcp. 8vo., 4 s. $6 d$. net.
Cochrane.-COLLECTED VERSES. By Alfred Cochrane, Author of 'The Kestrel's Nest, and other Verses,' 'I Leviore Plectro,' etc. With a Frontispiece by $\mathrm{H}$. J. FORD. Fcp. 8vo., 5s. net.

Dabney.-THE MUSICAL BASIS ON VERSE: a Scientific Study of the P'rinciples of Poetic Composition. By J. P. DaBney. Crown 8vo., 6s. 6d. net.

Graves. - CLYTAEMNESTRA : A TRAGEDY. By ArNold F. Graves. With a Preface by RoBert Y. Tyrrell, Litt.D. Crown 8vo., 5 s. net.

Hither and Thither: Songs and Verses. By the Author of 'Times and Days,' etc. Fcp. 8vo., 5 s.

\section{Ingelow (JEAN).}

POETICAL WORKS. Complete in One Volume. Crown 8vo., gilt top, 6s. net.

LYRICAL AND OTHER POEMS. Selected from the W'ritings of JEAN INGELOW. Fcp. 8vo., 2s. 6d. cloth plain, 3s. cloth gilt. 


\section{Poetry and the Drama-continued.}

Keary.-THE BROTHERS: a Fairy Masque. By C. F. Keary. Cr. 8 vo., 45 . net.

\section{Lang (ANDREW).}

Grass of Parnassus. Fcp. 8vo., 2s. $6 d$. net.

The Blue Poetry BOok. Edited by ANDRE W LANG. With IOo Illustrations. Crown 8 vo., gilt edges, $6 s$.

Lecky.-PoEMs. By the Right Hon. W. E. H. Lecky. Fcp. 8vo., 5s.

\section{Lytton (The Earl of), (OwEN MEREDITH).}

THE WANDERER. Cr. 8vo., ios. $6 d$.

LUCile. Crown 8vo., ios. 6 d.

Selected Poems. Cr. 8vo., ios. $6 d$.

Macaulay.-LAYS OF ANCIENT ROME, WITH 'IVRY' AND 'THE ARMADA'. By' Lord Macaulay.

Illustrated by G. Scharf. Fcp. 4to., 1os. $6 d$. 18mo., 2s. 6d. gilt top. Bijou Edition.

Fcp. 4to., 6d. sewed, Is. cloth.

Illustrated by J. R. Weguelin. Crown 8vo., 35. net.

Annotated Edition. Fcp. 8vo., 1s. sewed, Is. $6 d$. cloth.

MacDonald. - $A$ BOOK OF STRIFE, IN THE FORM OF THE DIARY OF AN OLD Soul: Poems. By George MacDonald, LL.D. $18 \mathrm{mo}$., 6 s.

\section{Morris (William).}

POETICAL WORKS-LIBRARY EDITION. Complete in II volumes. Crown 8vo., price 5s. net each.

The EARThLY PARADISE. 4 vols. Crown 8vo., 5s. net each.

THE LIFE AND DEATH OF JASON. Crown 8 vo., 5s. net.

THE DEFENCE OF GUENEVERE, and other Poems. Crown 8vo., 5s. net.

THE StoR Y OF SIGURD THE VOLSUNG, AND THE FALL OF THE NIBLUNGS. Cr. Svo., 5s. net.
Morris (William)-continued.

POEMS bY THE WAY, AND LOVE IS ENOUGH. Crown 8vo., 5s. net.

THE ODYSSEY OF HOMER. Done into English Verse. Crown 8vo., 5s. net.

THE ENEIDS OF VIRGIL. Done into English Verse. Crown 8vo., 55. net.

THE TALE OF BEOWULF, SOMETIME KING OF THE FOLK OF THE WEDERGEATS. Translated by WILLIAM MORRIS and A. J. Wyatr. Crown 8vo., 5s. net.

Certain of the Poetrical Works may also be had in the following. Editions :-

THE EARTHLY PARADISE.

Popular Edition. 5 vols. I2mo., 25s.; or 5s. each, sold separately.

The same in Ten Parts, 25s.; or 25. 6d. each, sold separately.

Cheap Edition, in I vol. Crown 8vo., 6s. net.

POEMS BY THE WAY. Square crown 8vo., $6 s$.

THE DEFENCE OF GUENEVERE, and Other Poems. Cheaper Impression. Fcp. 8vo., Is. 6d. net.

* * For Mr. William Morris's other Works, see pp. 27, 28, 37 and 40.

Mors et Victoria. Cr. 8vo., 5s, net. ** This is a drama in three acts, the scene of which is laid in France shortly after the massacre of St. Bartholomew.

Morte Arthur: an Alliterative Poem of the Fourteenth Century. Edited from the Thornton MS., with Introduction, Notes and Glossary. By Mary Macleod Banks. Fcp. 8vo., 35. 6d.

Nesbit.-LAYS AND LEGENDS. By E. Nesbit (Mrs. Hubert Bland). First Series. Crown 8vo., 3s. 6d. Second Series. With Portrait. Crown 8vo., 5 s.

Ramal.-SONGS OF CHILDHOOD. By Walter Ramal. With a Frontispiece from a Drawing by Richard Doyle. Fcp. 8vo., 3s. 6d. net.

Riley. - OLD FASHIONED ROSES: Poems. By James Whitcomb Riley. I2mo., gilt top, 5 s.

Romanes.-A SELECTION FROM THE POEMS OF GEORGE FOHN R'OMANES, M.A., LL.D., F.R.S. With an Introduction by T. Herbert Warren, President of Magdalen College, Oxford. Crown 8vo., 4s. $6 d$. 


\section{Poetry and the Drama-continued.}

Savage-Armstrong.-BALLADS OF DoWN. By G. F. Savage-Armstrong, M.A., D.Litt. Crown 8vo., 7s. $6 d$.

\section{Shakespeare.}

BOWDLER'S FAMILY SHAKESPEARE. With 36 Woodcuts. I vol. 8 vo., I4s. Or in 6 vols. Fep. 8 vo., 2 Is.

THESHAKESPEARE BIRTHDAY BOOK. By Mary F. Dunbar. 32mo., is. $6 d$.

Stevenson.- $A$ CHILD'S GARDEN OF VERSES. By Robert Louis StEvenson. Fcp. 8vo., gilt top, 5 s.
Trevelyan.-CECILIA GONZAGA : a Drama. By R. C. Trevelyan. Fep. 8 vo., 2s. $6 d$. net.

Wagner.-THE NIBELUNGEN RING. Done into English Verse by REgINald RANKIN, B.A., of the Inner Temple, Barrister-at-Law.

Vol. I. Rhine Gold, The Valkyrie. Fcp. 8 vo., gilt top, 4 s. $6 d$.

.Vol. II. Siegfried, The Twilight of the Gods. Fcp. 8 vo., gilt top, $4^{s} .6 d$.

\section{Fiction, Humour, \&e.}

Anstey (F.).

VOCES POPULI. (Reprinted from 'Punch'.)

First Series. With 20 Illustrations by J. Bernard Partridge. Cr. 8vo., gilt top, 3s. net.

Second Series. With 25 Illustrations by J. Bernard Partridge. Cr. 8vo., gilt top, 3s. net.

THE MAN FROM BLANKLEY'S, and other Sketches. (Reprinted from ' Punch'.) With 25 Illustrations by J. BERNARD Partridge. Cr. 8vo., gilt top, 3s. net.

Bailey (H. C.).

MY LADY OF ORANGE: a Romance of the Netherlands in the Days of Alva. With 8 Illustrations. Crown 8vo., $6 \mathrm{~s}$.

KARL OF $E_{R B A C H}$ : a Tale of the Thirty Years' War. Crown 8vo., 6s.

\section{Beaconsfield (The Earl of).}

NOVELS AND TALES. Complete in II vols. Crown Svo., Is. $6 d$. each, or in sets, I I vols., gilt top, I5s, net.

Vivian Grey. $\quad$ Contarini Fleming ;

The Young Duke; The Rise of IskanCount Alarcos: a der.

Tragedy.

Alroy ; Ixion in Henrietta Temple. Heaven; The In. Venetia. fernal Marriage; Coningsby. Popanilla.

Tancred.

Lothair.

Endymion.

NOVELS AND TALES. THE HUGHENDEN EDITION. With 2 Portraits and II Vignettes. I I vols. Crown 8vo., 425 .
Bottome.-LIFE, TIIE INTERPRETER. By Phyllis Bottome. Crown 8vo., 6s.

Churchill.-SAVRoLA : a Tale of the Revolution in Laurania. By Winston Spencer Churchill, M.P. Cr. 8vo., $6 s$.

Crawford.-THE AUTUBIOGRAPHY OF a Tramp. By J. H. Crawford. With a Photogravure Frontispiece 'The Vagrants,' by FRED. WALKER, and 8 other Illustrations. Crown 8vo., 5s. net.

Creed.-THE VICAR OF ST. LUKE'S. By Sibyl Creed. Crown 8vo., $6 s$.

Davenport.-BY THE RAMPARTS OF FEZREEL : a Romance of Jehu, King of Israel. By ARNOLD DAVENPORT. With Frontispiece by Lancelot Speed. Crown 8vo., 6 s.

Dougall.-BEGGARS ALL. By L. Dougall. Crown 8vo., 3s. $6 d$.

Doyle (Sir A. Conan).

MICAH CLARKE: A Tale of Monmouth's Rebellion. With ro Illustrations. Cr. 8 vo., 3s. $6 d$.

THE REFugEes: A Tale of the Huguenots. With 25 Illustrations. Cr. 8vo., 3s. $6 d$.

The Stark Munro letters. Cr. 8vo., 3s. $6 d$.

The Captain of the Polestar, and other Tales. Cr. 8vo., 3s. $6 d$. 


\section{Fiction, Humour, \&e.-continued.}

Dyson.-THE GOLD-STEALERS: a Story of Waddy. By EDward Dyson, Author of 'Rhymes from the Mines,' etc. Crown 8vo., $6 s$.

Farrar (F. W., late DEAN of CANTERBURY).

DARKNESS AND DAWN: or, Scenes in the Days of Nero. An Historic Tale. Cr. 8 vo., gilt top, $6 s$, net.

GATHERING Clouds: a Tale of the Days of St. Chrysostom. Cr. 8vo., gilt top, 6s. net.

\section{Fowler (Edith H.).}

THE Young PRETENDERs. A Story of Child Life. With 12 Illustrations by Sir Philip Burne-Jones, Bart. Crown 8 vo., $6 s$.

THE PROfEssoR's CHILDREN. With 24 Illustrations by ETHEL Kate Burgess. Crown 8vo., $6 s$.

\section{Francis (M. E.).}

FIANDER's WIDOW. Cr. 8vo., $6 \mathrm{~s}$.

YEOMAN FLEETWOOD. With Frontispiece. Crown 8vo., 3s. net.

Pastorals of Dorset. With 8 Illustrations. Crown 8vo., $6 s$.

THE MANOR FARM. With Frontispiece by Claud C. DU Pré Cooper. Crown 8vo., 6s.

Froude.-THE TWO CHIEFS OF DUNBOY: an Irish Romance of the Last Century. By James A. Froude. Cr. 8vo., 3s. $6 d$.

\section{Haggard (H. k'IDER).}

Allan Quatermain. With 3I Illustrations. Crown 8vo., 3s. $6 d$.

ALLAN'S WIFE. With 34 Illustrations. Crown 8vo., 3s. $6 d$.
Haggard (H. RIDER)-continued.

BEATRICE. With Frontispiece and Vignette. Crown 8vo., 35. $6 d$.

BLACK HEART AND WHITE HEART, AND OTHER STORIES. With 33 Illustrations. Crown 8vo., 3s. 6d.

CLEOPATRA. With 29 Illustrations. Crown 8vo., 3s. $6 d$.

Colonel Quaritch, V.C. With Frontispiece and Vignette. Cr. 8vo., 3s. 6d.

$D_{A W N}$. With 16 Illustrations. $\mathrm{Cr}$. 8vo., 3s. $6 d$.

DR. THERNE. Crown 8vo., 3s. $6 d$.

ERIC BRIGHTEYES. With 5I Illustrations. Crown 8vo., 3s. $6 d$.

HEART OF THE WORLD. With I5 Illustrations. Crown 8vo., 3s. $6 d$.

JOAN HASTE. With 20 Illustrations. Crown 8vo., 3s. $6 d$.

LYSBETH. With 26 Illustrations. Crown 8vo., 6s.

MAIWA's REVENGE. Cr. 8vo., is. $6 d$. MONTEZUMA'S DAUGHTER. With 24 Illustrations. Crown 8vo., 3s. $6 d$.

MR. MEESON'S WILL. With I6 Illustrations. Crown 8vo., 3s. $6 d$.

NADA THE LILY. With 23 Illustrations. Crown 8vo., 3s. 6d.

PEARL-MAIDEN : a Tale of the Fall of Jerusalem. With 16 Illustrations. Crown 8vo., $6 s$.

SHE. With 32 Illustrations. Crown 8vo., 3s. $6 d$.

SWALLOW : a Tale of the Great Trek. With 8 Illustrations. Crown 8vo., $3^{s .} 6 d$.

THE PEOPLE of THE Mist. With r6 Illustrations. Crown 8vo., 3s. $6 d$.

THE WITCH'S HEAD. With I6 Illustrations. Crown 8vo., 3s. $6 d$. 


\section{Fiction, Humour, \&e.-continued.}

Haggard and Lang. - THEWORLD's DESIRE. By H. RIDER HAGGARD and ANDREW LANG. With 27 Illustrations. Crown 8vo., 3s. $6 d$.

Harte. - IN THE CARQUINEZ WOODS. By Bret Harte. Crown 8vo., 3s. $6 d$,

Hope.-THE HEART OF PRINCESS OSRA. By ANThony Hope. With 9 Illustrations. Crown 8vo., 3s. $6 d$.

Howard.-THE FAILURE OF SUCCESS. By Lady Mabel Howard. Crown 8vo., $6 s$.

Hutchinson.- $A$ FRIEND OF NELSON. By Horace G. Hutchinson. Cr. 8vo., $6 s$.

Jerome.-SKETCHES IN LAVENDER: BLUE AND GREEN. BY JeRome K. Jerome, Author of 'Three Men in a Boat,' etc. Crown 8vo., 3s. $6 d$.

Joyce.-OLD CELTIC ROMANCES. 'Twelve of the most beautiful of the Ancient Irish Romantic Tales. Translated from the Gaelic. By P. W. JoycE, LL.D. Crown 8vo., 3s. 6d.

\section{Lang (ANDREW).}

$A$ MONK OF FIFE; a Story of the Days of Joan of Arc. With I3 Illustrations by Selwyn Image. Crown 8vo., 3s. $6 d$.

THE DISENTANGLERS. With 7 Full-page Illustrations by H. J. ForD. Crown 8vo., $6 s$.

\section{Lyall (EDNA).}

THE HINDERERS. Crown 8vo., 2s. $6 d$.

THE AUtobiography of a SLANDER. Fcp. 8vo., Is. sewed.

Presentation Edition. With 20 Illustra. tions by Lancelot Speed. Crown 8 vo., $2 s .6 d$. net.

DOREEN. The Story of a Singer. Crown 8vo., $6 s$.

WAYFARING MEN. Crown 8vo., 6s. HOPE THE HERMIT: a Romance of Borrowdale. Crown 8vo., $6 s$.
Marchmont. - IN THE NAME OF A WOMAN: a Romance. By ARTHUR W. Marchmont. With 8 Illustrations. Crown 8 vo., $6 s$.

Mason and Lang. - PARSON KELLY. By A. E. W. MASON and ANDREW LANG. Crown 8 vo., 3 s. $6 d$.

Max Müller. - DEUTSCHE LIEBE (GERMAN LOVE): Fragments from the Papers of an Alien. Collected by F. MAX MỨLLER. Translated from the German by G. A. M. Crown 8vo., gilt top, 5 s.

\section{Melville (G. J. Whyte).}

The Gladiators.

The Interpreter.

Good for Nothing.

Holmby House.

Kate Coventry.

The Queen's Maries. General Bounce.

Crown 8vo., is. 6d. each.

Merriman.-FLoTSAM : A Story of the Indian Mutiny. By Henry Seton MERriman. With Frontispiece and Vignette by H. G. Massey. Cr. 8vo., 3s. $6 d$.

\section{Morris (William).}

THE SUNDERING Fliood. Cr. 8vo., 7s. $6 d$.

THE WATER OF THE WONDROUS ISLES. Crown 8vo., $7 s, 6 d$.

THE WELL AT THE WORLD'S END. 2 vols. 8 vo., 28 s.

THE WOOD BEYOND THE WORLD. Crown 8vo., 6s. net.

THE STORY OF THE GLITTERING PLAIN, which has been also called The Land of the Living Men, or The Acre of the Undying. Square post 8 vo., 5s. net.

THE Roots of the MOUNTAINS, wheren is told somewhat of the Lives of the Men of Burgdale, their Friends, their Neighbours, their Foemen, and their Fellows-in-Arms. Written in Prose and Verse, Square crown 8 vo., 8 s. 


\section{Fietion, Humour, \&c.-continued.}

\section{Morris (William)-continued.}

A TALE OF tHE HOUSE OF THE WOLFINGS, and all the Kindreds of the Mark. Written in Prose and Verse. Square crown 8vo., $6 s$.

A DREAM OF JOHN BALL, AND A KING'S LESSON. I6mo., 2s. net.

NEWS FROM NOWHERE; or, An Epoch of Rest. Being some Chapters from an Utopian Romance. Post 8vo., Is. $6 d$.

THE StOR Y OF GRETTIR THE STRONG. Translated from the Icelandic by EIRikR Magnússon and William MorRis. Cr. 8 vo., 5s. net.

THREE NORTHERN LOVE STORIES, AND OTHER T ALES. Translated from the Icelandic by EIRÍKR MAGNÚSSON and William Morris. Crown 8vo., 6s. net.

* For Mr. William Morris's other Works, see pp. 24, 37 and 40.

Newman (Cardinal).

LosS AND GAIN : The Story of a Convert. Crown 8vo., 3s. $6 d$.

CALLISTA: A Tale of the Third Century. Crown 8 vo., 3 s. $6 d$.

Phillipps-Wolley.-SNAP: a Legend of the Lone Mountain. By C. PHILlippsWolley. With I3 Illustrations. Crown 8 vo., 3 s. $6 d$.

Portman.-STATion StUdies : being the Jottings of an African Official. By Lionel Portman. Crown 8vo., 5s. net.

\section{Sewell (Elizabeth M.).}

A Glimpse of the World. Laneton Parsonage. Margaret Percival.

Katharine Ashton.

The Earl's Daughter.

The Experience of Life. Ursula. Ivors.

Cr. 8vo., cloth plain, Is. $6 d$. each. Cloth extra, gilt edges, 2s. $6 d$. each.
Sheehan. - LUKE DELMEGE. By the Rev. P. A. ShenhaN, P.P., Author of 'My New Curate'. Crown 8vo., $6 s$.

\section{Somerville (E. E.) and Ross \\ (MARTIN).}

SOME EXPERIENCES OF AN IRISH R.M. With 3 I Illustrations by E. CE. Somerville. Crown 8vo., $6 s$.

ALL ON THE IRISH SHORE: Irish Sketches. With Io Illustrations by $\mathrm{E}$. (E. Somerville. Crown 8vo., $6 s$.

The Real Charlotte. Crown 8 vo., 3s. $6 d$.

THE SILVER FoX. Cr. 8vo., 3s. ód. An IRISH Cousin. Crown Svo., $6 s$.

Stebbing.-RACHEL WULFSTAN, and other Stories. By W. STEBbing, author of 'Probable Tales'. Crown 8vo., 4s. 6d.

Stevenson (Robert Louis).

The Strange CASE of DR. JenYll AND MR. HYDE. Fcp. 8vo., Is. sewed. Is. $6 d$. cloth.

THE Strange Case OF DR. FEKYLL AND MR. HYDE; WITH OTHER FABLES. Crown 8 vo., bound in buckram, with gilt top, 5s. net.

'Silver Library' Edition. Crown 8vo., 3s. $6 d$.

MORE NEW ARABIAN NIGHTS-THE DYNAMITER. BY ROBERT LOUIS STEVENson and Fanny van de Grift Stevenson. Crown 8 vo., 3 s. $6 d$.

THE WRONG BOX. By RoBert Louis Stevenson and Lloyd Osbourne. Crown 8vo., 3s. $6 d$. 


\section{Fiction, Humour, \&e.-continued.}

Suttner.-LAY DOWN YOUR ARMS (Die Waffen Nieder): The Autobiography of Martha von Tilling. By BERTHA VoN Suttner. Translated by T. Holmes. Cr. 8vo., Is. 6 d.

\section{Trollope (ANTHONY).}

THE WARDEN. Cr. 8vo., is. 6 d.

BARCHESTER TOWERs. Cr.8vo., Is.6d.

Walford (L. B.).

Stay-at-Homes. Crown 8vo., $6 s$.

Charlotte. Crown 8vo., $6 s$.

ONE OF OuRselves. Cr. 8vo., $6 \mathrm{s.}$

THE INTRUDERS. Crown 8vo., 2s. $6 d$.

LEDDY MARGET. Crown 8vo., 2s.6d.

IVA KILDARE : a Matrimonial Problem. Crown 8vo., 2s. $6 d$.

Mr. Smith: a Part of his Life. Crown 8vo., 2s. $6 d$.

THE BABY'S GRANDMOTHER. Cr. 8 vo., 2s. $6 d$.

Cousins. Crown 8vo., 2s. $6 d$.

TROUBLESOME DAUGHTERS. 8vo., 2s. $6 d$.

PAULINE. Crown 8vo., 2s. $6 d$.

DICK NETHERBY. Cr. 8vo., 2s. $6 d$. THE History OF A WEEK. Cr. 8vo. 2s. $6 d$.

A Stiff-NeCKED Generation. Cr. 8vo. 2s. $6 d$.

$N_{A N}$, and other Stories. Cr. 8vo., 2s. $6 d$.
Walford (L. B.)-continued.

The Mischief of Monica. Cr. 8vo., 2s. $6 d$.

The ONE Good Guest. Cr. 8vo. 2s. $6 d$.

'PLOUGHED,' and other Stories. Crown 8vo., 2s. $6 d$.

THE MATCHMAKER. Cr. 8vo., 2s. $6 d$.

Ward.-ONE POOR SCRUPLE. By Mrs. Wilfrid Ward. Crown 8vo., 6s.

\section{Weyman (Stanley).}

THE HOUSE OF THE WOLF. With Frontispiece and Vignette. Crown 8vo., 35. $6 d$.

A Gentleman of France. With Frontispiece and Vignette. Cr. 8vo., $6 s$.

THE RED COCKADE. With Frontispiece and Vignette. Crown 8vo., 6s.

SHREWSBURY. With 24 Illustrations by Cr.aude A. Shepperson. Cr. 8 vo., $6 s$.

SopHIA. With Frontispiece. Crown 8 vo., 6s.

Yeats (S. LevetT).

The ChEVALIER D'AURIAC. Crown 8vo., 3s. $6 d$.

THE TRAITOR'S WAY. Cr. 8vo., 6s.

Yoxall.-The Rommany Stone. By J. H. Yoxall, M.P. Crown 8vo., $6 s$. 


\section{Popular Science (Natural History, \&c.).}

\section{Furneaux (W.).}

\section{THE OUTDOOR WORLD; or The} Young Collector's Handbook. With I8 Plates ( 16 of which are coloured), and 549 Illustrations in the Text. Crown 8vo., gilt edges, 6 s. net.

BUTTERFLIES AND MOTHS (British). With 12 coloured Plates and 241 Illustrations in the Text. Crown 8vo., gilt edges, $6 s$. net.

LIFE IN PONDS AND STREAMS. With 8 coloured Plates and 331 Illustrations in the Text. Crown 8vo., gilt edges, $6 s$. net.

\section{Hartwig (GEORGE).}

THE SEA AND ITS LIVING WONDERS. With I 2 Plates and 303 Woodcuts. 8vo., gilt top, 7s. net.

\section{THE TROPICAL WORLD.} Plates and $\mathrm{I}_{72}$ Woodcuts. top, 7 s. net.

THE POLAR WORLD. With 3 Maps, 8 Plates and 85 Woodcuts. 8vo., gilt top, 7 s. net.

THE SUBTERRANEAN WORLD. With 3 Maps and 80 Woodcuts. 8vo., gilt top, 7s. net.

Helmholtz. - POPULAR LECTURES ON SCIENTIFIC SUBJECTS. By HERMANN voN HeLmholtz. With 68 Woodcuts. 2 vols. Cr. 8 vo., 3 s. $6 d$. each.

Hoffmann.-ALPINE FLORA: For Tourists and Amateur Botanists. With Text descriptive of the most widely distributed and attractive Alpine Plants. By Julius Hofrmans. Translated by E. S. Barton (Mrs. A. Gepp). With 40 Plates containing 250 Coloured Figures from Water-Colour Sketches by HERMANN Friese. 8vo., 7s. $6 d$. net.
Hudson (W. H.).

HAMPSHIRE DAYS. With II Plates and 36 Illustrations in the Text from Drawings by BRYAN HooK, etc. 8vo., Ios. $6 d$. net.

BIRDS AND MAN. Large crown 8vo., 6s. net.

NATURE IN DOWNLAND. With I2 Plates and $I_{4}$ Illustrations in the Text by A. D. McCormick. 8vo., ios. $6 d$. net.

BRITISH BIRDS. With a Chapter on Structure and Classification by FRANK E. BEDdard, F.R.S. With I6 Plates (8 of which are Coloured), and over Ioo Illustrations in the Text. Crown 8vo., gilt edges, $6 s$. net.

Millais. - THE NATURAL HISTORY OF THE BRITISH SURFACE FEEDING-DUCKS. By Јohn Guille Millais, F.Z.S., etc. With 6 Photogravures and 66 Plates $(4 \mathrm{I}$ in Colours) from Drawings by the Author, Archibald Thorburn, and from Photographs. Royal 4to., $£^{6} 6 s$.

\section{Proctor (RICHARD A.).}

LIGHT SCIENCE FOR LEISUR E HOURS. Familiar Essays on Scientific Subjects. Crown 8vo., 3s. $6 d$.

Rovgh Ways made Smooth. Familiar Essays on Scientific Subjects. Crown 8 vo., 3s. $6 d$.

PLEASANT WAyS IN SCIENCE. Crown 8vo., 3s. $6 d$.

Nature Studies. By R. A. Proctor, Grant Allen, A. Wilson, T. Foster and E. Clodd. Cr. 8vo., 3s. $6 d$.

Leisure Readings. By R. A. ProcTOR, E. Clodd, A. Wilson, T. Foster and A. C. Ranyard. Cr. 8vo., 3s. $6 d$.

* * For Mr. Proctor's other books see pp. 16 and 35 , and Messrs. Longmans \&o Co.'s Catalogue of Scientific Works. 


\section{Popular Science (Natural History, \&c.)-continued.}

Stanley. - A FAMILIAR HISTORY OF BIRDS. By E. STANLEY, D.D., formerly Bishop of Norwich. With 160 Illustrations. Cr. 8vo., 3s. $6 d$.

Wood (Rev. J. G.).

HOMES WITHOUT HANDS: A Description of the Habitations of Animals, classed according to their Principle of Construc. tion. With I $^{\circ}$ Illustrations. 8vo., gilt top, 7 s. net.

Insects at Home : A Popular Account of British Insects, their Structure, Habits and Transformations. With 700 lllustrations. 8 vo., gilt top, 7 s. net.
Wood (Rev. J. G.)-continued.

INSECTS ABROAD: A Popular Account of Foreign Insects, their Structure, Habits and Transformations. With 600 Illustrations. 8vo., 7s. net.

OUT OF DOORS; a Selection of Original Articles on Practical Natural History. With II Illustrations. Cr. 8 vo., 3s. $6 d$.

Petland Revisited. With 33 Illustrations. Cr. 8vo., 3s. $6 d$.

STRANGE DWELLINGS : a Description of the Habitations of Animals, abridged from 'Homes without Hands'. With 60 Illustrations. Cr. 8vo., 3s. $6 d$.

\section{Works of Reference.}

Gwilt.-AN ENCYCLOPAEDIA OF ARCHITBCTURE. By JosepH GWILT, F.S.A. With 1700 Engravings. Revised (1888), with Alterations and Considerable Additions by WyatT PAPWORTH. 8vo., 2 Is. net.

\section{Longmans' GAZETTEER OF THE} WORLD. Edited by GEORGE G. CHISноцм, M.A., B.Sc. Imperial 8vo., I8s, net cloth ; 2 Is. half-morocco.

\section{Maunder (Samuel).}

BIOGRAPHICAL TREASURY. With Supplement brought down to 1889 . By Rev. James Wood. Fcp. 8vo., $6 s$.

THE TREASURY OF BIBLE KNOWLEDGE. By the Rev. J. AYRE, M.A. With 5 Maps, 15 Plates, and 300 Woodcuts. Fcp. 8vo., 6s.

TREASURY OF KNOWLEDGE AND LIBRARY OF REFERENCE. Fcp. 8vo., 6s.
Maunder (Samuel)—continued.

THE TREASURY OF BOTANY. Edited by J. LindLey, F.R.S., and T. Moore, F.L.S. With 274 Woodcuts and 20 Steel Plates. 2 vols. Fcp. 8vo., I2s.

Roget. - THESAURUS OF ENGLISH WORDS AND PHRASES. Classified and Arranged so as to Facilitate the Expression of Ideas and assist in Literary Composition. By Peter Mark Roget, M.D., F.R.S. Recomposed throughout, enlarged and improved, partly from the Author's Notes, and with a full Index, by the Author's Son, John Lewis Roget. Crown 8vo., gs. net.

Willich.--POPULAR TABLES for giving information for ascertaining the value of Lifehold, Leasehold, and Church Property, the Public Funds, etc. By Charles M. Willich. Edited by H. Bence Jones. Crown 8vo., Ios. $6 d$. 


\section{Children's Books.}

Adelborg.-CLEAN PETER AND THE CHILDREN OF GRUBBYLEA. By OtTILIA Adelborg. Translated from the Swedish by Mrs. Graham Wallas. With 23 Coloured Plates. Oblong 4to., boards, 3s. $6 d$. net.

Alick's Adventures. - By G. R. With 8 Illustrations by JoHN Hassall. Crown 8vo., 3s. $6 d$.

Brown.-THE BOOK OF SAINTS AND FRIENDLY BEASTS. By ABBIE FARWELL BRown. With 8 Illustrations by FANNY Y. Cory. Crown 8vo., 4 s. 6d. net.

Buckland.-Two LiTTLERUNAWAYS. Adapted from the French of Lours DesNOYERS. BY JAMES BuckLAND. With IIo Illustrations by Cecil Aldin. Cr. 8vo., $6 \mathrm{~s}$.

Crake (Rev. A. D.).

$E_{D W Y}$ THE $F_{A I R}$; or, The First Chronicle of Æscendune. Cr. 8 vo., silver top, 2s. net.

ALFGAR THE DANE; or, The Second Chronicle of Æscendune. Cr. 8vo., silver top, 2s. net.

THE RIVAL HEIRS : being the Third and Last Chronicle of Æssendune. $\mathrm{Cr}$. 8 vo., silver top, 2s. net.

THE House of WALDERNE. A Tale of the Cloister and the Forest in the Days of the Barons' Wars. Crown 8vo., silver top, 2s. net.

BRIAN FITZ-COUNT. A Story of Wallingford Castle and Dorchester Abbey. Cr. 8vo., silver top, 2s. net.

\section{Henty (G. A.).-Edited BY.}

YULE LOGS: A Story-Book for Boys. By Various Authors. With 6i Illustrations. Crown 8vo., gilt edges, 3 s. net.

YULE TIDE YARNS: a Story-Book for Boys. By Various Authors. With 45 Illustrations. Cr. 8vo., gilt edges, 35. net.
Lang (ANDREw).-EDited By.

THE BLUE FAIRY BOOK: With ${ }_{13} 8$ Illustrations. Crown 8vo., gilt edges, 6 s. ThE RED F FIRY BOOK. With 100 Illustrations. Crown 8vo., gilt edges, 6 s. THE GREEN FAIRY BOOK. With 99 Illustrations. Crown 8 vo., gilt edges, $6 s$. THE GREY F FIRY BOOK. With 65 Illustrations. Crown 8 vo., gilt edges, $6 s$. THE YELLOW FAIRY BOOK. With ro4 Illustrations. Cr. 8vo., gilt edges, 6 s.

THE PINK FAIRY BOOK. With 67 Illustrations. Crown 8vo., gilt edges, 6 s.

THE VIOLET F FIRY BOOK. With 8 Coloured Plates and 54 other Illustrations. Crown 8 vo., gilt edges, $6 s$.

THE BLUE POETRY BOOK. With 100 Illustrations. Crown 8vo., gilt edges, $6 \mathrm{~s}$.

THE TRUE STORY BOOK. With 66 Illustrations. Crown 8vo., gilt edges, 6s.

THE RED TRUE STORY BOOK. With roo Illustrations. Cr. 8vo., gilt edges, 6s.

THE ANImal STORY BOOK. With 67 Illustrations. Cr. 8vo., gilt edges, $6 \mathrm{~s}$.

THE RED BOOK OF ANIMAL STORIES. With 65 Illustrations. Crown 8vo., gilt edges, 6 s.

THE ARABIAN NightS ENTERTAINMENTS. With 66 Illustrations. Cr. 8 vo., gilt edges, $6 \mathrm{~s}$.

THE BOOK OF ROMANCE. With 8 Coloured Plates and 44 other Illustrations. Crown 8 vo., gilt edges, 6 s.

Lyall.-THE BURGES LETTERS: a Record of Child Life in the Sixties. By Edna Lyall. With Coloured Frontispiece and 8 other Full-page Illustrations by Walter S. Stacey. Crown 8vo., 2s. $6 d$.

Meade (L. T.).

DADDY'S BOY. With 8 Illustrations. Crown 8vo., gilt edges, 3 s. net.

DEB AND THE DUCHESS. With 7 Illustrations. Cr. 8vo., gilt edges, 3 s. net. THE BERESFORD PRIZE. With 7 Illustrations. Cr. 8 vo., gilt edges, 3 s. net. THE HOUSE OF SURPRISES. With 6 Illustrations. Cr. 8 vo., gilt edges, 3 s. net. 


\section{Children's Books-continued.}

Murray. - FLOWER LEGENDS FOR CHILDREN. By HiLda MuRRay (the Hon. Mrs. MURRAY of Elibank). Pictured by J. S. ELAND. With numerous Coloured and other Illustrations. Oblong 4 to., $6 s$.

Penrose. - CHUBBY: a NUISANCE. By Mrs. Penrose. With 8, Illustrations by G. G. Manton. Chown 8vo., 3s. $6 d$.

\section{Praeger (Rosamond).}

THE AdVENTURES OF THE ThreE BOLD BABES: HECTOR, HONORIA AND ALISANDER. A Story in Pictures. With ${ }_{24}$ Coloured Plates and 24 Outline Pictures. Oblong 4to., 3s. 6d.

THE FUR THER DoINGs of the THREE BOLD BABES. With 24 Coloured Pictures and 24 Outline Pictures. Oblong 4 to.,3s.6d.

Roberts. - THE ADVENTURES OF CAPTAIN FOHN SMITH : Captain of Two Hundred and Fifty Horse, and sometime President of Virginia. By E. P. RoBerTs. With 17 Illustrations and 3 Maps. Crown 8vo., 5s. net.

Stevenson.-A CHILD'S GARDEN OF VERSES. By Robert Louis Stevenson. Fcp. 8vo., gilt top, 5 s.

Tappan.-OLD BALLADS IN PROSE. By Eva March Tappan. With 4 Illustrations by FanNy Y. CoRy. Crown 8 vo., gilt top, 4s. $6 d$. net.

\section{Upton (Florence K. and Bertha).}

THE ADVENTURES OF TWO DUTCH DOLLS AND A 'GOLLIWOGG'. With $3^{1}$ Coloured Plates and numerous Illustra. tions in the Text. Oblong 4 to., $6 \mathrm{~s}$.

THE GolliwogG'S BICYCLE CLUB. With 31 Coloured Plates and numerous Illustrations in the Text. Oblong ${ }_{4}$ to., $6 s$.

THE Golliwogg at the SEASIDE. With 31 Coloured Plates and numerous Illustrations in the Text. Oblong ${ }_{4}$ to., $6 \mathrm{~s}$.

THE GOLLIWOGG IN WAR. With 3 I Coloured Plates. Oblong 4 to., $6 s$.

THE GolliwogG's POLAR ADVENTURES. With $3 \mathrm{I}$ Coloured Plates. Oblong 4 to., $6 \mathrm{s.}$

THE GolliwogG'S AUto-Go-CART. With 31 Coloured Plates and numerous Illustrations in the Text. Oblong 4 to., $6 s$.

THE GOLLIWOGG'S AIR-SHIP. With 3o Coloured Pictures and numerous Illustrations in the Text. Oblong 4 to., $6 s$.

THE VEGE-MEN'S REVENGE. With ${ }_{31}$ Coloured Plates and numerous Illustrations in the Text. Oblong 4 to., $6 s$.

Wemyss.-'THINGS WE THOUGHT $O F^{\prime}$ : Told from a Child's Point of View. By Mary C. E. Wemyss, Author of 'All About All of Us'. With 8 Illustrations in Colour by S. R. Praeger. Crown 8 vo, 3s. $6 d$.

\section{The Silver Library.}

\section{Crown 8vo. 35. 6d. Еach Volume.}

Aenold's ( Sir Edwin) Seas and Lands. With 7 I Illustrations. $35.6 d$.

Bagehot's (W.) Biographical Studies, 35. $6 d$.

Bagehot's (W.) Economic Studies, 3s. $6 d$.

Bagehot's (W.) Literary Studies. With Portrait. 3 vols., 3 s. $6 d$. each.

Baker's (Sir S. W.) Eight Years in Ceylon. With 6 Illustrations. 35. $6 d$.

Baker's (Sir S. W.) Rifle and Hound In Ceylon. With 6 lllustrations. $35.6 d$.

Baring-Gould's (Rey. S.) Curlous Myths of the Middle Ages. 3s. $6 d$.

Baring-Gould's (Rey. S.) Origin and Deyelopment of Rellglous Bellef. 2 vols. 3 s. $6 d$. each.

Becker's (W. A.) Gallus : or, Roman Scenes in the Time of Augustus. With 26 Illus. 35. $6 d$.
Becker's (W. A.) Charicles: or, llustrations of the Private Life of the Ancient Greeks. With 26 Illustrations. $35.6 d$.

Bent's (J. T.) The Rulned Clties of Mashonaland. With II7 Illustrations. 3s. $6 d$.

Brassey's (Lady) A Yoyage In the 'Sunbeam'. With 66 Illustrations. $35.6 d$.

Buckle's (H. T.) History of Clyllisation in England. 3 vols. Ios. $6 d$.

Churchlll's (WInston 8.) The Story of the Malakand Fleld Force, 1897. With 6 Maps and Plans. $35.6 d$.

Clodd's (E.) Story of Creation: a Plain Account of Evolution. With 77 Illustrations. 35. 6d.

Conybeare (Rey. W. J.) and Howson's (Yory Rev. J. S.) Life and Epistles of St. Paul. With 46 Illustrations. $35.6 d$.

Dougall's (L.) Begfars All : a Novel. 35. $6 d$.

Doyle's (Sir A. Conan) Micah Clarke. A Tale of Monmouth's Rebellion. With ro Illusts. $35.6 d$. 


\section{The Silver Library-continued.}

Doyle's (Sir A. Conan) The Captain of the Polestar, and other Tales. $35.6 d$.

Doyle's (Sir A. Conan) The Refugees: A Tale of the Huguenots. With 2.5 Illustrations. $356 d$.

Doyle's (Sir A. Conan) The Stark Munro Letters. 35. $6 d$.

Froude's (J. A.) The History of England, from the Fall of Wolsey to the Defeat of the Spanish Armada. 12 vols, 3s. $6 d$. each.

Froude's (J. A.) The English in Ireland. 3 vols. Ios. $6 d$.

Froude's (J. A.) The Diyorce of Catherine of Aragon. 3 s. $6 d$.

Froude's (J. A.) The Spanish Story of the Armada, and other Essays. $3 s .6 d$.

Froude's (J.A.) Engiish Seamen in the Sixteenth Century. $3 s .6 d$.

Froude's (J. A.) Short Studies on Great Subjects. 4 vols. $3 s$. 6 d. each.

Froude's (J. A.) Oceana, or England and Her Colonies. With 9 Illustrations. 3 s. $6 d$.

Froude's (J. A.) The Council of Trent. 3s. $6 d$.

Froude's (J. A.) The Life and Letters of

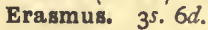

Froude's (J. A.) Thomas Carlyle: a History of his Life.

I795-1835. 2 vols. 7s. I834-I881. 2 vols. $7 s$.

Froude's (J. А.) Cæsar: a Sketch. 35. 6u.

Froude's (J. A.) The Two Chlefs of Dunboy: an Irish Romance of the Last Century. $3^{s .6 d \text {. }}$

Froude's (J. A.) Writings, Selections from.

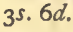

Gieig's (Rey. G. R.) Life of the Duke of Wellington. With Portrait. 3s. $6 d$.

Greville's (C. C. F.) Journal of the Reigns of KIng George IY., King William IY., and Queen Yictoria. 8 vols., $3^{s}$, $6 d$, each.

Hagfard'a (H. R.) She : A History of Adventure. With 32 Illustrations. $3^{5}$. $6 d$.

Hagfard's (H. R.) Allan Quatermain. With 20 Illustrations. 3 s. $6 d$.

Haggard's (H. R.) Colonel Quaritch, V.C. : a Tale of Country Life. With Frontispiece and Vignette. $35.6 d$.

Haggard's (H. R.);Cleopatra. With 29 Illustra. tions. $3 s .6 d$.

Haggard's (H. R.) Eric Brighteyes, With 5t Illustrations. $3 s .6 d$.
Haggard's (H. R.) Beatrice. With Frontispiece and Vignette. $35.6 d$.

Haggard's (H. R.) Black Heart and White Heart. With 33 Illustrations. $35.6 d$.

Haggard's (H. R.) Allan's Wife. With 34 Illus. trations. $35.6 d$.

Haggard (H. R.) Heart of the Worid. With I5 Illustrations. $35.6 d$.

Haggard's (H. R.) Montezuma's Daughter. With 25 Illustrations. $35.6 d$.

Hagsard's (H. R.) Swallow: a Tale of the Great Trek. With 8 Illustrations. $3 s$. $6 \mathrm{~d}$.

Haggard's (H. R.) The Witch's Head. With I6 Illustrations. $35.6 d$.

Haggard's (H. R.) Mr. Meeson's Will, With I6 Illustrations. $35.6 d$.

Haggard's (H. R.) Nada the Lily. With 23 Illustrations. $35.6 d$.

Haggard's (H. R.) Dawn. With I6 Illusts. $35.6 d$.

Haggard's $(H, R$.) The People of the Mist. With I6 Illustrations. $3^{s}$. $6 d$.

Haggard's (H. R.) Joan Haste. With 20 Illustrations. $3 s .6 d$.

Haggard (H. R.) and Lang's (A.) The World'A Desire. With 27 Illustrations, 3s. $6 d$.

Harte's (Bret) In the Carquinez Woods and other stories. $35.6 \%$.

Helmholtz's (Hermann yon) Popuiar Lectures on Scientific Subjects. With 68 lllustrations. 2 vols. $35.6 d$. each.

Hope's (Anthony) The Heart of Princess Osra. With 9 Illustrations. $3^{s}$. $6 d$.

Howitt's (W.) Yisits to Remarkable Places. With 80 Illustrations. $35.6 d$.

Jefferles' (R.) The story of My Heart: My Autobiography. With Portrait. $3^{5} .6 d$.

Jefferies' (R.) Field and Hedgerow. With Portrait. $35,6 d$.

Jefferies' (R.) Red Deer. With I7 Illusts. 3s. $6 d$.

Jefferies' (R.) Wood Magic: a Fable. With Frontispiece and Vignette by E. V. B. 3s. $6 d$.

Jefferies (R.) The Tollers of the Field. With Portrait from the Bust in Salisbury Cathedral. 3s. $6 d$.

Kaye (Sir J.) and Malleson's (Colonel) History of the Indian Mutiny of 1857-8. 6 vols. $3^{5}$. $6 d$. each.

Knight's (E. F.) The Cruise of the 'Alerte ': the Narrative of a Search for Treasure on the Desert Island of Trinidad. With 2 Maps and 23 Illuștrations. 3s. $6 d$. 


\section{The Silver Library-continued.}

Knlght's (E. F.) Where Three Empires Meet: a Narrative of Recent Travel in Kashmir, Western Tibet, Baltistan, Gilgit. With a Map and 54 Illustrations. 3 s. $6 d$.

Knight's (E. F.) The 'Falcon' on the Baltic: a Coasting Voyage from Hammersmith to Copenhagen in a Three-Ton Yacht. With Map and II Illustrations. $3^{s}$. $6 d$.

Kostlin's (J.) Life of Luther. With 62 Illustrations and 4 Facsimiles of MSS. 35. $6 d$.

Lang's (A.)Angllng Sketches. With zo Illustrations. $3 s .6 d$.

Lang's (A.) Custom and Myth: Studies of Early Usage and Belief. $35.6 d$.

Lang's (A.) Cock Lane and Common-Sense. $35.6 d$.

Lang's (A.) The Book of Dreams and Ghosts, 3. 6 .

Lang's (A.) A Monk of Flfe: a Story of the Days of Joan of Arc. With $1_{3}$ Illustrations. 3s. $6 d$.

Lang's (A.) Myth, Ritual, and Religion. 2 vols. 75 .

Lees (J. A.) and Clutterbuck's (W. J.) B.C. 1887, A Ramble In Britlsh Columbia. With Maps and 75 Illustrations. $35.6 d$

Leyett-Yeats' (S.) The Cheyaller D'Auriac. 35. $6 d$.

Macaulay's (Lord) Complete Works. 'Albany' Edition. With 12 Portraits. I2 vols. $35.6 d$. each.

Macaulay's (Lord) Essays and Lays of Anclent Rome, etc. With Portrait and 4 Illustrations to the 'Lays'. 3s. $6 d$.

Macleod's (H. D.) Elements of Banking. $35.6 d$.

Marshman's (J. C.) Memolrs of Sir Henry Hayelock. 3 s. $6 d$.

Mason (A. E. W.) and Lang's (A.) Parson Kelly. 35. $6 d$.

Merivale's (Dean) History of the Romans under the Emplre. 8 vols. 3 s. $6 d$. each.

Merriman's (H. S. Flotsam : A Tale of the Indian Mutiny. $35.6 d$.

Mlli's (J. S.) Polltical Economy. 3s. 6d.

Mill's (J. S.) System of Logic. 3s. $6 d$.

Mllner's (Geo.) Country Pleasures : the Chronicle of a Year chiefly in a Garden. 3s. $6 d$.

Nansen's (F.) The First Crossing of Greenland. With 142 Illustrations and a Map. 35. $6 d$.

Phill pps-Wolley's (C.) Snap : a Legend of the Lone Mountain With $x_{3}$ Illustrations. $35.6 d$.
Proctor's (R. A.) The Orbs Around Us. $35.6 d$.

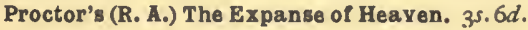

Proctor's (R. A.) Light Science for Leisure Hours. $35.6 d$.

Proctor's (R. A.) The Moon. 3s. $6 d$.

Proctor's (R. A.) Other Worlds than Ours. $35.6 d$.

Proctor's (R. A.) Our Place among Infinitles: a Series of Essays contrasting our Little Abode in Space and Time with the Infinities around us. 3 s. $6 d$.

Proctor's (R. A.) Other Suns than Ours. $3^{5 .} 6 d$.

Proctor's (R. A.) Rough Ways made Smooth. 3s. $6 d$.

Proctor's(R.A.)PleasantWays in Science. $3^{\text {s.6d. }}$

Proctor's (R. A.) Myths and Maryels of Astronomy. $35.6 d$.

Proctor's (R. A.) Nature Studles. 3s. $6 d$.

Proctor's (R. A.) Leisure Rearings, By R. A. PROCTOR, EDWARD CLODD, ANDREW Wilson, Thomas Foster, and A. C. RANYARD. With Illustrations. 35. $6 d$.

Rossettl's (Maria F.) A Shadow of Dante. $35.6 d$.

Smith's (R. Bosworth) Carthage and the Carthaginlans. With Maps, Plans, etc. $35.6 d$.

Stanley's (Bishop) Famillar History of Birds. With 160 Illustrations. $35.6 d$.

Stephen's (SIr Leslle) The Playground of Europe (The Alps). With + Illustrations. 3 s. $6 d$.

Steyenson's (R. L.) The Strange Case of Dr. Jekyll and Mr. Hyde; with other Fables. $35.6 d$.

Steyenson (R. L.) and Osbourne's (Ll.) The Wrong Box. $35.6 d$.

Stevenson (Robert Louis) and Stevenson's (Fanny yan de Grift) More New Arabian Nights.-The Dynamiter. $35.6 d$.

Treyelyan's (Slr G. O.) The Early History of Charles James Fox. $35.6 d$.

Weyman's (Stanley J.) The House of the Wolf: a Romance. $35.6 d$.

Wood's (Rey. J. G.) Petland Reyisited. With 33 Illustrations $3^{\text {s. } 6 d \text {. }}$

Wood's (Rey. J. G.) Strange Dwellings. With 60 Illustrations. $35.6 d$.

Wood's (Rey. J. G.) Out of Doors. With II Illustrations. $35.6 d$. 


\section{Cookery, Domestic Management, \&e.}

Acton. - MODERN COOKERY. By
Eliza Acton. With I50 Woodcuts. Fcp. 8vo., 4s. 6 d.

Angwin.-SIMPLE HINTS ON CHOICE $O F$ FOOD, with Tested and Economical Recipes. For Schools, Homes, and Classes for Technical Instruction. By M.C. ANGWIN, Diplomate (First Class) of the National Union for the Technical Training of Women, etc. Crown 8vo., Is.

Ashby.-HEALTH IN THE NURSERY. By Henry Ashby, M.D., F.R.C.P., Physician to the Manchester Children's Hospital. With 25 Illustrations. Crown 8vo., 3s. net.

\section{Bull (Thomas, M.D.).}

HINTS TO MOTHERS ON THE MANAGEMENT OF THEIR HEALTH DURING THE PERIOD OF PREGNANCY. Fcp. 8vo., sewed, Is. $6 d$. ; cloth, gilt edges, $2 s$. net.

THE MATERNAL MANAGEMENT OF CHILDREN IN HEALTH AND DISEASE. Fcp. 8vo., sewed, Is. 6d.; cloth, gilt edges, 2s. net.

De Salis (Mrs.).

A LA MODE COOKERY: Up-todate Recipes. With 24 Plates ( 16 in Colour). Crown 8vo., 5s. net.

CAKES AND CONFECTIONS A LA MODE. Fcp. 8vo., Is. $6 d$.

Dogs: A Manual for Amateurs. Fcp. 8vo., is. 6d.

DRESSED GAME AND PUULTRY A LA MODE. Fcp. 8vo., Is. $6 d$.

DRESSED VEGETABLES À LA MODE. Fcp. 8vo., is $6 d$.

DRINKS A LA MODE. Fcp.8vo., is.6d.
De Salis (Mrs.)-continued.

ENTREES Aे LA MODE. Fcp. 8vo., Is. $6 d$.

FLORAL DECORATIONS. Fcp. 8vo., Is. 6 d.

GARDENING A LA MODE. Fcp. 8vo. Part I., Vegetables, Is. $6 d$. Part II., Fruits, Is. 6d.

NATIONAL VIANDS À LA MODE. Fcp. 8vo., Is. $6 d$.

NEW-LAID EGGS. Fcp. 8vo., is. 6d.

Oysters à la Mode. Fcp. 8vo., Is. $6 d$.

Puddings and PAstry À LA Mode. Fcp. 8vo., is. $6 d$.

SAVOURIES À LA MODE. Fcp. 8vo., Is. $6 d$.

SOUPS AND DRESSED FISH A LA MODE. Fcp. 8vo., Is. $6 d$.

SWEETS AND SUPPER DISHES Aे LA MODE. Fcp. 8vo., Is. $6 d$.

TEMPTING DISHES FOR SMALL INCOMES. Fcp. 8vo., Is. $6 d$.

WRINKLES AND NOTIONS FOR EVERY HOUSEHOLD. Crown 8vo., is. $6 d$.

Lear.-MAigre COOKERY. By H. L. SIDNEY LEAR. I6mo., $2 s$.

Poole.-COOKERY FOR THE DIABETIC. By W. H. and Mrs. Poole. With Preface by Dr. Pavy. Fcp. 8vo., 2s. $6 d$.

Rotheram. - HOUSEHOLD COOKERY RECIPES. By M. A. Rotheram, First Class Diplomée, National Training School of Cookery, London; Instructress to the Bedfordshire County Council. Crown 8vo., 2s.

\section{The Fine Arts and Musie.}

Burne-Jones.-THE BEGINNING OF THE WORLD: Twenty-five Pictures by Sir Edward Burne-Jones, Bart. Medium 4 to., Boards, 7s. $6 d$. net.

Burns and Colenso.-LIVING ANATOMY. By Cecil L. Burns, R.B.A., and Robert J. Colenso, M.A., M.D. 4o Plates, II 1 by 83 ins., each Plate containing Two Figures-(a) A Natural Male or Female Figure; (b) The same Figure Anatomatised. In a Portfolio, $7 s .6 d$. net.
Hamlin.- $A$ TEXT-BOOK OF THE HISTORY OF ARCHITECTURE. By A. D. F. Hamlin, A.M. With 229 Illustrations. Crown 8vo., 7 s. $6 d$.

Haweis (Rev. H. R.).

MUSIC AND MORALS. With Portrait of the Author. Crown 8vo., 6s, net.

MY MUSICAL LIFE. With Portrait of Richard Wagner and 3 Illustrations. Crown 8vo., 6s. net. 


\section{The Fine Arts and Music-continued.}

Huish, Head, and Longman.SAMPLERS AND TAPESTRY EMMBROIDERIES. By Marcus B. Huish, LL.B.; also 'The Stitchery of the Same,' by Mrs. Head; and 'Foreign Samplers,' by Mrs. C. J. LoNGMAN. With 30 Reproductions in Colour, and 40 Illustrations in Monochrome. 4to., $£^{2}$ 2s. net.

Hullah.-THE HISTORY OF MODERN Music. By John Hullah. 8vo., 8s. $6 d$.

Jameson (Mrs. ANNA).

SACRED AND LEGENDARY ART, containing Legends of the Angels and Archangels, the Evangelists, the Apostles, the Doctors of the Church, St. Mary Magdalene, the Patron Saints, the Martyrs, the Early Bishops, the Hermits, and the Warrior-Saints of Christendom, as represented in the Fine Arts. With Ig Etchings and 187 Woodcuts. 2 vols. 8vo., 20s. net.

LEGENDS OF THE MONASTIC ORDERS, as represented in the Fine Arts, comprising the Benedictines and Augustines, and Orders derived from their Rules, the Mendicant Orders, the Jesuits, and the Order of the Visitation of St. Mary. With I I Etchings and 88 Woodcuts. I vol. 8 vo., Ios, net.

LEGENDS OF THE MADONNA, OR BLESSED VIRGIN MARY. Devotional with and without the Infant Jesus, Historical from the Annunciation to the Assumption, as represented in Sacred and Legendary Christian Art. With 27 Etchings and I65 Woodcuts. I vol. 8vo., Ios. net.

THE HISTORY OF OUR LORD, as eXemplified in Works of Art, with that of His Types, St. John the Baptist, and other persons of the Old and New Testament. Commenced by the late Mrs. JAMESON; continued and completed by LADY EASTLAKE. With 31 Etchings and 28I Woodcuts. 2 vols. 8vo., 20s. net.

Kristeller. - ANDREA MANTEGNA. By Paul Kristeller. English Edition by S. ARthur Strong, M.A., Librarian to the House of Lords, and at Chatsworth. With 26 Photogravure Plates and 162 Illustrations in the Text. 4to., gilt top, $£ 3$ Ios. net.

Macfarren. - LECTURES ON HARMONY. By Sir George A. Macfarren. 8vo., $12 s$.

\section{Morris (William).}

ARCHITECTURE, INDUSTRY AND WEALTH. Collected Papers. Crown 8 vo., 6s. net.
Morris (William)-continued.

HOPES AND FEARS FOR ART. Five Lectures delivered in Birmingham, London, etc., in 1878-1881. Cr 8vo., 4s. $6 d$. AN ADDRESS DELIVERED AT THE DISTRIBUTION OF PRIZES TO STUDENTS OF THE BIRMINGHAM MUNICIPAL SCHOOL OF ART ON 2IST FEBRUARY, 1894. 8vo., 2s. 6d. net. (Printed in 'Golden' Type.) SOME HINTS on PATTERN-DEsigN$I N G$ : a Lecture delivered at the Working Men's College, London, on Ioth December, 1881. 8vo., 2s. 6d. net. (Printed in 'Golden' Type.)

ARTS AND ITS PRODUCERS (1888) AND THE ARTS AND CRAFTS OF TO-DAY (1889). 8vo., 2s. 6d. net. (Printed in 'Golden' Type.)

ARTS AND CRAFTS ESSAYS. By Members of the Arts and Crafts Exhibition Society. With a Preface by William Morris. Crown 8vo., 2s. 6d. net.

* * For Mr. William Morris's other Works, see pp. 24, 27, 28 and 40.

Robertson.-OLD ENGLISH SONGS AND DANCES. Decorated in Colour by W. Graham Robertson. Royal 4to., 42s. net.

Scott.-PORTRAITURES OF JULIUS C ESAR: a Monograph. By Frank JesuP Scotr. With 38 Plates and 49 Figures in the Text. Imperial 8vo., 2is. net.

Vanderpoel. - COLOUR PROBLEMS: a Practical Manual for the Lay Student of Colour. By Emily Noyes Vanderpoel. With II7 Plates in Colour. Sq. 8vo., 2 Is. net.

Van Dyke.-A TEXT-BOOK ON THE History of PAINTING. By John C. Van DyкE. With I Io Illustrations. Cr. 8vo., $6 \mathrm{~s}$.

Wellington.-A DESCRIPTIVE AND Historical Catalogue of the CollecTIONS OF PICTURES AND SCULPTURE AT APSLEY HOUSE, LONDON. By Evelyn, Duchess of Wellington. Illustrated by $\mathbf{5 2}$ Photo-Engravings, specially executed by Braun, ClÉment, \& Co., of Paris. 2 vols., royal 4 to., $£ 66$ s. net.

Willard. - HISTORY OF MODERN ITALIAN ART. By AsHTON RoLLINS Willard. Part I. Sculpture. Part II. Painting. Part III. Architecture. With Photogravure Frontispiece and num erous full-page Illustrations. 8vo,, 2Is, net.

Wotton.-THE ELEMENTS OF ARCHITECTURE. Collected by HENRY WotTon, Kt., from the best Authors and Example' Royal I6mo., boards, Ios. $6 d$. net. 


\section{Miscellaneous and Critical Works.}

Auto da Fé and other Essays: some being Essays in Fiction. By the Author of 'Essays in Paradox' and 'Exploded Ideas'. Crown 8vo., 5 s.

Bagehot.-LITERARY STURIES. By Walter Bagehot. With Portrait. 3 vols. Crown 8vo., 3s. $6 d$. each.

Baker. - EDUCATION AND LIFE : Papers and Addresses. By James $H$. BAKER, M.A., LL.D. Crown 8vo., 4 s. $6 d$.

Baring-Gould.-CURIOUS MYTHS OF THE MIDDLE AgEs. By Rev. S. BaringGould. Crown 8vo., 3s. $6 d$.

Baynes. - SHAKESPEARE STUDIES, and other Essays. By the late ThомAs Spencer Baynes, LL.B., LL.D. With a Biographical Preface by Professor Lewis Campbell. Crown 8vo., 75. $6 \mathrm{~d}$.

Bonnell. - ChARLOTtE BRoNTË, GEORGE ELIOT, FANE AUSTEN: Studies in their Works. By Henry H. Bonnell. Crown 8vo., 7s. 6d. net.

Booth.-THE DISCOVERY AND DECIPHERMENT OF THE TRILINGUAL CUNETFORM INSCRIPTIONS. BY ARTHUR JOHN Booth, M.A. With a Plan of Persepolis. 8vo. I4s. net.

\section{Charities Register, The Annual,} AND DIGEST: being a Classified Register of Charities in or available in the Metropolis. 8 vo., 5s. net.

Christie.-SELECTED ESSAYS. By Richard Copley Christie, M.A., Oxon. Hon. LL.D., Vict. With 2 Portraits and 3 other Illustrations. 8vo., I2s. net.

Dickinson.-KING ARTHUR IN CORNWALL. By W. Howship Dickinson, M.D. With 5 Illustrations. Crown 8vo., 4 s. $6 d$.

Essays in Paradox. By the Author of 'Exploded Ideas' and 'Times and Days'. Crown 8vo., $5 s$.

Evans.-The ANCIENT STONE TMPLEMENTS, WEAPONS AND ORNAMENTS OF GREAT BRITAIN. By Sir John Evans, K.C.13. With 537 Illustrations. 8vo., Ios. $6 d$. net.

Exploded Ideas, ANDO THER ESSAYS. By the Author of 'Times and Days'. $\mathrm{Cr}$. 8vo., 5s.
Frost. - $A$ MEDLEY BOOK. By George Frost. Crown 8vo., 35. 6 d. net.

Geikie. -THE VICAR AND HIS FRIENDS. Reported by Cunningham Geikie, D.D., LL.D. Crown 8vo., 5s, net.

Gilkes. - THE NEW REVOLUTION. By A. H. Gilkes, Master of Dulwich College. Fcp. 8vo., Is. net.

Haggard (H. RIDER).

A FARMER'S YEAR : being his Commonplace Book for 1898 . With 36 Illustrations. Crown 8vo., 7 s. $6 d$. net.

RURAL ENGLAND. With 23 Agricultural Maps and 56 Illustrations from Photographs. 2 vols., 8 vo., $36 s$. net.

Hoenig. - INQUIRIES CONCERNING THE TACTICS OF THE FUTURE. By FRITZ HoEnig. With I Sketch in the Text and 5 Maps. Translated by Captain H. M. Bower. 8 vo., ${ }^{5}$ s. net.

Hutchinson.-DREAMS AND THEIR MEANINGS. By HORACE G. HuTCHINSON. 8 vo., gilt top, gs. $6 d$. net.

Jefferies (RICHARD).

FIELD AND HEDGEROW: With Portrait. Crown 8vo., 3s. 6d.

THE STORY OF MY HEART: my Autobiography. Crown 8vo., 3s. 6d.

RED DEER. With I7 lllustrations. Crown 8vo., 3s. 6d.

THE TOILERS OF THE FIELD. Crown 8vo., 3s. $6 d$.

WOOD MAGIC: a Fable. Crown 8vo., 3s. $6 d$.

Jekyll (GERTRUDE).

HOME AND GARDEN: Notes and Thoughts, Practical and Critical, of a Worker in both. With 53 Illustrations from Photographs. 8vo., ros. $6 d$. net.

WOOD AND GARDEN: Notes and Thoughts, Practical and Critical, of a Working Amateur. With $7 x$ Photographs. 8 vo., Ios. $6 d$. net. 


\section{Miscellaneous and Critical Works-continued.}

Johnson (J. \& J. H.).

ThE PATENTEE'S MANUAL : a Treatise on the Law and Practice of Letters Patent. 8vo., ros. $6 d$.

\section{AN EPITOME OF THE LAW AND} PRACTICE CONNECTED WITH PATENTS FOR INVENTIONS; with a reprint of the Patents Acts of $1883,1885,1886$ and 1888. Crown 8 vo., 2s. $6 d$.

\section{JOyce.-THE ORIGIN AND HISTORY} OF IRISH NAMES OF PLACES. BY P. W. Joyce, LL.D. 2 vols. Crown 8vo., 5s. each.

\section{Lang (ANDREW).}

LetTers to Dead Authors. Fcp. 8 vo., 25. $6 d$. net.

BOOKS AND BOOKMEN. With 2 Coloured Plates and 17 Illustrations. Fcp. 8vo., 2s. 6d. net.

OLD FRIENDS. Fcp. 8vo., 2s. 6d. net.

LETTERs ON Literature. Fcp. 8 vo., 2s. $6 d$. net.

Essays IN LITTLE. With Portrait of the Author. Crown 8vo., 2s. 6d.

Cock Lane and Common-Sense. Crown 8vo., $3^{5.6 d \text {. }}$

THE BOOK OF DREAMS AND GHOSTS. Crown 8vo., 3s. 6 d.

Maryon.-HOW THE GARDEN GREW. By Maud Maryon. With 4 Illustrations. Crown 8vo., 5s. net.

Matthews. - Notes oN SPEECHMaKiNG. By Brander Matthews. Fcp. 8 vo., Is. 6d. net.
Max Miller (The Right Hon. F.).

Collected.WORKs. I 8 vols. Crown 8 vo., 5s. each.

Vol. I. NATURAL RELIGION: the Gifford Lectures, 1888.

Vol. II. PHYSICAL RELIGION : the Gifford Lectures, 1890 .

Vol. III. ANTHROPOLOGICAL RELIGION: - the Gifford Lectures, I89r.

Vol. IV. THEOSOPHY; or, Psychological Religion: the Gifford Lectures, 1892.

ChIPS FROM A GERMAN WORKSHOP.

Vol. V. Recent Essays and Addresses.

Vol. VI. Biographical Essays.

Vol. VII. Essays on Language and Literature.

Vol. VIII. Essays on Mythology and Folk-lore.

Vol. IX. THB ORIGIN AND GROWTH OF RELIGION, as Illustrated by the Religions of India: the Hibbert Lectures, 1878.

Vol. X. BIOGRAPHIES OF WORDS, AND THE HOME OF THE ARYAS.

Vols. XI., XII. THE SCIENCE OF $L_{A N G U A G E}$ : Founded on Lectures delivered at the Royal Institution in 1861 and 1863.2 vols. Ios.

Vol. XIII. INDIA: What can it Teach Us?

VOl. XIV. INTRODUCTION TO THE SCIENCE OF RELIGION. Four Lectures, 1870 .

Vol. XV. RAMAKRISHNA: his Life and Sayings.

Vol. XVI. THREE LECTURES ON THB VEDÂNTA PHILOSOPHY, 1894 .

Vol. XVII. LAST ESSAYS. First Series. Essays on Language, Folk-lore, etc.

Vol. XVIII. Last Essays. Second Series. Essays on the Science of Religion. 


\section{Miscellaneous and Critical Works-continued.}

Milner.-Country PLeAsures: the Chronicle of a Year chiefly in a Garden. By George Milner. Crown 8vo., 3s. 6d.

Morris.-SIGNS OF CHANGE. Seven Lectures delivered on various Occasions. By William Morris. Post 8vo., 4 s. $6 d$.

Parker and Unwin.- THE $A_{R T}$ OF BUILDING A HOME : a Collection of Lectures and Illustrations. By BARRY Parker and RAYMOND Unwin. With 68 Full-page Plates. 8 vo., Ios. $6 d$. net.

Pollock.-JANE AUSTEN: her Contemporaries and Herself. By WALTER Herries Pollock. Cr. 8 vo., 3 s. $6 d$. net.

Poore (George Vivian, M.D.).

Essays on RURAL HYGIENE. With 13 Illustrations. Crown 8vo., 6s. $6 d$.

The DWelling House. With 36 Illustrations. Crown 8vo., 3s. $6 d$.

THE EARTH IN RELATION TO THE PRESERVATION AND DESTRUCTION OF CONTAGIA : being the Milroy Lectures delivered at the Royal College of Physicians in 1899 , together with other Papers on Sanitation. With 13 Illustrations. Crown 8vo., 5 s.

Colonial and Camp Sanitation. With II Illustrations. $\mathrm{C}_{\mathrm{r}} 8$ vo., 2s, net.

Rossetti.-A SHADOW OF DANTE: being an Essay towards studying Himself, his World and his Pilgrimage. By MariA Francesca Rossetti. Crown 8vo., 3s. $6 d$.

Seria Ludo. By a Dilettante. Post 4 to., 5s. net.

* * Sketches and Verses, mainly reprinted from the St. Fames's Gazctte.

Shadwell. - DRINK : TEMPERANCE AND Legislation. By ARTHur Shadwell, M.A., M.D. Crown 8̈vo., 5s. net.

Soulsby (Lucy H. M.).

STRAY THOUGHTS ON READING. Fcp. 8vo., 2s. $6 d$. net.

STRAY THOUGHTS FOR GIRLS. I6mo., Is. $6 d$ net.

เ0,000/7/03. -A. U. P.
Soulsby (Lucy H. M.)-continued.

STRAY THOUGHTS FOR MOTHERS AND TEACHERS. Fcp. 8vo., 2s. 6d. net.

STRAY THOUGIITS FOR INVALIDS. I6mo., 2s. net.

StRaY THOUghts ON CHARACTER. Fcp. 8vo., 2s. 6d. net.

Southey.-THE CORRESPONDENCE OF ROBERT SOUTHEY WITH CAROLINE BOWLES. Edited by EDWARD DowDEN. 8vo., I 4 s.

Stevens.-ON THE STOWAGE OF SHIPS AND THEIR CARGOES. With Information regarding Freights, Charter-Parties, etc. By Robert White Stevens. 8vo., 21 s.

Thuillier. - THE PRINCIPLES OF LAND DEFENCE, AND THEIR APPLICATION TO THE Conditions of TO-DAY. By Captain $\mathrm{H}$. F. Thuillier, R.E. With Maps and Plans. 8 vo., I2s. $6 d$. net.

Turner and Sutherland.-THE $D E$ VELOPMENT OF AUSTRALIAN LITERATURE. By Henry Gyles TuRner and AlExander Sutherland. With Portraits and Illustrations. Crown 8vo., 5 s.

Warwick.-PROGRESS IN WOMEN'S EDUCATION IN THE BRITISH EMPIRE : being the Report of Conferences and a Congress held in connection with the Educational Section, Victorian Era Exhibition. Edited by the Countess of Warwick. Cr. 8vo. 6 s.

Weathers. - A PRACTICAL GUIDE TO GARDEN PLANTS. By John Weathers, F.R.H.S. With 159 Diagrams. 8vo., 21s. net.

Whittall.-HREDERICK THE GREAT ON KINGCRAFT, from the Original Manuscript; with Reminiscences and Turkish Stories. By Sir J. William Whitrall, President of the British Chamber of Commerce of Turkey. 8 vo., $7 s .6 d$. net. 
ras

1

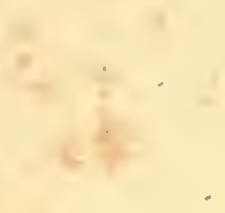

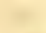

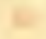

(1)

$-$

.

t.

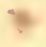

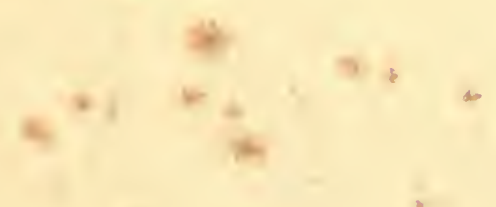

18

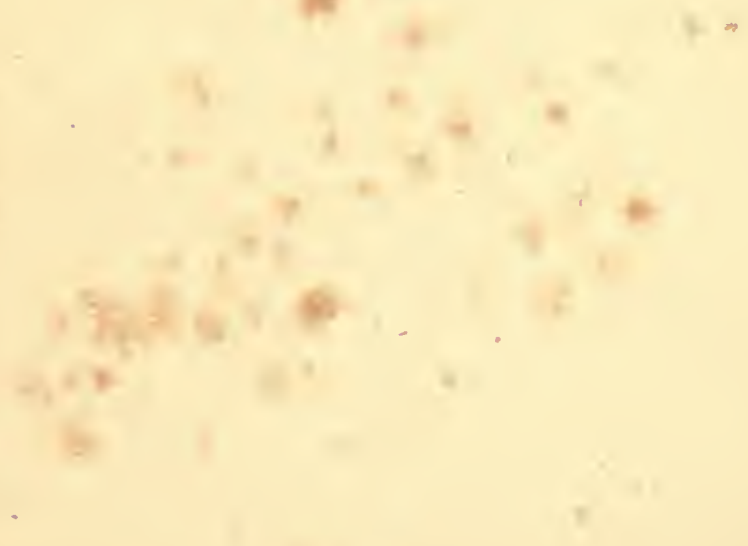




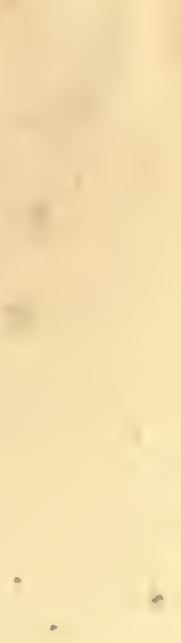

I

r

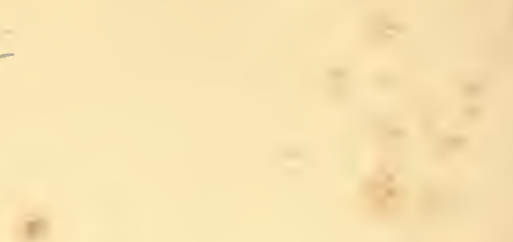

$=$

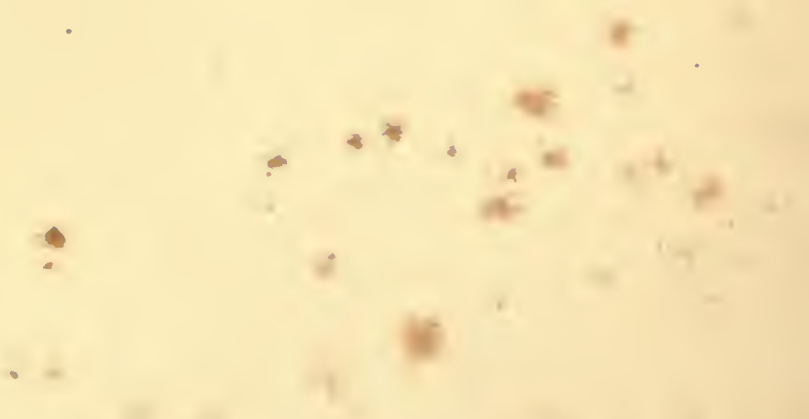

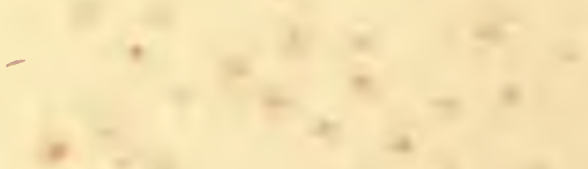

$$
\begin{aligned}
& + \\
& +2+2-1
\end{aligned}
$$

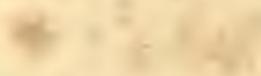

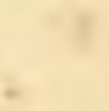$$
\text { . }
$$ 
UNIVERSITY OF CALIFORNIA LIBRARY

Los Angeles

This book is DUE on the last date stamped below.

\section{OCT 161950}

Form L9-15m-10,'48 (B1039) 444

\section{Thi LWRAT}

\section{UNIVERSTTY OR' CALIFORNIA}

LOS ANGELES 
F Fountain 1013 The great NorthF82g west

\section{OCT 161950}

F

1013

F82:

UC SOUTHERN REGIONAL LUBPARY FACITYY

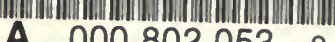

A 000802053

E.
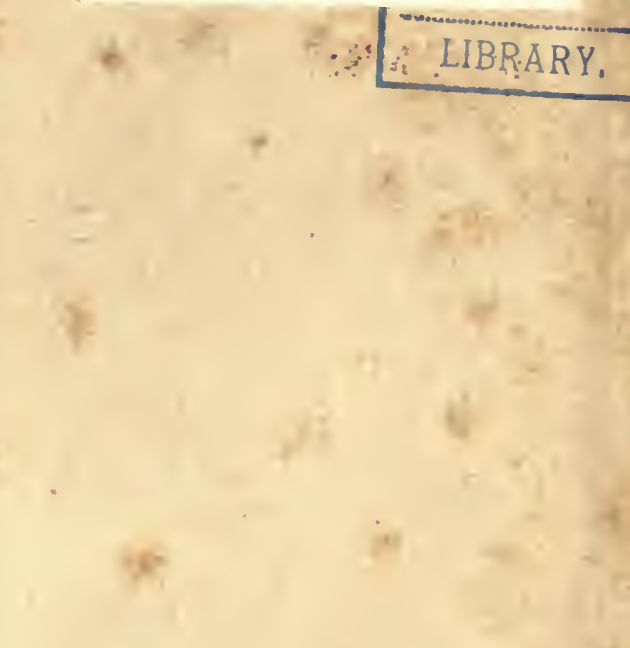
